\title{
WestVirginiaUniversity
}

THE RESEARCH REPOSITORY @ WVU

Graduate Theses, Dissertations, and Problem Reports

1998

\section{Droplet coalescence in the shear flow of model emulsions}

Adam Abdallah Al-Mulla

West Virginia University

Follow this and additional works at: https://researchrepository.wvu.edu/etd

\section{Recommended Citation}

Al-Mulla, Adam Abdallah, "Droplet coalescence in the shear flow of model emulsions" (1998). Graduate Theses, Dissertations, and Problem Reports. 903.

https://researchrepository.wvu.edu/etd/903

This Thesis is protected by copyright and/or related rights. It has been brought to you by the The Research Repository @ WVU with permission from the rights-holder(s). You are free to use this Thesis in any way that is permitted by the copyright and related rights legislation that applies to your use. For other uses you must obtain permission from the rights-holder(s) directly, unless additional rights are indicated by a Creative Commons license in the record and/ or on the work itself. This Thesis has been accepted for inclusion in WVU Graduate Theses, Dissertations, and Problem Reports collection by an authorized administrator of The Research Repository @ WVU. For more information, please contact researchrepository@mail.wvu.edu. 


\section{DROPLET COALESCENCE IN THE SHEAR FLOW OF MODEL EMULSIONS}

By

Adam Al-Mulla

A Thesis

Submitted to the College of Engineering and Mineral Resources at

West Virginia University

In Partial Fulfillment of the Requirements for the Degree of Master of Science in Chemical Engineering

Department of Chemical Engineering

West Virginia University

Morgantown, West Virginia

1998

Advisor: Dr. Rakesh K. Gupta 


\section{DEDICATION.............}

I would like to dedicate this thesis to my wife Enas Salmeen for her support, encouragement, and patience during the course of this thesis. 


\section{ACKNOWLEDGMENT}

I would like to thank Dr. Rakesh K. Gupta for his guidance in the development of this thesis. His advises and suggestions were invaluable.

I would also like to thank the members of my advising committee, Dr. J. Zondlo and Dr. C. Stinespring for their helful advice.

I thank Dr. Zondlo for helping me getting access to the Ultra Sonic Vibrator.

I would like to express my gratitude to Kuwait University and Dupont Inc. for funding that made this research possible.

I would like to express my appreciation to Linda Rogers for great secretarial work performed. I am thankful to the technician Mr. Hall for his technical help. Special thanks to my family in Kuwait for their continuous support. 


\section{ABSTRACT \\ DROPLET COALESCENCE IN THE SHEAR FLOW \\ OF MODEL EMULSIONS \\ By Adam Al-Mulla}

During the flow of an emulsion, droplets of the dispersed phase can deform, breakup, coalesce or migrate to other regions within the flow field. Understanding these different processes, both individually and jointly, is relevant, for example, to the development of morphology in immiscible liquidliquid systems such as polymer blends formulated using single screw or twin screw extruders. While deformation and breakup have been well researched for single drops, migration occurs only for concentrated emulsions. In this study, dilute emulsions of silicone oil and castor oil were employed to observe drop coalescence in the absence of drop breakup; flow fields utilized were Poiseuille flow through a tube and Couette flow in a cone-and-plate device. The influence of variables such as the continuous phase viscosity, the viscosity ratio, concentration of the dispersed phase, shear rate, the time of shearing, and temperature was studied.

By measuring the average droplet size under steady state conditions, it was found that the extent of coalescence was not influenced by the spatially non-homogeneous nature of the flow field; results correlated very well with the average shear rate. Other results were that coalescence could be promoted by increasing the concentration of the dispersed phase, decreasing the viscosity of the continuous phase, lowering the shear rate and reducing the temperature. In 
quantitative terms, it was found that available coalescence theory gave the correct order of magnitude for the average droplet size as a function of the imposed shear rate, but the actual variation of drop size with shear rate was gentler than that predicted by the theory. 


\section{TABLE OF CONTENTS}

Title Page $\quad$ i

Acknowledgments

Abstract

List of Contents vi

$\begin{array}{ll}\text { List of Tables } & \text { ix }\end{array}$

Lists of Figures $\quad$ X

Symbols and Abbreviations xvii

\section{Chapter 1 INTRODUCTION}

1.1 Definition of Emulsions, their Properties and Applications 1

1.2 Research Objectives $\quad 2$

\section{Chapter 2 LITERATURE REVIEW}

2.1 Rheology of Emulsions 4

2.2 Stability of Emulsions $\quad 7$

2.3 Droplet Break-up 9

2.4 Coalescence of Emulsions 11

Chapter 3 EXPERIMENTAL EQUIPMENT AND PROCEDURE

$\begin{array}{lr}3.1 \text { Experimental Apparatus } & 18\end{array}$

3.2 Experimental Procedure 23

3.2.1 Materials Used 
3.2.3 Shearing of Emulsions

3.2.4 Photographing the Emulsion and Image Analysis 26

3.3 Data Analysis 27

3.3.1 Coalescence and Droplet Break-up

\section{Chapter 4 RESULTS AND DISCUSSION}

4.1 Coalescence

4.1.1 Cone-and-Plate Versus Tube Flow

4.1.2 Effect of Residence Time

4.1.3 Effect of Shear Rate

4.1.4 Effect of Concentration of the Dispersed Phase

4.1.5 Effect of Size Distribution

4.1.6 Effect of Temperature

4.2 Step-up and Step-down of Shear Rate

4.3 Effects of Phase Inversion

63

\section{Chapter 5 CONCLUSIONS AND RECOMMENDATIONS}

5.1 Conclusions

5.2 Recommendations

\section{Appendix A}


Appendix B

Tables of Results

Appendix C

Size Distribution Graphs and Photographs of Emulsions 


\section{LIST OF TABLES}

Table 2.1 Particle collision rate, neglecting hydrodynamic interaction in various flows.

Table 2.2 Coalescence systems used by other authors.

Table 3.1 Sources of materials used.

Table 4.1 Overview of all the experiments conducted.

Table 4.2 Values of $h_{\text {crit }}, p, \eta_{c}$, and $\sigma$ for $1 \%$ emulsion at room

temperature.

Table 4.3 Emulsion viscosity ratios used for step-up and step-down experiments

Table A.1 Shear rates and stresses at the wall for $1.0 \%$ emulsion.

Table B.1 Effect of the flow type on coalescence.

Table B.2 Effect of the residence time on coalescence.

Table B.3 Effect of shear rate on coalescence.

Table B.4 Effect of the concentration on the dispersed phase on coalescence.

Table B.5 Effect of temperature on the viscosity of silicone

oil and castor oil.

Table B.6 Effect of temperature on the coalescence of

$1.0 \%$ emulsion.

Table B.7 Effect of step-up and step-down on coalescence.

Table B.8 Effect of step-up on coalescence for sample B and sample C. 86 


\section{LIST OF FIGURES}

Figure 2.1 The critical Capillary number for breakup of droplets in simple shear f low (curve, results by Grace, 1982) and for the resulting average droplet size in a colloid mill (hatched area, results by Ambruster, 1990) as a function of the viscosity ratio of the dispersed to the continuous phase.

Figure 2.2 Collision between two drops: A) the drops coalesce after reaching the critical distance $\left(\mathrm{h}_{\text {crit }}\right)$. B) the drops tumble and separate.

Figure 3.1 Experimental set up.

Figure 3.2 Hot water bath.

Figure 3.3 Cone-and-plate device.

Figure 3.4 A picture of evenly spaced lined used for calibration. There are 300 evenly spaced dark lines per inch.

Figure 3.5 Coalescence and break up mechanism

Figure 3.6 Over all flow sheet.

Figure 4.1 Collision of two deformable drops in simple shear flow with drainage of the film in between.

Figure 4.2 Collision probability (concentration $0.5 \%, 1.0 \%$, and $5.0 \%)$

Figure 4.3 Collision probability (shear rates 10, 30, and $50 \mathrm{~s}^{-1}$ ). 
Figure 4.4 Tube flow and cone-and-plate.

Figure 4.5 Effect of residence time on 1\% emulsion. 41

Figure 4.6 The drainage film between small and large droplets. $\quad 40$

Figure 4.7 Effect of shear rate on 1\% emulsion. 44

Figure 4.8 Effect of shear rate where the time of shearing is $35 \mathrm{~min} . \quad 45$

Figure 4.9 Droplets in low shear rate zone and high shear rate zone. 43

Figure 4.10 Effect of shear rate on coalescence using equations 4.2,

4.3, and experimental results.

Figure 4.11 Effect of residence time and concentration on $0.5 \%$, $1.0 \%$, and $5.0 \%$ emulsion (shear rate is $11 \mathrm{~s}^{-1}$ ).

Figure 4.12A $5.0 \%$ emulsion with narrow and large size distribution sheared for $30 \mathrm{~min}$. at room temperature using capillary tubes.

Figure 4.12B $5.0 \%$ emulsion with large size distribution sheared for 30 min. at room temperature using capillary tubes.

Figure 4.13 Aggregation at high and low shear rate, 5\% emulsion sheared for $30 \mathrm{~min}$. at room temperature using capillary tubes.

Figure 4.14 Effect of temperature on the viscosity of silicone oil and castor oil.

Figure 4.15 Effect of the interfacial tension on the film between the droplets. 
Figure 4.16 Effect of temperature on coalescence of 1\% emulsion. 58

Figure 4.17 Step-up and step-down for sample A. 61

Figure 4.18 Step-up and step-down for samples B and C. 62

$\begin{array}{lll}\text { Figure A.1 Slip flow through a capillary. } & 72\end{array}$

$\begin{array}{lll}\text { Figure A.2 } & \text { Force balance on a cylindrical control volume. }\end{array}$

$\begin{array}{lll}\text { Figure A.3 Data for Kraft full-fat mayonnaise. } & 73\end{array}$

Figure A.4 Stress vs. shear rate for $1 \%$ emulsion using capillary tubes.

Figure A.5 Stress vs. shear rate for silicone oil using capillary tubes. 77

$\begin{array}{lll}\text { Figure C.1 } & \text { Fresh emulsion. } & 92\end{array}$

Figure C.2 Fresh emulsion, average diameter $=8.1 \mu \mathrm{m} . \quad 93$

Figure C.3 $\quad 0.5 \%$ emulsion, time of shearing $=4.30 \mathrm{~min}, \dot{\gamma}=11 \mathrm{~s}^{-1} . \quad 94$

Figure C.4 $0.5 \%$ emulsion, average diameter $=11.66 \mu \mathrm{m}$, time of shearing $=4.30 \mathrm{~min}, \dot{\gamma}=11 \mathrm{~s}^{-1}$.

Figure C.5 $\quad 0.5 \%$ emulsion, time of shearing $=6.87 \mathrm{~min}, \dot{\gamma}=11 \mathrm{~s}^{-1} \quad 96$

Figure C.6 $\quad 0.5 \%$ emulsion, average diameter $=11.87 \mu \mathrm{m}$, time of shearing $=6.87 \mathrm{~min}, \dot{\gamma}=11 \mathrm{~s}^{-1}$.

Figure C.7 $\quad 0.5 \%$ emulsion, time of shearing $=11.42 \mathrm{~min}, \dot{\gamma}=11 \mathrm{~s}^{-1} \quad 98$

Figure C.8 $\quad 0.5 \%$ emulsion, average diameter $=12.29 \mu \mathrm{m}$, time of shearing $=11.42 \mathrm{~min}, \dot{\gamma}=11 \mathrm{~s}^{-1}$.

Figure C.9 $\quad 0.5 \%$ emulsion, time of shearing $=16.83 \mathrm{~min}, \dot{\gamma}=11 \mathrm{~s}^{-1} . \quad 100$

Figure C.10 $0.5 \%$ emulsion, average diameter $=12.39 \mu \mathrm{m}$, time of 101 
shearing $=16.83 \min , \dot{\gamma}=11 \mathrm{~s}^{-1}$.

Figure C.11 $0.5 \%$ emulsion, time of shearing $=23.43 \mathrm{~min}, \dot{\gamma}=11 \mathrm{~s}^{-1}$.

102

Figure C.12 $0.5 \%$ emulsion, average diameter $=12.81 \mu \mathrm{m}$, time of shearing $=23.43 \mathrm{~min}, \dot{\gamma}=11 \mathrm{~s}^{-1}$.

Figure C.13 $0.5 \%$ emulsion, time of shearing $=35.00 \mathrm{~min}, \dot{\gamma}=11 \mathrm{~s}^{-1}$.

Figure C.14 $0.5 \%$ emulsion, average diameter $=13.13 \mu \mathrm{m}$, time of shearing $=35.00 \min , \dot{\gamma}=11 \mathrm{~s}^{-1}$.

Figure C.15 Fresh emulsion.

Figure C.16 $1.0 \%$ emulsion, time of shearing $=4.00 \mathrm{~min}, \dot{\gamma}=11 \mathrm{~s}^{-1}$.

107

Figure C.17 $1.0 \%$ emulsion, time of shearing $=6.90 \mathrm{~min}, \dot{\gamma}=11 \mathrm{~s}^{-1}$. 108

Figure C.18 $1.0 \%$ emulsion, time of shearing $=10.78 \mathrm{~min}, \dot{\gamma}=11 \mathrm{~s}^{-1}$.

Figure C.19 $1.0 \%$ emulsion, time of shearing $=17.27 \mathrm{~min}, \dot{\gamma}=11 \mathrm{~s}^{-1}$.

Figure C.20 $1.0 \%$ emulsion, time of shearing $=24.18 \mathrm{~min}, \dot{\gamma}=11 \mathrm{~s}^{-1}$.

Figure C.21 $1.0 \%$ emulsion, time of shearing $=34.85 \mathrm{~min}, \dot{\gamma}=11 \mathrm{~s}^{-1}$.

Figure C.22 Fresh emulsion.

Figure C.23 5.0\% emulsion, time of shearing $=4.55 \mathrm{~min}, \dot{\gamma}=11 \mathrm{~s}^{-1}$.

Figure C.24 5.0\% emulsion, average diameter $=12.32 \mu \mathrm{m}$, time of shearing $=4.55 \mathrm{~min}, \dot{\gamma}=11 \mathrm{~s}^{-1}$.

Figure C.25 5.0\% emulsion, time of shearing $=6.68 \mathrm{~min}, \dot{\gamma}=11 \mathrm{~s}^{-1}$.

Figure C.26 5.0\% emulsion, average diameter $=13.44 \mu \mathrm{m}$, time of shearing $=6.68 \mathrm{~min}, \dot{\gamma}=11 \mathrm{~s}^{-1}$. 
Figure C.27 5.0\% emulsion, time of shearing $=11.40 \mathrm{~min}, \dot{\gamma}=11 \mathrm{~s}^{-1}$.

Figure C.28 $5.0 \%$ emulsion, average diameter $=14.81 \mu \mathrm{m}$, time of shearing $=11.40 \mathrm{~min}, \dot{\gamma}=11 \mathrm{~s}^{-1}$.

Figure C.29 5.0\% emulsion, time of shearing $=15.40 \mathrm{~min}, \dot{\gamma}=11 \mathrm{~s}^{-1}$.

Figure C.30 $5.0 \%$ emulsion, average diameter $=16.59 \mu \mathrm{m}$, time of shearing $=15.40 \min , \dot{\gamma}=11 \mathrm{~s}^{-1}$.

Figure C.31 5.0\% emulsion, time of shearing $=34.17 \mathrm{~min}, \dot{\gamma}=11 \mathrm{~s}^{-1}$.

Figure C.32 $5.0 \%$ emulsion, average diameter $=18.69 \mu \mathrm{m}$, time of shearing $=34.17 \mathrm{~min}, \dot{\gamma}=11 \mathrm{~s}^{-1}$.

Figure C.33 Fresh emulsion.

Figure C.34 Fresh emulsion, average diameter $=8.07 \mu \mathrm{m}$.

125

Figure C.35 $1.0 \%$ emulsion, time of shearing $=4.00 \mathrm{~min}, \dot{\gamma}=10 \mathrm{~s}^{-1}$.

Figure C.36 $1.0 \%$ emulsion, average diameter $=11.78 \mu \mathrm{m}$, time of shearing $=4 \mathrm{~min}, \dot{\gamma}=10 \mathrm{~s}^{-1}$.

Figure C.37 $1.0 \%$ emulsion, time of shearing $=10.00 \mathrm{~min}, \dot{\gamma}=10 \mathrm{~s}^{-1}$.

Figure C.38 $1.0 \%$ emulsion, average diameter $=12.94 \mu \mathrm{m}$, time of shearing $=10 \mathrm{~min}, \dot{\gamma}=10 \mathrm{~s}^{-1}$.

Figure C.39 $1.0 \%$ emulsion, time of shearing $=15.00 \mathrm{~min}, \dot{\gamma}=10 \mathrm{~s}^{-1}$.

Figure C.40 $1.0 \%$ emulsion, average diameter $=13.57 \mu \mathrm{m}$, time of shearing $=15 \min , \dot{\gamma}=10 \mathrm{~s}^{-1}$.

Figure C.41 $1.0 \%$ emulsion, time of shearing $=20.00 \mathrm{~min}, \dot{\gamma}=10 \mathrm{~s}^{-1}$. 
Figure C.41 $1.0 \%$ emulsion, average diameter $=14.10 \mu \mathrm{m}$, time of shearing $=20 \min , \dot{\gamma}=10 \mathrm{~s}^{-1}$.

Figure C.42 $1.0 \%$ emulsion, time of shearing $=35.00 \mathrm{~min}, \dot{\gamma}=10 \mathrm{~s}^{-1}$.

Figure C.43 $1.0 \%$ emulsion, average diameter $=14.83 \mu \mathrm{m}$, time of shearing $=35 \min , \dot{\gamma}=10 \mathrm{~s}^{-1}$.

Figure C.45 $1.0 \%$ emulsion, time of shearing $=4.00 \mathrm{~min}, \dot{\gamma}=30 \mathrm{~s}^{-1}$.

Figure C.46 $1.0 \%$ emulsion, average diameter $=11.68 \mu \mathrm{m}$, time of shearing $=4 \min , \dot{\gamma}=30 \mathrm{~s}^{-1}$.

Figure C.47 $1.0 \%$ emulsion, time of shearing $=10.00 \mathrm{~min}, \dot{\gamma}=30 \mathrm{~s}^{-1}$.

Figure C.48 $1.0 \%$ emulsion, average diameter $=12.62 \mu \mathrm{m}$, time of shearing $=10 \min , \dot{\gamma}=30 \mathrm{~s}^{-1}$.

Figure C.49 $1.0 \%$ emulsion, time of shearing $=15.00 \mathrm{~min}, \dot{\gamma}=30 \mathrm{~s}^{-1}$.

Figure C.50 $1.0 \%$ emulsion, average diameter $=13.26 \mu \mathrm{m}$, time of shearing $=15 \min , \dot{\gamma}=30 \mathrm{~s}^{-1}$.

Figure C.51 $1.0 \%$ emulsion, time of shearing $=20.00 \mathrm{~min}, \dot{\gamma}=30 \mathrm{~s}^{-1}$.

Figure C.52 $1.0 \%$ emulsion, average diameter $=13.57 \mu \mathrm{m}$, time of shearing $=20 \min , \dot{\gamma}=30 \mathrm{~s}^{-1}$.

Figure C.53 $1.0 \%$ emulsion, time of shearing $=35.00 \mathrm{~min}, \dot{\gamma}=30 \mathrm{~s}^{-1}$.

Figure C.54 $1.0 \%$ emulsion, average diameter $=13.78 \mu \mathrm{m}$, time of shearing $=35 \mathrm{~min}, \dot{\gamma}=30 \mathrm{~s}^{-1}$.

Figure C.55 $1.0 \%$ emulsion, time of shearing $=4.00 \mathrm{~min}, \dot{\gamma}=50 \mathrm{~s}^{-1}$. 
Figure C.56 $1.0 \%$ emulsion, average diameter $=11.68 \mu \mathrm{m}$, time of shearing $=4 \min , \dot{\gamma}=50 \mathrm{~s}^{-1}$.

Figure C.57 $1.0 \%$ emulsion, time of shearing $=10.00 \mathrm{~min}, \dot{\gamma}=50 \mathrm{~s}^{-1}$.

Figure C.58 $1.0 \%$ emulsion, average diameter $=12.41 \mu \mathrm{m}$, time of shearing $=10 \mathrm{~min}, \dot{\gamma}=50 \mathrm{~s}^{-1}$.

Figure C.59 $1.0 \%$ emulsion, time of shearing $=15.00 \mathrm{~min}, \dot{\gamma}=50 \mathrm{~s}^{-1}$.

Figure C.60 $1.0 \%$ emulsion, average diameter $=12.73 \mu \mathrm{m}$, time of shearing $=15 \min , \dot{\gamma}=50 \mathrm{~s}^{-1}$.

Figure C.61 $1.0 \%$ emulsion, time of shearing $=20.00 \mathrm{~min}, \dot{\gamma}=50 \mathrm{~s}^{-1}$.

Figure C.62 $1.0 \%$ emulsion, average diameter $=13.04 \mu \mathrm{m}$, time of shearing $=20 \min , \dot{\gamma}=50 \mathrm{~s}^{-1}$.

Figure C.63 $1.0 \%$ emulsion, time of shearing $=35.00 \mathrm{~min}, \dot{\gamma}=50 \mathrm{~s}^{-1}$.

Figure C.64 $1.0 \%$ emulsion, average diameter $=13.26 \mu \mathrm{m}$, time of shearing $=35 \min , \dot{\gamma}=50 \mathrm{~s}^{-1}$. 


\section{SYMBOLS AND ABBREVIATIONS}
A
Hamaker Constant $\left(\sim 10^{-20}\right)$. [J]
C
Collision frequency per unit time and volume. [1/s]
Ca
Capillary number.
$\mathbf{C a}_{\text {cr }}$
Critical Capillary number.
Cas.
Castor oil.
D
Diameter. [m]
$\mathbf{F}$
Force. $[\mathrm{N}]$
$\mathbf{h}_{0}$
Initial distance. $[\mathrm{m}]$
$\mathbf{h}_{\text {crit }}$
Critical distance. $[\mathrm{m}]$
$\mathbf{k}$
Boltzmann's constant $\left(1.38 \cdot 10^{-23}\right)$. [J/K]
$\mathbf{L}$
Tube length. [m]
n
Number of droplets per volume. $\left[1 / \mathrm{m}^{3}\right]$
p
Viscosity ratio of the dispersed phase to the continuous phase.
$\mathbf{P}_{\text {coll }}$
Collision Probability.
PDMS Polydimethylsiloxane.
PIB
Polyisobutene
$\mathbf{P}_{\mathrm{k}}$
Capillary pressure. $[\mathrm{Pa}]$
Q
Flow rate. $\left[\mathrm{m}^{3} / \mathrm{s}\right]$
$\mathbf{r}_{\mathbf{i}}$
Principal radius of curvature of the interface. [m] 


\begin{tabular}{|c|c|}
\hline $\mathbf{R}$ & Radius of droplet. [m] \\
\hline $\mathbf{S i}$ & Silicone oil. \\
\hline $\mathbf{R e}_{\mathrm{d}}$ & Particle Reynolds number. \\
\hline $\mathbf{t}$ & Time. [s] \\
\hline $\mathbf{t}_{\text {coll }}$ & Time of collision. [s] \\
\hline $\mathbf{v}$ & Velocity. [m/s] \\
\hline $\mathbf{V}$ & Volume. $\left[\mathrm{m}^{3}\right]$ \\
\hline$\eta_{\mathbf{E}}$ & Emulsion viscosity. [Pa.s] \\
\hline$\eta_{m}$ & Continuous phase viscosity. [Pa.s] \\
\hline$\eta_{\mathbf{P}}$ & Dispersed phase viscosity. [Pa.s] \\
\hline$\dot{\gamma}$ & Shear rate. $\left[\mathrm{s}^{-1}\right]$ \\
\hline$\dot{\gamma}_{w}$ & Shear rate at the tube wall. $\left[\mathrm{s}^{-1}\right]$ \\
\hline$\phi$ & Volume fraction. \\
\hline$\sigma$ & Interfacial tension. $[\mathrm{N} / \mathrm{m}]$ \\
\hline$\rho$ & Density. $\left[\mathrm{kg} / \mathrm{m}^{3}\right]$ \\
\hline$\tau$ & Shear stress. $[\mathrm{Pa}]$ \\
\hline$\tau_{\mathrm{w}}$ & Shear stress at the wall. $[\mathrm{Pa}]$ \\
\hline$\Omega$ & Number of revolution per minute. \\
\hline$\Delta \mathbf{p}$ & Pressure drop across the tube. $[\mathrm{Pa}]$ \\
\hline
\end{tabular}




\section{CHAPTER 1}

\section{INTRODUCTION}

\subsection{Definition of Emulsions, their Properties and Applications}

Emulsions are dispersed, multiphase systems consisting of two or more almost mutually insoluble liquids, with the dispersed (internal) phase present in the form of droplets in a continuous (external) phase. The dispersed state means that emulsions have a large interfacial area between the fluid phases, allowing exchange processes and chemical reactions to take place more rapidly at the phase interface than in the undispersed state. Emulsions have special properties that make them very useful in many diverse fields such as in foodstuffs, pharmaceuticals, lubricants, cosmetics, laundry and cleaning agents. When the emulsions are mixed with other liquid materials, a unique behavior in particular flow results, which gives the emulsions those special properties. Emulsions are also important in the industries of textile, photography, and plastics, and find use in mining and enhanced oil recovery, and, in addition, are also widely used in agents for crop protection (Sherman, 1983). In all these applications, it is necessary to know the shape, size, and size distribution of the dispersed phase and how these quantities change during processing. In the literature, there has been extensive work done on the behavior of single drops in a flow field. Because of the 
difficulty in the study of the interaction of a collection of droplets, much less work has been done up to this point on a collection of droplets in a flow field.

Often, for slurries, gels, emulsions, and foams, inhomogeneous fluid properties at solid boundaries create "apparent wall slip." The reduced fluid viscosity at the boundary creates a thin layer of fluid having a large velocity gradient that can be treated as a "slipping layer." In measurements of fluid viscosity this is a complicating factor, and it is necessary to correct for wall slip to determine the true deformation experienced by the bulk of the sample and thereby the true viscosity.

\subsection{Research Objectives}

The overall objective of the present research was to examine the coalescence and break-up of model emulsion droplets, during shear flow in capillary tubes and also in a cone-and-plate viscometer. Both material and process parameters are likely to affect coalescence and break-up of the emulsion. The material variables affecting these phenomena are the emulsion's chemical nature, the droplet size and size distribution, the viscosity ratio, and the relative amounts of the two phases. The process variables are shear rate, temperature, and time of shearing.

If the emulsion concentration is low (less than 10\%) wall slip and droplet migration will not occur. According to Goldsmith and Mason (1962), if the concentration is low (less than 10\%) there will be no migration and the 
concentration profile will be uniform at the beginning and end of the tube. In view of this, dilute emulsions were employed in this study which covers only coalescence and break-up.

To minimize experimental work, coalescence was observed at three different shear rates. For each value of shear rate, the average diameter of the droplets was measured at three residence times using three tube lengths. This gave us the relationship between the droplet diameter and the residence time of the emulsion in the tubes. In each case, the steady state value of the droplet diameter was also determined.

To further understand the relationship between the shear rate and the droplet diameter, the measurement of the droplet diameter was carried out in a cone-and-plate geometry for several different shear rates at the same residence times as in the tube flow experiments.

The shear rate and residence time experiment was repeated at two other temperatures, 29 and 35 degrees Celsius, which gave us the temperature effect on coalescence. To accomplish this, tubes were immersed in a water bath, in water heated to the appropriate temperatures.

The effect of the concentration of the disperse phase on droplet coalescence was also examined. This was done by repeating the shear rate and residence time experiments at different concentrations. 


\section{CHAPTER 2}

\section{LITERATURE REVIEW}

\subsection{Rheology of Emulsions}

Depending on the emulsification process, the diameter of droplets in the internal phase lies between $0.1 \mu \mathrm{m}$ and $0.1 \mathrm{~mm}$ (Shubert and Armbruster, 1992). Usually, there is a broad droplet size-distribution; a narrow distribution can be considered as one where the ratio between the smallest and the largest droplet size ranges between 1 and 10. Emulsions of this kind are normally thermodynamically unstable. However, droplet coalescence of quiescent emulsions can be reduced or even eliminated through a stabilization mechanism of some sort (Shubert and Armbruster, 1992).

The rheological behavior of an emulsion can be Newtonian or nonNewtonian depending upon the emulsion composition. At low to moderate values (less than 1\%) of the dispersed-phase concentration, emulsions generally exhibit Newtonian behavior. In the high concentration range, emulsions behave as shearthinning fluids.

The viscosity of an emulsion, defined as the ratio of shear stress to shear rate, depends upon several factors (Pal and Masliyah, 1992; Utracki, 1989):

1. The viscosity of the continuous and dispersed phases.

2. The volume fraction of the dispersed phase. 
3. The average droplet size and droplet size distribution.

4. Shear rate.

5. The nature and concentration of the emulsifying agent, if any.

6. Temperature.

The viscosity of an emulsion is directly proportional to the continuousphase viscosity $\left(\eta_{c}\right)$, and therefore, all the viscosity equations proposed in the literature are written in terms of the relative viscosity $\left(\eta_{\mathrm{r}}\right)$ which is defined as the ratio of the emulsion viscosity to the matrix viscosity. The volume fraction of the dispersed phase is the most important factor that affects the viscosity of emulsions.

When droplets are introduced into a given flow field, the flow pattern becomes distorted, and consequently the rate of energy dissipation increases, leading, in turn, to an increase in the viscosity of the system. For suspensions, Einstein showed that at an extremely low concentration the increase in the viscosity of the system due to addition of particles is a linear function of the volume fraction of the dispersed particles.

Unlike a solid-in-liquid suspension, the viscosity of an emulsion may depend upon the viscosity of the dispersed phase as well. This dependence is especially true when internal circulation occurs within the dispersed droplets.

In systems where the dispersed phase size is sub-micron and Brownian motion is significant, the relative viscosity decreases with an increase in the particles' size (Krieger, 1973). 
The effect of particle size distribution on the viscosity of emulsions has been investigated by several researchers (Chong et al, 1971 for example). Most of these studies indicate that the effect of particle size distribution is enormous at high values of the dispersed phase concentration. At low concentrations, however, the effect is small.

The viscosity of emulsions is a strong function of temperature; it decreases with increasing temperature (Chong et al, 1971). The decrease in emulsion viscosity that occurs with raising the temperature is mainly due to a decrease in the continuous phase viscosity. The increase in temperature may also affect the average droplet size and droplet size distribution.

For infinite dilution, neglecting the influence of the interface, an expression for the intrinsic viscosity of an emulsion is (see, for example, Utracki, 1989),

$$
[\eta]_{\mathrm{E}}=2.5 \frac{\left(\eta_{\mathrm{d}}+\frac{2 \eta_{\mathrm{c}}}{5}\right)}{\eta_{\mathrm{d}}+\eta_{\mathrm{c}}}
$$

Where,

$[\eta]_{\mathrm{E}}:$ is the emulsion viscosity

$\eta_{\mathrm{d}}$ : is the droplet viscosity

$\eta_{\mathrm{c}}:$ is the medium viscosity

At the other extreme of extremely high concentrations, emulsions can behave like soft, elastic solids. In the intermediate concentrations region, a spectrum of non-Newtonian behavior can be observed. Specific expressions for 
the viscosity may be found in the book by Utracki (1989). Recent work on relating emulsion rheology to emulsion structure may be found in Palierne (1990), Doi and Ohta (1991), and Lee and Park (1994).

\subsection{Stability of Emulsions}

A consequence of the small droplet size and presence of an interfacial film between the droplets in emulsions is that a fairly stable dispersion of these species can be made. That is, the suspended droplets do not settle out or float rapidly, and the droplets do not coalesce quickly.

Colloidal species can come together in very different ways. In the definition of emulsion stability, stability is considered against three different processes: creaming (sedimentation), aggregation, and coalescence. Creaming is the opposite of sedimentation and also results from a density difference between two liquid phases. In aggregation two or more droplets clump together, touching only at certain points, and with virtually no changes in total surface area. Aggregation is sometimes referred to as flocculation or coagulation. In coalescence two or more droplets fuse together to form single larger unit with a reduced total surface area (Schramm, 1992).

In aggregation the species retain their identity but lose their kinetic independence because the aggregate moves as a single unit. Aggregation of droplets may lead to coalescence and the formation of larger droplets until the 
phases become separated. In coalescence, on the other hand, the original species lose their identity and become part of a new species. Kinetic stability can thus have different meanings. An emulsion can be kinetically stable with respect to coalescence but unstable with respect to aggregation. Or a system can be kinetically stable with respect to aggregation but unstable with respect to sedimentation or flotation (Schramm, 1992).

According to Mitchel et al (1983) emulsion stability may be improved by:

1. Reducing the particle size and narrowing the particle size distribution.

2. Minimizing the density difference of the two phases.

3. Increasing the viscosity of the external phase.

Encounters between droplets in a dispersion can occur frequently because of Brownian motion, sedimentation, or stirring. The stability of the dispersion depends upon whether particles attract or repel each other when these encounters occur. The main cause of repulsive forces is the electrostatic repulsion between like-charged droplets. The main attractive forces are the van der Waals forces between droplets (Schramm, 1992).

In summary, emulsions are stable, if the repulsive forces between the dispersed droplets are sufficiently strong and the dispersed phase has sufficiently limited mobility in the direction of the external force field. The repulsive forces prevent aggregation and coalescence of the droplets, while the restricted mobility prevents the droplets from settling (Shubert and Armbruster, 1992). 


\subsection{Droplet Break-up}

During flow droplets are deformed by the normal and tangential stresses on the interfaces between the internal and external phases. Droplet break-up occurs when the deforming forces locally exceed the shape-preserving interfacial forces. The shape-preserving forces can be characterized by the capillary pressure $\mathrm{p}_{\mathrm{k}}$, which can be calculated from the Laplace equation:

$$
\mathrm{P}_{\mathrm{k}}=\sigma\left(\frac{1}{\mathrm{r}_{\mathrm{a}}}+\frac{1}{\mathrm{r}_{\mathrm{b}}}\right)
$$

Where $\sigma$ is the interfacial tension between the internal and external phases, and $r_{a}$ and $r_{b}$ are the two principal radii of curvature of the interface.

For spherical droplets of diameter D, equation (2.2) simplifies to

$$
\mathrm{P}_{\mathrm{k}}=\frac{4 \sigma}{\mathrm{D}}
$$

Thus a droplet can no longer be broken up in a flow field, if the forces acting on its interface are in equilibrium with the capillary forces. Since the capillary pressure increases hyperbolically with decreasing droplet diameter, a droplet size $\mathrm{D}_{\max }$ exists below which, for constant flow-pressure, no further droplet break-up is possible (Whorlow, 1980, for example).

In laminar shear flow, the Capillary number incorporates both the shear stress and the Capillary pressure:

$$
\mathrm{Ca}_{1}=\frac{\tau \mathrm{D}}{2 \sigma}
$$


The critical Capillary number:

$$
\mathrm{Ca}_{\mathrm{cr}}=\frac{\tau \mathrm{D}_{\max }}{2 \sigma}
$$

Where,

$\mathrm{Ca}_{1} \quad$ : Capillary number

$\mathrm{Ca}_{\mathrm{cr}} \quad$ : critical Capillary number

D : diameter of the droplet $(\mathrm{m})$

$\mathrm{D}_{\max } \quad$ : limiting diameter of the droplet (m)

$\tau \quad:$ shear stress $(\mathrm{Pa})$

$\sigma \quad$ : interfacial tension between the internal and external phases $(\mathrm{N} / \mathrm{m})$

Equation (2.5) gives the limiting diameter $\mathrm{D}_{\max }$ of droplet that can just still exist in a laminar flow-field. If the critical value $\mathrm{Ca}_{\text {cr }}$ is exceeded, the drop breaks-up. $\mathrm{Ca}_{\text {cr }}$ depends on the type of flow and on the ratio of the drop viscosity to that of the continuous phase $\left(\eta_{d} / \eta_{c}\right)$. The break-up of single droplets in simple shear flow has been well studied and some results are shown as the curve in Figure 2.1 (Taylor, 1932; Grace, 1982). Note that above a certain viscosity ratio, shear flow is ineffective in breaking droplets regardless of the shear stress imposed. 


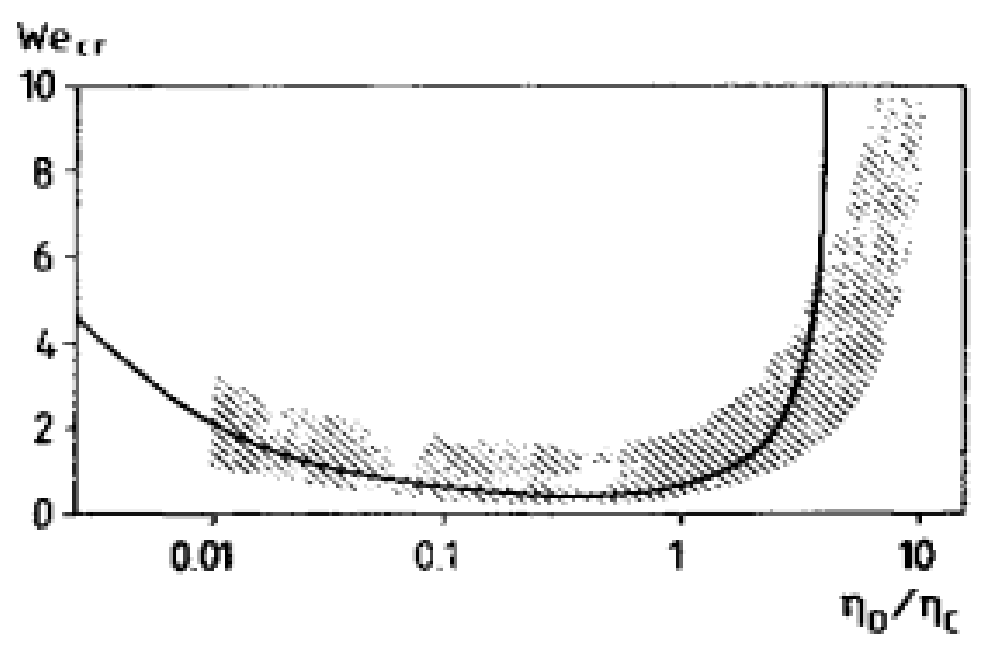

Figure 2.1 The critical Capillary number for breakup of droplets in simple shear flow (curve, results by Grace, 1982) and for the resulting average droplet size in a colloid mill (hatched area, results by Ambruster, 1990) as a function of the viscosity ratio of the dispersed to the continuous phase.

\subsection{Coalescence of Emulsions}

The coalescence of two drops is usually considered to consist of a combination of three events: the collision process, the film drainage process, and interface rupture. The collision process is taken to be the relative movement of the two drops starting at the point of initial contact and lasting as long as the close contact remains. This time span is called the interaction time. The drops trap a liquid film between them that needs to be drained if coalescence is to take place. The time needed for this drainage is the drainage or coalescence time. At a certain film thickness, the film ruptures and coalescence follows almost immediately. The 
rupture time is usually considered small and negligible compared to the drainage time and interaction times (Hallvard and Luo, 1996).

Expressions for the collision frequency, $\mathrm{C}$, per unit time and volume can be derived if the particles are assumed to be spherical and to follow the streamlines of the continuous phase flow. For droplets of equal size $\mathrm{C}$ is then given by (Chesters, 1991):

$$
C=k v d^{2} n^{2}
$$

where $v$ is a characteristic velocity between two points a distance $d$ apart in the basic flow, and $\mathrm{n}$ is the number of droplets per volume. Choices of $v$ together with the corresponding values of $k$ are given in Table 2.1.

Table 2.1 Particle collision rates, neglecting hydrodynamic interaction in various flows (Chesters, 1991).

\begin{tabular}{lcc}
\hline Flow type & $v$ & $k$ \\
\hline Viscous simple shear & $\dot{\gamma} \mathrm{d}$ & $2 / 3$ \\
Fine-scale turbulence & $(\varepsilon / v)^{1 / 2} \mathrm{~d}$ & $(2 \pi / 15)^{1 / 2}$ \\
Inertial-subrange turbulence & $(\varepsilon \mathrm{d})^{1 / 3}$ & $(8 \pi / 3)^{1 / 2}$ \\
\hline
\end{tabular}

Depending on whether the particle Reynolds number $\operatorname{Re}_{\mathrm{d}}$ is much smaller or much greater than unity, the respective forces governing the collision will be predominantly viscous or inertial. Laminar flows being typically characterized by 
a small Reynolds number, the collision generally is viscous. The force exerted by the viscous simple shear flow on a colliding particle is:

$$
\mathrm{F} \sim 6 \pi \eta_{\mathrm{c}} \mathrm{R}(\dot{\gamma} \mathrm{R})
$$

the typical collision duration, the time spent by the particles in close proximity, is given by:

$$
t_{i} \sim(\dot{\gamma})^{-1}
$$

Where $\mathrm{R}$ is the particle radius, $\eta_{\mathrm{c}}$ is the continuous phase viscosity, $\dot{\gamma}$ is the shear rate. The film drainage time depends on the rigidity (or mobility) of the particle interface, and the rigidity (or mobility) depend on the viscosity ratio of the dispersed phase to the continuous phase. Note that in our experiments, the liquid film between the droplets is likely to be partially mobile because the viscosity of the continuous phase is low ( $\sim .5$ poise), and the viscosity ratio of the dispersed phase to the continuous phase is approximately equal to 15 .

According to Ross et al. (1978) the collision probability function is

$$
P_{\text {coll }}=\exp \left(-\frac{t_{\text {coll }}}{t_{\text {proc }}}\right)=\exp \left(\frac{-\pi}{8 \dot{\gamma} \phi t_{\text {proc }}}\right)
$$

Where $\mathrm{t}_{\text {coll }}$ is the time of collision, $\mathrm{t}_{\text {proc }}$ is the time of process, $\dot{\gamma}$ is the shear rate, and $\phi$ is the volume fraction. The collision probability increases with increasing shear rate and the volume fraction of the dispersed phase. Clearly coalescence is 
not possible unless drops collide with each other. Collisions occur only when the collision probability is high.

The second part of the modeling of coalescence deals with drainage of the liquid film between the colliding drops. Initially, at large separation the drops approach each other according to the velocity gradient of the external flow field. At a certain separation $\left(h_{\mathrm{o}}\right)$, hydrodynamic interaction becomes significant and collision starts. When they reach a critical distance $\left(\mathrm{h}_{\text {crit }}\right)$, instabilities grow at the interface and suddenly film rupture occurs where the drops coalesce. If the interaction time of the collision is insufficient to reach $\mathrm{h}_{\text {crit }}$, the drops only tumble and separate, see Figure 2.2.

According to Chesters (1991) for partially mobile film drainage between two drops:

$$
t_{\text {drain }} \sim \frac{\pi \eta_{d} F^{1 / 2}}{2(2 \pi \sigma / R)^{3 / 2}}\left(\frac{1}{h_{\text {crit }}}-\frac{1}{h_{o}}\right)
$$

where $t_{\text {drain }}$ is the required drainage time to reach coalescence, $\eta_{d}$ is the dispersed phase viscosity, $\sigma$ is the interfacial tension, $\mathrm{F}$ is the Stokes drag force acting on the drops, and $h_{o}$ is the initial distance between the two drops.

$$
\mathrm{h}_{\mathrm{o}} \sim \mathrm{R}(3 / 16)^{1 / 4} \mathrm{p}^{1 / 2} \mathrm{Ca}^{3 / 4}
$$

where $\mathrm{p}$ is the viscosity ratio between dispersed phase and continuous phase $\left(\eta_{\mathrm{d}} / \eta_{\mathrm{c}}\right)$, and Ca is the capillary number $\left(=\eta_{\mathrm{c}} \dot{\gamma} \mathrm{R} / \sigma\right)$ 


$$
\mathrm{h}_{\text {crit }} \sim\left(\frac{\mathrm{AR}}{8 \pi \sigma}\right)^{1 / 3}
$$

in which A is the material dependent Hamaker constant (typically $10^{-20} \mathrm{~J}$ ).

From the above, it is seen that drops will coalesce if the film between the two drops is drained. This requires that the interaction time be much larger than the collision time, and the distance between the drops be less than the critical distance $\mathrm{h}_{\text {crit }}($ Chesters, 1991).

There are several researchers who have studied the coalescence of liquid droplets dispersed in various immiscible liquids. These researchers and the materials that they used are listed in Table 2.2. However, none of these drew definitive conclusions about the validity of the coalescence theory presented in this chapter. 
Table 2.2 Coalescence systems used by others authors.

\begin{tabular}{||c|c|c|c|c|c||}
\hline Author & Dispersed phase & Continuous phase & Viscosity ratio & $\begin{array}{c}\text { Interfacial tension } \\
(\mathbf{m N} / \mathbf{m})\end{array}$ & $\begin{array}{c}\text { Temperature } \\
\left({ }^{0} \mathbf{C}\right)\end{array}$ \\
\hline $\begin{array}{c}\text { I. Vinckier and P. } \\
\text { Moldenaers } \\
\text { (1998) }\end{array}$ & Polyisobutene & Polydimethylsiloxane & 0.5 & 3 & 23 \\
\hline $\begin{array}{c}\text { N. Grizzuti and O. } \\
\text { Bifulco } \\
\text { (1997) }\end{array}$ & Polyisobutylene & Polydimethylsiloxane & 0.5 & 3 & 23 \\
\hline $\begin{array}{c}\text { J. M. H. Janssen } \\
\text { (1993) }\end{array}$ & Castor oil & Silicone oil & 0.07 to 7 & 4.1 & 23 \\
\hline $\begin{array}{l}\text { J. M. H. Janssen } \\
\text { (1993) }\end{array}$ & Corn syrup/water & Silicone oil & 0.007 to 34 & & 23 \\
\hline
\end{tabular}




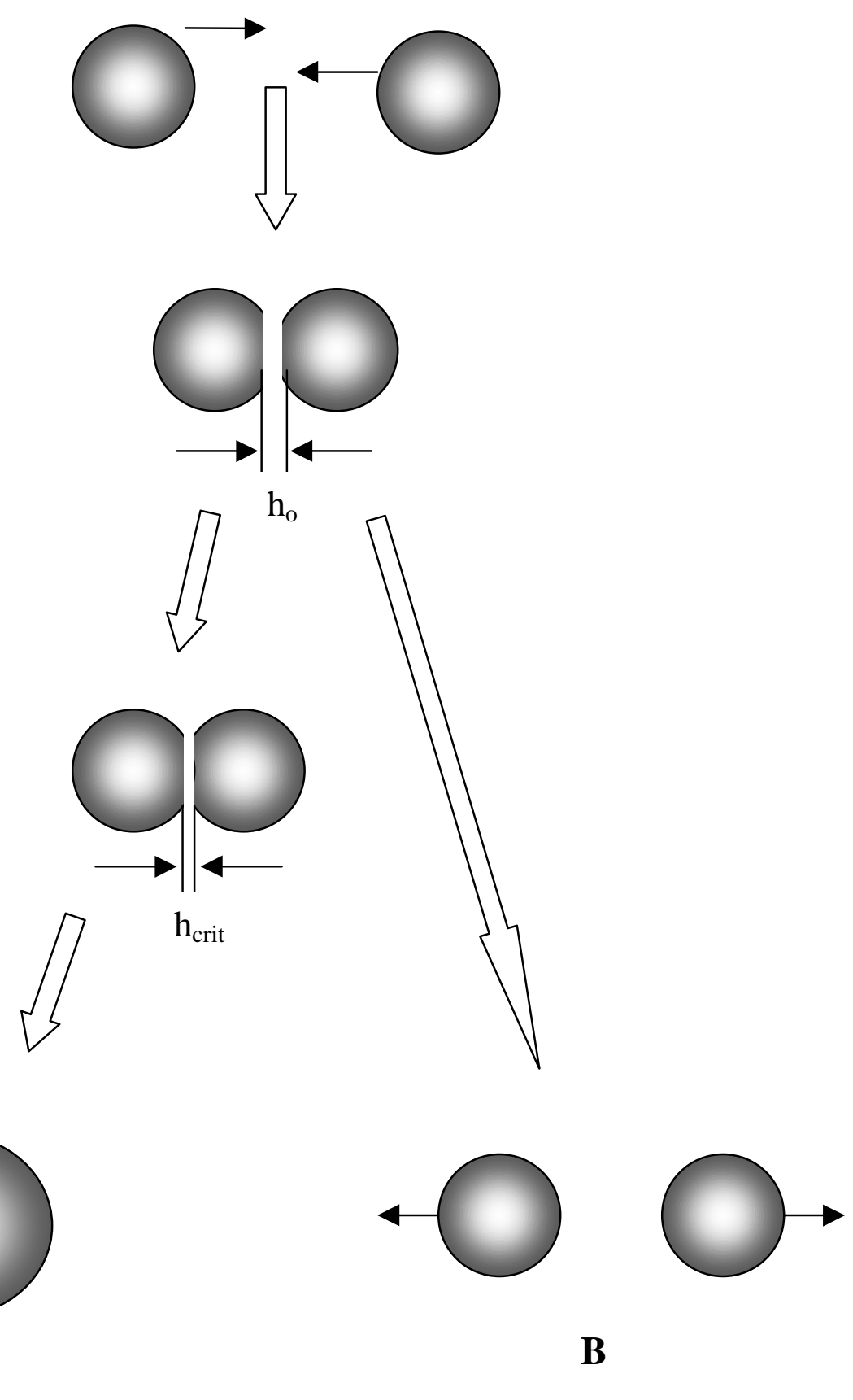

Figure 2.2 Collision between two drops: A) the drops coalesce after reaching the critical distance $\left(\mathrm{h}_{\text {crit }}\right)$. B) the drops tumble and separate. 


\section{CHAPTER 3}

\subsection{EXPERIMENTAL APPARATUS}

A schematic diagram of the apparatus that was used in the research is shown in Figure 3.1. It consists of a 1-quart cylindrical reservoir from which the emulsion is extruded by means of a plunger with the help of a screw attached to a motor. In this apparatus there are several main components: the capillary tubes, the pump, a digital readout which indicates the pressure drop across the capillary tube, a pressure transducer, microscope, camera, ultrasonic processor, image analyzer, and scanner. The emulsion is sheared in capillary tubes and also in a cone-andplate device. Also a hot water bath is used to raise the temperature of the emulsion; this is shown in Figure 3.2.

The emulsion samples flow through stainless steel capillaries of different diameters and different lengths to eliminate end effects (Whorlow, 1980). The frictional pressure drop associated with laminar flow of the emulsion is measured in the capillary tube itself. This pressure drop is measured using an Omega model PX-302 pressure transducer having a range of 0 to $100 \mathrm{psi}$; the reading is displayed on a digital pressure meter. The pressure transducer is calibrated by using another calibrated pressure transducer. The pump used has a maximum flow rate of $0.28 \mathrm{ml} / \mathrm{s}$, and a minimum flow rate of $0.018 \mathrm{ml} / \mathrm{s}$. 
In this study, a locally fabricated cone-and-plate device is also used to study the coalescence and break-up of the emulsion system. Figure 3.3 shows the cone-and-plate device where both the cone and the plate are made of Plexiglas.

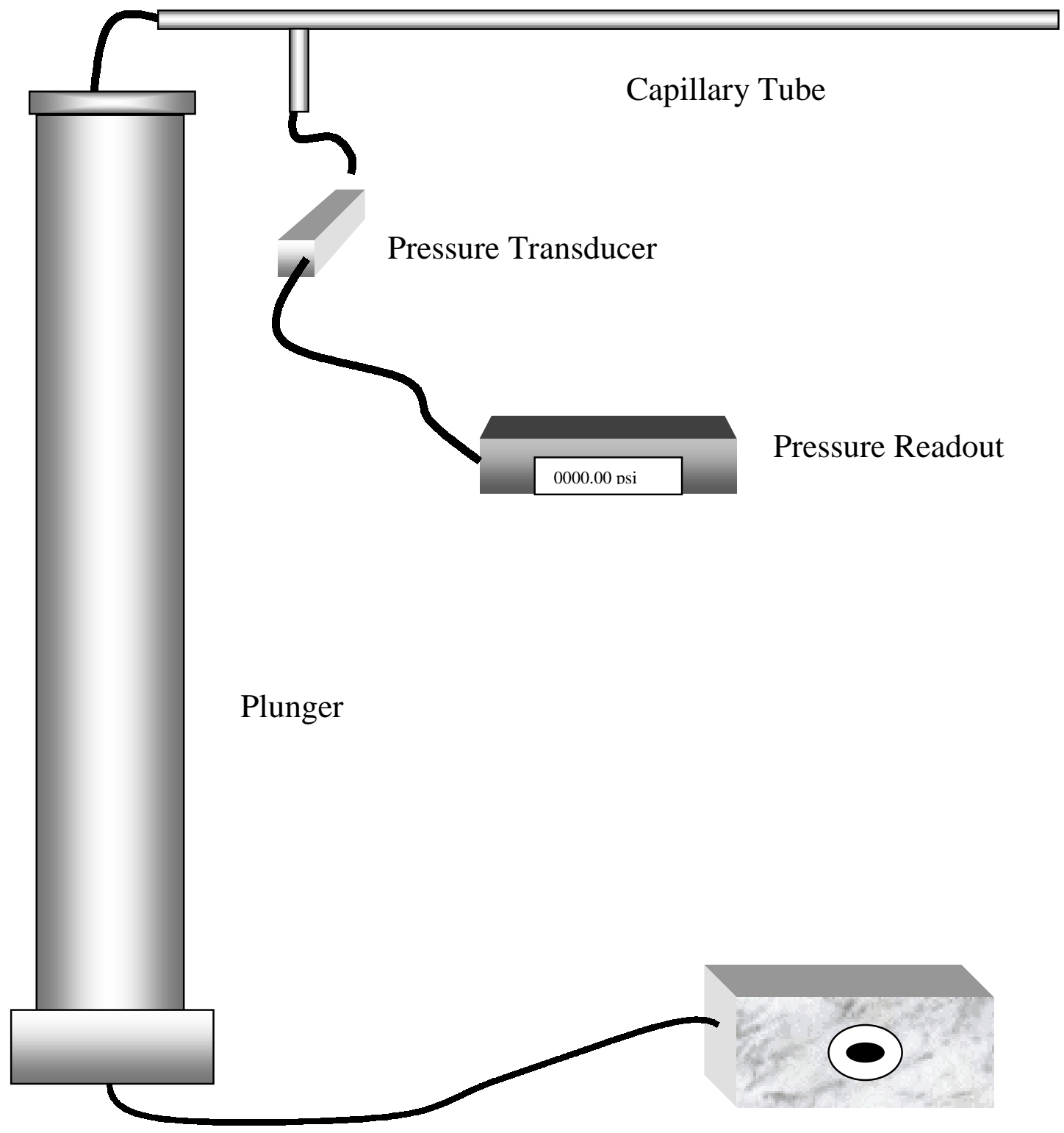

Flow Controller 
Figure 3.1 Experimental set up

A motor is used to drive the cone, while the plate is kept stationary. The cone has an angle of $4^{0}$ and is about $8 \mathrm{~cm}$ in diameter.

A Fisher Stereomaster Zoom microscope having a magnification range of $32 \mathrm{x}$ to $160 \mathrm{x}$, with a field of view of approximately $1.8-\mathrm{mm}$ was used to view the emulsion samples. The working distance of the microscope is $37.7 \mathrm{~mm}$. A Minolta $\mathrm{X}-700$ camera is mounted on the microscope photo tube with the help of a T-joint. A transmitted light source is used in the microscope for getting pictures with good contrast. The camera has an auto winder capable of shooting 2 frames per second; this enables picture taking at high shutter speeds. A sensitive film such as T-max 3200 is used in order to ensure better quality of high shutter speed pictures.

Emulsions were prepared using an ultrasonic power supply, or generator, which converts low voltage to high frequency (20,000 cycles per second) electrical energy. This electrical energy is then changed to mechanical vibrations. These vibrations are intensified by the horn (probe), creating pressure waves in liquid. This action forms millions of microscopic bubbles that emulsify the emulsion. The ultrasonic device is made by Sonics \& Materials Inc. 


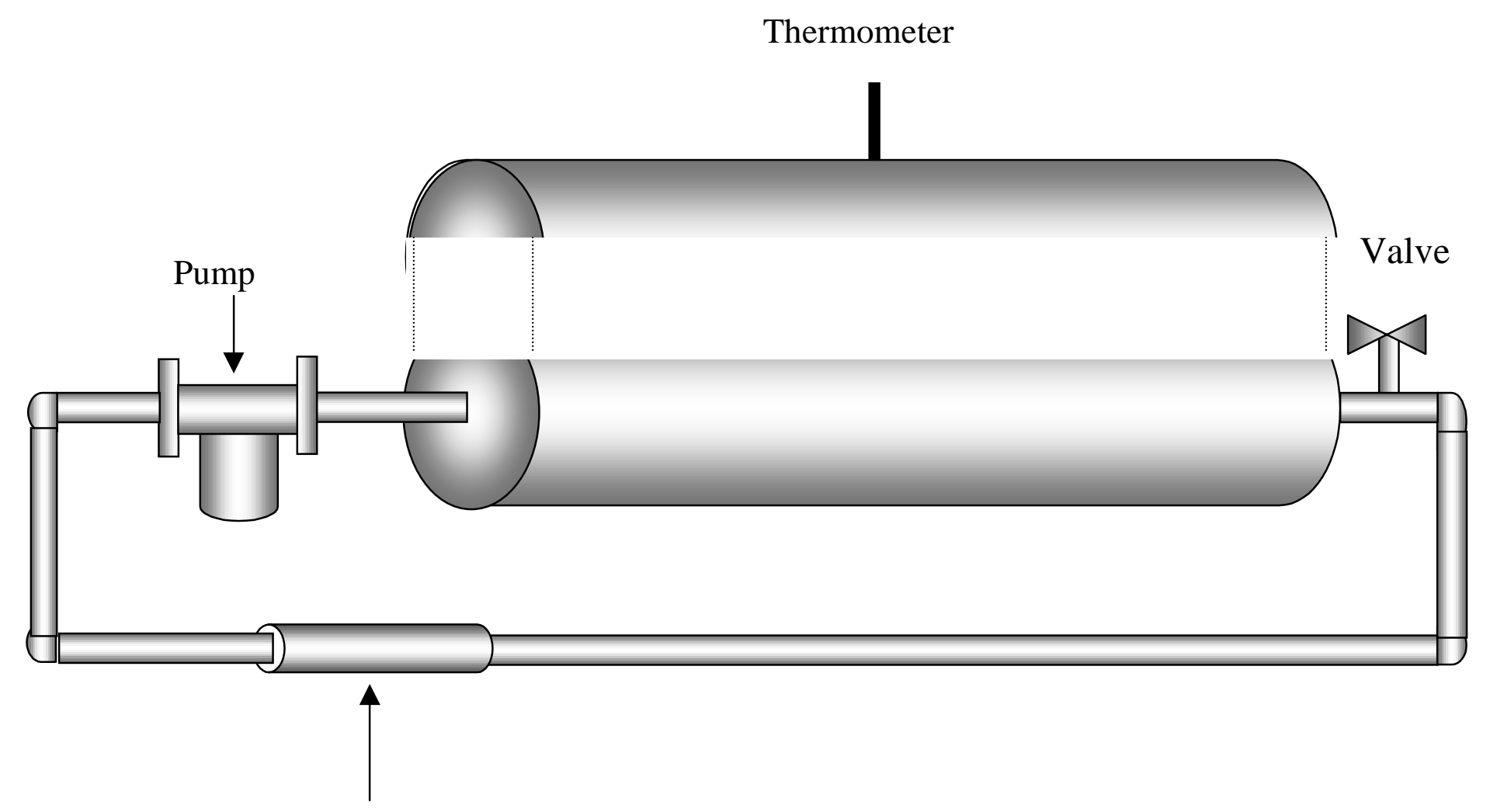

Heating element

Figure 3.2 Hot water bath 


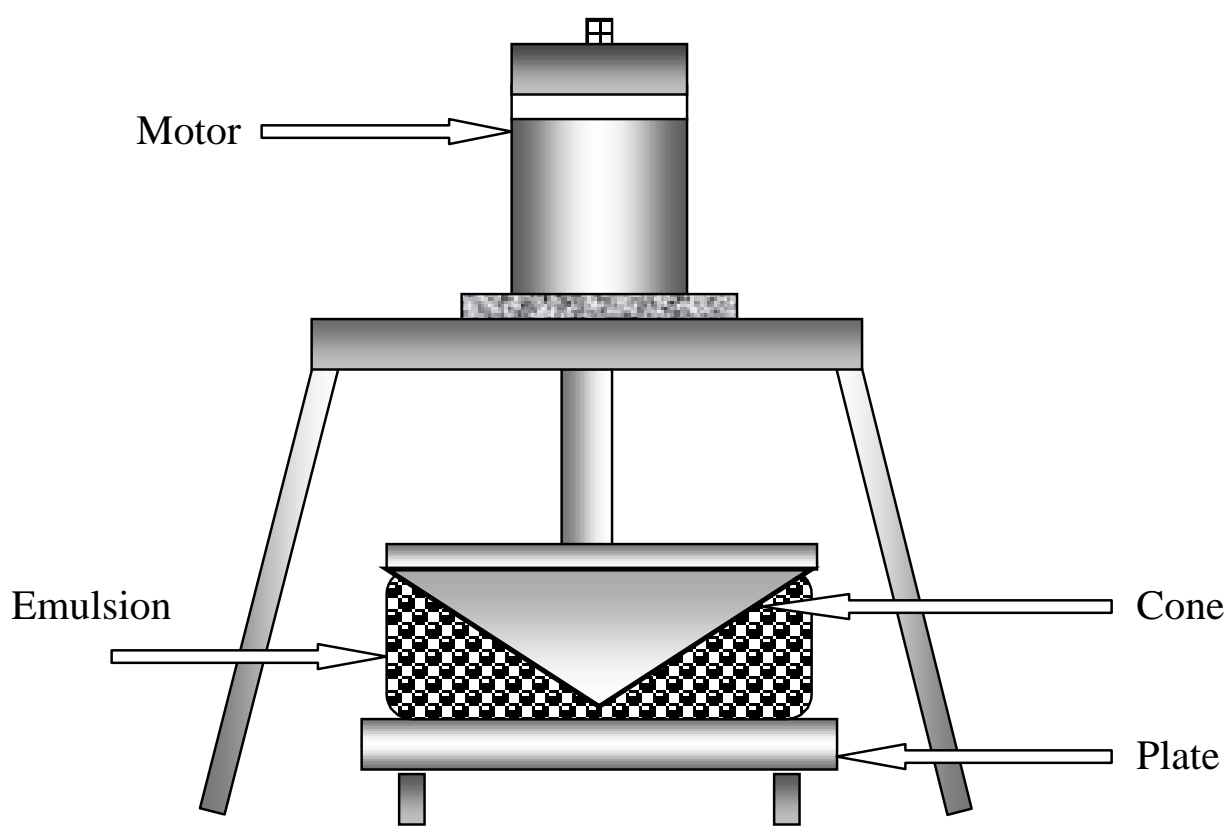

Figure 3.3 Cone-and-plate apparatus 


\subsection{EXPERIMENTAL PROCEDURE}

\subsubsection{Materials Used}

An initial objective of this research was to find an emulsion system that fulfills several requirements. It had to be stable over the time period of the experiments. The emulsion system had to show coalescence of droplets when subject to simple shear flow in a capillary tube. For the droplet break-up experiment, the viscosity ratio of the dispersed phase to the continuous phase must be less than four (see Figure 2.1). At high viscosity ratios, the shear strain transferred over from the external medium is too small to break up the droplets (Shubert and Armbruster, 1992). In this range, an emulsion can still be produced but by using machines like high-pressure homogenizers in which laminar flow is not used to break up the droplets.

After a significant amount of trial and error, the emulsion system chosen for coalescence experiments alone was silicone oil and castor oil. At room temperature, the castor oil has a viscosity of 7.42 poise, and the silicone oil has a viscosity of 0.48 poise. The castor oil is dispersed in silicone oil. Thus, their viscosity ratio is greater than four. The emulsion was stable even over a period of several days. Emulsions were allowed to sit on a slide and also in a beaker. No creaming was observed because both oils have densities very close to each other. The density of silicone oil is $0.963 \mathrm{~g} / \mathrm{cc}$, and the density of castor oil is $0.961 \mathrm{~g} / \mathrm{cc}$. In the break-up experiment the viscosity ratio of the dispersed to the 
continuous phase must be less than four. Two systems were used. The first one was made of silicone oil with a viscosity $\sim 10.22$ poise at room temperature, and castor oil having a viscosity of 7.42 poise at room temperature. The castor oil is the dispersed phase and silicone oil is the continuous phase. The viscosity ratio is 0.73. The other system uses silicone oil. It has a viscosity of 0.48 poise at room temperature and castor oil has a viscosity of 7.42 poise. The silicone oil is the dispersed phase and the castor oil is the continuous phase. The viscosity ratio is 0.06. Table 3.1 lists the sources of the liquids used.

Table 3.1 Sources of the materials used.

\begin{tabular}{|l|l||}
\hline \multicolumn{1}{|c|}{ Material } & Company \\
\hline silicone fluid) & Thomas scientific \\
\hline Silicone oil DC 200 viscosity $\sim 10.0$ poise at $25^{\circ} \mathrm{C}$ & Fluka chemical \\
\hline Silicone oil DC 200 viscosity $\sim 1.0$ poise at $25{ }^{\circ} \mathrm{C}$ & Fluka chemical \\
\hline $\begin{array}{l}\text { Castor oil } \\
\text { Triglyceride of fatty acids. Fatty acid composition is } \\
\text { approximate ricinoleic } 87 \%, \text { oleic } 7 \%, \text { linoleic } 3 \%\end{array}$ & Aldrich chemical \\
palmitic $2 \%$, stearic $1 \%$ and dihydroxystearic trace & \\
amounts. &
\end{tabular}




\subsubsection{Preparation of the Emulsions}

The emulsion sample is prepared by mixing silicone oil with castor oil to the desired concentration. An ultrasonic vibrator horn is used to emulsify the castor oil in silicone oil. A stable and homogeneous emulsion is obtained. By changing the power of the ultrasonic vibrator the droplets sizes could be changed. Furthermore, the longer the time of emulsification, the smaller the droplet size and narrow the size distribution became. In the concentration effect study, a 5\% emulsion was prepared and emulsified and then diluted to $1 \%$ and $0.5 \%$ to start with same size distribution emulsion. Not that the ability to emulsify a liquid improves as the liquid viscosity decreased.

The $1 \%$ emulsion was pumped through the capillary tubes, and the pressure drop was then recorded. For the wall slip experiment (see Appendix A) stainless steel tubes were used. These tubes were 0.4 meter in length, but with different diameters: $1.74 \mathrm{~mm}, 1.3725 \mathrm{~mm}, 1.053 \mathrm{~mm}$, and $0.74 \mathrm{~mm}$. For the coalescence and break-up experiment PVC tubes were used; lengths varied from $1 \mathrm{~m}$ to $15 \mathrm{~m}$ with diameters ranging from of $1.588 \mathrm{~mm}$ to $2.381 \mathrm{~mm}$.

\subsubsection{Shearing the Emulsions}

The emulsion to be sheared is placed in the pump. The flow rate is set to give the desired shear rate. The average shear rate in the capillary tubes can be computed by using the following equation: 


$$
\dot{\gamma}=\frac{4 \overline{\mathrm{v}}}{\mathrm{D}}
$$

where $\dot{\gamma}=$ average shear rate $\left(\mathrm{s}^{-1}\right)$.

$$
\begin{aligned}
& \overline{\mathrm{v}}=\text { average velocity in the tube }(\mathrm{m} / \mathrm{s}) \text {. } \\
& \mathrm{D}=\text { inside tube diameter }(\mathrm{m})
\end{aligned}
$$

In the cone-and-plate experiment, the emulsion is poured on the plate and the cone is lowered onto the emulsion. The speed of rotation of the cone determines the shear rate applied to the emulsion. The speed of rotation is measured by counting the number of revolutions per minute. Using the following equation the shear rate can be calculated in the cone-and-plate rheometer. The shear rate is the same everywhere in the region between the cone-and-plate.

$$
\dot{\gamma}=\frac{2 \pi \Omega}{60 \tan \left(4^{\circ}\right)}
$$

where $\Omega=$ number of rotation per minute.

$4^{\mathrm{o}}$ is the angle of the cone.

\subsubsection{Photographing the Emulsion and Image Analysis}

A drop of the sample is placed under the microscope and observed to determine if coalescence and break-up have occurred both before and after shearing the emulsion. Samples are typically taken from central region between the cone and plate. In tube flow, the sample was collected on a slide approximately 
30 minutes after inception of flow. To measure the droplet size of the dispersed phase, a drop of emulsion is placed on the slide and a picture is taken using a photomicroscope. This picture is then digitized, and analyzed using the analysis software NIH-image. The software calculates the perimeter and area of each droplet, which is used to ascertain droplet size distribution. The analysis software NIH-image is calibrated from pixel unit to micrometer unit using the photograph of evenly spaced lines calibration. There are 300 evenly spaced dark lines per inch. The sample photograph of these lines is shown in the Figure 3.4.

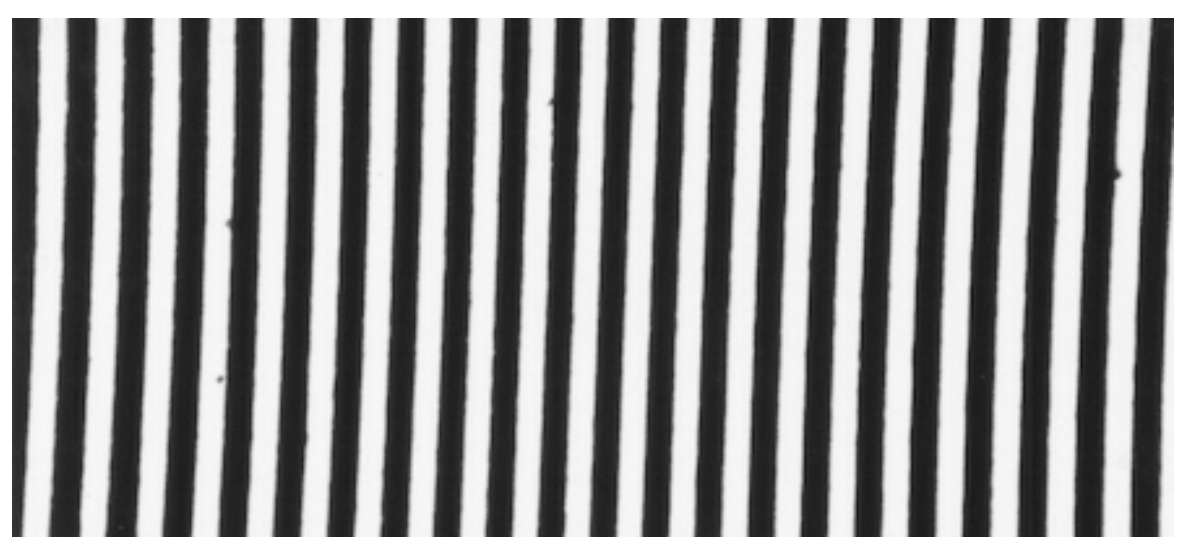

Figure 3.4 A picture of evenly spaced lines used for calibration. There are 300 evenly spaced dark lines per inch.

In the temperature effect experiment the tubes were submerged in the water bath. The temperature of the water was raised and three different temperatures, 22, 29, and 35 degree Celsius, were obtained using an electrical heater that is controlled by a temperature thermostat. 


\subsection{DATA ANALYSIS}

\subsubsection{Coalescence and Droplet Break-up}

The phenomena of coalescence and break-up can be studied by comparing the droplet sizes before and after pumping the emulsion through the capillary tubes as shown in Figure 3.5. This can be done by taking a picture of the emulsion and then analyzing the sample using image analysis software, which measures the area of the emulsion droplets.

The shear rate, residence time, temperature, and concentration effects on the emulsion droplets were examined. The results from this study were also compared to work done by other students on agglomeration of suspended particles in a fluid at similar conditions. Figure 3.6 shows the over all flow sheet of this study. 


\title{
Coalescence Mechanism
}
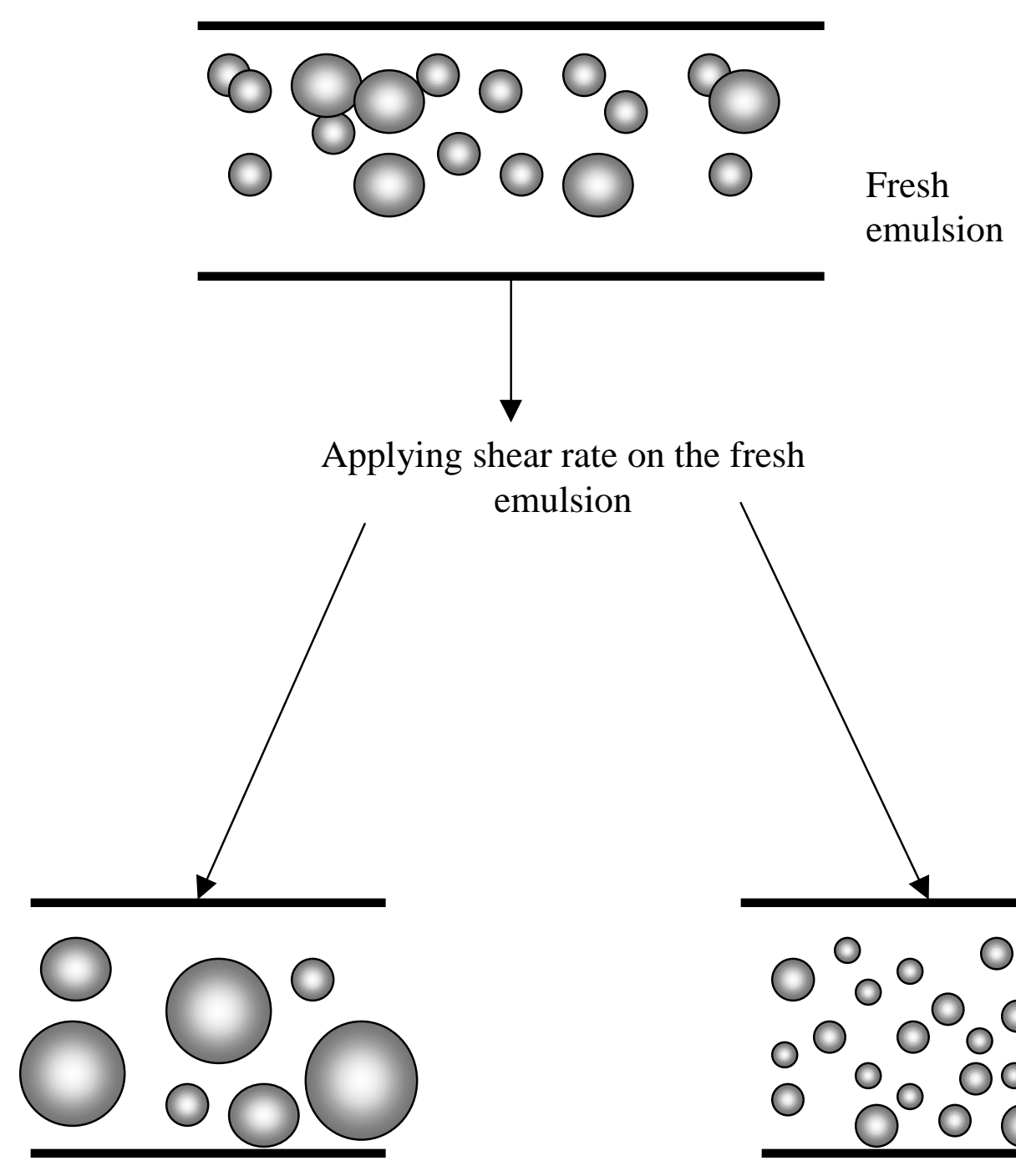

\begin{abstract}
emulsion
\end{abstract}

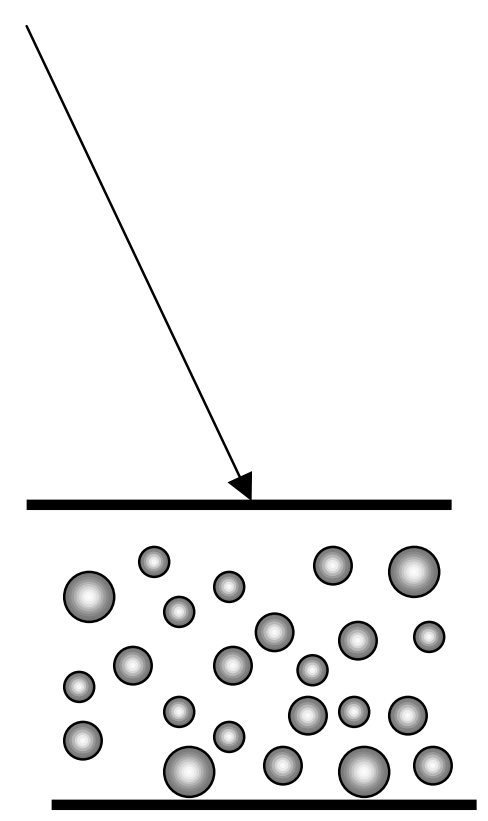

Coalescence occurs

Break-up occurs

Figure 3.5 Coalescence mechanism. 

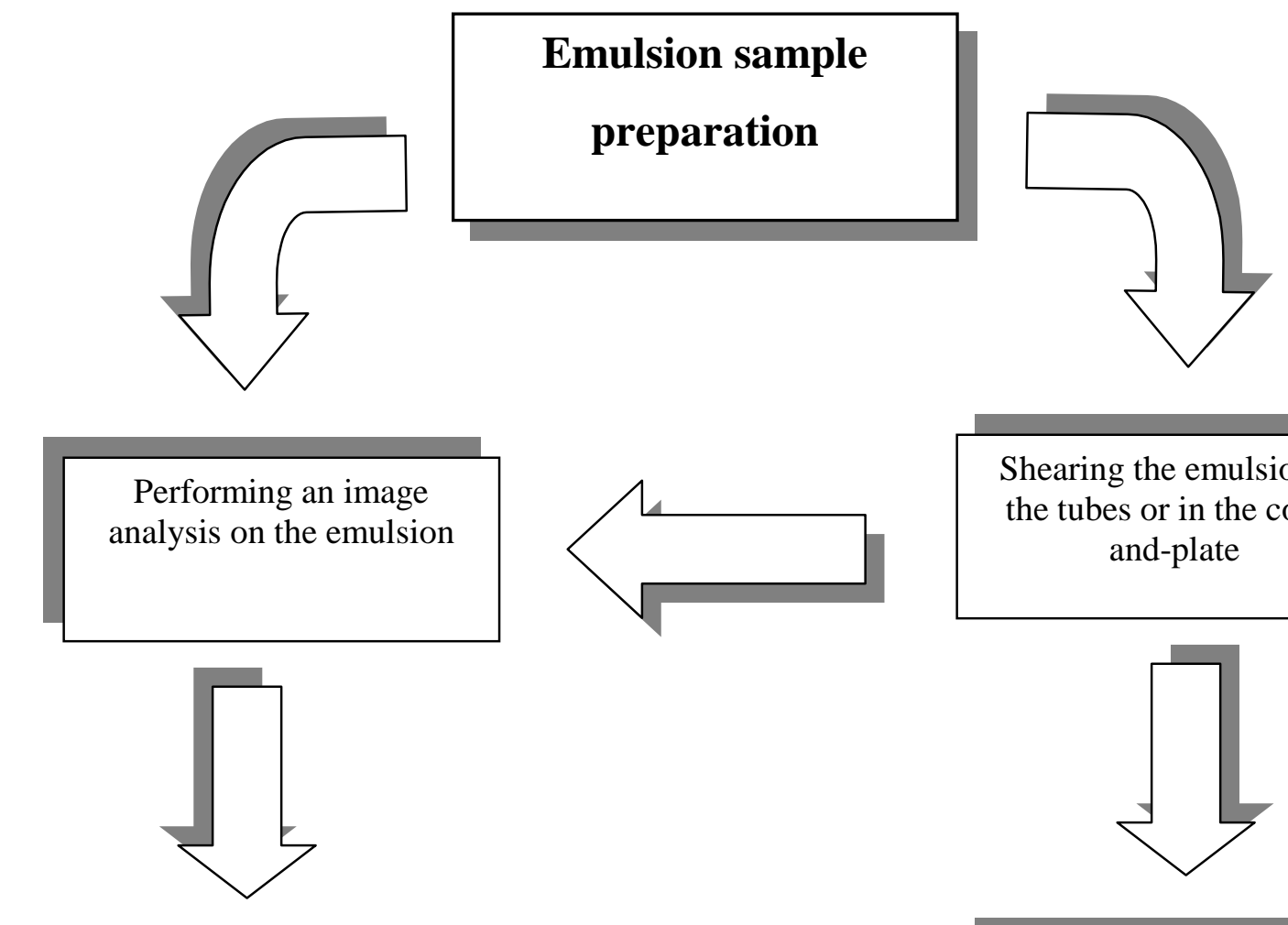

Shearing the emulsion in the tubes or in the coneand-plate

Measuring the droplet size (droplet diameter)

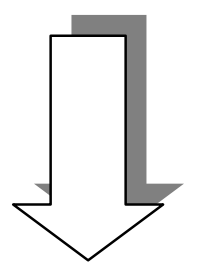

Reading the flow rate and pressure drop across the capillary tube

Checking if coalescence occurs or not

Measuring the wall shear stress and shear rate to check if wall slip occurs or not

Figure 3.6 Over all flow sheet. 


\section{CHAPTER 4}

\section{RESULTS AND DISCUSSION}

In this Chapter results of this research and their interpretation are reported. The effect of several parameters on coalescence of emulsion droplets is described here. The parameters are time of shearing, the shear rate, the concentration of the dispersed phase, the initial size and size distribution of the droplets, and the temperature. Table 4.1 gives an overview of all the experiments that were conducted, showing the materials and experimental conditions.. The results showing the absence of wall slip of emulsions are describes in Appendix A, and Appendix B gives the tables showing the results of all the experiments conducted. The particles size distributions are given in Appendix C, and the actual emulsion photographs are given in Appendix C.

The results of this study are also compared to results of other researchers.

\subsection{COALESCENCE}

In the study of coalescence, two questions have to be taken into account. Firstly, will drops collide within a given process shearing time? And secondly, will a collision be successful? A successful collision means that the film between the drops will drain sufficiently during the available time. Figure 4.1 shows two colliding drops in simple shear flow. The external flow and the volume fraction of the dispersed phase govern the collision frequency. 
Table 4.1 Overview of all the experiments conducted.

\begin{tabular}{|c|c|c|c|c|c|c|c|c|c|}
\hline $\begin{array}{c}\text { Exp } \\
\text { t. } \\
\text { No. }\end{array}$ & Objective & $\begin{array}{c}\text { Device } \\
\text { used }\end{array}$ & $\begin{array}{c}\dot{\gamma} \\
\mathbf{s}^{-1}\end{array}$ & $\begin{array}{l}\phi \\
\%\end{array}$ & d-phase & c-phase & $\eta_{d}$ & $\eta_{\mathbf{c}}$ & $\underset{{ }^{0} \mathrm{C}}{\text { Temp. }}$ \\
\hline 1 & $\begin{array}{l}\text { Tube flow vs. } \\
\text { cone-and-plate }\end{array}$ & $\begin{array}{c}\text { Tubes and cone- } \\
\text { and-plate }\end{array}$ & 11 & 1 & Cas. & $\mathrm{Si}$. & 7.42 & 0.48 & 23 \\
\hline 2 & Time of shearing & Flow through tubes & 11 & 1 & Cas. & $\mathrm{Si}$. & 7.42 & 0.48 & 23 \\
\hline 3 & Shear rate & Cone-and-plate & $\begin{array}{l}7,10,20 \\
30,50, \\
\text { and } 60\end{array}$ & 1 & Cas. & Si. & 7.42 & 0.48 & 23 \\
\hline 4 & $\begin{array}{c}\text { Concentration of } \\
\text { d-phase }\end{array}$ & Flow through tubes & 11 & $\begin{array}{l}0.5,1.0, \\
\text { and } 5.0\end{array}$ & Cas. & Si. & 7.42 & 0.48 & 23 \\
\hline 5 & Size distribution & Cone-and-plate & 10 , and 50 & $\begin{array}{l}1.0, \text { and } \\
5.0\end{array}$ & Cas. & $\mathrm{Si}$. & 7.42 & 0.48 & 23 \\
\hline 6 & Temperature & $\begin{array}{l}\text { Flow through tubes } \\
\text { and water bath }\end{array}$ & 11 & 1 & Cas. & Si. & 7.42 & 0.48 & $\begin{array}{l}22,29, \\
\text { and } 35\end{array}$ \\
\hline 7 & Step-up & Cone-and-plate & $\begin{array}{l}10,20,30, \\
\text { and } 50\end{array}$ & 1 & Cas. & Si. & 7.42 & 0.48 & 23 \\
\hline 8 & Step-down & Cone-and-plate & $\begin{array}{c}10,20,30, \\
\text { and } 50\end{array}$ & 1 & Cas. & Si. & 7.42 & 0.48 & 23 \\
\hline 9 & Step-down & Cone-and-plate & $\begin{array}{l}\text { 13, } 17,30, \\
\text { and50 }\end{array}$ & 1 & Cas. & Si. & 7.42 & 10.22 & 23 \\
\hline 10 & Phase inversion & Cone-and-plate & $\begin{array}{l}13,17,30, \\
\text { and50 }\end{array}$ & 1 & Si. & Cas. & 0.48 & 7.42 & 23 \\
\hline
\end{tabular}

- $\quad \dot{\gamma}$ : Shear rate $\mathrm{s}^{-1}$.

- $\phi$ : Volume percentage.

- d-phase : Dispersed phase.
- c-phase : Continuous phase.

- $\eta_{\mathrm{d}}$ : Viscosity of the dispersed phase.

- $\eta_{\mathrm{c}}$ : Viscosity of the continuous phase.
- Si. : Silicone oil.

- Cas. : Castor oil. 


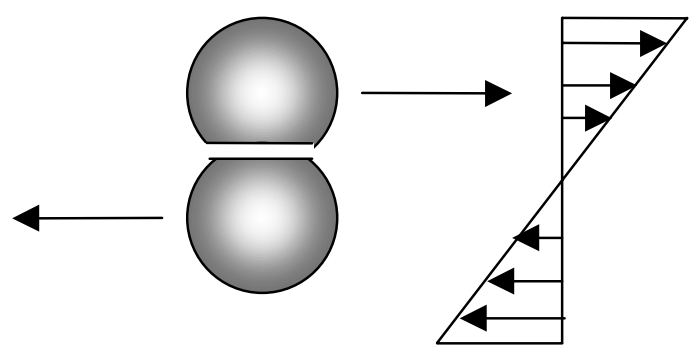

Figure 4.1 Collision of two deformable drops in simple shear flow with drainage of the film in between.

The collision probabilities for the $0.5 \%, 1.0 \%$, and $5.0 \%$ concentrations at shear rate $11 \mathrm{~s}^{-1}$ are shown in Figure 4.2. These have been calculated using equation (4.1) (Ross el al., 1978):

$$
\mathrm{P}_{\text {coll }}=\exp \left(-\frac{\pi}{8 \dot{\gamma} \phi \mathrm{t}_{\text {proc }}}\right)
$$

where $\mathrm{P}_{\text {coll }}$ is the collision probability, $\dot{\gamma}$ is the shear rate, $\phi$ is the volume fraction of the dispersed phase, and $\mathrm{t}_{\text {proc }}$ is the process time.

It is found that as the concentration increases, the collision probability also increases. Additionally, as the shear rate increases, the collision probability increases; see Figure 4.3. We see from Figure 4.2 and Figure 4.3, the time of shearing (process time) is employed in our experiments long enough for the droplets to collide $\left(\mathrm{P}_{\text {coll }}=1\right)$. Thus the limiting step for coalescence is the film drainage step and not the collision step, since after 25 minutes of shearing the 
collision probability is equal to one for all the concentrations and shear rates of interest. The droplets reach their steady state size at $\sim 35$ minutes. For 5\% (v/v) emulsion the collision probability equals 1 after only 4 minutes of shearing time. For the $1 \%(\mathrm{v} / \mathrm{v})$ emulsion the collision probability equals 1 after 25 minutes. At the high shear rate of $50 \mathrm{~s}^{-1}$, the collision probability reached 1 after $\sim 5$ minutes, and at $10 \mathrm{~s}^{-1}$ the collision probability reached 1 after $\sim 25$ minutes.

According to Janssen (1993) the steady state radius of the droplets is given by equation (4.2) for a partially mobile interface:

$$
\mathrm{R}_{\mathrm{ss}}=\left(\frac{4}{\sqrt{3}} \mathrm{~h}_{\text {crit }}\right)^{2 / 5} \mathrm{p}^{-2 / 5}\left(\frac{\eta_{\mathrm{c}} \dot{\gamma}}{\sigma}\right)^{-3 / 5}
$$

where $\mathrm{R}_{\mathrm{ss}}$ is the steady state droplet radius, $\mathrm{p}$ is the viscosity ratio of the dispersed phase to the continuous phase, $\eta_{\mathrm{c}}$ is the viscosity of the continuous phase, $\dot{\gamma}$ is the shear rate, $h_{\text {crit }}$ is the critical distance between the droplets which can be calculated using equation (2.12), and $\sigma$ is the interfacial tension. Thus, if $h_{\text {crit }}$ is known one can measure the steady state diameter for the emulsion droplets. For the silicone oil-castor oil system, Jenssen determined $\mathrm{h}_{\text {crit }}$ to be $5.0 \mathrm{E}-09 \mathrm{~m}$. In general, though, for a given concentration, the values of $h_{\text {crit }}, p, \eta_{c}$, and $\sigma$ are constant. Increasing the shear rate $(\dot{\gamma})$ will decrease the value of $\mathrm{R}_{\mathrm{ss}}$ as equation (4.2) shows. Steady state arise because the rate of coalescence becomes negligibly small with increasing $\mathrm{R}$.

Although Elmendrop and Van der Vegt (1986) and Janssen (1993) took $\mathrm{h}_{\text {crit }}$ 
to be constant, Grizzuti and Bifulco (1996) and Vinckier et al. (1998) made the value of $h_{\text {crit }}$ an adjustable parameter for describing coalescence in semiconcentrated blends; $h_{\text {crit }}$ was made to depend on the concentration of the blend. It is for this that reason Grizzuti and Bifulco (1996) as well Vinckier et al (1998) reported that the concentration of the emulsion had no effect on the steady state droplet size. However, eventhough both Grizzuti and Bifulco (1996) and Vinckier et al. (1998) used the same material (Table 2.1), they found different values for $h_{\text {crit }}$. The value of $h_{\text {crit }}$ for (10/90) (10\% PIB and 90\% PDMS) reported by Grizzuti and Bifulco (1996) is equal to $200 \mathrm{~nm}$, where as Vinckier et al.'s value (1998) is equal to $15 \mathrm{~nm}$. Vinckier et al. (1998) obtained several values of $\mathrm{h}_{\text {crit }}$ for the polymer blend ranging from $12 \mathrm{~nm}$ for the most dilute blend (2.5/97.5 blend) to $60 \mathrm{~nm}$ for the most concentrated one (20/80). 


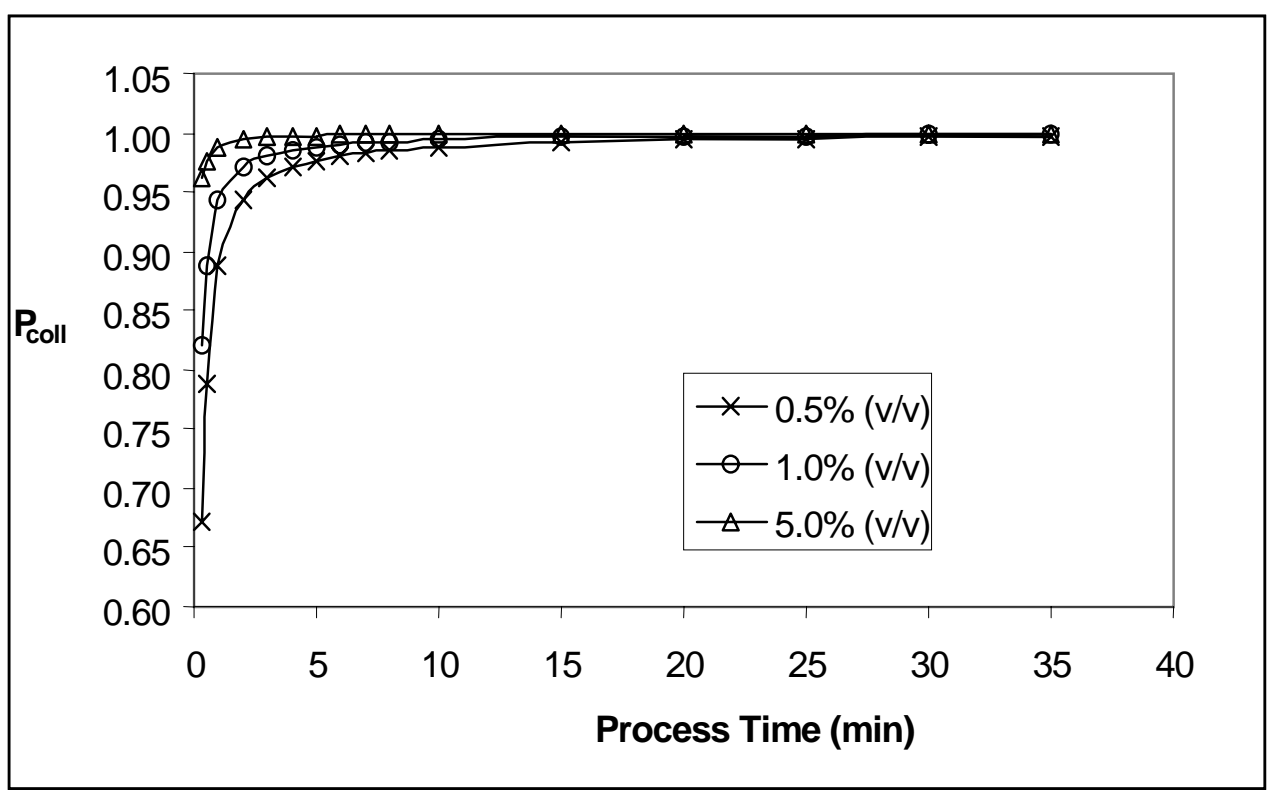

Figure 4.2 Collision probability using equation (4.1).

- Concentration is $0.5 \%, 1.0 \%$, and $5.0 \%(\mathrm{v} / \mathrm{v})$.

- Shear rate is $11 \mathrm{~s}^{-1}$.

- $\mathrm{P}_{\text {coll }}$ is the collision probability. 


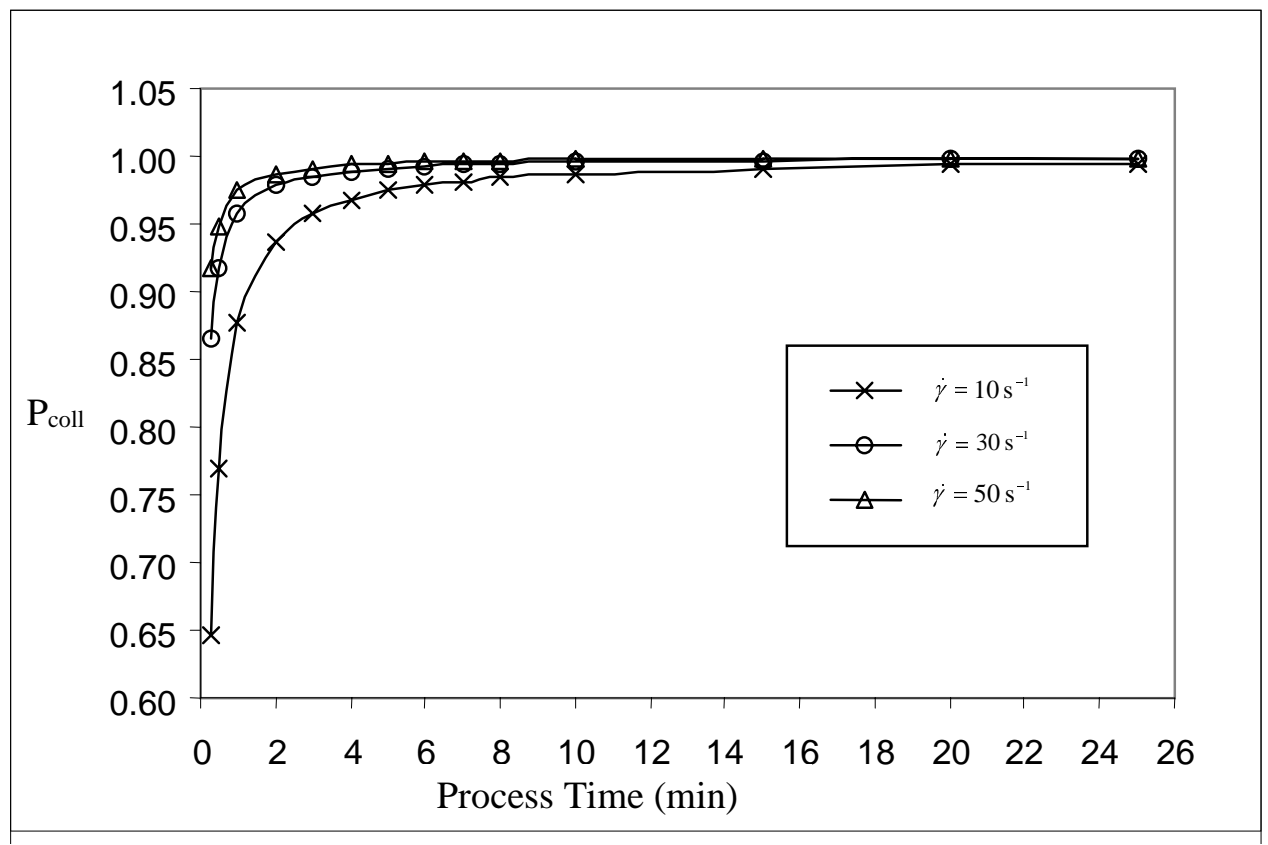

Figure 4.3 Collision probability for $0.5 \%$ emulsion using equation (4.1).

- Shear rates is 10,30 , and $50 \mathrm{~s}^{-1}$.

- Concentration is $0.5 \%(\mathrm{v} / \mathrm{v})$.

- $\mathrm{P}_{\text {coll }}$ is the collision probability.

\subsubsection{Cone-and-Plate versus Tube Flow}

Coalescence during flow through a tube is, in principle, the same as that in a cone-and-plate device. However, there could be differences because the shear rate in capillary tubes varies with position, while in the cone-and-plate it is constant. Note that even in our cone-and-plate apparatus, the shear rate had to be 
adjusted throughout the experiment. For example, if one were to perform an experiment at a shear rate of $10 \mathrm{~s}^{-1}$, the shear rate would go up to 12 and then down to 8 and so the speed of rotation had to be adjusted frequently. Figure 4.4 shows the effect of flow type on coalescence.

The values of the shear rate were chosen to range from 7 to $60 \mathrm{~s}^{-1}$ due to three reasons: the pump output for the flow through tubes, the tube lengths, and the amount of emulsion that had to be sheared. For example, for shear rates $\sim 10 \mathrm{~s}^{-}$ ${ }^{1}$ using tubes with an inside diameter equal to $2.381 \mathrm{~mm}$ one needs $200 \mathrm{ml}$ of emulsion to be sheared for 40 minutes. For the experiments that required a long time (more than an hour) to reach a steady state, a cone-and-plate device was used instead of flow through capillary tubes.

Results displayed in Figure 4.4 are practically useful and show that there is no difference in the coalescence behavior in the two devices. Thus there is a spatial variation in shear rate, and this is the more common situation, one can use the average shear rate to predict the extent of coalescence. Figure 4.4 also shows that the phenomenon of coalescence can serve to coarsen the morphology quite considerably. 


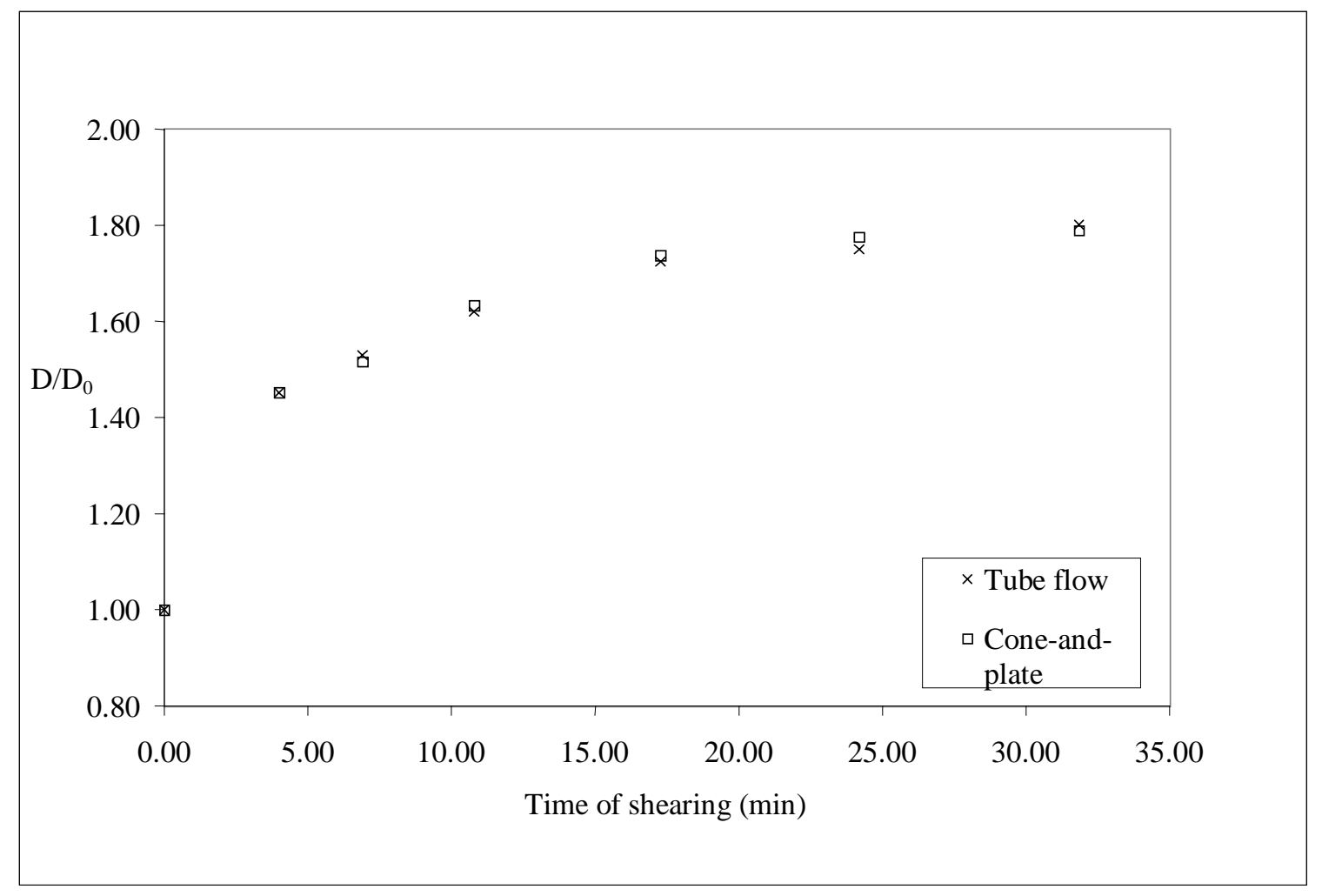

Figure 4.4 Tube flow and cone-and-plate.

- Tube diameter 3/32 in.

- Flow rate $0.0295 \mathrm{ml} / \mathrm{s}$.

- Concentration $1 \%(\mathrm{v} / \mathrm{v})$.

- Shear rate $11 \mathrm{~s}^{-1}$ for both tube and cone-and-plate devices.

- Silicone oil is the continuous phase with viscosity $=0.48$ poise.

- Castor oil is the dispersed phase with viscosity $=7.42$ poise.

- Temperature $23{ }^{\circ} \mathrm{C}$.

- $\mathrm{D}_{0}=8.1 \mu \mathrm{m}$. 


\subsubsection{Effect of Residence Time}

Keeping the shear rate, the concentration, and temperature all constant, coalescence increases as the residence time or the time of shearing increases. This is seen in Figure 4.5. The coalescence increase is due to the droplets having enough time to collide, while the film between the droplets also has enough time to drain and rupture. This is consistent with other results from the literature. After a period of time, the coalescence reaches a constant value and therefore coalescence will stop occurring. Physically coalescence stops because large sizes imply a larger flattened area between drops, which requires more liquid to drain. This is shown in Figure 4.6. Thus, small drops coalescence at a higher rate compare to larger drops. For all practical purpose though coalescence stops once drops become large enough (Elmendorp and Van der Vegt, 1986; Janssen, 1993). 


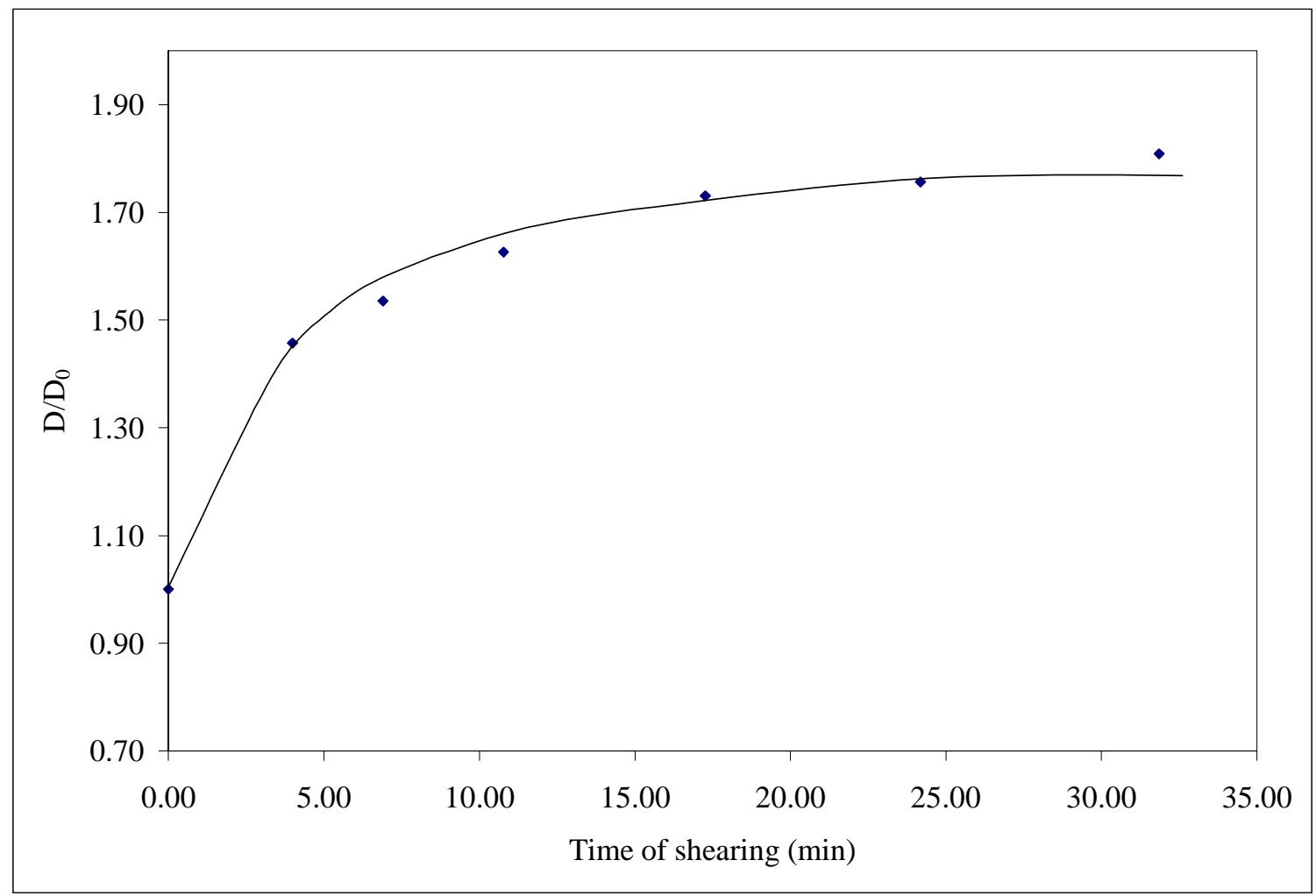

Figure 4.5 Effect of residence time on coalescence.

- Emulsion is sheared using flow through tube.

- Tube diameter $2.381 \mathrm{~mm}$.

- Concentration $1 \%(\mathrm{v} / \mathrm{v})$.

- Shear rate $11 \mathrm{~s}^{-1}$.

- Flow rate $0.0295 \mathrm{ml} / \mathrm{s}$.

- Silicone oil is the continuous phase with viscosity $=0.48$ poise.

- Castor oil is the dispersed phase with viscosity $=7.42$ poise.

- $\quad$ Temperature $23{ }^{\circ} \mathrm{C}$.

- $\mathrm{D}_{0}=8.07 \mu \mathrm{m}$. 

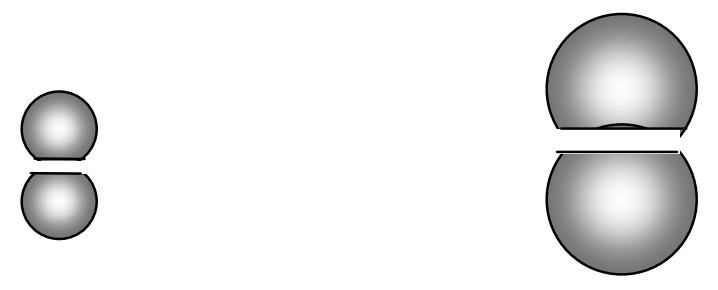

Figure 4.6 The drainage film between small and large droplets.

\subsubsection{Effect of Shear Rate}

The effect of shear rate on coalescence is shown in Figures 4.7 and 4.8. Coalescence decreases as the shear rate increases. The results are qualitatively consistent with those of Chesters (1991) and Grizzuti and Bifulco (1997). In order for coalescence to occur, the droplets must collide softly which results in a small flattened area between the two droplets. Since the flattened area is small, there is less liquid to drain. Conversely, when the droplets do not collide softly, a larger flattened area results, and there will be more liquid to drain. Increasing the shear rate means increasing the collision forces between the droplets. This leads to a larger flattened area between the drops and slower film drainage. Thus, increasing shear rates mean less coalescence. This is shown schematically in Figure 4.9. So coalescence preferentially takes place in relatively quiet zones with soft collisions (low shear rate zones) and not in regions with high deformation rates (large drainage time and small interaction time). To examine the phenomenon in a 
quantitative way, the interaction time can be approximated from the external shear rate: $\mathrm{t}_{\mathrm{int}} \sim 1 / \dot{\gamma}$.

from equation (4.2): $\mathrm{R}_{\mathrm{ss}}=\left(\frac{4}{\sqrt{3}} \mathrm{~h}_{\text {crit }}\right)^{2 / 5} \mathrm{p}^{-2 / 5}\left(\frac{\eta_{\mathrm{c}} \dot{\gamma}}{\sigma}\right)^{-3 / 5}$. Table 4.2 gives the values of $h_{\text {crit }}, p, \eta_{c}$, and $\sigma$ for the $1 \%$ emulsion The emulsion is made of castor oil (dispersed phase with viscosity equal 7.42 poise) and silicone oil (continuous phase with viscosity equal 0.48 poise). However, all the data of Figure 4.8 cannot be filled with these equations. This is seen clearly in Figure 4.10. The situation is not improved even when one considered the interface to be immobile.

Table 4.2 Values of $h_{\text {crit }}, p, \eta_{c}$, and $\sigma$ for $1 \%$ emulsion at room temperature.

\begin{tabular}{|c|c|c|c|}
\hline $\mathbf{h}_{\text {crit }}(\mathbf{m})$ & $\mathbf{p}$ & $\eta_{\mathbf{c}}(\mathbf{p o i s e})$ & $\boldsymbol{\sigma}(\mathbf{N} / \mathbf{m})$ \\
\hline $5.5 \mathrm{E}-09$ & 15.5 & 0.48 & 0.0041 \\
\hline
\end{tabular}

According to Janssen (1993) for an immobile interface the steady state droplet size is equal to:

$$
\mathrm{R}_{\mathrm{ss}}=\left(\frac{8}{9}\right)^{1 / 4} \mathrm{~h}_{\text {crit }} 1 / 2\left(\frac{\eta_{\mathrm{c}} \dot{\gamma}}{\sigma}\right)
$$

where $\mathrm{R}_{\mathrm{ss}}$ is the steady state droplet radius, $\mathrm{p}$ is the viscosity ratio of the dispersed phase to the continuous phase, $\eta_{\mathrm{c}}$ is the viscosity of the continuous phase, $\dot{\gamma}$ is the 
shear rate, $\mathrm{h}_{\text {crit }}$ is the critical distance between the droplets which can be calculated using equation (2.12), and $\sigma$ is the interfacial tension.

The conclusion that one can draw from Figure 4.10 is that available coalescence theory, whether for partially immobile or fully immobile interfaces, gives the correct order of magnitude for the steady state droplet size. However, agreement between theory and experiment is not quantitative. In particulate there is a discrepancy between observations and predictions for the slope of the $\mathrm{R}_{\mathrm{ss}}$ versus $\dot{\gamma}$ plot on logarithmic coordinates. One can correct the situation by making $\mathrm{h}_{\text {crit }}$ a variable, but this modification may not have a physical basis. 


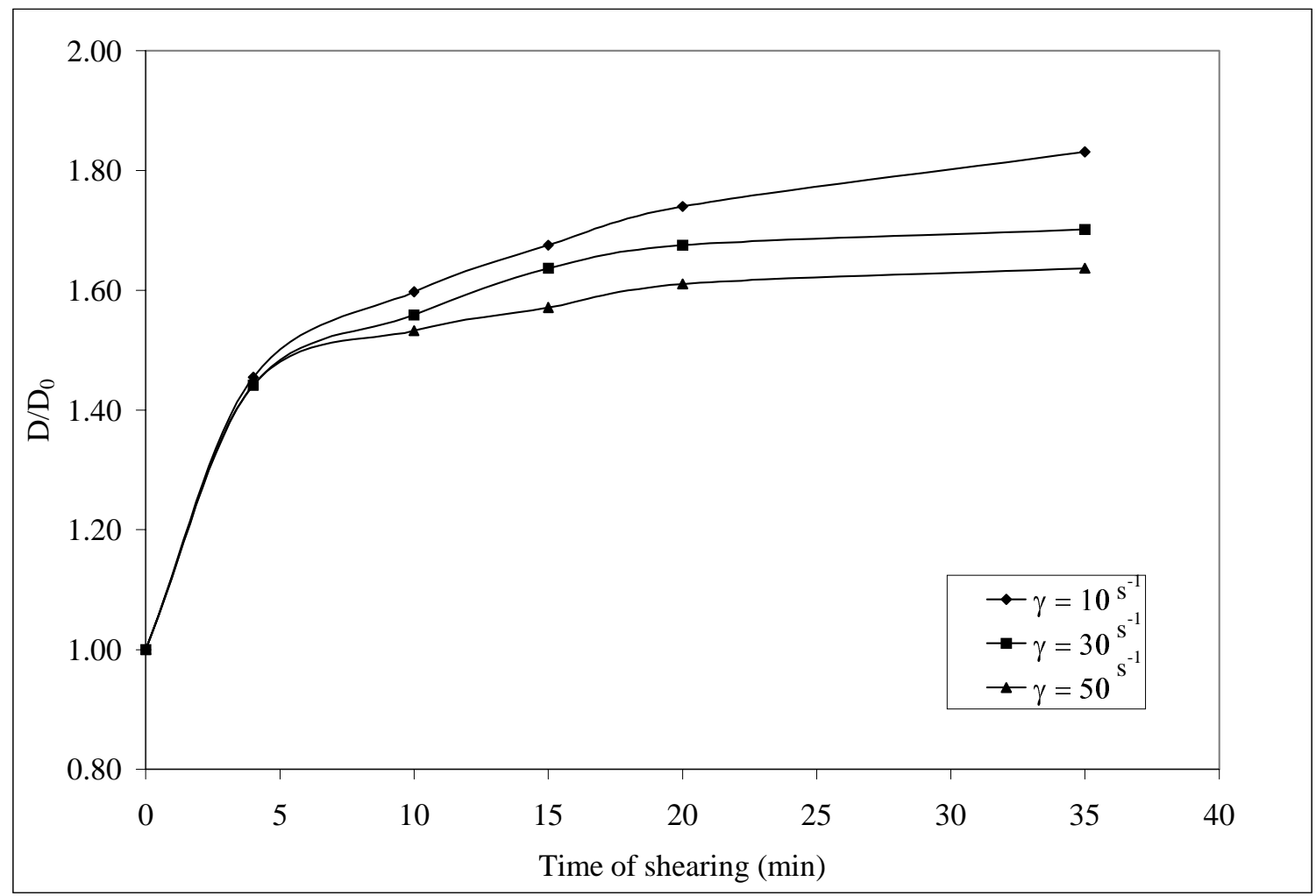

Figure 4.7 Effect of shear rate and time of shearing on coalescence.

- Emulsion is sheared using cone-and-plate device.

- Concentration $1 \%(\mathrm{v} / \mathrm{v})$.

- Shear rates 10,30 , and $50 \mathrm{~s}^{-1}$.

- Silicone oil is the continuous phase with viscosity $=0.48$ poise.

- Castor oil is the dispersed phase with viscosity $=7.42$ poise.

- Temperature $23{ }^{\circ} \mathrm{C}$.

- $\mathrm{D}_{0}=8.1 \mu \mathrm{m}$. 


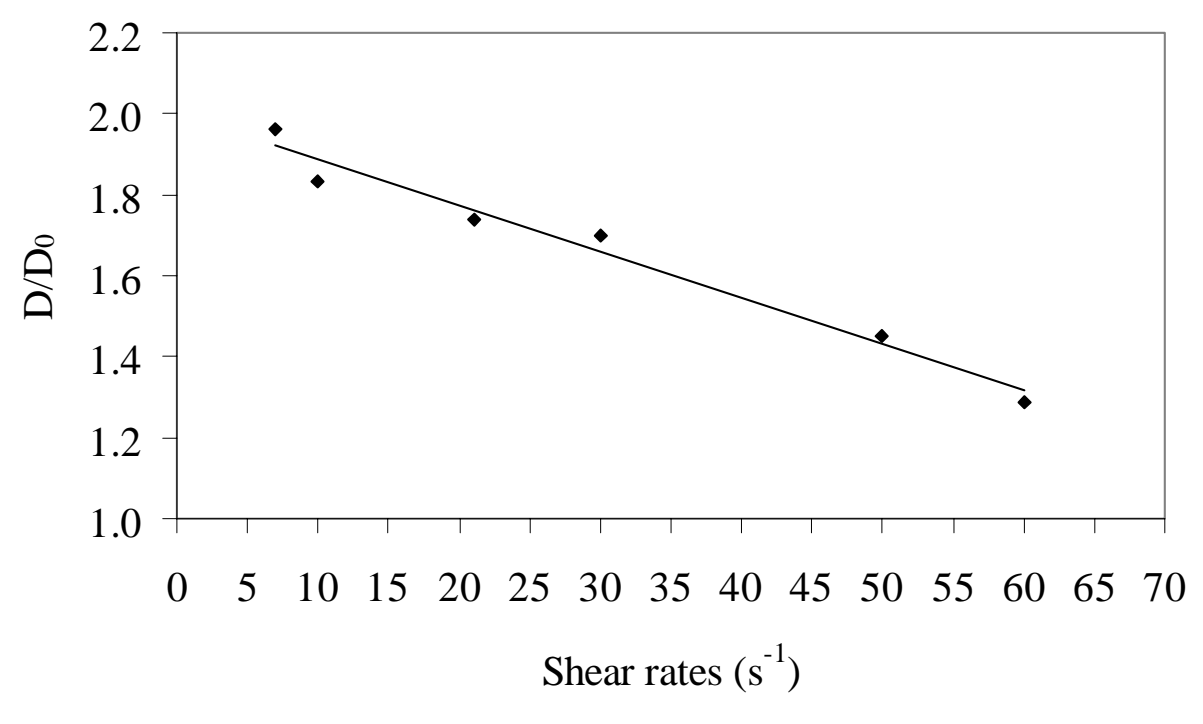

Figure 4.8 Effect of shear rate.

- Emulsion is sheared using cone-and-plate device.

- Time of shearing $35 \mathrm{~min}$ (steady state reached).

- Concentration $1 \%(\mathrm{v} / \mathrm{v})$.

- Shear rates $7,10,20,30,50$, and $60 \mathrm{~s}^{-1}$.

- Silicone oil is the continuous phase with viscosity $=0.48$ poise

- Castor oil is the dispersed phase with viscosity $=7.42$ poise

- Temperature $23{ }^{\circ} \mathrm{C}$.

- $\mathrm{D}_{0}=8.1 \mu \mathrm{m}$. 


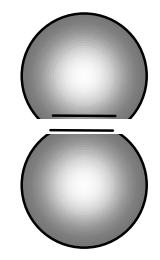

Low shear rate

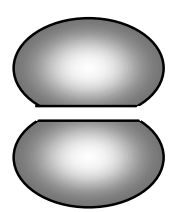

High shear rate

Figure 4.9 Droplets in low shear rate zone and high shear rate zone. 


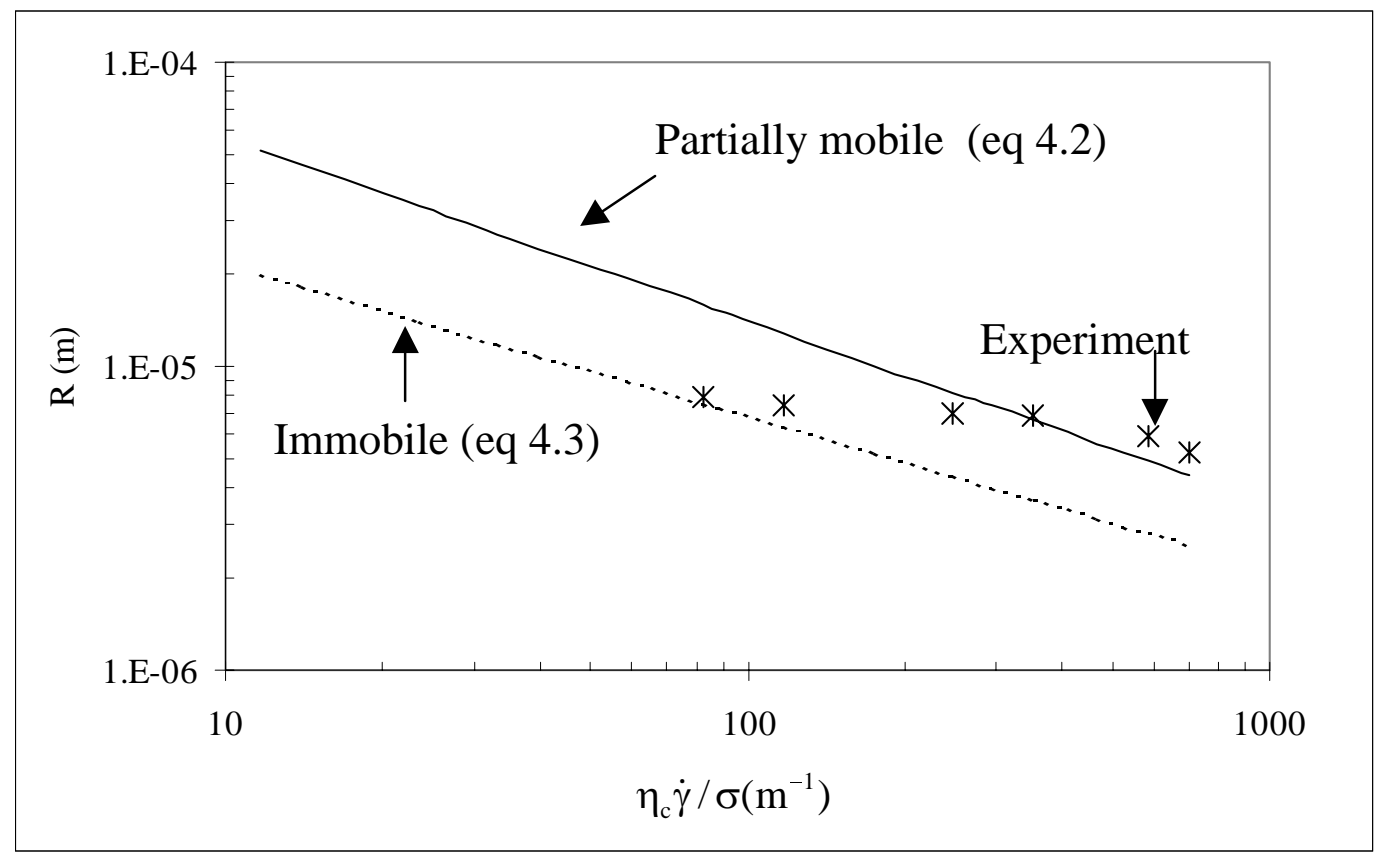

Figure 4.10 Drop size resulting from coalescence of drops using equation 4.2 for partially mobile interface, equation 4.3 for immobile interface and the experimental data at the same viscosity ratio $(\mathrm{p}=15.5)$.

- The line using equation 4.2 Has aslope of -0.6

- The experimental data has a viscosity ratio 15.5 and the slope of the line is $-0.2$

- The immobile line is plotted using equation 4.3. Comparing the experimental results in Figure with the results from Janssen. The slope using Jenssen results is equal to -0.6 where our experimental results is -0.2 .

- Concentration is $1 \%(\mathrm{v} / \mathrm{v})$ emulsion.

- Silicone oil is the continuous phase with viscosity $=0.48$ poise.

- Castor oil is the dispersed phase with viscosity $=7.42$ poise.

- Temperature $23{ }^{\circ} \mathrm{C}$ 


\subsubsection{Effect of Concentration of the Dispersed Phase}

The effect of dispersed phase concentration on coalescence is shown in Figure 4.11. It is found that as the concentration of the dispersed phase increases, the coalescence of droplets also increases. The reason is that there are more droplets to collide resulting in enhanced coalescence. The probability of coalescence depends on the probability of the collisions of the droplets. With the increase of the concentration, the number of collisions per unit volume increases leading to an increase in the average droplet size. Thus the equilibrium droplet size for the 5\% emulsions is larger than the equilibrium droplets size for $1 \%$ and $0.5 \%$ emulsions because there are more droplets to collide. Coalescence stops after 35 minutes (see Figure 4.11) because the droplets' size reached a point where the flattened area between the drops is large and contains a large amount of liquid that needs to be drained. This phenomenon has been explained earlier, and the results are consistent with the work of Elmendorp and Van der Vegt (1986). Note though that Grizzuti and Bifulco (1997) did not observe this influence of dispersed phase concentration in their work on PDMS/PIB emulsions. 


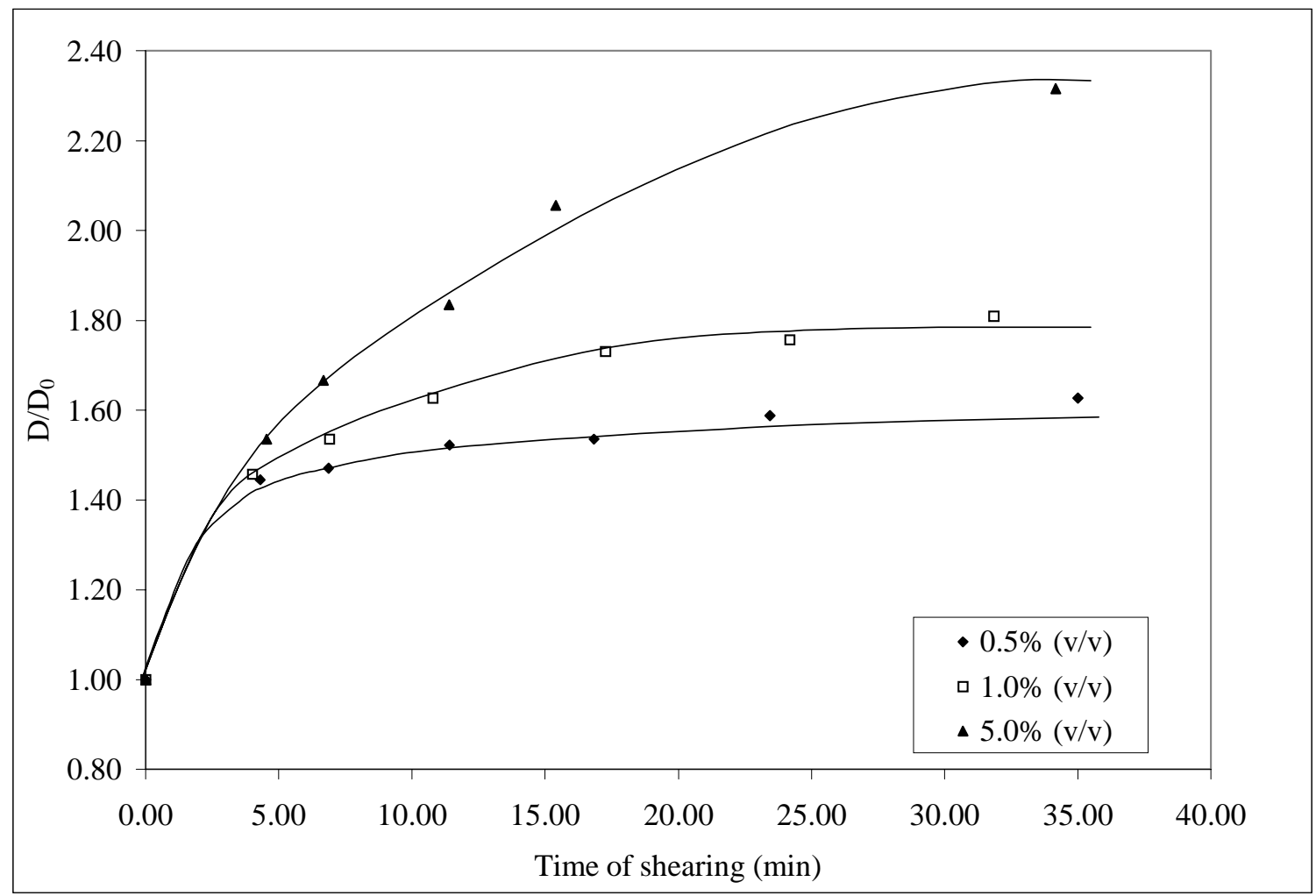

Figure 4.11 Effect of residence time and concentration.

- Emulsion is sheared using flow through tube.

- Tube diameter $3 / 32$ in.

- Concentration $0.5 \%, 1.0 \%$, and $5.0 \%(\mathrm{v} / \mathrm{v})$.

- Shear rate $11 \mathrm{~s}^{-1}$.

- Flow rate $0.0295 \mathrm{ml} / \mathrm{s}$.

- Silicone oil is the continuous phase with viscosity $=0.48$ poise

- Castor oil is the dispersed phase with viscosity $=7.42$ poise

- Temperature $23{ }^{\circ} \mathrm{C}$.

- $\mathrm{D}_{0}=8.07 \mu \mathrm{m}$. 


\subsubsection{Effect of Size Distribution}

Initially it was assumed that the droplet size distribution has an effect on coalescence, since narrowing the size distribution by emulsifying the emulsion for a long time period gave droplets that would aggregate instead of coalescing under the same conditions. Figure 4.12 shows how due it appears that to different size distributions, two sample emulsions that have the same concentration when sheared at the same shear rate for the same time, lead to one sample to coalesce while the other one to aggregate. Also we see that the aggregation decreases as the shear rate increases as shown in Figure 4.13. In aggregation the film between the droplets does not drain and rupture.

Further experiments proved that size distribution is not the cause of the aggregation. In one experiment, castor oil was extracted from a sample that had been aggregated, then emulsified with a fresh sample of silicone oil to a large size distribution. Coalescence did not occur, instead aggregation occurred again. The same experiment was repeated using castor oil that was not aggregated, but emulsified with silicone oil to the same large size distribution. In this case, coalescence occurred instead of aggregation. This experiment clearly shows that size distribution is not the cause of aggregation as previous experiments had led us to believe. Perhaps sonication changes the nature of castor oil. Note that sonication can result in localized heating of the liquids.

From here a further assumption was made: that there is a connection 
between castor oil and aggregation. Experiments were made to investigate this hypothesis. In one experiment, before preparing the emulsion, the castor oil was heated to $160{ }^{0} \mathrm{C}$. After it was emulsified with silicone oil to a large size distribution and sheared, coalescence occurred. When it was emulsified with silicone oil to a narrow size distribution and sheared, aggregation occurred. Sonicated alone similar results were found when the castor oil was sonicated alone for a long period of time before being mixed with silicone oil. Both of these experiments do not show any support for the hypothesis that aggregation is related to change in castor oil since neither heating nor emulsifying the castor oil caused of aggregation.

The emulsion is made-up of silicone oil and castor oil. Since castor oil had no connection with aggregation, several experiments were performed on silicone oil to see if it had a connection. The same experiments that were made on the castor oil were now made on the silicone oil. Heating the silicone oil before preparing the emulsion is not the reason for aggregation since in the large size distribution experiments aggregation did not occur. Therefore, silicone oil was first sonicated, then the castor oil was added to the silicone oil that had been emulsified, then both emulsified again to prepare an emulsion sample. Aggregation did indeed occur for both narrow and large size distribution samples. A conclusion is thus made: aggregation will occur to any size distribution when significant energy is added to the silicone oil before it is emulsified with castor oil. 
Several similar experiments performed using silicone oil but with higher visscosities equal to 1 poise and 10 poise also led to aggregation. The viscosity of the silicone oil, though, did not change during these experiments. Therefore, aggregation probably results from some, as yet to be identified, changes in the interfacial properties of silicone oil. 


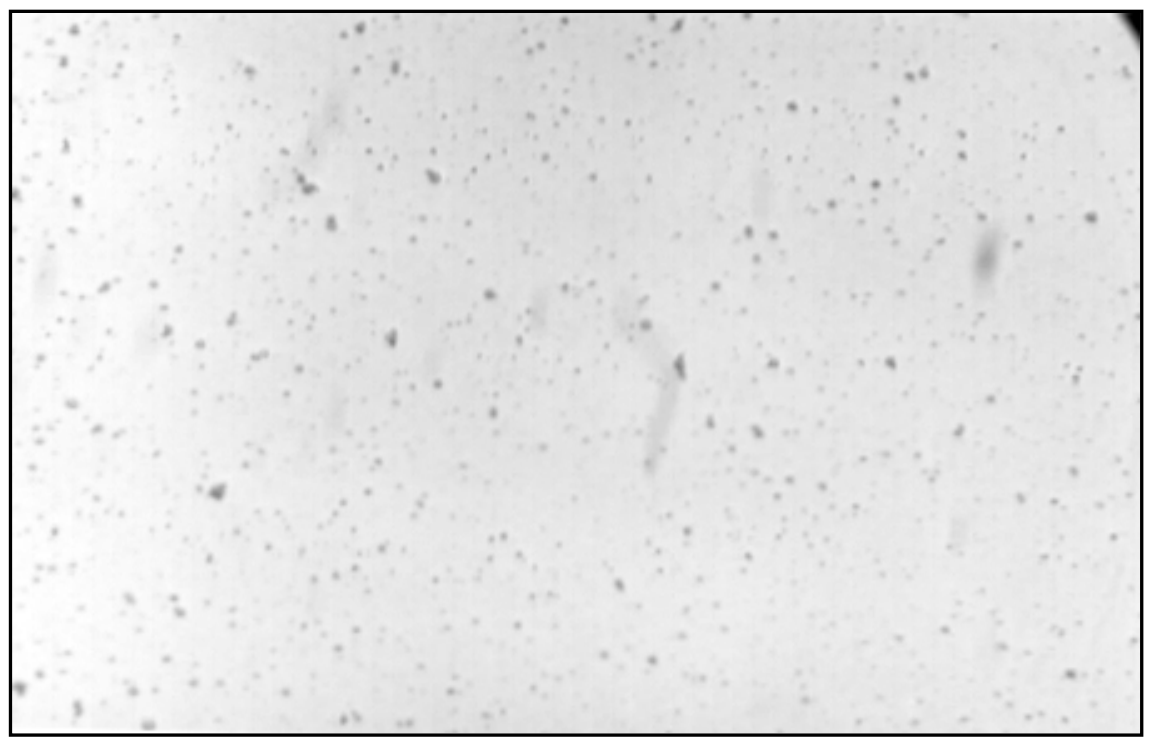

Fresh 5\% emulsion with narrow size distribution.

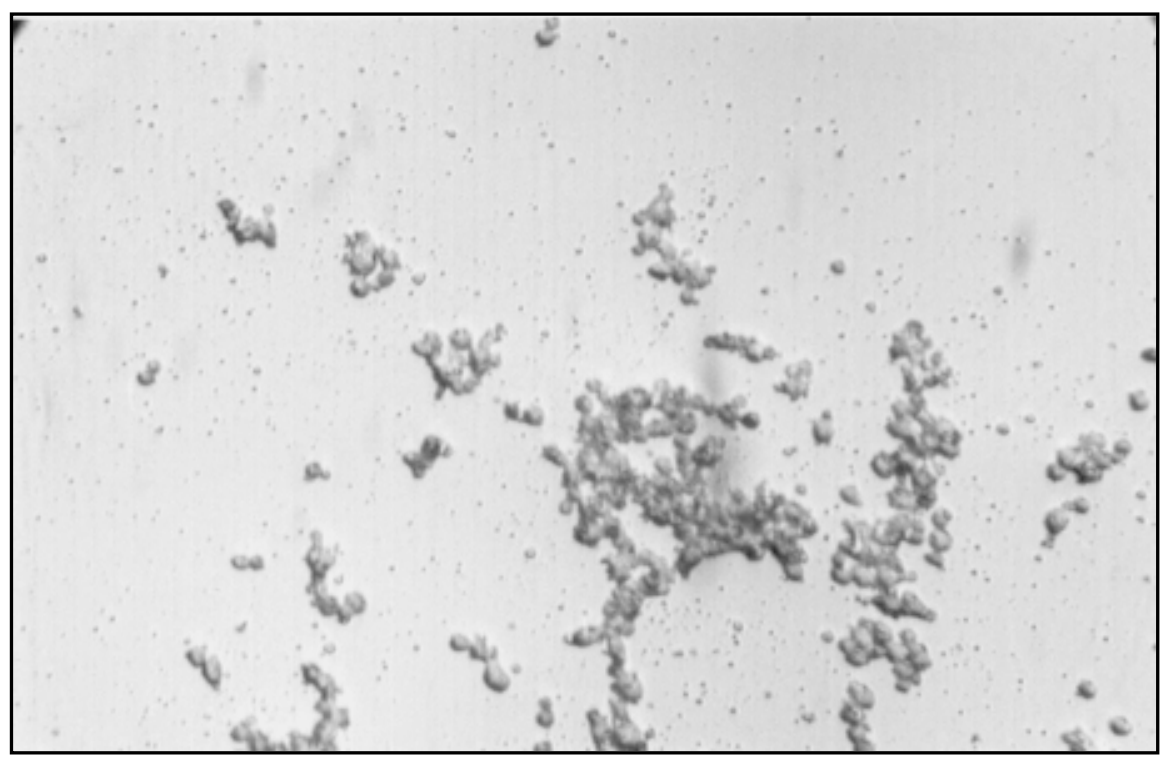

Narrow size distribution sheared for 30 min. using capillary tubes.

Figure 4.12A. 5\% emulsion with narrow size distribution sheared for $30 \mathrm{~min}$. (shear rate equal to $11 \mathrm{~s}^{-1}$ ) at room temperature using capillary tubes. 


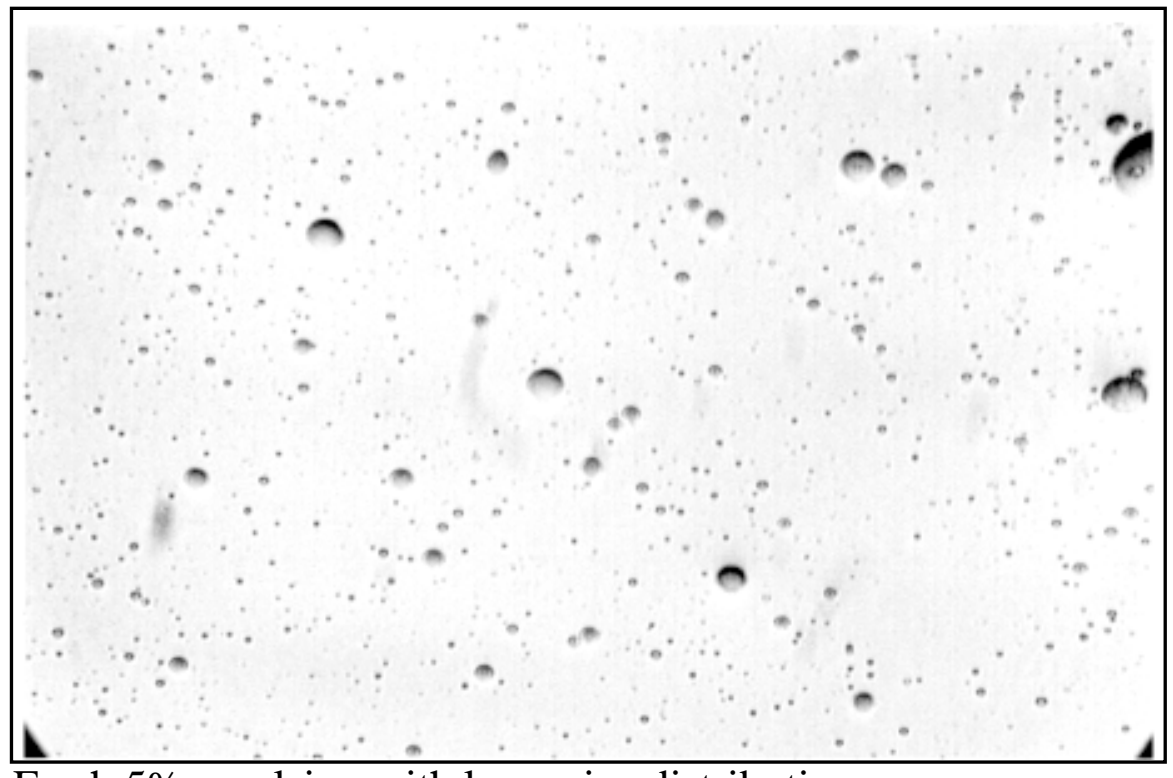

Fresh 5\% emulsion with large size distribution.

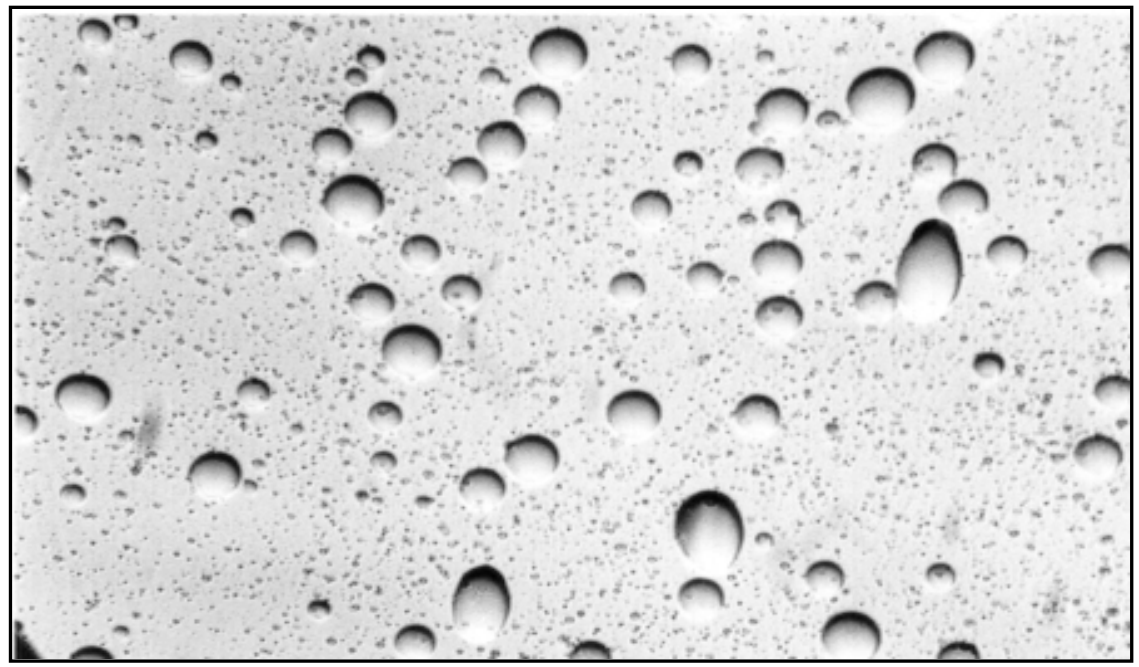

Large size distribution sheared for 30 min. using capillary tubes.

Figure 4.12B. 5\% emulsion with large size distribution sheared for 30 min. (shear rate equal to $11 \mathrm{~s}^{-1}$ ) at room temperature using capillary tubes. 


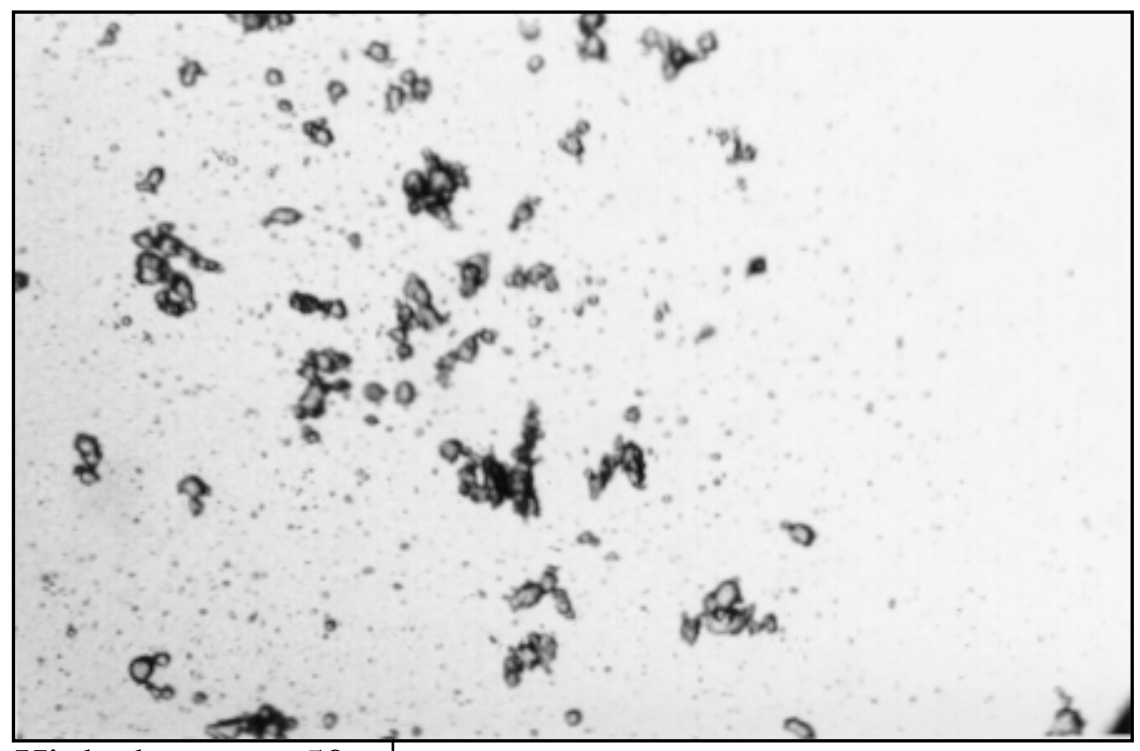

High shear rate $50 \mathrm{~s}^{-1}$.

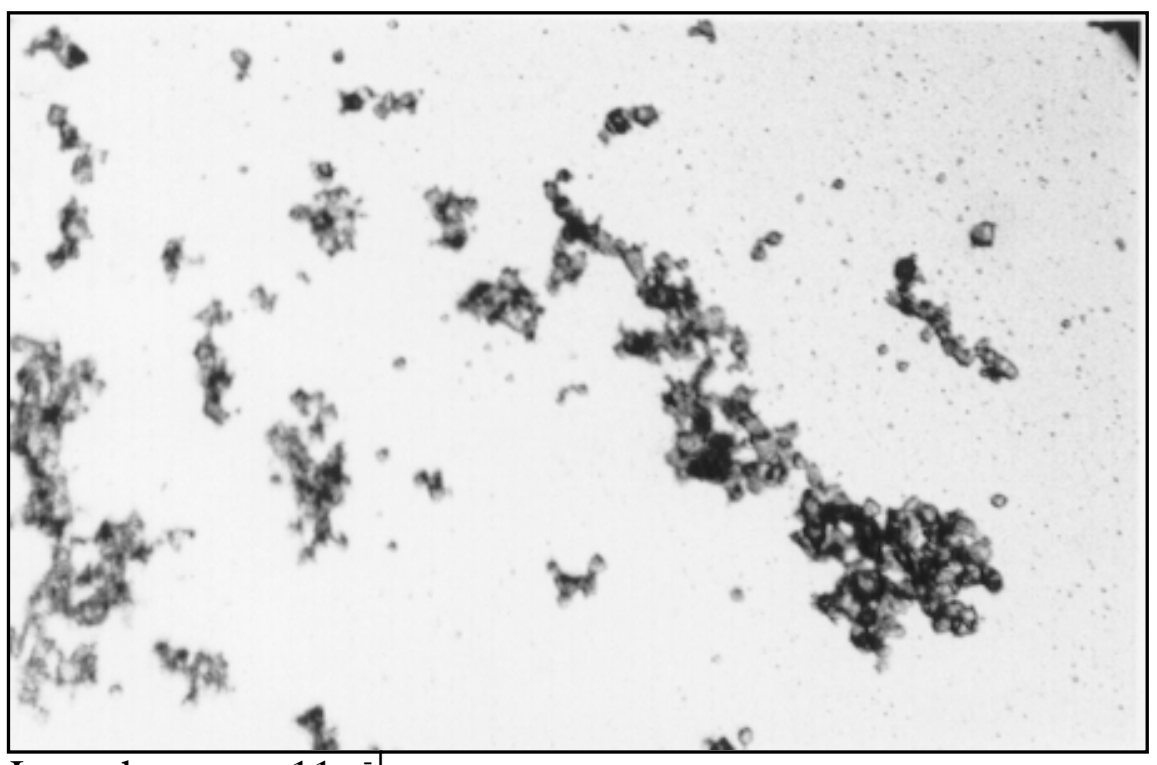

Low shear rate $11 \mathrm{~s}^{-1}$.

Figure 4.13 Aggregation at high and low shear rate, 5\% emulsion sheared for 30 min. at room temperature using capillary tubes. 


\subsubsection{Effect of Temperature}

The effect of temperature on coalescence was investigated by using a hot water bath. Copper tubes were submerged in a bath of water, where the temperature of water could be controlled. The use of copper tubes maximizes the heat transfer between the water and the emulsion. The effect of temperature on coalescence consists of two parts: (i) the effect of temperature on the viscosity of the dispersed phase and (ii) the continuous phase (see Figure 4.14). As the temperature increases, the viscosity of both the dispersed and continuous phase decreases while the ratio of the two viscosities decreases. Note that even at higher temperature used, the viscosity ratio is still prohibit drop break up by shearing. These viscosities are measured using a cone-and-plate rheometer. The temperature also has an effect on the interfacial tension between the dispersed phase and the continuous phase. Increasing the temperature decreases the interfacial tension between the droplet and the continuous phase. This reduces the thermodynamic driving force for coalescence, and decreasing the interfacial tension should lead to a decrease in coalescence. The interfacial tension has an influence on the deformation of the droplet also. This is because a large interfacial tension tends to make the drops more spherical resulting in a smaller flattened area and shorter drainage time, as Figure 4.15 shows. Experimentally it is found that keeping the other parameters constant, an increase in temperature leads to a decrease in

coalescence (see Figure 4.16). At a temperature of $35{ }^{0} \mathrm{C}$ the interfacial tension 
between the silicone oil and castor oil is less than what it would be at room temperature. This causes the droplets to be more flattened resulting to more silicone oil between the castor oil droplets which makes it hard to drain the silicone oil for coalescence to occur. The results are consistent with Kumars' (1993) work, in which it is stated that increasing the interfacial tension increases coalescence efficiency. When the emulsion is sheared at the shear rate of $11 \mathrm{~s}^{-1}$ and at temperature $\sim 70{ }^{0} \mathrm{C}$, a different phenomenon occurs: the emulsion starts to break-up. When the emulsion is heated to temperature $\sim 70{ }^{0} \mathrm{C}$ using a heater without shearing, the droplets again break-up. Thus at $70{ }^{\circ} \mathrm{C}$ there is only breakup, while at temperatures up to $35^{\circ} \mathrm{C}$ there is only coalescence. Between these two temperatures, we might expect that both coalescence and break-up will occur at the same time since the viscosity ratio drops rapidly on increasing the temperature. 


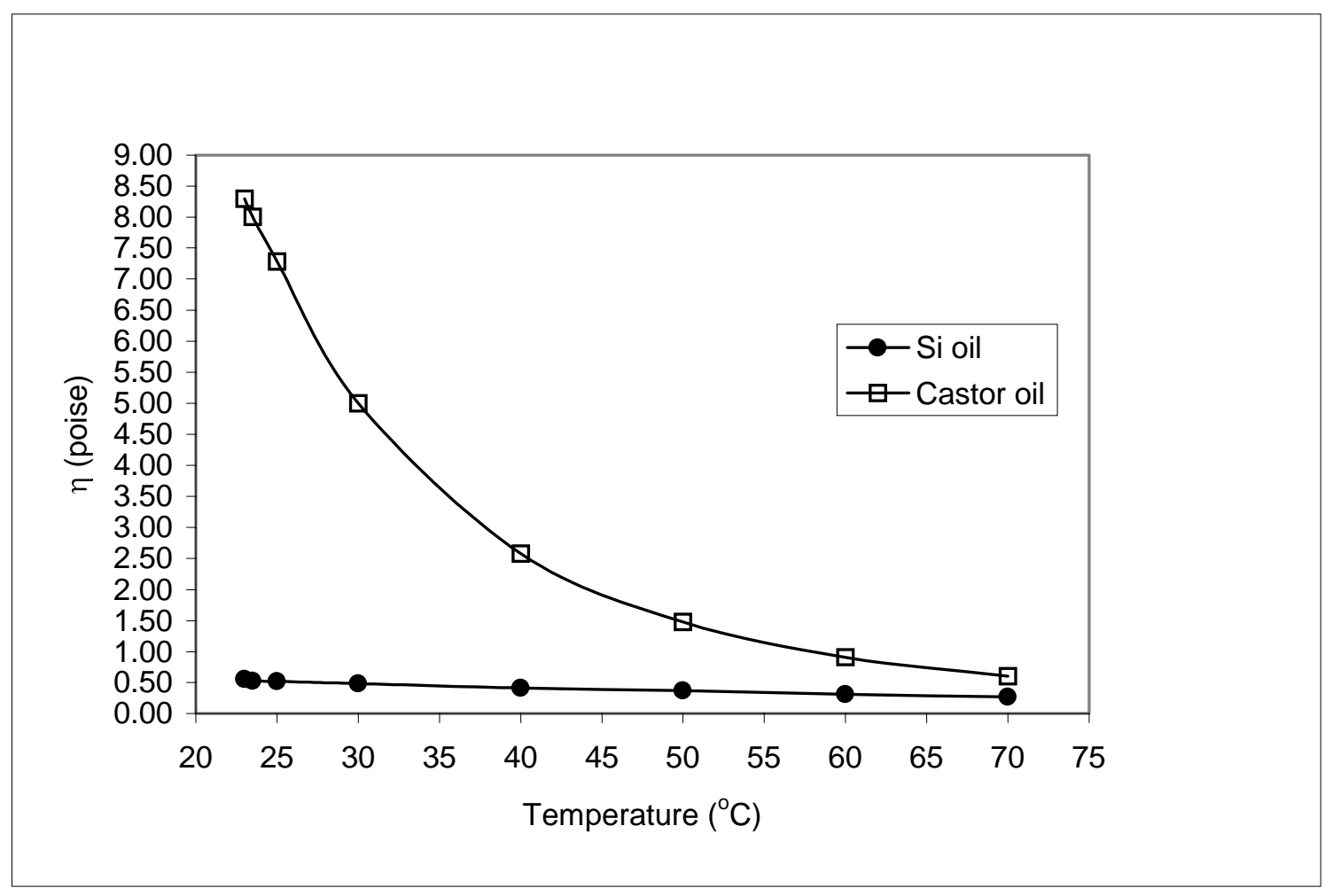

Figure 4.14. Effect of temperature on the viscosity of silicone oil and castor oil.

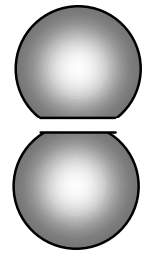

High interfacial tension

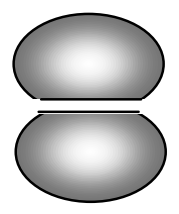

Low interfacial tension

Figure 4.15 Effect of the interfacial tension on the droplets. 


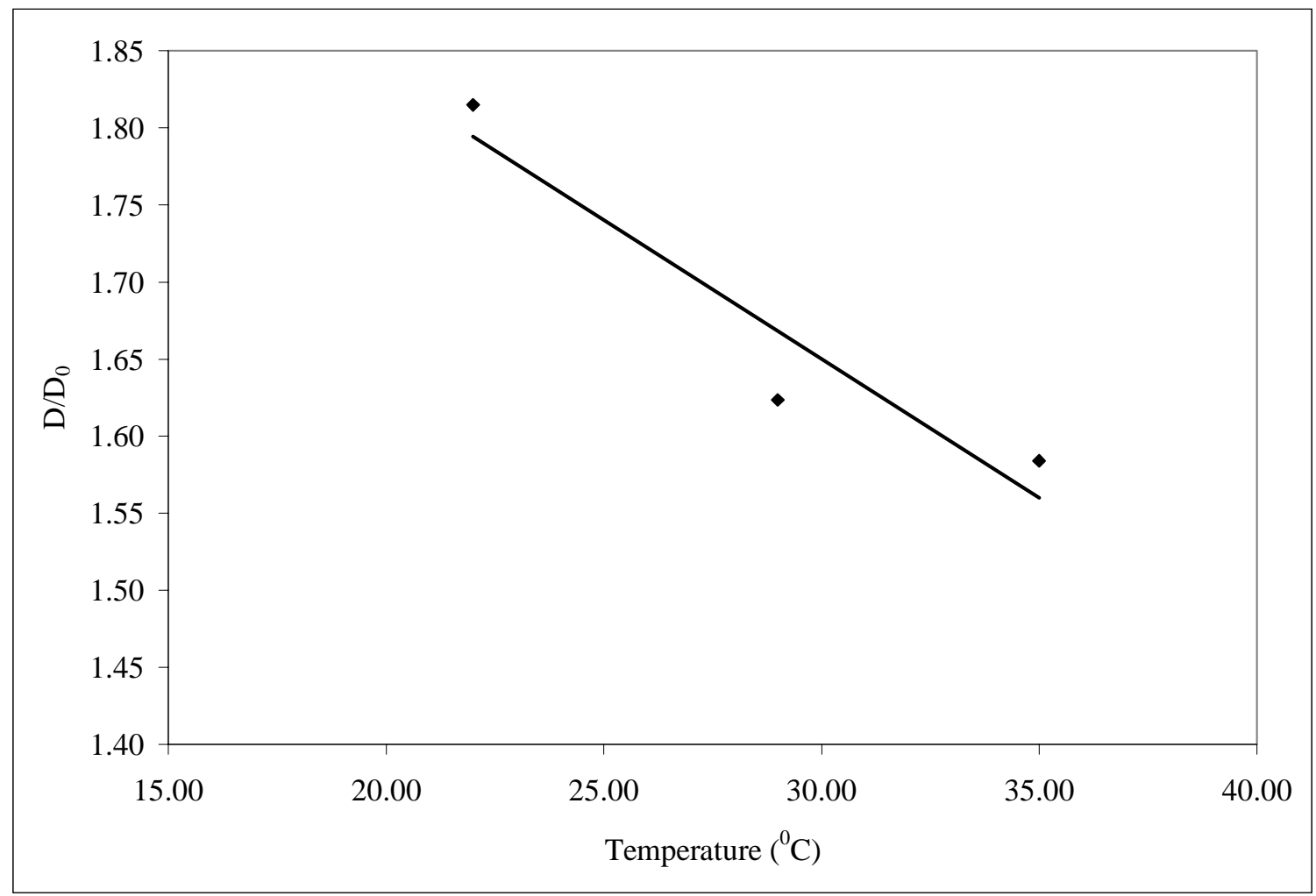

Figure 4.16 Effect of temperature on coalescence.

- Emulsion is sheared using flow through copper tubes.

- Tube inside diameter $3.24 \mathrm{~mm}$.

- Concentration $1 \%(\mathrm{v} / \mathrm{v})$.

- Shear rate $11 \mathrm{~s}^{-1}$.

- Time of shearing 35 minutes (steady state reached).

- Flow rate $0.0734 \mathrm{ml} / \mathrm{s}$.

- Silicone oil is the continuous phase with viscosity $=0.48$ poise

- Castor oil is the dispersed phase with viscosity $=7.42$ poise .

- Temperature 22,29 , and $35^{\circ} \mathrm{C}$.

- $\mathrm{D}_{0}=8.1 \mu \mathrm{m}$. 


\subsection{STEP-UP AND STEP-DOWN OF SHEAR RATE}

In the step-up experiment the cone-and-plate device is used. The sample is sheared until the droplets reach equilibrium. Then the shear rate is increased and the sample is sheared again until it reaches equilibrium. The step-up experiment is performed using three systems (see Table 4.3).

Table 4.3. Emulsion viscosity ratios used for step-up and step-down experiments.

\begin{tabular}{|c|c|c|c|}
\hline $\begin{array}{c}\text { Sample } \\
\text { designation }\end{array}$ & Continuous phase & Dispersed phase & $\begin{array}{l}\text { Viscosity ratio } \\
\qquad P=\eta_{d} / \eta_{c}\end{array}$ \\
\hline A & Silicone oil & Castor oil & 15.45 \\
\hline B & Silicone oil & Castor oil & 0.72 \\
\hline $\mathrm{C}$ & Castor oil & Silicone oil & 0.06 \\
\hline
\end{tabular}

We start with a shear rate of $13 \mathrm{~s}^{-1}$, then step-ups to 17,40 , and $50 \mathrm{~s}^{-1}$. In the step-down we start with a shear rate of $50 \mathrm{~s}^{-1}$, then step-down to 40, 17, and 13 $\mathrm{s}^{-1}$. Sample A shows no effect in the step-up experiments even though equilibrium drop sizes decreases on increasing the shear rate. This is because the viscosity ratio is greater than 4, and break-up cannot occur; this agrees with the literature (see Figure 2.1). In the step-down experiment using sample A, the droplet size increases as the shear rate decreases because the collisions are softer, and the 
chances of droplets to coalesce increase (see Figure 4.17). Samples B and C show the same droplets' sizes at the same shear rate in the step-up and step-down experiments; since the viscosity ratio is less than four as the shear rate increases the droplets start to break-up to their critical diameter value at that shear rate (see Figure 4.18). Under other conditions hysteresis can also be observed (Minale et al. 1998) 


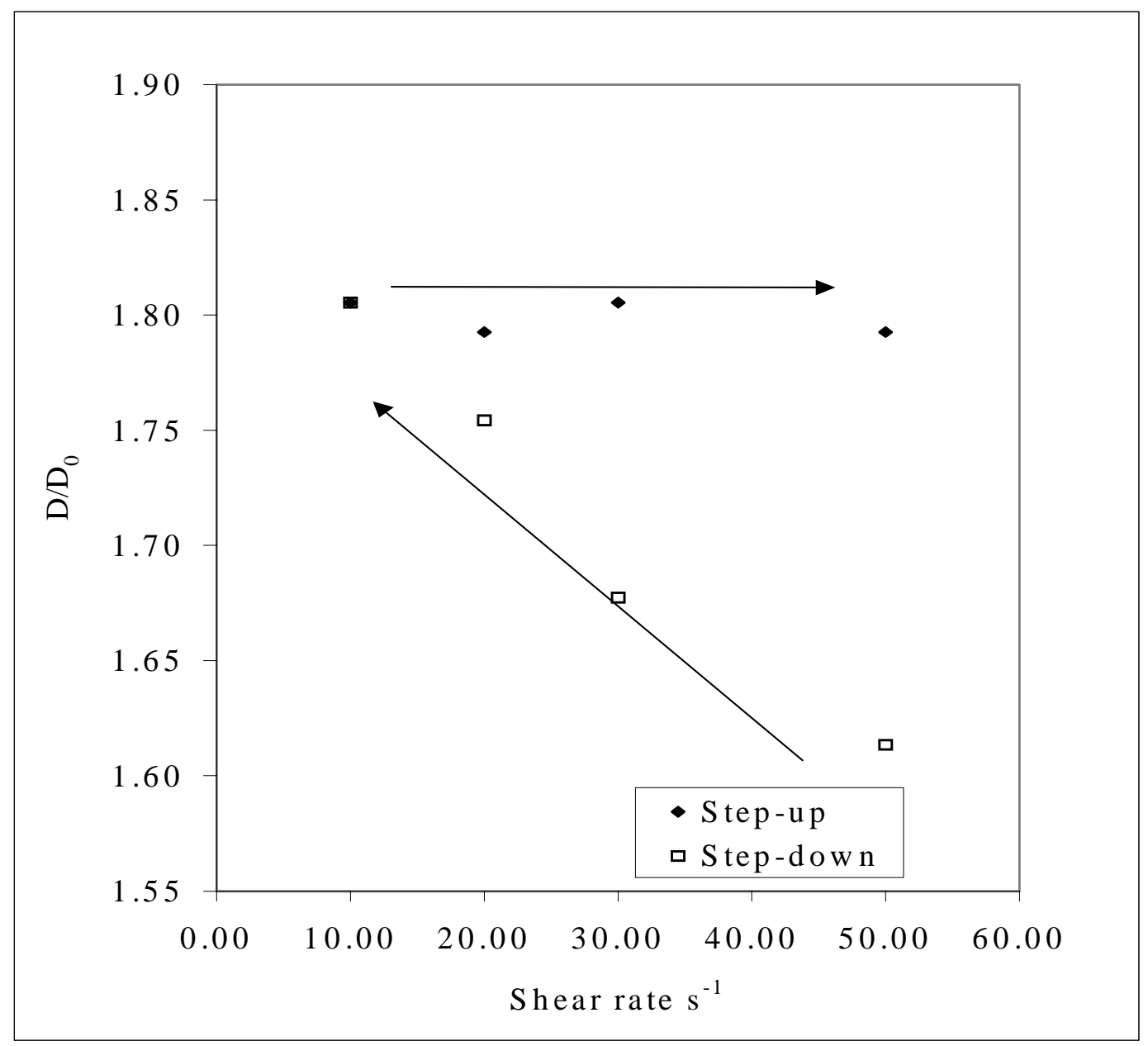

Figure 4.17 Step-up and step-down for sample A.

- Emulsion is sheared using cone-and-plate device.

- Time of shearing $35 \mathrm{~min}$ (steady state reached).

- Concentration $1 \%(\mathrm{v} / \mathrm{v})$.

- Silicone oil is the continuous phase with viscosity $=0.48$ poise

- Castor oil is the dispersed phase with viscosity $=7.42$ poise

- Temperature $23{ }^{\circ} \mathrm{C}$.

- $\mathrm{D}_{0}=8.2 \mu \mathrm{m}$. 


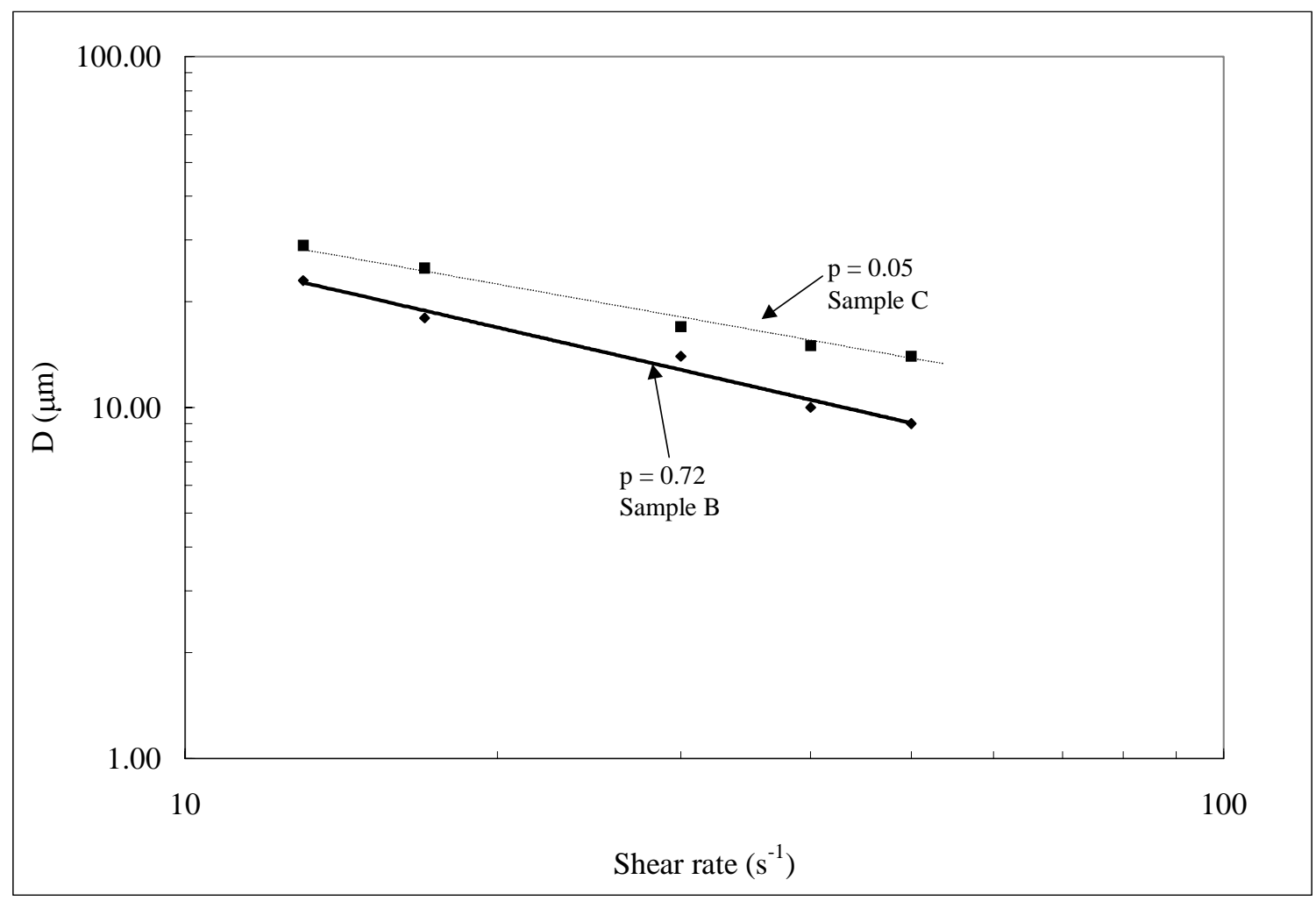

Figure 4.18 Step-up and step-down for samples B and C.

- Emulsion is sheared using cone-and-plate device.

- Concentration $1 \%(\mathrm{v} / \mathrm{v})$.

- Total time of shearing 61 hours (steady state reached).

- Temperature $23{ }^{\circ} \mathrm{C}$.

- Sample B silicone oil is the continuous phase with viscosity $=10.22$ poise, and castor oil is the dispersed phase with viscosity $=7.42$ poise.

- Sample C castor oil is the continuous phase with viscosity $=7.42$ poise, and silicone oil is the dispersed phase with viscosity $=0.48$ poise. 


\subsection{EFFECTS OF PHASE INVERSION}

Increasing the shear rate and time of shearing have no effect on phase inversion. Coalescence again increases as the time of shearing increases, and decreases as the shear rate increases. When the viscosity ratio $\sim 0.7$, the droplets' size reach equilibrium after a longer period of time than when the viscosity $\sim 15$. That is due to the high viscosity of the continuous phase, due to which the droplets have a harder time to mobilize through the continuous phase and the film between the droplets is more viscous so it will take a longer time to drain. It took 12 hours for droplets of a $1 \%$ emulsion to reach their equilibrium size when they were sheared at $13 \mathrm{~s}^{-1}$ and having a viscosity ratio of 0.7 , and 35 minutes at the viscosity ratio 15 . In the step-up experiments the droplets break when the viscosity ratio 0.7 , and do not break when the viscosity ratio $\sim 15$.

The study of Grizzuti and Bifulco (1997) shows no qualitative changes in the size vs. shear rate when the two phases are inverted. This is because the viscosity ratios are 0.5 and 2 , thus break-up will occur in both cases. 


\section{CHAPTER 5}

\section{CONCLUSIONS AND RECOMMENDATIONS}

The objective of this study was to examine the coalescence of model emulsion droplets during shear flow in capillary tubes and also in a cone-and-plate viscometer. Since material and process parameters affect the coalescence of emulsions, they were studied and their effects are summarized below.

\subsection{Conclusions}

1. For our emulsion system there was no wall slip since the emulsion system is dilute.

2. Coalescence of the emulsion droplets was the same when shearing the emulsion using flow through tubes or using cone-and-plate devices.

3. Increasing the time of shearing increased the droplets' size until they reached a steady state size.

4. Increasing the shear rate decreased the coalescence of emulsion droplets.

5. As the concentration of the dispersed phase increases, the coalescence of droplets increases.

6. As the temperature increases, the viscosity of both the dispersed and continuous phase decreases while the ratio of the two viscosities decreases. The temperature has an effect on the interfacial tension between the dispersed phase and the continuous phase as well. Increasing the temperature decreases 
the interfacial tension between the droplet and the continuous phase. Decreasing the interfacial tension leads to a decrease in coalescence.

7. When the silicone oil is sonicated for a long time (adding energy to silicone oil) the emulsions aggregate at any shear rate and at any concentration regardless of the silicone oil with different viscosity.

8. When the shear rate increases (step-up) the emulsion droplets with viscosity ratio $\sim 15$ did not break-up, while those with a viscosity ratio $\sim 0.72$ the emulsion droplets did break-up.

9. The droplets steady state size was reached much quicker when the continuous phase has low viscosity ( 0.48 poise) than in the continuous phase with high viscosity (10.22 poise).

\subsection{Recommendations}

1. Heating the emulsions before shearing them and testing the emulsions at much higher temperatures.

2. Using a digital camera to take more pictures of the samples. This not only saves time, but will also be more accurate quality wise than developed pictures.

3. Using emulsions that are made up of polymer materials that are in liquid state at room temperature.

4. Using emulsions with higher concentrations. 


\section{LITERATURE CITED}

Ambruster, H. “ Untersuchungen zum kontinuierlichen Emulgierproz in Kolloidmuheln unter Beruck-sichtigung spezifischer Emulgatoreigenschaften und der stromungsverhaltnisse im Dispergierspalt." Ph.D. Thesis, University of Karlsruhe (1990)

Chesters, A. K., “ The Modeling of coalescence processes in fluid-liquid dispersions", Trans IchemE, 69, 259-270 (1991).

Chong, J. S., E. B. Christiansen and A. D. Baer, "Rheology of concentrated suspensions" J. Appl. Polym. Sci., 15, 2007-2021 (1971).

Elmendorp, J. J., and A. K. Van der Vegt, " Study on polymer blend microrheology: part IV. The influence of coalescence on blend morphology origination.”, Polym Eng Sci, 26, 1332-1338, (1986).

Grizzuti, N., and O. Bifulco, "Effects of coalescence and breakup on the study-state morphology of an immiscible polymer blend in shear flow," Rheol. Acta., 36, 406-415 (1997). 
Goldsmith, H. L., and S. G. Mason, "The flow of suspensions through tubes" J. Colloid Sci., 17, 448-462 (1962)

Grace, H. P. "Dispersion of high viscosity immiscible fluids systems and applications of static mixers as dispersion devices in such systems". Chem. Eng. Commun., 14, 225-277 (1982)

Janssen, J. M. H., "Dynamics of liquid/liquid mixing," $P h D$ Thesis, Eindhoven University of Technology, Eindhoven, The Netherlands (1993).

Karnis, A., H. Goldsmith and S. G. Mason, "Kinetics of flowing dispersions", Journal of Colloidal and Interface Science, 22, 531-553 (1966).

Krieger, I, M. Adv. Colloid Interface. Sci., 3, 111 (1973).

Kumar, S. K. R. and K. S. Gandhi, "A new model for coalescence efficiency of drops in stirred dispersion", Chemical Engineering Science, 48, 2025$2038(1993)$ 
Schramm, L., Emulsions Fundamentals and Applications in the Petroleum

Industry, American Chemical Society, Washington DC, 5-44 (1992).

Minale, M., J. Mewis and P. Moldenares, "Study of the morphological hysteresis in immiscible polymers blends", AICHE J., 44, 943-950 (1998)

Mitchel, D.J.T., L. Waring, T. Bostoch, T., and M. P. McDonald, J. Chem. Soc., Faraday Trans. I 79, 975-983 (1983).

Lee, H. M. and O. O. Park, "Rheology and dynamics of immiscible polymer blends", J. Rheol., 38, 1405-1425 (1994)

Mooney, M., "Explicit formulas for slip and fluidity", J. Rheol., 2, 210-222 (1931).

Pal, R., and J. Masliyah, J., Rheology of Emulsions, American Chemical Society, Washington DC, 132-163 (1992). 
Palierne, J. F., "Linear rheology of viscoelastic emulsions with interfacial tension" Rheol. Acta., 29, 204-214 (1990)

Ross S. I., F. H. Verhoff and R. I. Curl, "Droplet breaking and coalescence process in agitated dispersion em dash 2. Measurement and interpretation of mixing experiments", Ind Eng Chem Fundl, 17, 101-108 (1978).

Sherman P. In Encyclopedia of Emulsion Technology; Beacher, P., Ed., Dekker: New York, 416 (1983).

Shubert, H., and H. Armbruster, "Principles of formation and stability of emulsions, International Chemical Eng., 32, 14-28 (1992)

Svendsen, H. F., and H. Luo, "Modeling of approach process for equal or unequal sized fluid particles." The Canadian Journal of Chemical Engineering, 74, 321-330 (1996).

Taylor, G.T., "The viscosity of fluid of a fluid containing small drops of another fluid" Proc. Royal Soc. A128, 41-48 (1932) 
Utracki, L. A., Polymer Alloys and Blends, Hanser Pubkishers, New York, $160(1989)$

Vinckier I., P. Moldenaers, A. M. Terracciano, and N. Grizzuti “Droplet size evolution during coalescence in semiconcentrated model blends", AIChE J., 44, 951-957 (1998).

Whorlow, R. W. Rheological Techniques, Ellis Horwood, Ltd., United Kingdom (1980). 


\section{APPENDIX A}

\section{WALL SLIP VELOCITY OF EMULSIONS}




\section{APPENDEX A}

\section{Wall Slip Velocity}

To confirm that viscosity data are not influenced by wall slip, one can use the analysis of Mooney (1931) and Figure A.1. The capillary viscometer consists essentially of a capillary tube through which a liquid is forced under pressure. If the flow velocity is $\mathrm{v}_{\mathrm{z}}(\mathrm{r})$ then the volumetric flow rate $\mathrm{Q}$ is given as:

$$
Q=\int_{0}^{R} 2 \pi r v_{z} d r
$$

Integrating equation (1) by parts and noting that the fluid velocity at the wall is $\mathrm{v}_{\mathrm{s}}$, the slip velocity:

$$
Q=\pi R^{2} v_{s}-\pi \int_{0}^{R} r^{2} \dot{\gamma} d r
$$

Where $\dot{\gamma}$ is the shear rate given by $\frac{d v_{z}}{d r}$

Doing a force balance on a cylindrical control volume (see Figure A.2), one can show that:

$$
\left(p_{1}-p_{2}\right) \pi r^{2}=\tau 2 \pi r L
$$

Where $\left(\mathrm{p}_{1}-\mathrm{p}_{2}\right)$ is equal to the pressure drop across the capillary tube, $\Delta \mathrm{p}$, and $\tau$ is the shear stress.

Rearranging equation (3):

$$
r=\frac{2 \tau L}{\Delta p}
$$


Introducing equation (4) into equation (2):

$$
Q=\pi R^{2} v_{s}-\frac{8 \pi L^{3}}{(\Delta p)^{3}} \int_{0}^{\tau_{w}} \tau^{2} \dot{\gamma} d \tau
$$

Where $\tau_{\mathrm{w}}$ is the wall shear stress. Multiplying both sides of equation (5) by $4 /\left(\pi \mathrm{R}^{3}\right)$ :

$$
\frac{4 Q}{\pi R^{3}}=\frac{4 v_{s}}{R}-\frac{4}{\tau_{w}^{3}} \int_{0}^{\tau_{w}} \tau^{2} \dot{\gamma} d \tau
$$

Differentiating equation (6) with respect to $1 / \mathrm{R}$ keeping $\tau_{\mathrm{w}}$ constant:

$$
\left.\frac{\partial\left[\frac{4 Q}{\pi R^{3}}\right] \mid}{\partial\left[\frac{1}{R}\right]}\right|_{\tau_{w}=c o n s \tan t}=4 v_{s}
$$

so that the slip velocity is obtained from the slope of plots of $\left[\frac{4 Q}{\pi R^{3}}\right]$ as a function of $(1 / \mathrm{R})$ at constant values of the wall shear stress. The wall shear stress is given by:

$$
\tau_{w}=\frac{R}{2} \frac{\Delta p}{L}
$$

In practice, fix $R$ and measure $\tau_{w}$ as a function of $4 Q /\left(\pi R^{3}\right)$. Then change the value of $\mathrm{R}$ and repeat the experiment. The approach used is to plot $\tau_{\mathrm{w}}$ versus $\frac{4 Q}{\pi R^{3}}$ for each value of $\mathrm{R}$ and then use these plots to read corresponding values of $\frac{4 Q}{\pi R^{3}}$ and $1 / \mathrm{R}$ for constant values of $\tau_{\mathrm{w}}$. 
If using three different tube diameters results in three different curves, this observation would suggest the occurrence of slip (see Figure A.3).

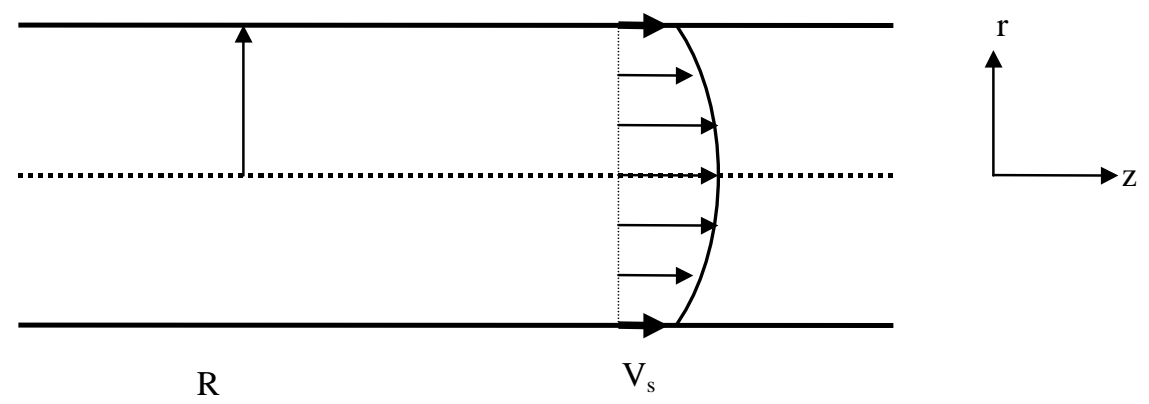

Figure A.1 Slip flow through a capillary.

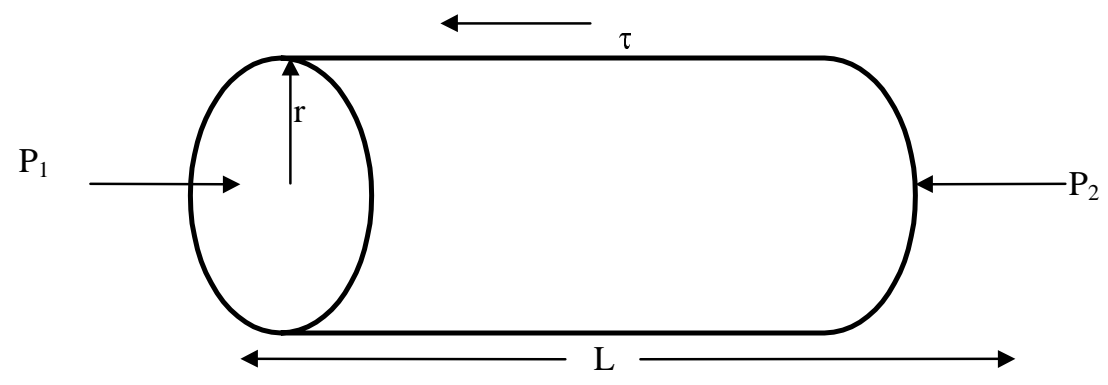

Figure A.2 Force balance on a cylindrical control volume. 


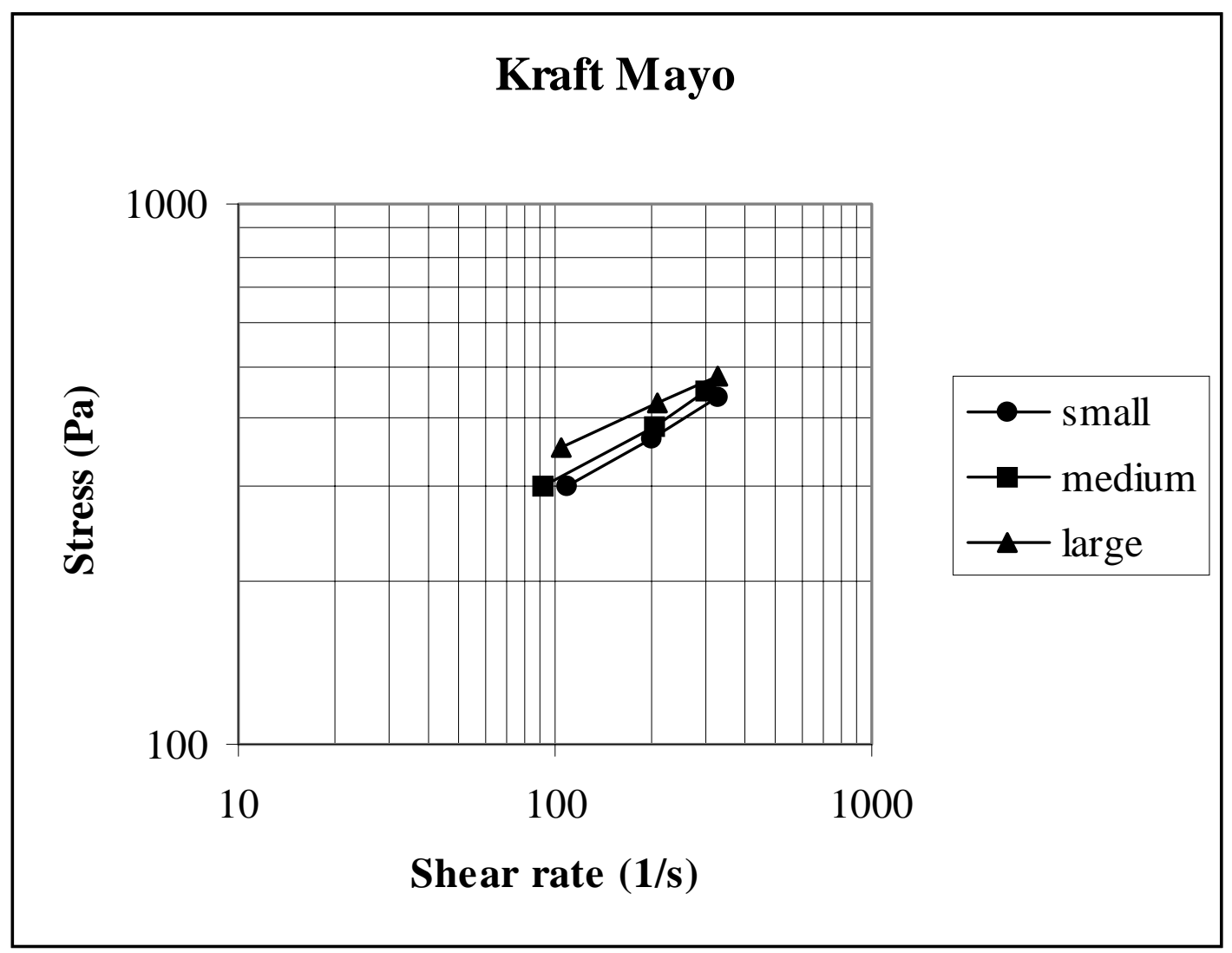

Figure A.3 Data for Kraft full-fat mayonnaise. Each line is data on a single sample (Results by R. K. Gupta, 1994). 
To rule out the possibility of wall slip, three main steps were followed:

1. Measure the flow rate and the pressure drop across the capillary tubes. Change the diameter of the tubes and then repeat the experiment.

2. Calculate the shear rate and the shear stress at the wall for each flow rate and each tube diameter. The shear rate can be calculated using the HagenPoiseuille equation to be $\left(\frac{4 Q}{\pi R^{3}}\right)$; while the shear stress at the wall $\left(\tau_{\mathrm{w}}\right)$ can be calculated using equation $12\left(\tau_{w}=\frac{R \Delta P}{2 L}\right)$. By fixing a value of $\mathrm{R}$, one can measure $\tau_{\mathrm{w}}$ as a function of $\left(4 \mathrm{Q} / \pi \mathrm{R}^{3}\right)$, then change the value of $\mathrm{R}$ and repeat the same experiment. A plot of the shear stress at the wall versus the shear rate for each tube diameter is plotted. If for each tube diameter there is a different plot, then this will indicate that a wall slip velocity exists.

3. Wall slip velocity can be obtained from the slope of plots of $\left(4 Q / \pi R^{3}\right)$ as a function of $1 / \mathrm{R}$ at constant values of the wall shear rate $\left(\tau_{\mathrm{w}}\right)$ equation (8).

\section{RESULTS}

Table A.1 summarizes the shear rates and stresses at the wall for the $1 \%$ emulsion using three different tube diameters. For the $1 \%$ emulsion system, no wall slip velocity was observed. This is clear from Figure A.4. This is because the system was very dilute and the viscosity of the emulsion was almost equal to the viscosity of silicone oil. The viscosity of silicone oil measured using a 
parallel plate viscometer is 0.49 poise, and 0.51 poise using the capillary tube viscometer (see Figure A.5). The viscosity of the $1 \%$ emulsion using the capillary tubes is equal to 0.51 poise (see Figure A.4).

Table A.1 Shear rates and stresses at the wall for $1 \%$ emulsion.

\begin{tabular}{|c|c|c|c|c|c||}
\hline \multicolumn{2}{|c|}{ D4 (1.3725mm) } & \multicolumn{2}{c|}{ D5 (1.053 mm) } & \multicolumn{2}{c||}{ D6 (0.74 mm) } \\
\hline$\gamma_{\mathrm{w}}\left(\mathrm{s}^{-1}\right)$ & $\tau_{\mathrm{w}}(\mathrm{Pa})$ & $\gamma_{\mathrm{w}}\left(\mathrm{s}^{-1}\right)$ & $\tau_{\mathrm{w}}(\mathrm{Pa})$ & $\gamma_{\mathrm{w}}\left(\mathrm{s}^{-1}\right)$ & $\tau_{\mathrm{w}}(\mathrm{Pa})$ \\
\hline 373 & 19 & 832 & 43 & 802 & 41 \\
\hline 516 & 26 & 1153 & 61 & 1517 & 84 \\
\hline 660 & 32 & 1474 & 77 & 1898 & 99 \\
\hline 804 & 40 & 1795 & 91 & 2279 & 117 \\
\hline 948 & 48 & & & & \\
\hline
\end{tabular}

Because of the above work, one can neglect any possible wall slip effects. 


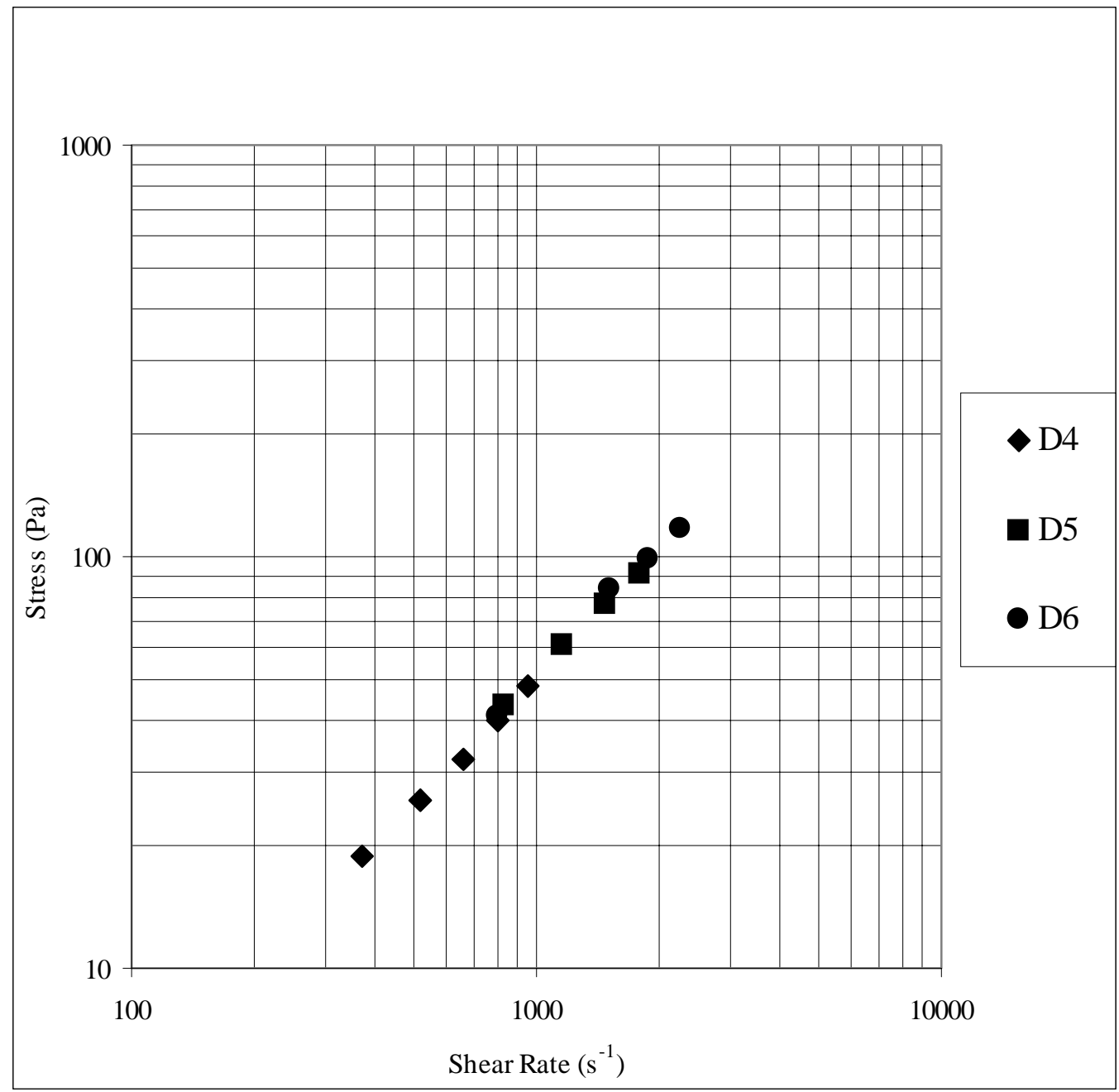

Figure A.4 Stress vs. shear rate for $1 \%$ emulsion using capillary tubes (D4>D5>D6). 


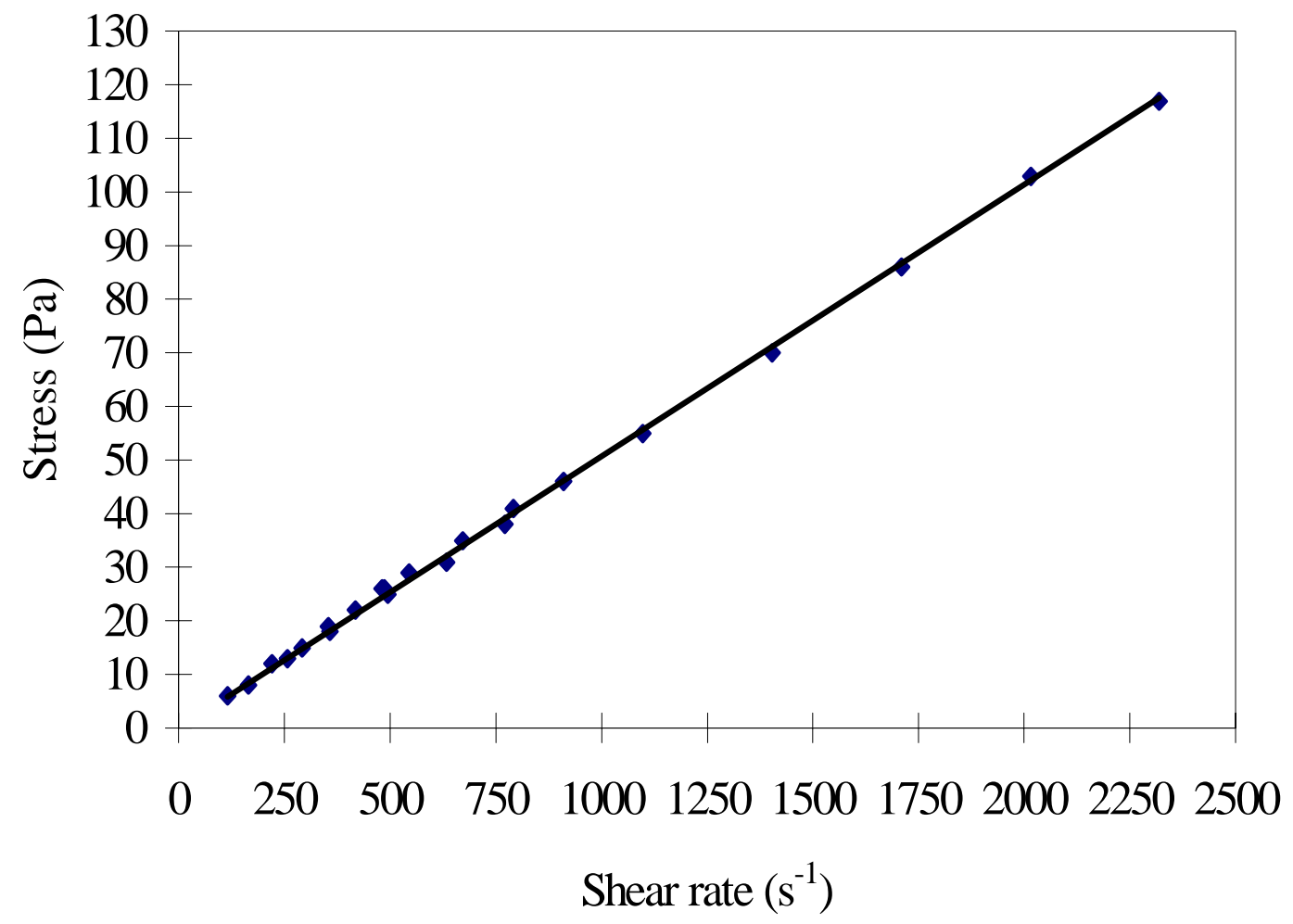

Figure A.5 Stress vs. shear rate for silicone oil using capillary tubes. 


\section{APPENDIX B}

\section{TABLES OF RESULTS}




\section{APPENDIX B}

Table B.1. Effect of the flow type on coalescence.

\begin{tabular}{|c|c|c||}
\hline \multirow{2}{*}{ Time (min) } & \multicolumn{2}{|c|}{ D/D } \\
\cline { 2 - 3 } & Tube flow & Cone-and-plate \\
\hline \hline 0.00 & 1 & 1 \\
\hline 4.00 & 1.45 & 1.44 \\
\hline 6.90 & 1.53 & 1.52 \\
\hline 10.78 & 1.62 & 1.63 \\
\hline 17.27 & 1.72 & 1.74 \\
\hline 24.18 & 1.75 & 1.77 \\
\hline 31.85 & 1.80 & 1.79 \\
\hline
\end{tabular}

- Tube diameter 3/32 in.

- Flow rate $0.0295 \mathrm{ml} / \mathrm{s}$.

- Concentration $1 \%(\mathrm{v} / \mathrm{v})$.

- Shear rate $11 \mathrm{~s}^{-1}$ for both tube and cone-and-plate devices.

- Silicone oil is the continuous phase with viscosity $=0.48$ poise

- Castor oil is the dispersed phase with viscosity $=7.42$ poise.

- Temperature $23{ }^{\circ} \mathrm{C}$.

- $\mathrm{D}_{0}=8.1 \mu \mathrm{m}$. 
Table B.2 Effect of the residence time on coalescence.

\begin{tabular}{|c|c|c||}
\hline Time (min) & Tube length (m) & D/D $_{\mathbf{0}}$ \\
\hline 0.00 & 0 & 1 \\
\hline 4.00 & 1.6 & 1.45 \\
\hline 6.90 & 2.7 & 1.53 \\
\hline 10.78 & 4.3 & 1.62 \\
\hline 17.27 & 6.8 & 1.72 \\
\hline 24.18 & 9.6 & 1.75 \\
\hline 31.85 & 12.6 & 1.80 \\
\hline
\end{tabular}

- Emulsion is sheared using flow through tube.

- Tube diameter $3 / 32$ in.

- Concentration $1 \%(\mathrm{v} / \mathrm{v})$.

- Shear rate $11 \mathrm{~s}^{-1}$.

- Flow rate $0.0295 \mathrm{ml} / \mathrm{s}$.

- Silicone oil is the continuous phase with viscosity $=0.48$ poise

- Castor oil is the dispersed phase with viscosity $=7.42$ poise.

- Temperature $23{ }^{\circ} \mathrm{C}$.

- $\mathrm{D}_{0}=8.07 \mu \mathrm{m}$. 
Table B.3 Effect of shear rate on coalescence.

\begin{tabular}{||c|c|c|c||}
\hline \multirow{2}{*}{ Time (min) } & $\dot{\gamma}=\mathbf{1 0} \mathrm{s}^{\mathbf{1}}$ & $\dot{\gamma}=\mathbf{3 0 ~ s}^{\mathbf{- 1}}$ & $\dot{\gamma}=\mathbf{5 0} \mathbf{s}^{-1}$ \\
\hline 0.00 & $\mathbf{D} / \mathbf{D}_{\mathbf{0}}$ & $\mathbf{D} / \mathbf{D}_{\mathbf{0}}$ & $\mathbf{D} / \mathbf{D}_{\mathbf{o}}$ \\
\hline 4.00 & 1.00 & 1.00 & 1.00 \\
\hline 10.00 & 1.45 & 1.44 & 1.44 \\
\hline 15.00 & 1.68 & 1.56 & 1.53 \\
\hline 20.00 & 1.74 & 1.64 & 1.57 \\
\hline 35.00 & 1.82 & 1.68 & 1.61 \\
\hline
\end{tabular}

- Emulsion is sheared using cone-and-plate device.

- Concentration $1 \%(\mathrm{v} / \mathrm{v})$.

- Shear rates 10,30 , and $50 \mathrm{~s}^{-1}$.

- Silicone oil is the continuous phase with viscosity $=0.48$ poise

- Castor oil is the dispersed phase with viscosity $=7.42$ poise.

- Temperature $23^{\circ} \mathrm{C}$.

- $\mathrm{D}_{0}=8.1 \mu \mathrm{m}$. 
Table B.4 Effect of the concentration of the dispersed phase on coalescence.

\begin{tabular}{|c|c|c|c|c|c|}
\hline \multicolumn{2}{|c|}{$\Phi=0.5 \%$} & \multicolumn{2}{|c|}{$\Phi=1.0 \%$} & \multicolumn{2}{|c|}{$\Phi=\mathbf{5 . 0 \%}$} \\
\hline Time (min) & $\mathrm{D} / \mathrm{D}_{\mathbf{0}}$ & Time (min) & $\mathrm{D} / \mathrm{D}_{\mathbf{o}}$ & Time (min) & D/D \\
\hline 0.00 & 1.00 & 0.00 & 1.00 & 0.00 & 1.00 \\
\hline 4.30 & 1.44 & 4.00 & 1.45 & 4.55 & 1.54 \\
\hline 6.87 & 1.47 & 6.90 & 1.53 & 6.68 & 1.66 \\
\hline 11.42 & 1.52 & 10.78 & 1.62 & 11.40 & 1.84 \\
\hline 16.83 & 1.53 & 17.27 & 1.72 & 15.40 & 2.06 \\
\hline 23.43 & 1.59 & 24.18 & 1.75 & 34.17 & 2.31 \\
\hline 35.00 & 1.62 & 31.85 & 1.80 & & \\
\hline
\end{tabular}

- Emulsion is sheared using flow through tube.

- Tube diameter $3 / 32$ in.

- Concentration $0.5 \%, 1.0 \%$, and $5.0 \%(\mathrm{v} / \mathrm{v})$.

- Shear rate $11 \mathrm{~s}^{-1}$.

- Flow rate $0.0295 \mathrm{ml} / \mathrm{s}$.

- Silicone oil is the continuous phase with viscosity $=0.48$ poise.

- Castor oil is the dispersed phase with viscosity $=7.42$ poise.

- Temperature $23{ }^{\circ} \mathrm{C}$.

- $\mathrm{D}_{0}=8.07 \mu \mathrm{m}$. 
Table B.5 Effect of temperature on the viscosity of silicone oil and castor oil.

\begin{tabular}{||c|c|c|c||}
\hline Temperature ${ }^{\mathbf{0}} \mathbf{C}$ & $\eta_{\mathbf{m}}$ (poise) & $\eta_{\mathbf{d}}$ (poise) & $\eta_{\mathbf{d}} / \eta_{\mathbf{m}}$ \\
\hline 23 & 0.55 & 8.30 & 15.09 \\
\hline 23.5 & 0.53 & 8.01 & 15.25 \\
\hline 25 & 0.52 & 7.28 & 14.10 \\
\hline 30 & 0.48 & 5.00 & 10.42 \\
\hline 40 & 0.41 & 2.58 & 6.29 \\
\hline 50 & 0.37 & 1.48 & 4.00 \\
\hline 60 & 0.31 & 0.91 & 2.94 \\
\hline 70 & 0.27 & 0.60 & 2.22 \\
\hline
\end{tabular}

- Viscosities are measured using CSL100 Rheometer.

- The Viscosity is independent of shear rate.

- Shear rate $10-70 \mathrm{~s}^{-1}$.

- $\mathrm{m}=$ silicone oil.

- $\mathrm{d}=$ castor oil. 
Table B.6 Effect of temperature on the coalescence using copper tubes submerged in hot water.

\begin{tabular}{|c|c|}
\hline Temperature $^{\mathbf{0}} \mathbf{C}$ & $\mathbf{D} / \mathbf{D}_{\mathbf{o}}$ \\
\hline 22 & 1.40 \\
\hline 29 & 1.28 \\
\hline 35 & 1.22 \\
\hline
\end{tabular}

- Emulsion is sheared using flow through copper tubes.

- Tube inside diameter $3.24 \mathrm{~mm}$.

- Concentration $1 \%(\mathrm{v} / \mathrm{v})$.

- Shear rate $11 \mathrm{~s}^{-1}$.

- Time of shearing 35 minutes (steady state reached).

- Flow rate $0.0734 \mathrm{ml} / \mathrm{s}$.

- Silicone oil is the continuous phase with viscosity $=0.48$ poise

- Castor oil is the dispersed phase with viscosity $=7.42$ poise

- Temperature 22,29 , and $35^{\circ} \mathrm{C}$.

- $\mathrm{D}_{0}=8.1 \mu \mathrm{m}$. 
Table B.7 Effect of step-up and step-down on coalescence.

\begin{tabular}{|c|c|c|c|}
\hline Shear rate $s^{-1}$ & Step-up D/D & Shear rate $s^{-1}$ & Step-down $\mathrm{D} / \mathrm{D}_{0}$ \\
\hline 10 & 1.81 & 50 & 1.61 \\
\hline 20 & 1.79 & 30 & 1.68 \\
\hline 30 & 1.80 & 20 & 1.75 \\
\hline 50 & 1.79 & 10 & 1.81 \\
\hline
\end{tabular}

- Emulsion is sheared using cone-and-plate device.

- Time of shearing $35 \mathrm{~min}$ (steady state reached).

- Concentration $1 \%(\mathrm{v} / \mathrm{v})$.

- Silicone oil is the continuous phase with viscosity $=0.48$ poise

- Castor oil is the dispersed phase with viscosity $=7.42$ poise.

- Temperature $23{ }^{\circ} \mathrm{C}$.

- $\mathrm{D}_{0}=8.2 \mu \mathrm{m}$. 
Table B.8 Effect of step-up on coalescence for sample B and sample C.

\begin{tabular}{|c|c|c||}
\hline Shear rate $\left(\mathbf{s}^{-\mathbf{1}}\right)$ & $\mathbf{D}(\boldsymbol{\mu m})$ sample B & $\mathbf{D}(\boldsymbol{\mu m})$ sample $\mathbf{C}$ \\
\hline 13 & 23.1 & 28.3 \\
\hline 17 & 18.2 & 25.1 \\
\hline 30 & 14.4 & 17.2 \\
\hline 40 & 10.6 & 15.4 \\
\hline 50 & 9.1 & 14.1 \\
\hline
\end{tabular}

- Emulsion is sheared using cone-and-plate device.

- Concentration $1 \%(\mathrm{v} / \mathrm{v})$.

- Total time of shearing 61 hours (steady state reached).

- Temperature $23{ }^{\circ} \mathrm{C}$.

- Sample B silicone oil is the continuous phase with viscosity $=10.22$ poise, and castor oil is the dispersed phase with viscosity $=7.42$ poise. The initial average droplets size is $7.8 \mu \mathrm{m}$.

- Sample $\mathrm{C}$ castor oil is the continuous phase with viscosity $=7.42$ poise, and silicone oil is the dispersed phase with viscosity $=0.48$. The initial average droplets size is $8.1 \mu \mathrm{m}$. 


\section{APPENDIX C}

\section{PHOTOGRAPHS AND SIZE DISTRIBUTIONS \\ GRAPHS OF EMULSIONS}




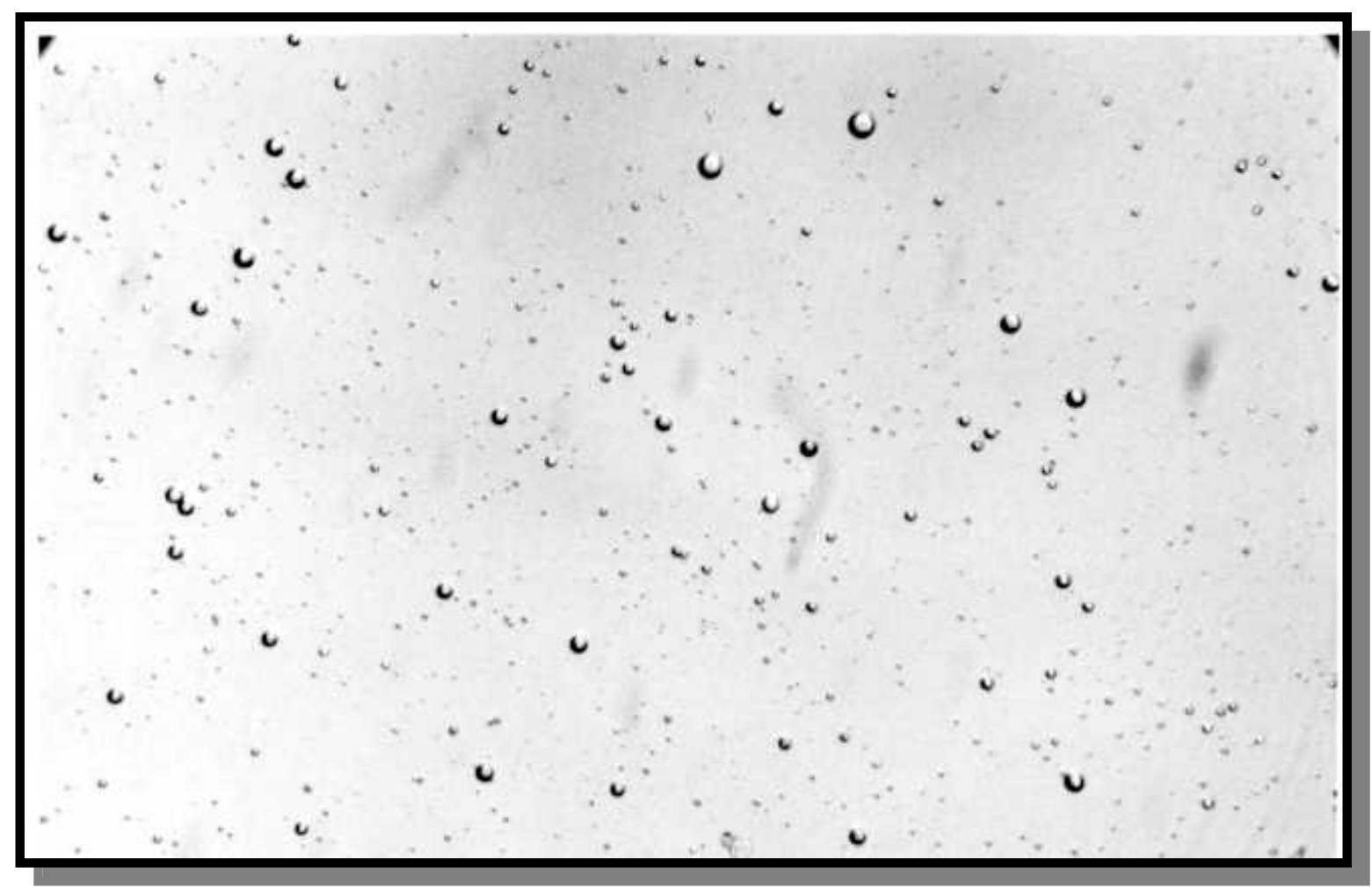

Figure C.1 Fresh emulsion.

- Silicone oil is the continuous phase with viscosity $=0.48$ poise

- Castor oil is the dispersed phase with viscosity $=7.42$ poise

- Temperature $23{ }^{\circ} \mathrm{C}$.

- $\mathrm{D}=8.1 \mu \mathrm{m}$.

- Concentration less than $0.5 \%(\mathrm{v} / \mathrm{v})$. 


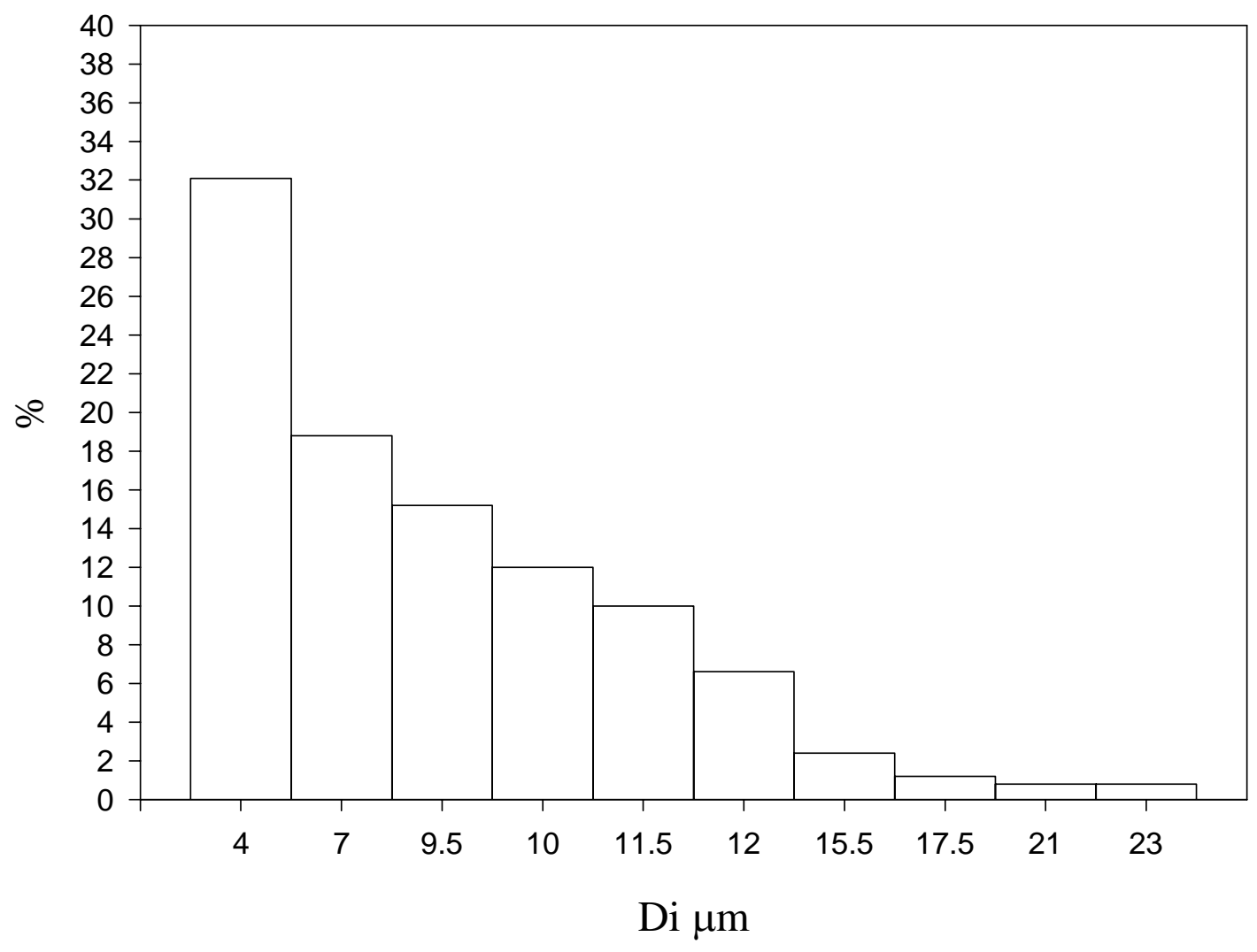

Figure C.2 Fresh emulsion 


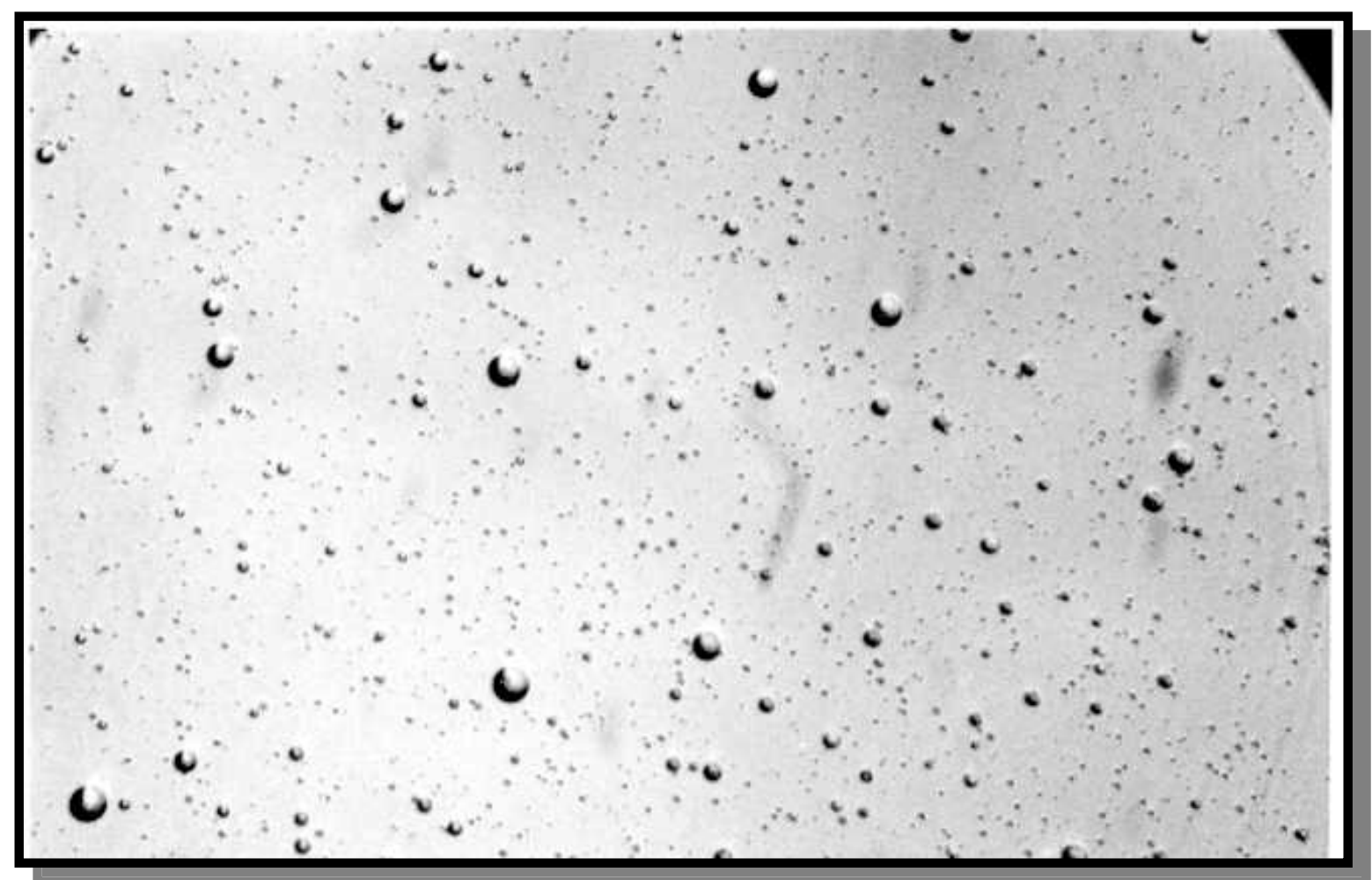

Figure C.3

- Tube diameter $3 / 32$ in.

- Time of shearing 4.30 minutes.

- Concentration $0.5 \%(\mathrm{v} / \mathrm{v})$.

- Shear rate $11 \mathrm{~s}^{-1}$.

- Silicone oil is the continuous phase with viscosity $=0.48$ poise.

- Castor oil is the dispersed phase with viscosity $=7.42$ poise.

- Temperature $23{ }^{\circ} \mathrm{C}$.

- $\mathrm{D}=11.66 \mu \mathrm{m}$. 


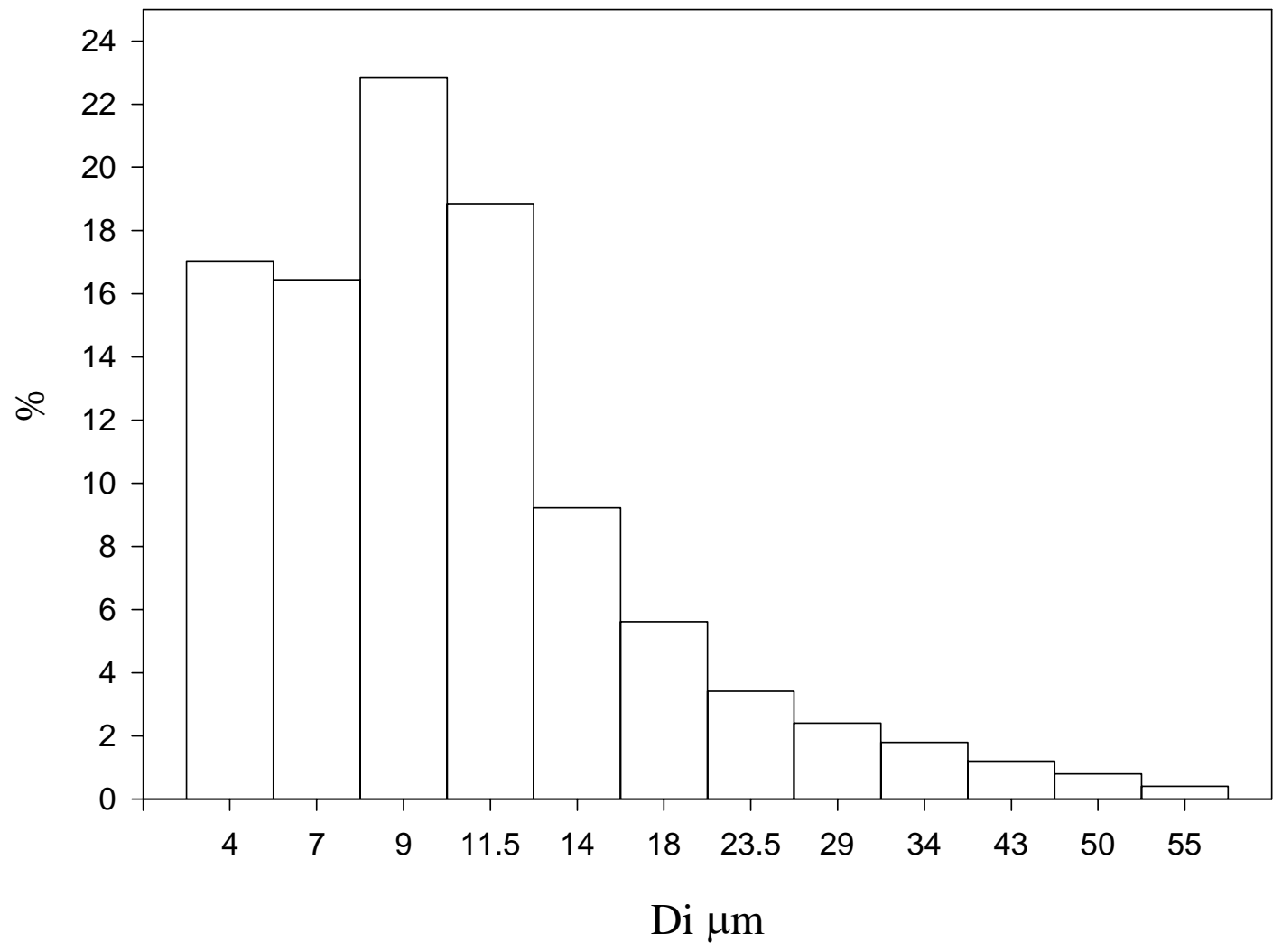

Figure C.4

- The size distribution reflect on Figure C.3 and Figure 4.11 


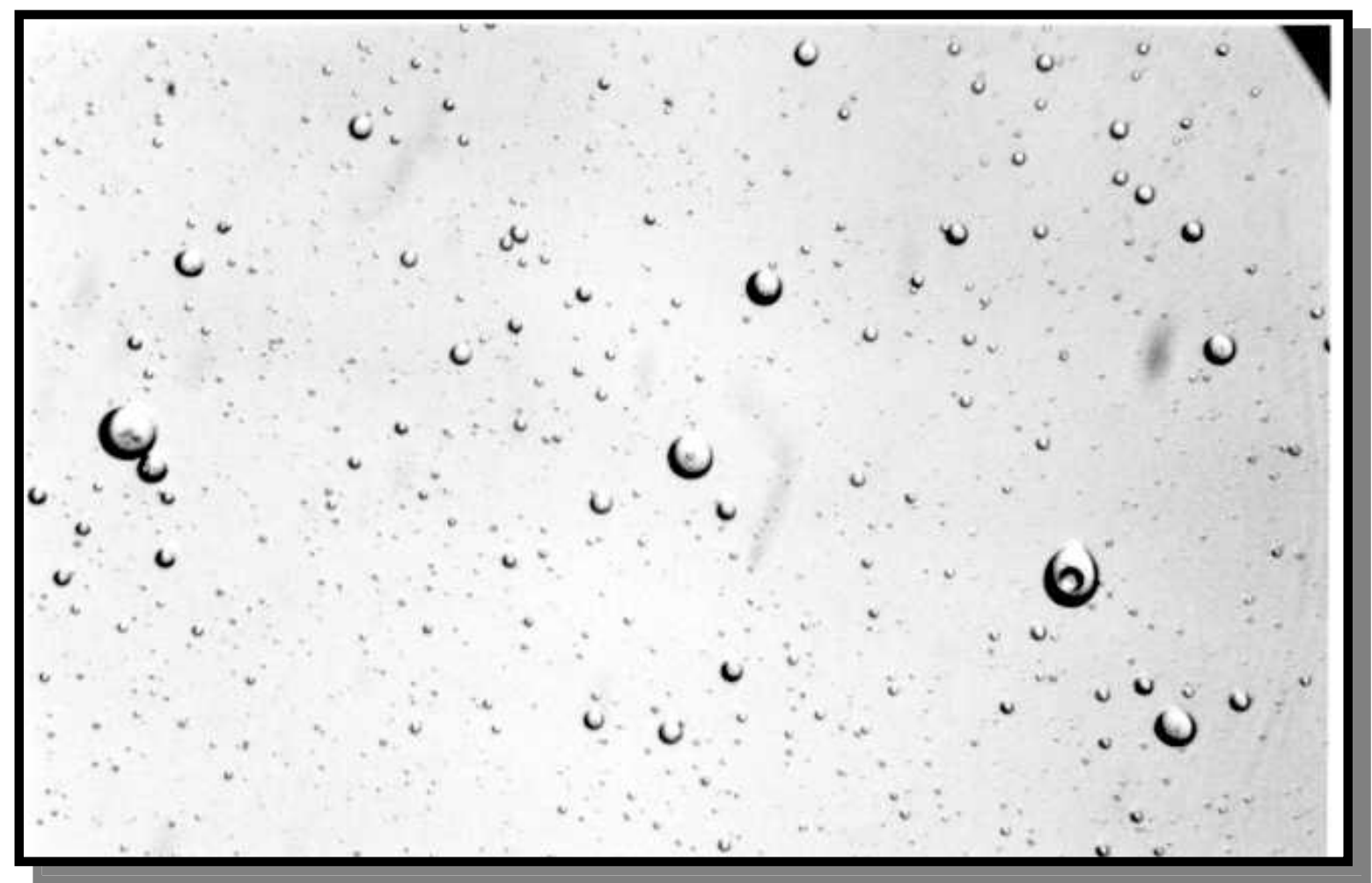

Figure C.5

- Tube diameter $3 / 32$ in.

- Time of shearing 6.87 minutes.

- Concentration $0.5 \%(\mathrm{v} / \mathrm{v})$.

- Shear rate $11 \mathrm{~s}^{-1}$.

- Silicone oil is the continuous phase with viscosity $=0.48$ poise

- Castor oil is the dispersed phase with viscosity $=7.42$ poise

- Temperature $23{ }^{\circ} \mathrm{C}$.

- $\mathrm{D}=11.87 \mu \mathrm{m}$. 


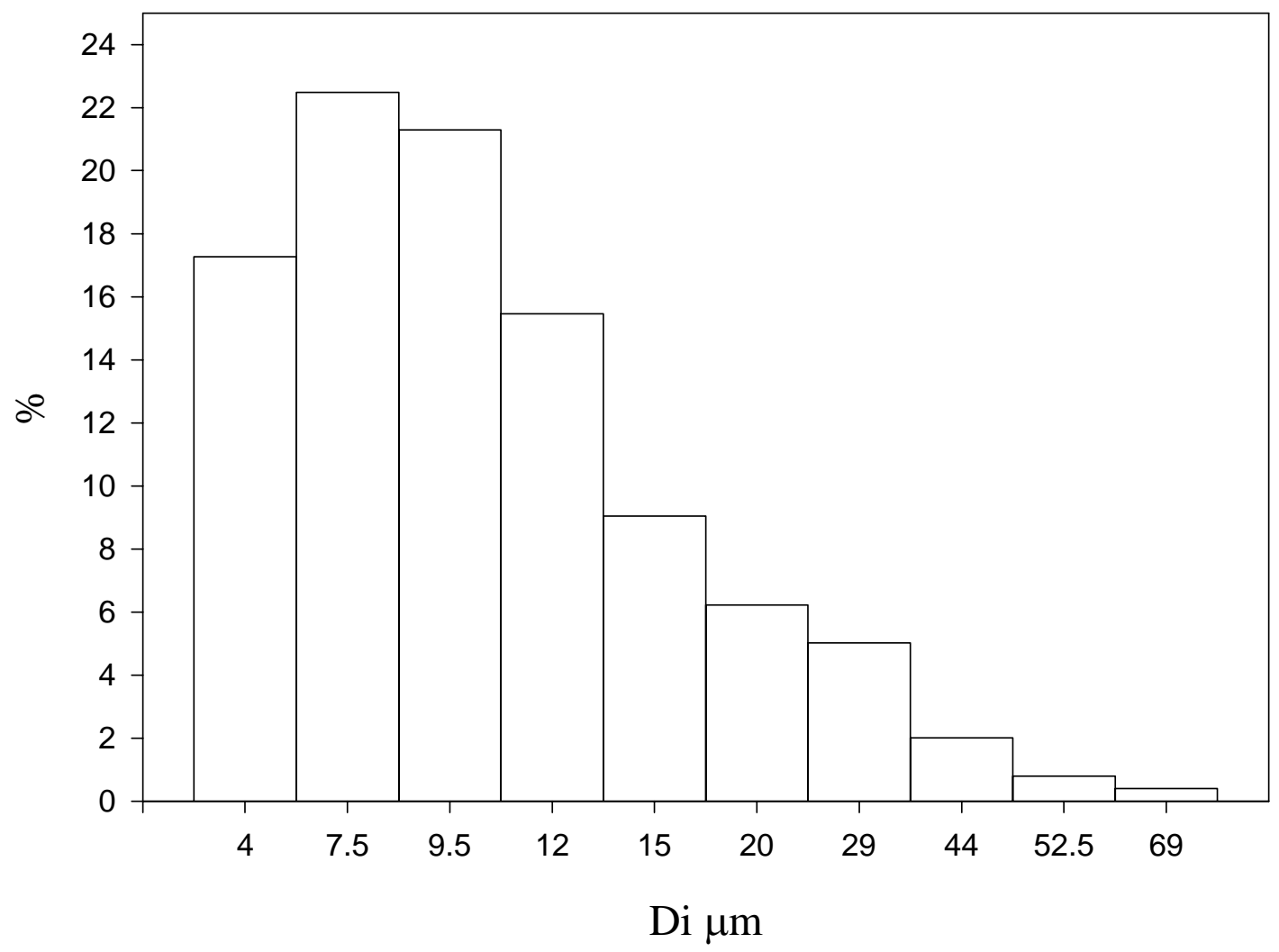

Figure C.6

- The size distribution reflect on Figure C.5 and Figure 4.11 


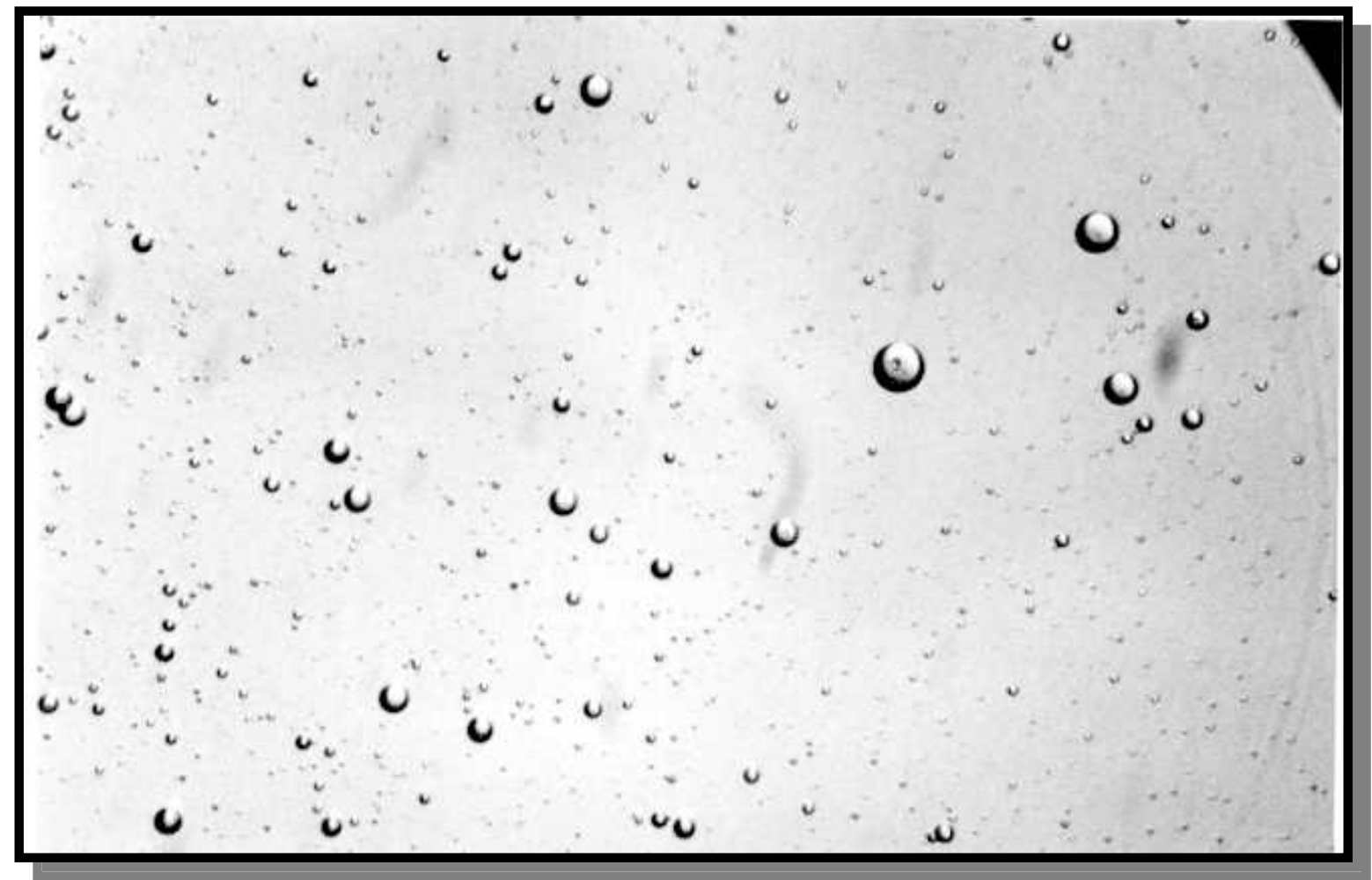

Figure C.7

- Tube diameter 3/32 in.

- Time of shearing 11.42 minutes.

- Concentration $0.5 \%(\mathrm{v} / \mathrm{v})$.

- Shear rate $11 \mathrm{~s}^{-1}$.

- Silicone oil is the continuous phase with viscosity $=0.48$ poise.

- Castor oil is the dispersed phase with viscosity $=7.42$ poise.

- Temperature $23{ }^{\circ} \mathrm{C}$.

- $\mathrm{D}=12.29 \mu \mathrm{m}$. 


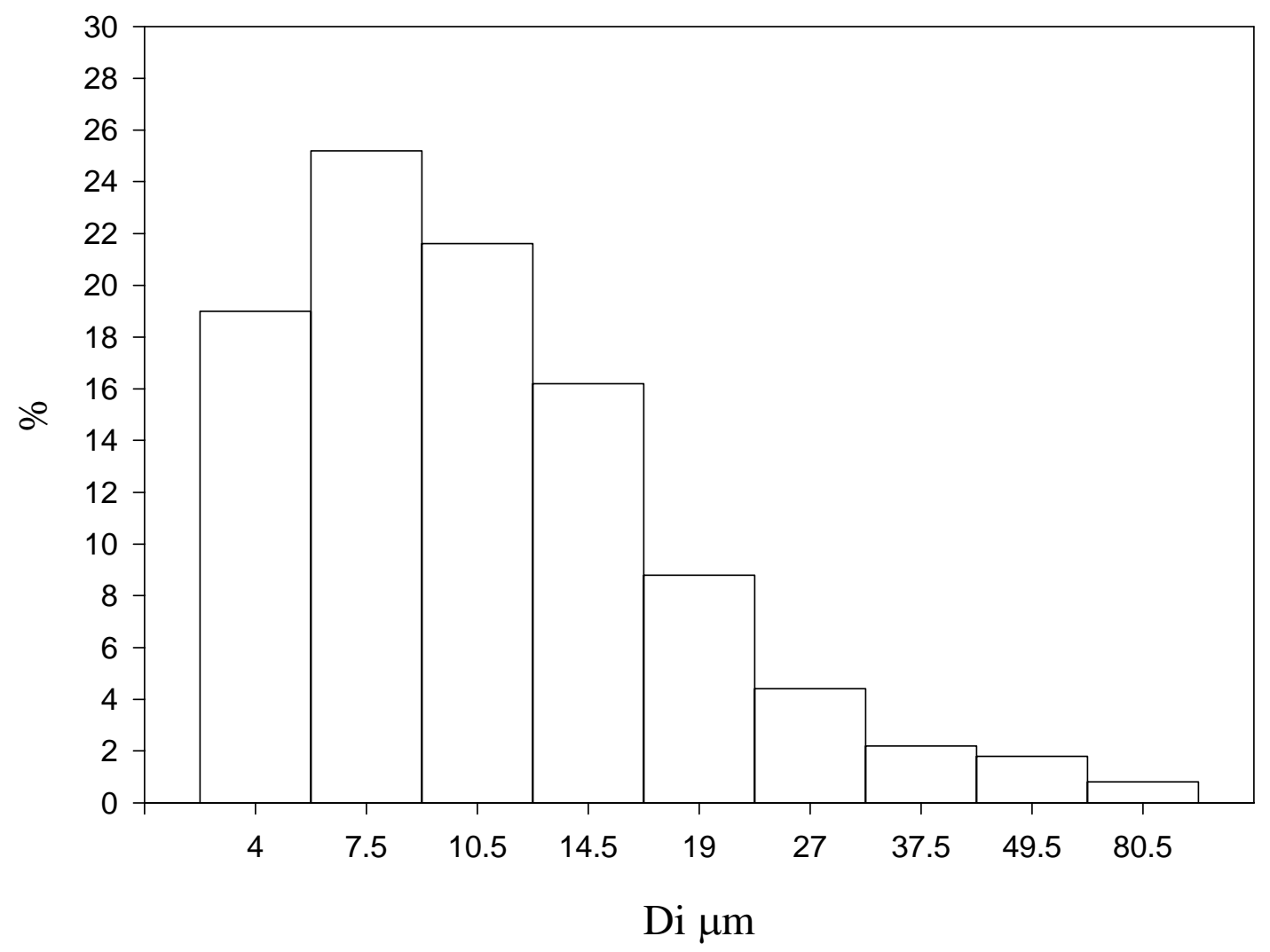

Figure C.8

- The size distribution reflect on Figure C.7 and Figure 4.11 


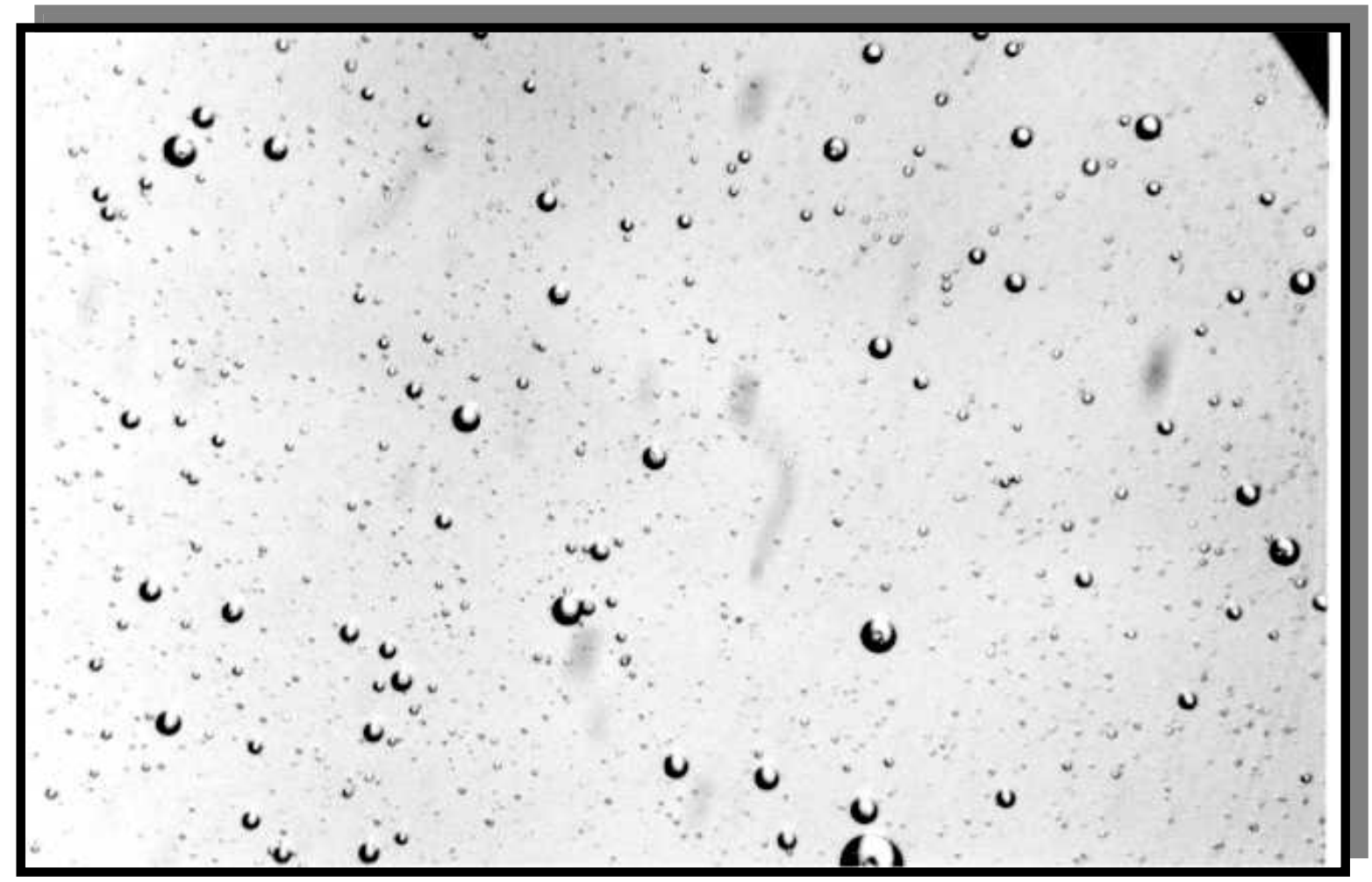

Figure C.9

- Tube diameter $3 / 32$ in.

- Time of shearing 16.83 minutes.

- Concentration $0.5 \%(\mathrm{v} / \mathrm{v})$.

- Shear rate $11 \mathrm{~s}^{-1}$.

- Silicone oil is the continuous phase with viscosity $=0.48$ poise.

- Castor oil is the dispersed phase with viscosity $=7.42$ poise.

- Temperature $23{ }^{\circ} \mathrm{C}$.

- $\mathrm{D}=12.39 \mu \mathrm{m}$. 


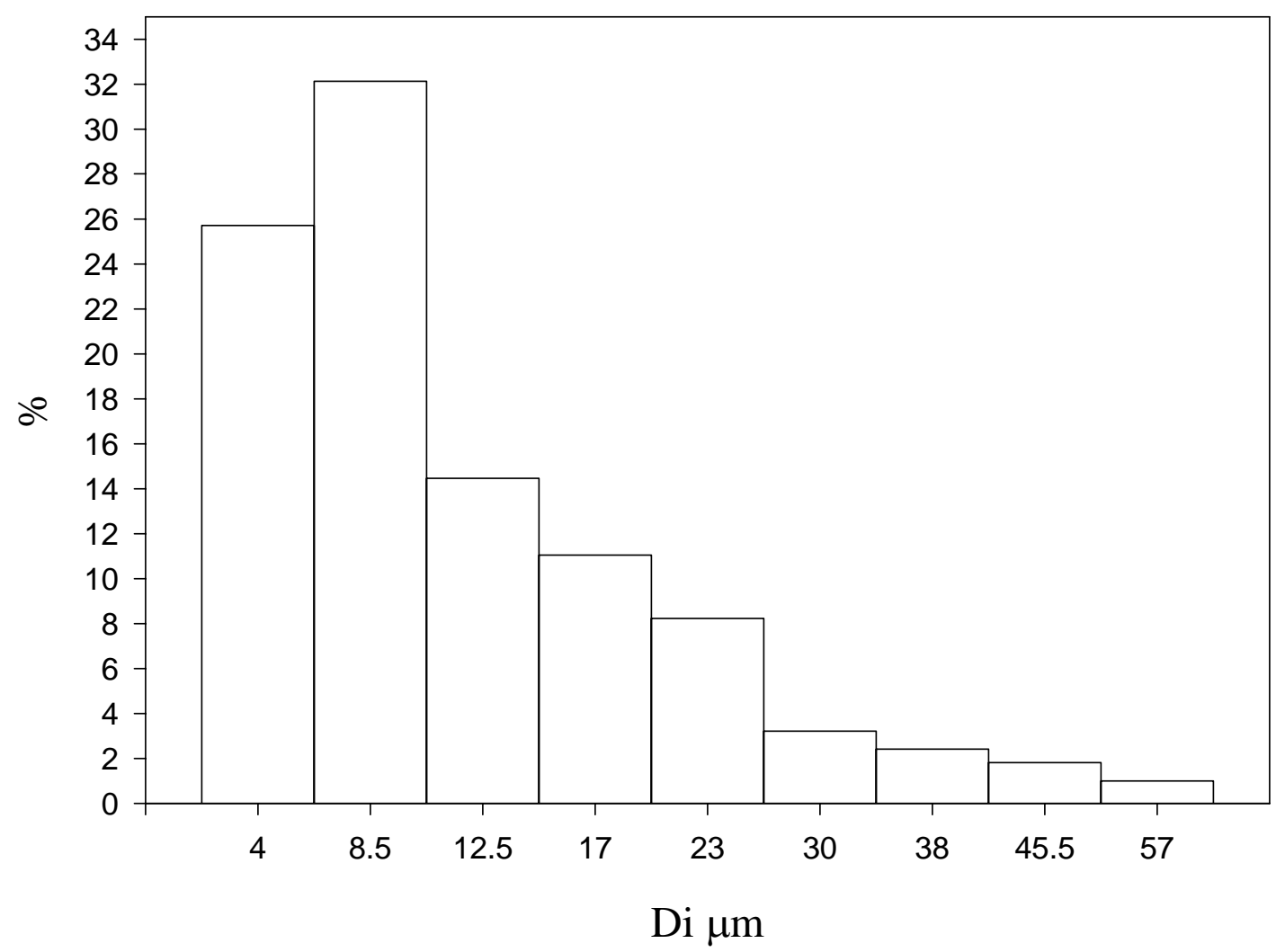

Figure C.10

- The size distribution reflect on Figure C.9 and Figure 4.11 


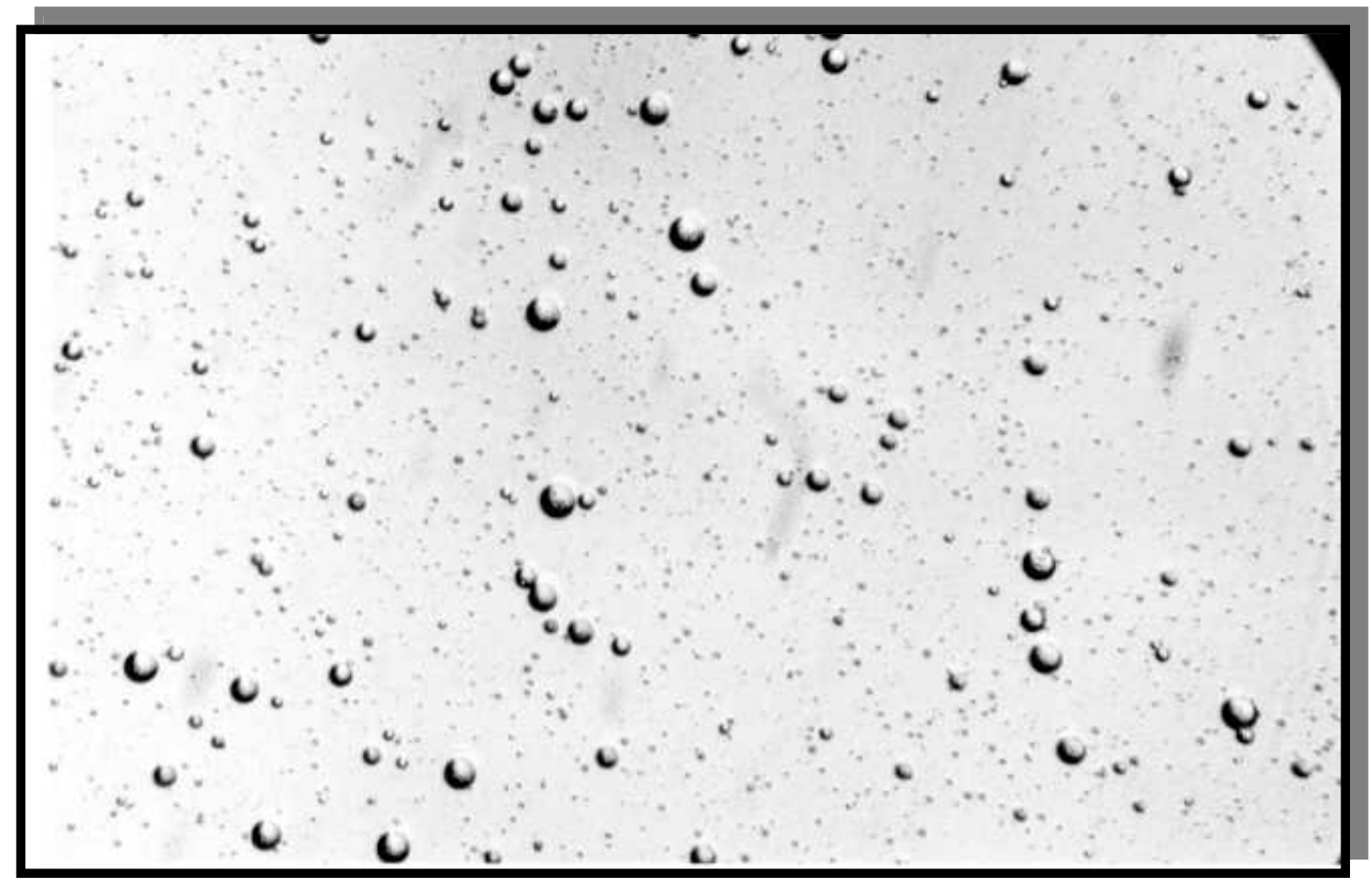

Figure C.11

- Tube diameter $3 / 32$ in.

- Time of shearing 23.43 minutes.

- Concentration $0.5 \%(\mathrm{v} / \mathrm{v})$.

- Shear rate $11 \mathrm{~s}^{-1}$.

- Silicone oil is the continuous phase with viscosity $=0.48$ poise

- Castor oil is the dispersed phase with viscosity $=7.42$ poise

- Temperature $23{ }^{\circ} \mathrm{C}$.

- $\mathrm{D}=12.81 \mu \mathrm{m}$. 


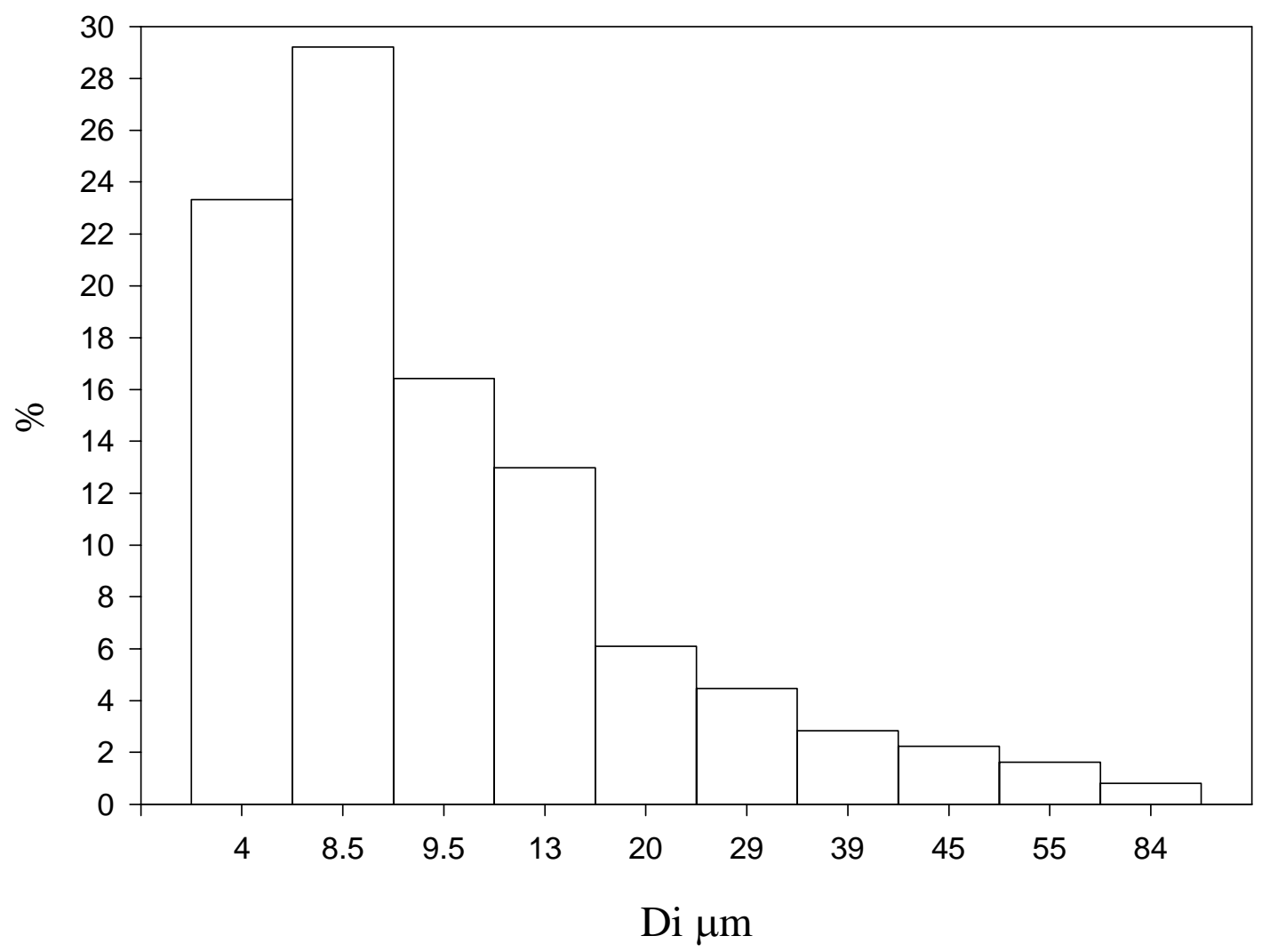

Figure C.12

- The size distribution reflect on Figure C.11 and Figure 4.11 


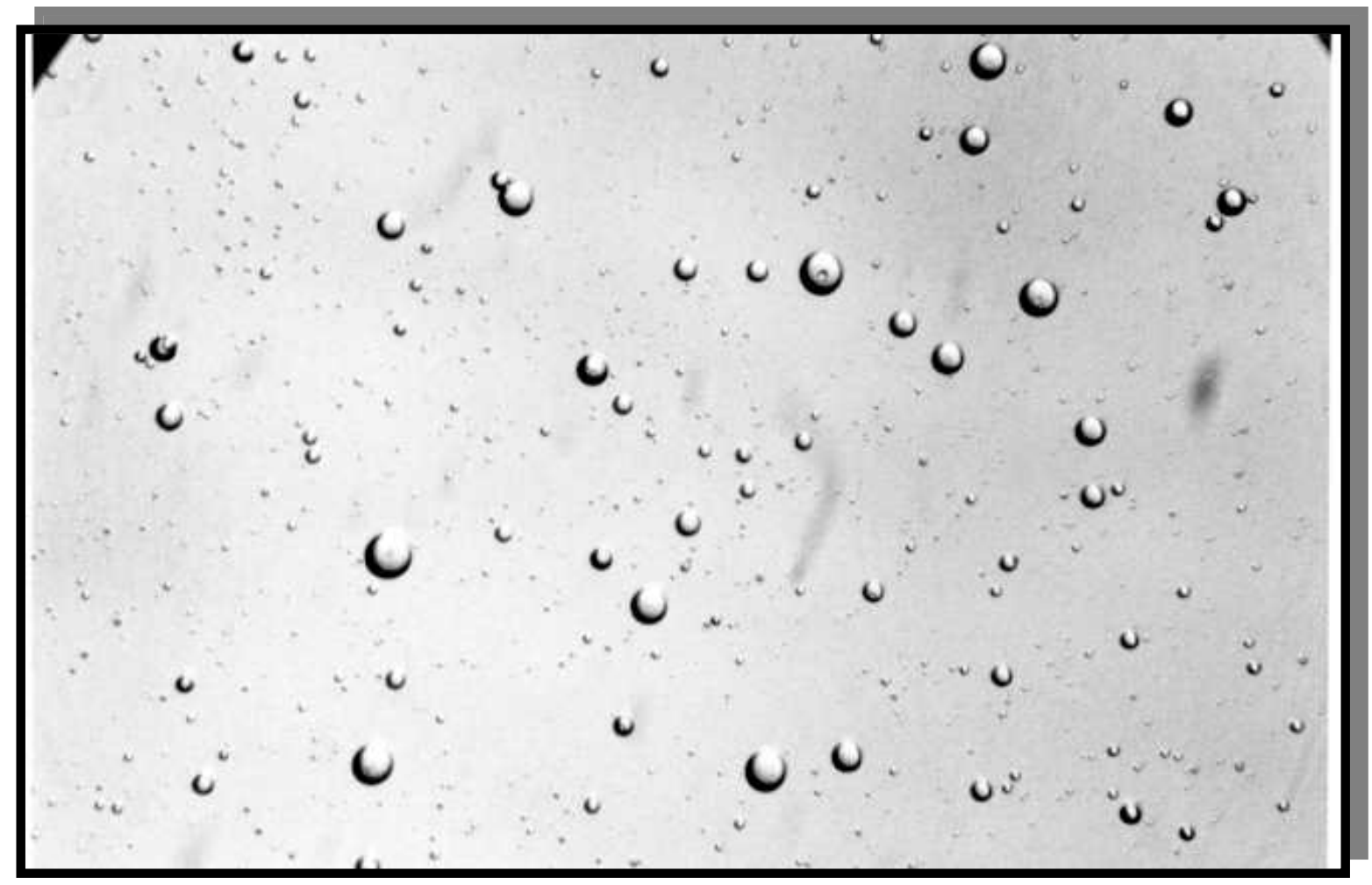

Figure C.13

- Tube diameter $3 / 32$ in.

- Time of shearing 35.00 minutes.

- Concentration $0.5 \%(\mathrm{v} / \mathrm{v})$.

- Shear rate $11 \mathrm{~s}^{-1}$.

- Silicone oil is the continuous phase with viscosity $=0.48$ poise

- Castor oil is the dispersed phase with viscosity $=7.42$ poise

- Temperature $23{ }^{\circ} \mathrm{C}$.

- $\mathrm{D}=13.13 \mu \mathrm{m}$. 


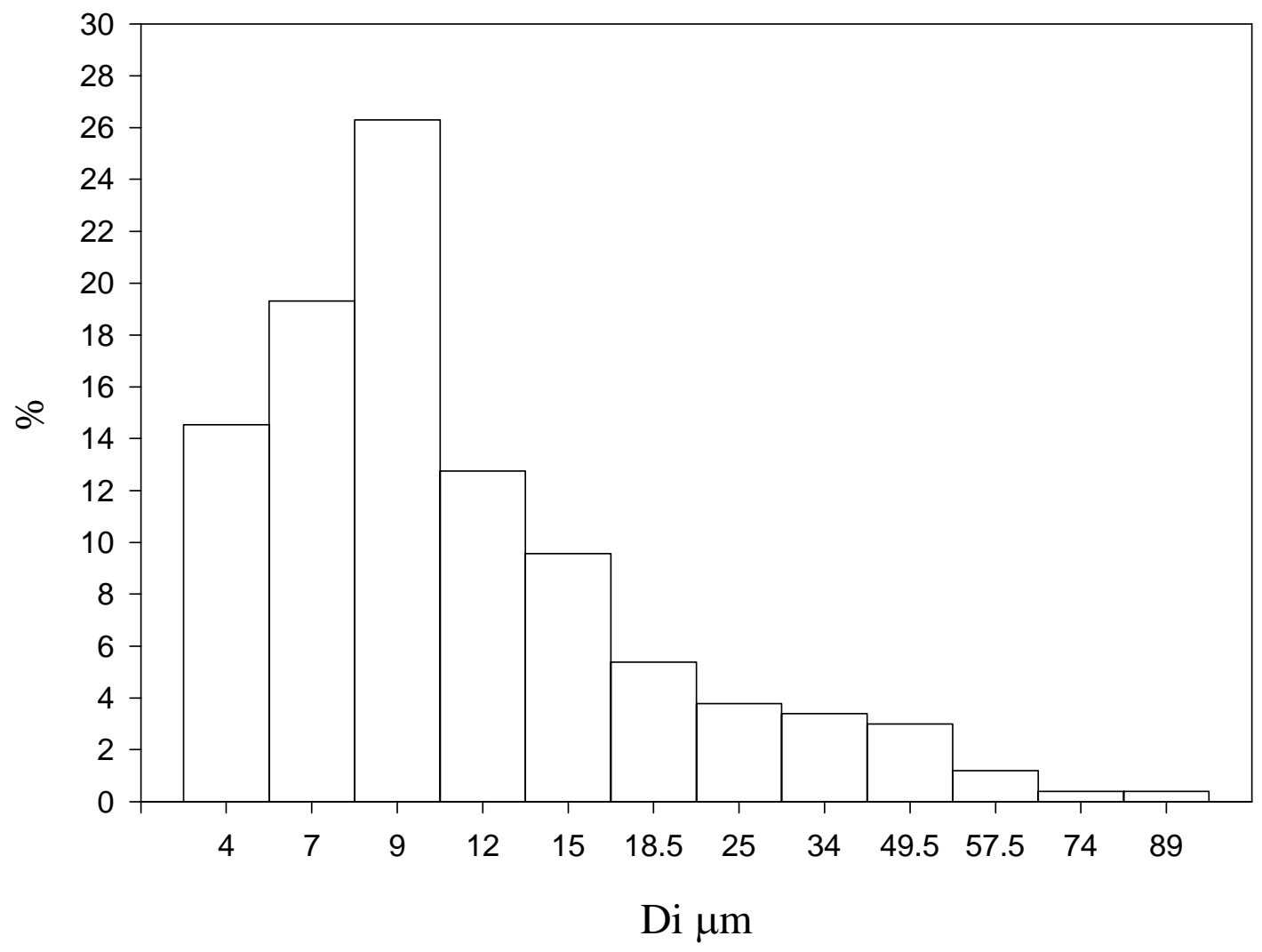

Figure C.14

The size distribution reflect on Figure C.13 and Figure 4.11 


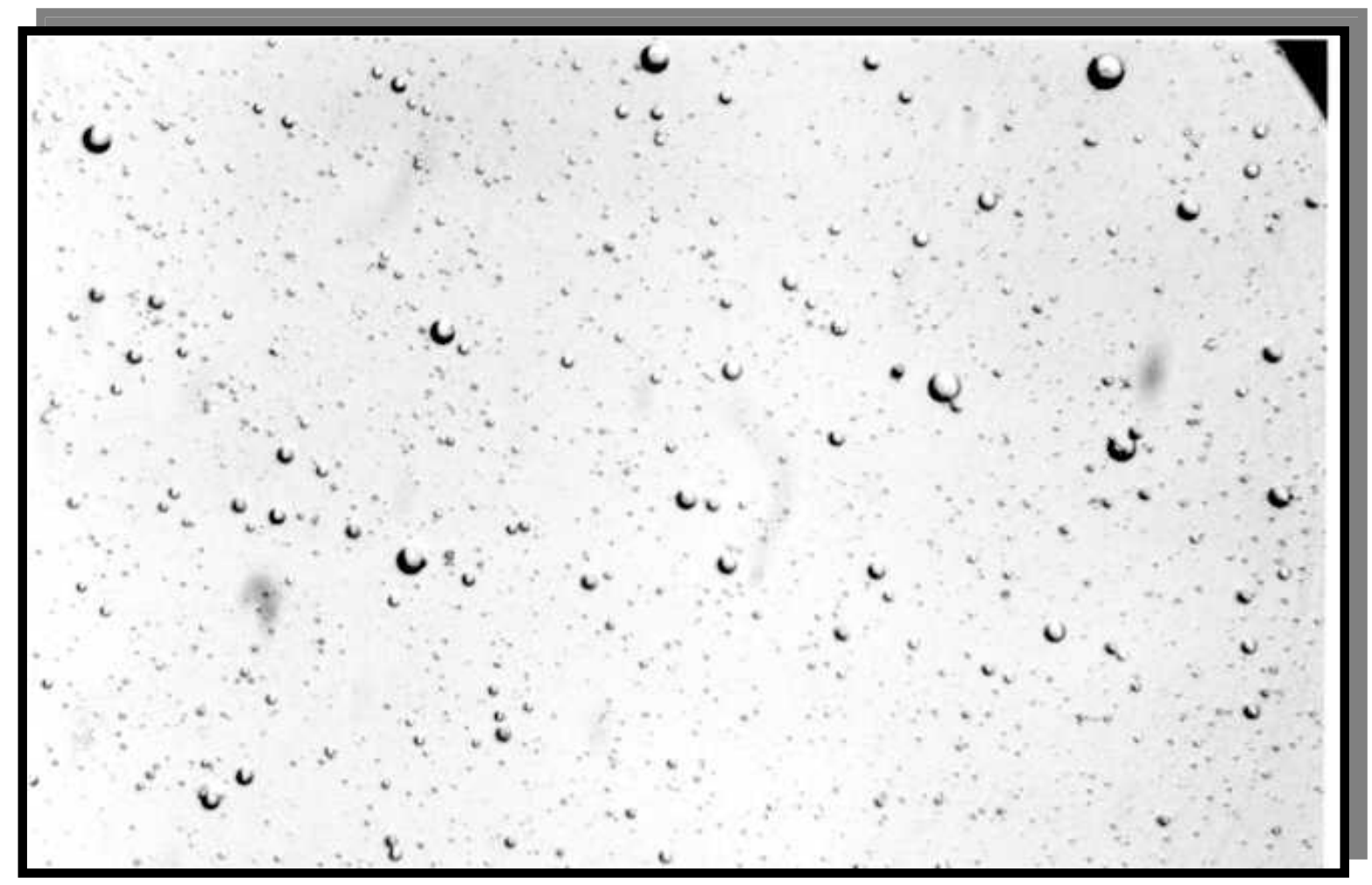

Figure C.15

- fresh emulsion

- Silicone oil is the continuous phase with viscosity $=0.48$ poise

- Castor oil is the dispersed phase with viscosity $=7.42$ poise

- Temperature $23{ }^{\circ} \mathrm{C}$.

- $\mathrm{D}=8.1 \mu \mathrm{m}$. 


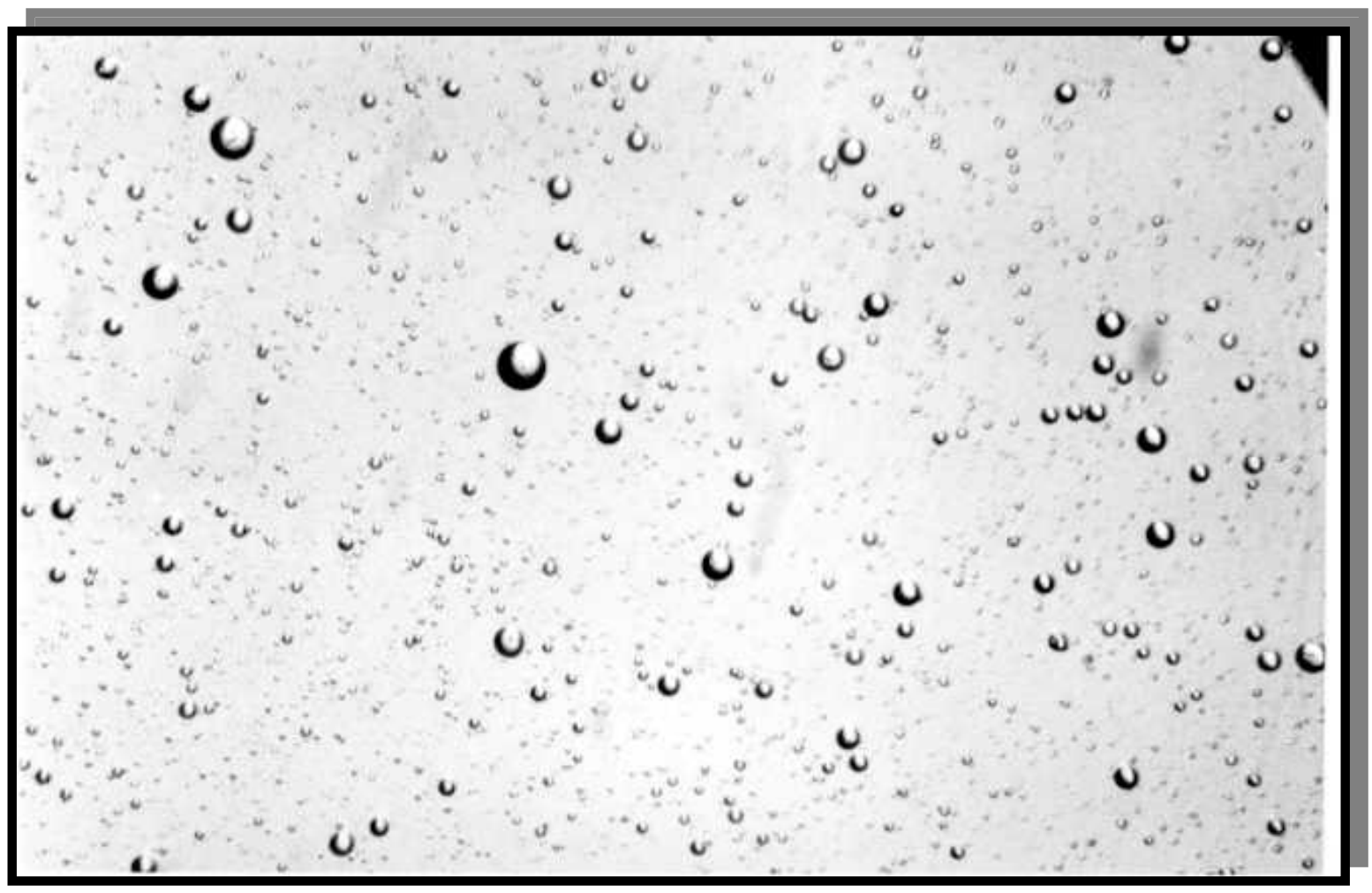

Figure C.16

- Tube diameter $3 / 32$ in.

- Time of shearing 4.00 minutes.

- Concentration $1.0 \%(\mathrm{v} / \mathrm{v})$.

- Shear rate $11 \mathrm{~s}^{-1}$.

- Silicone oil is the continuous phase with viscosity $=0.48$ poise.

- Castor oil is the dispersed phase with viscosity $=7.42$ poise.

- Temperature $23{ }^{\circ} \mathrm{C}$.

- $\mathrm{D}=11.76 \mu \mathrm{m}$. 


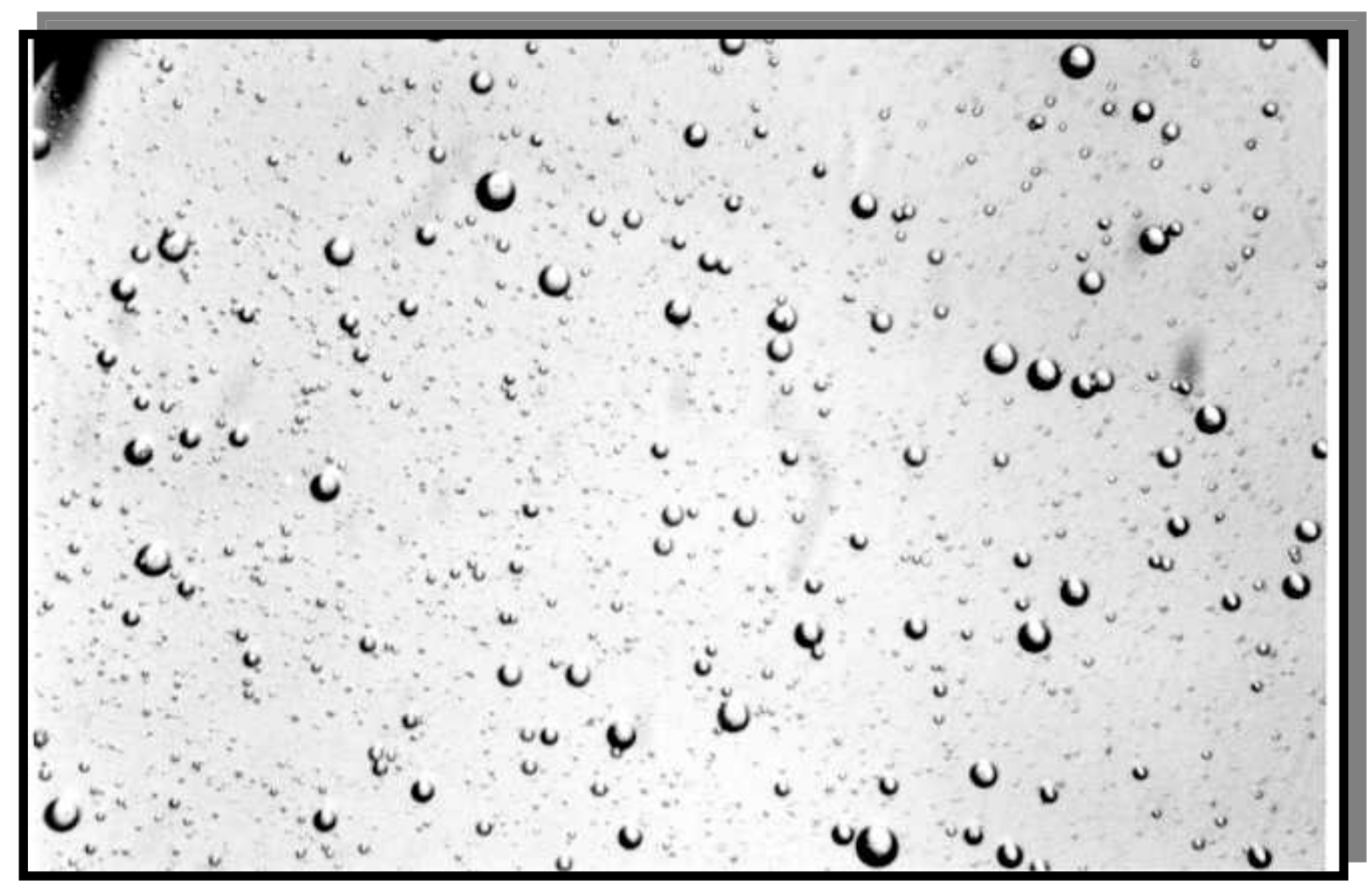

Figure C.17

- Tube diameter $3 / 32$ in.

- Time of shearing 6.90 minutes.

- Concentration $1.0 \%(\mathrm{v} / \mathrm{v})$.

- Shear rate $11 \mathrm{~s}^{-1}$.

- Silicone oil is the continuous phase with viscosity $=0.48$ poise.

- Castor oil is the dispersed phase with viscosity $=7.42$ poise.

- Temperature $23{ }^{\circ} \mathrm{C}$.

- $\mathrm{D}=12.39 \mu \mathrm{m}$ 


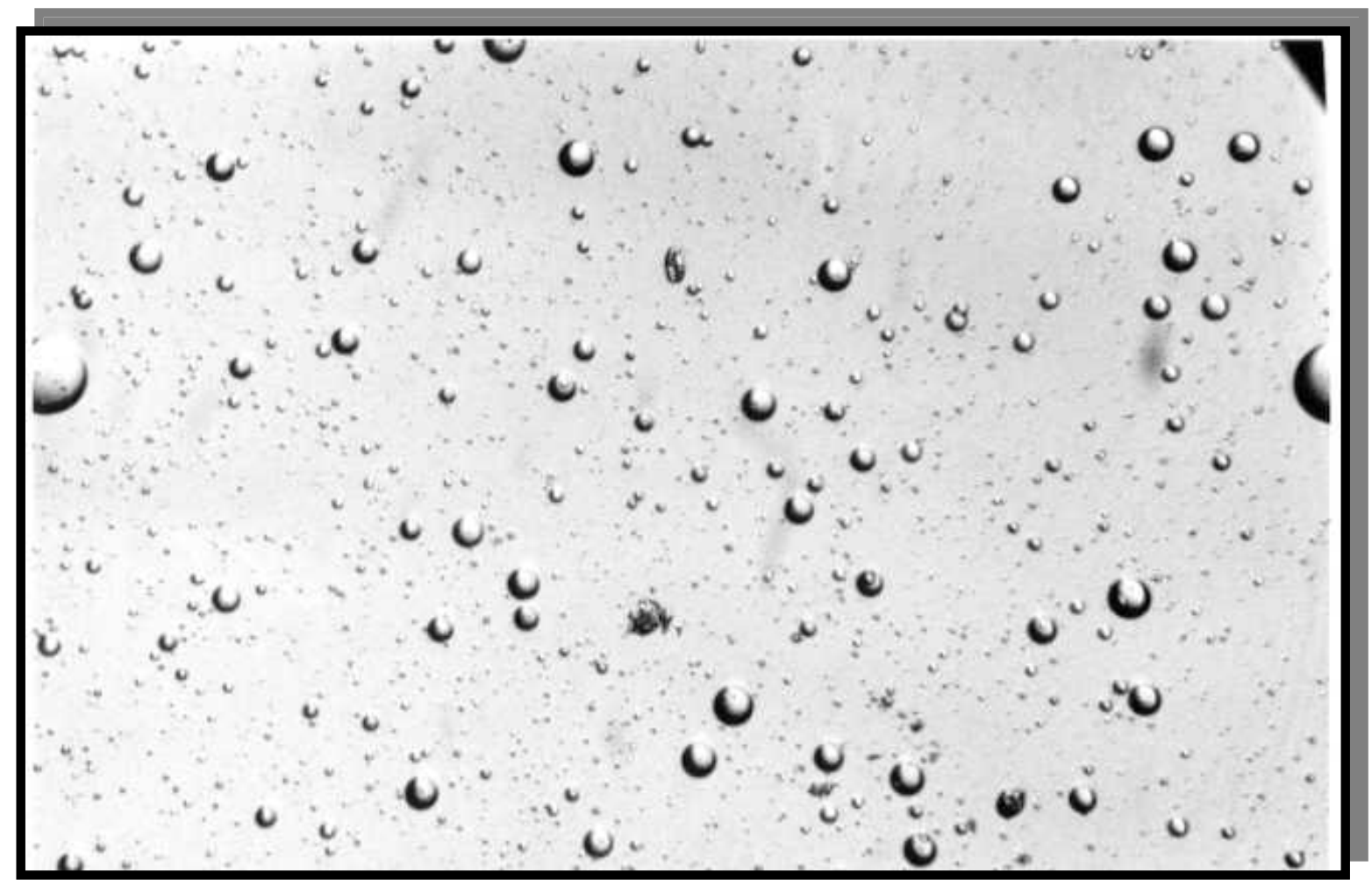

Figure C.18

- Tube diameter $3 / 32$ in.

- Time of shearing 10.78 minutes.

- Concentration $1.0 \%(\mathrm{v} / \mathrm{v})$.

- Shear rate $11 \mathrm{~s}^{-1}$.

- Silicone oil is the continuous phase with viscosity $=0.48$ poise.

- Castor oil is the dispersed phase with viscosity $=7.42$ poise.

- Temperature $23{ }^{\circ} \mathrm{C}$.

- $\mathrm{D}=13.13 \mu \mathrm{m}$. 


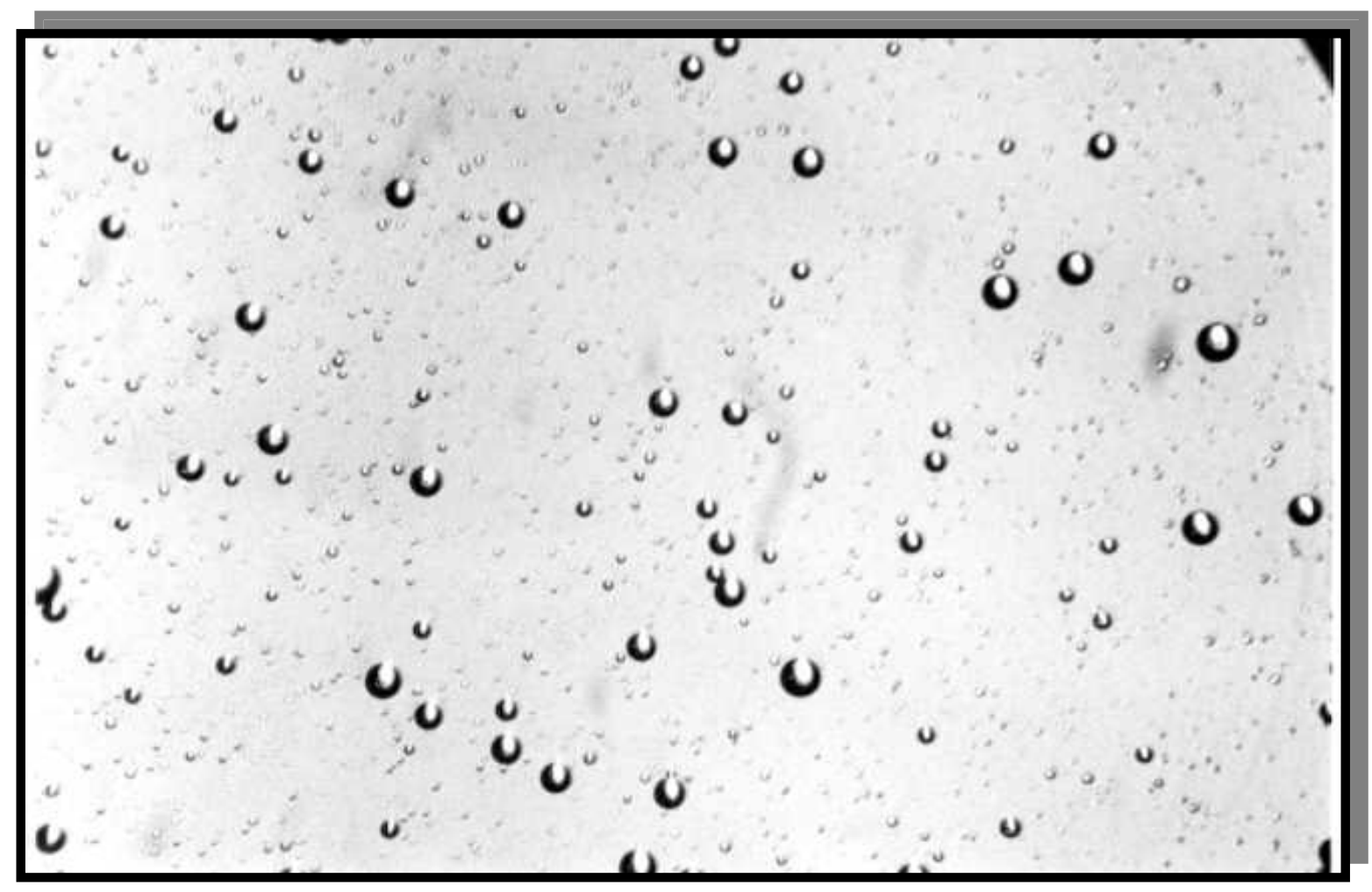

Figure C.19

- Tube diameter $3 / 32$ in.

- Time of shearing 17.27 minutes.

- Concentration $1.0 \%(\mathrm{v} / \mathrm{v})$.

- Shear rate $11 \mathrm{~s}^{-1}$.

- Silicone oil is the continuous phase with viscosity $=0.48$ poise

- Castor oil is the dispersed phase with viscosity $=7.42$ poise.

- Temperature $23{ }^{\circ} \mathrm{C}$.

- $\mathrm{D}=13.97 \mu \mathrm{m}$. 


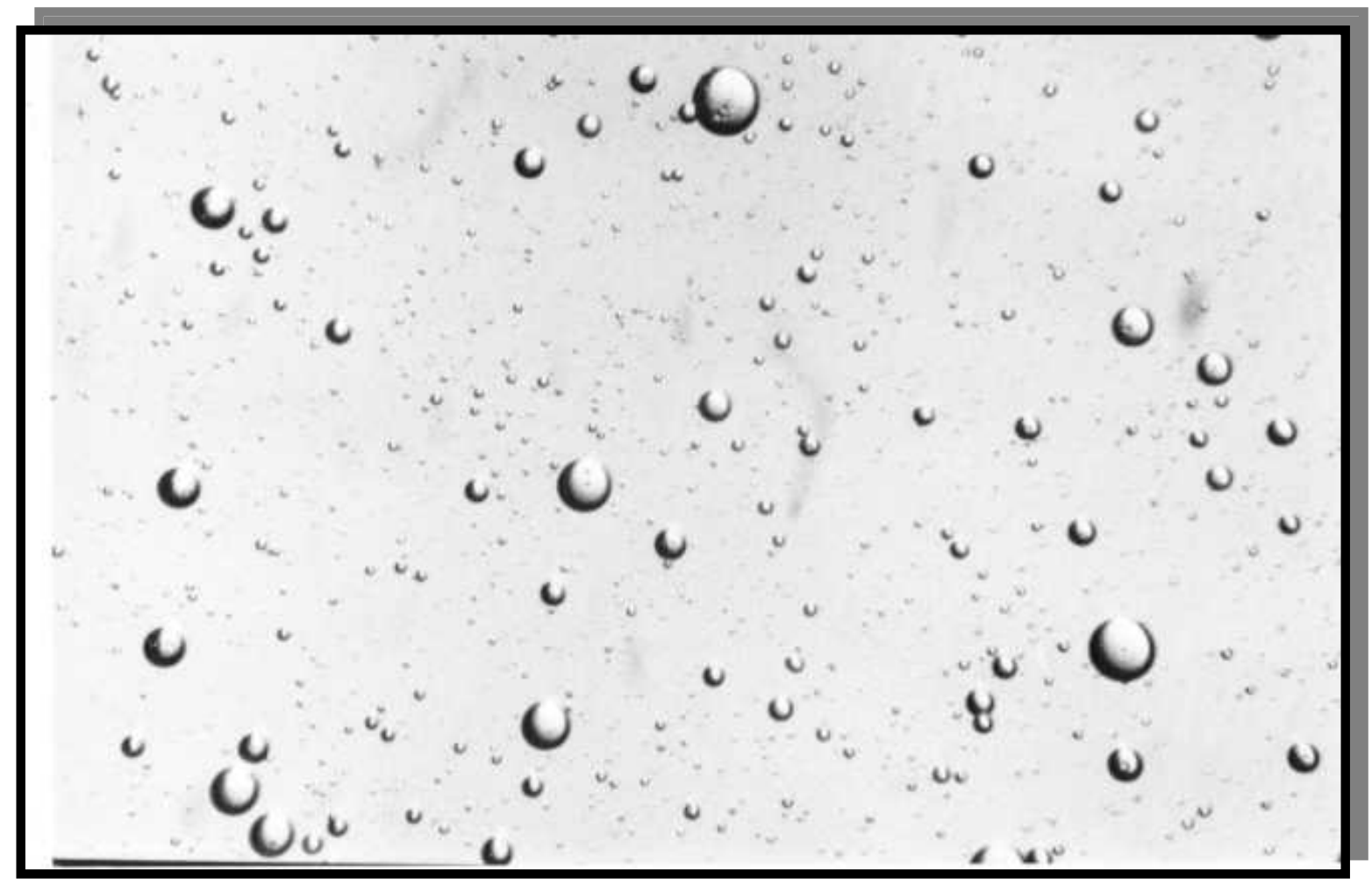

Figure C.20

- Tube diameter $3 / 32$ in.

- Time of shearing 24.18 minutes.

- Concentration $1.0 \%(\mathrm{v} / \mathrm{v})$.

- Shear rate $11 \mathrm{~s}^{-1}$.

- Silicone oil is the continuous phase with viscosity $=0.48$ poise

- Castor oil is the dispersed phase with viscosity $=7.42$ poise.

- Temperature $23{ }^{\circ} \mathrm{C}$.

- $\mathrm{D}=14.18 \mu \mathrm{m}$. 


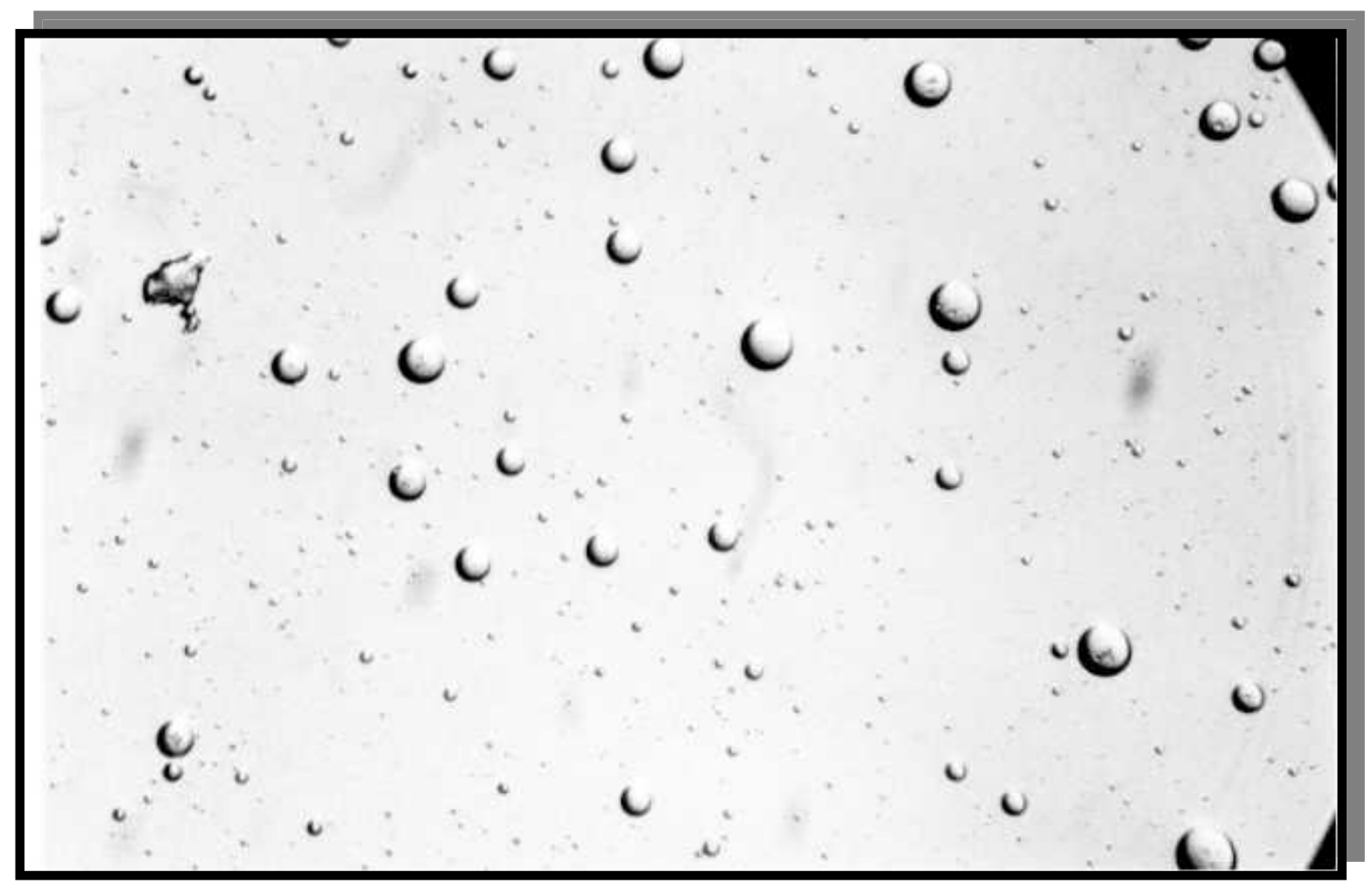

Figure C.21

- Tube diameter $3 / 32$ in.

- Time of shearing 31.85 minutes.

- Concentration $1.0 \%(\mathrm{v} / \mathrm{v})$.

- Shear rate $11 \mathrm{~s}^{-1}$.

- Silicone oil is the continuous phase with viscosity $=0.48$ poise

- Castor oil is the dispersed phase with viscosity $=7.42$ poise.

- Temperature $23{ }^{\circ} \mathrm{C}$.

- $\mathrm{D}=14.60 \mu \mathrm{m}$. 


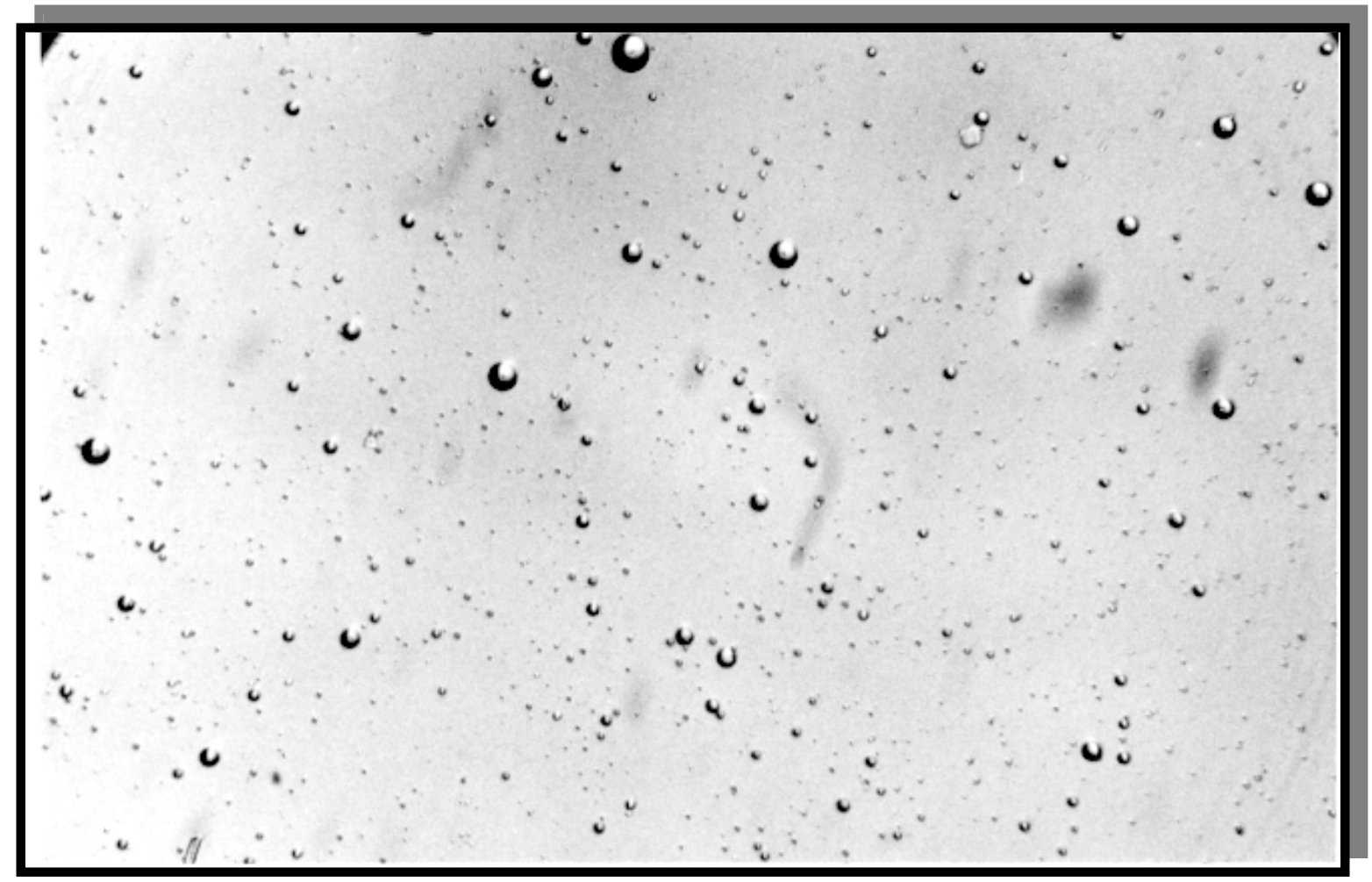

Figure C.22

- fresh emulsion

- Silicone oil is the continuous phase with viscosity $=0.48$ poise

- Castor oil is the dispersed phase with viscosity $=7.42$ poise.

- Temperature $23{ }^{\circ} \mathrm{C}$.

- $\mathrm{D}=8.2 \mu \mathrm{m}$. 


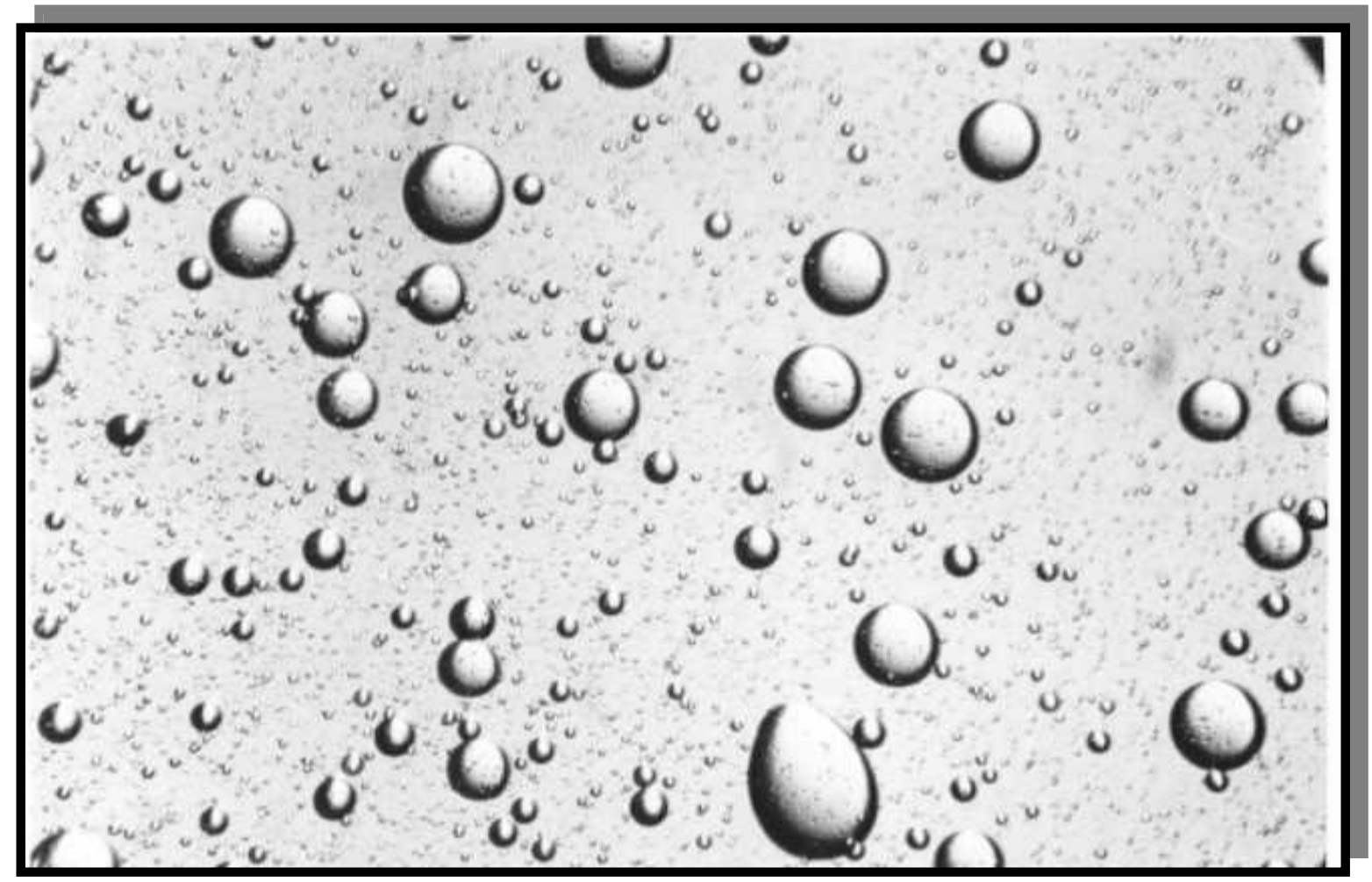

Figure C.23

- Tube diameter $3 / 32$ in.

- Time of shearing 4.55 minutes.

- Concentration $5.0 \%(\mathrm{v} / \mathrm{v})$.

- Shear rate $11 \mathrm{~s}^{-1}$.

- Silicone oil is the continuous phase with viscosity $=0.48$ poise

- Castor oil is the dispersed phase with viscosity $=7.42$ poise.

- Temperature $23{ }^{\circ} \mathrm{C}$.

- $\mathrm{D}=12.39 \mu \mathrm{m}$. 


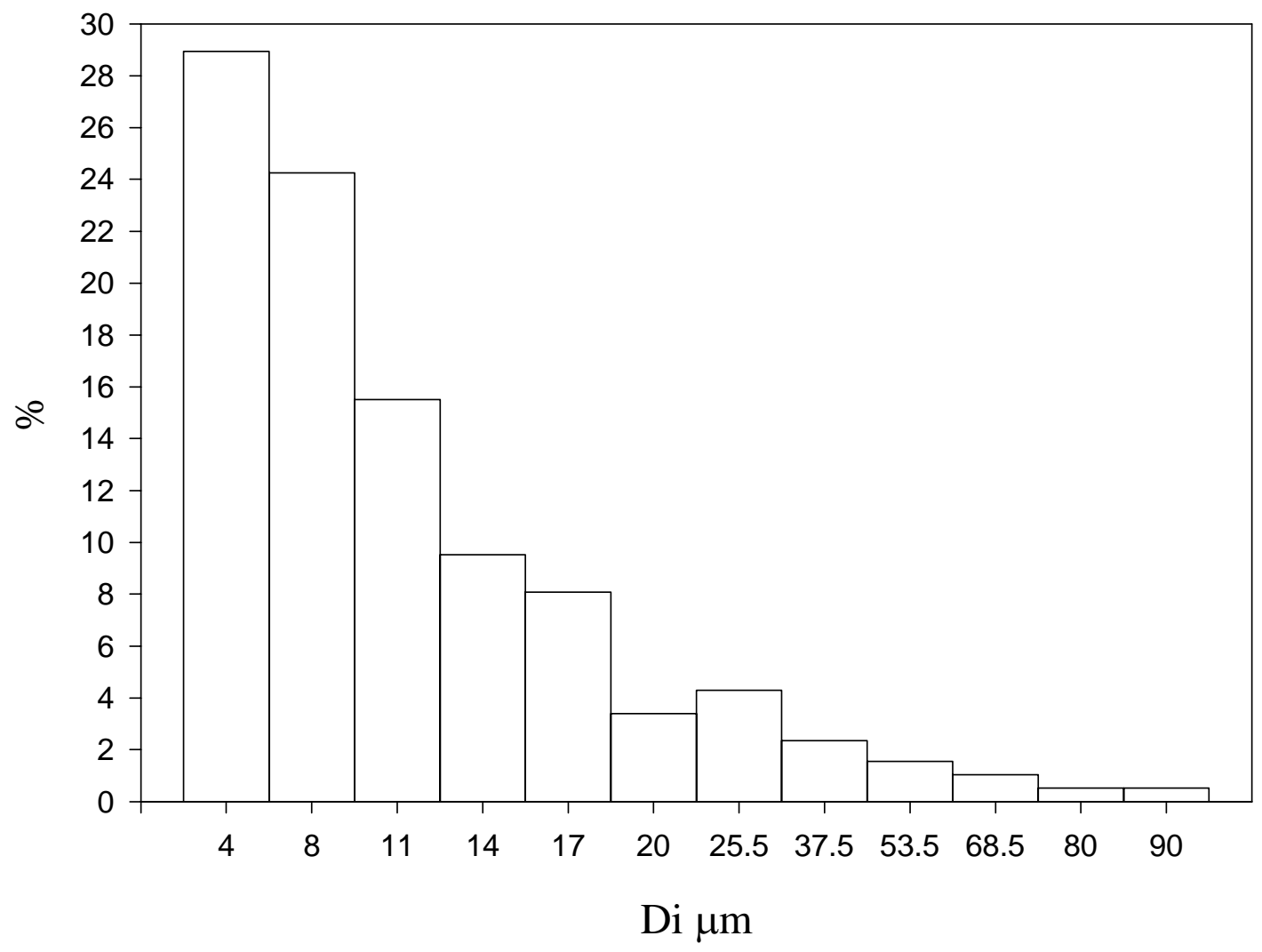

Figure C.24

- The size distribution reflect on Figure C.23 and Figure 4.11 


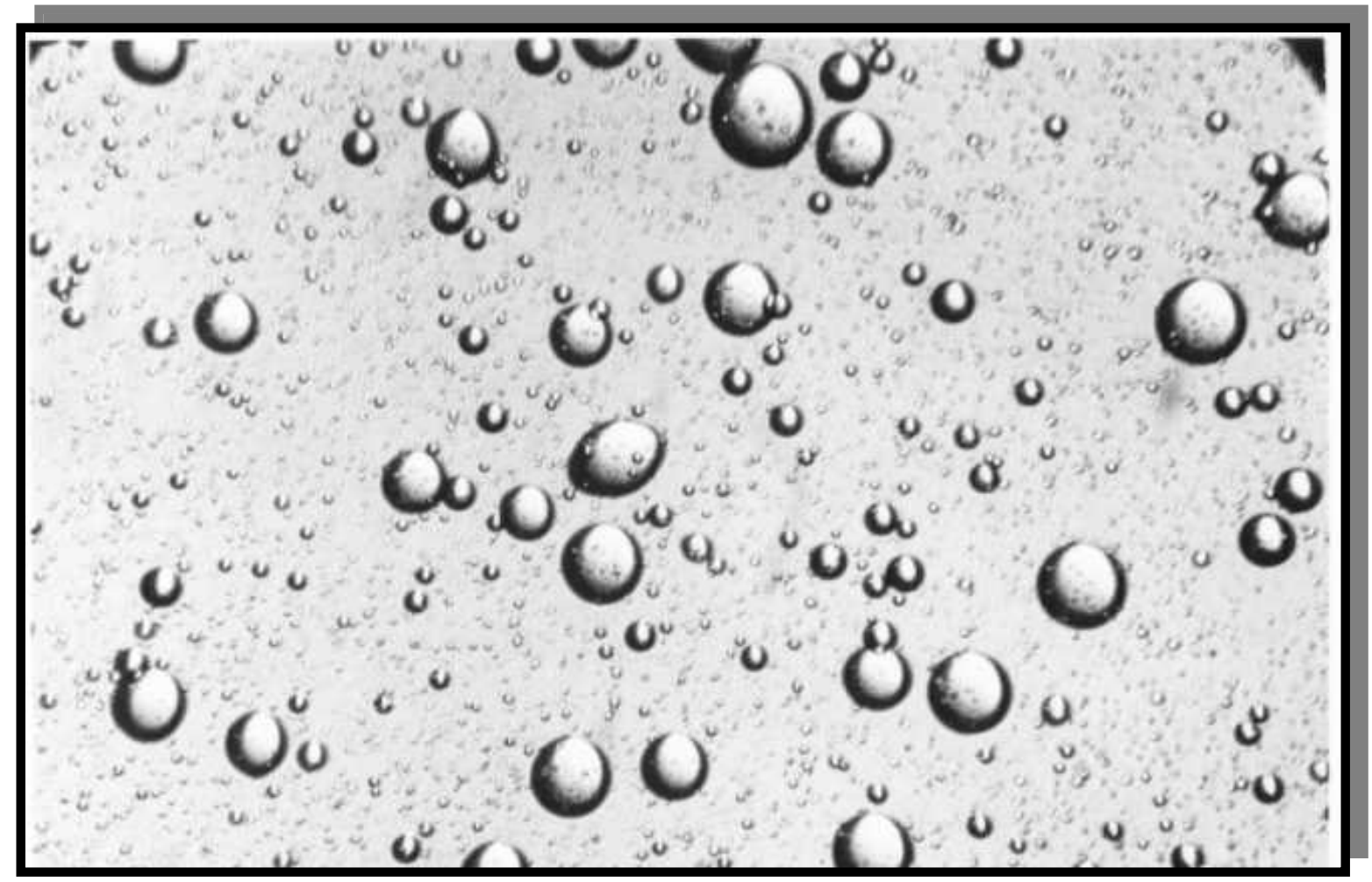

Figure C.25

- Tube diameter $3 / 32$ in.

- Time of shearing 6.68 minutes.

- Concentration $5.0 \%(\mathrm{v} / \mathrm{v})$.

- Shear rate $11 \mathrm{~s}^{-1}$.

- Silicone oil is the continuous phase with viscosity $=0.48$ poise

- Castor oil is the dispersed phase with viscosity $=7.42$ poise

- Temperature $23{ }^{\circ} \mathrm{C}$.

- $\mathrm{D}=13.44 \mu \mathrm{m}$. 


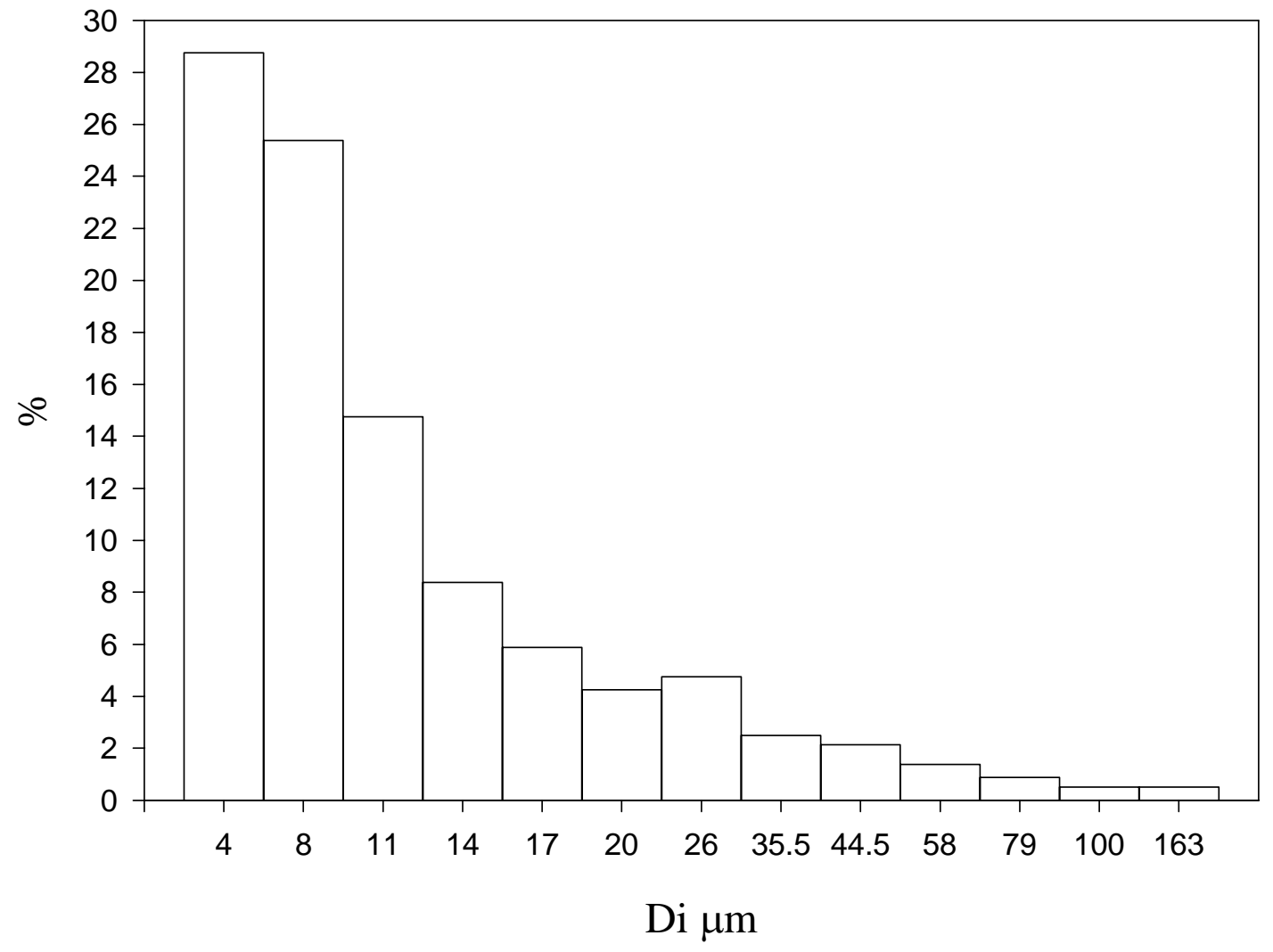

Figure C.26

- The size distribution reflect on Figure C.25 and Figure 4.11 


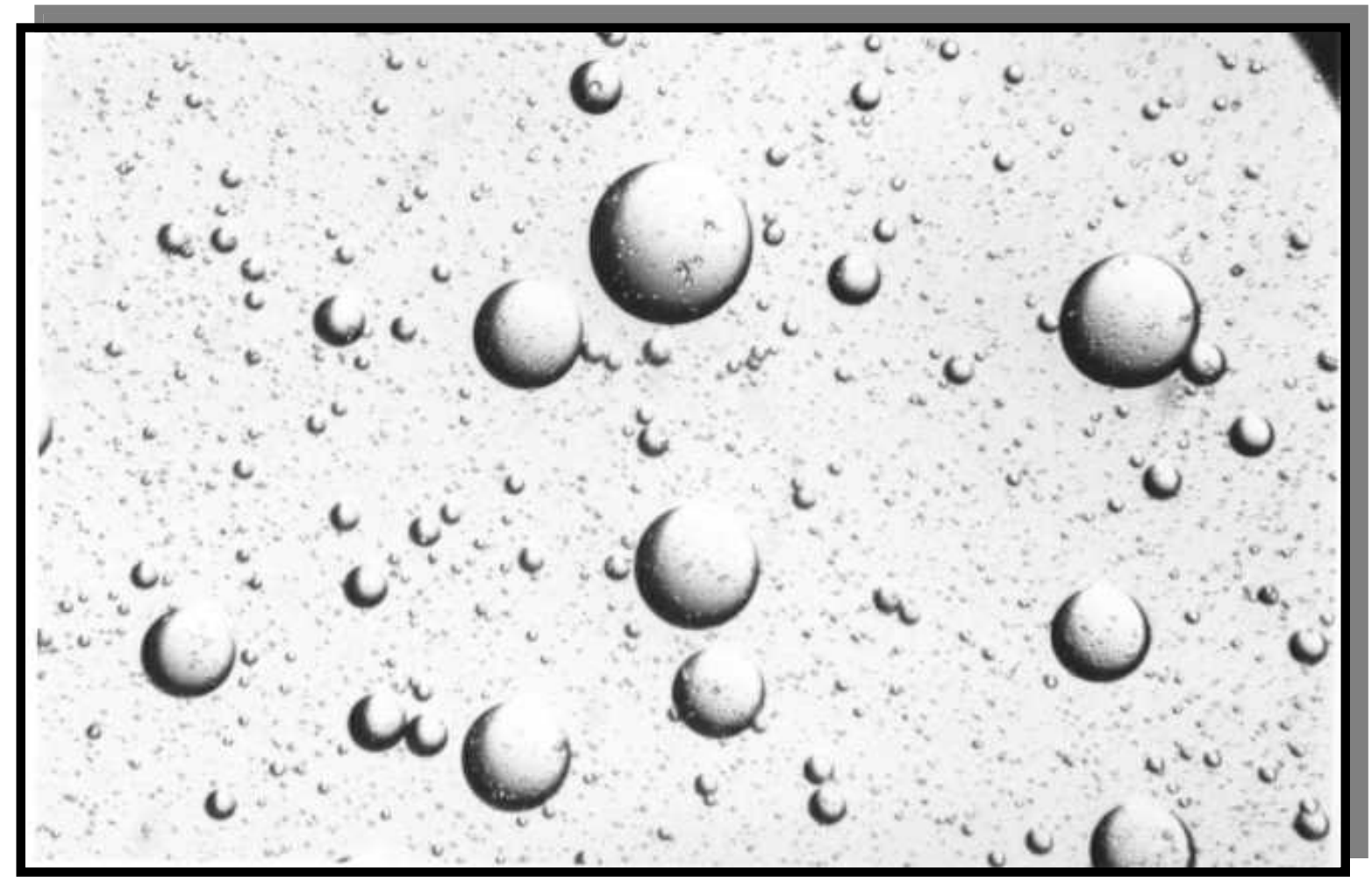

Figure C.27

- Tube diameter $3 / 32$ in.

- Time of shearing 11.40 minutes.

- Concentration $5.0 \%(\mathrm{v} / \mathrm{v})$.

- Shear rate $11 \mathrm{~s}^{-1}$.

- Silicone oil is the continuous phase with viscosity $=0.48$ poise

- Castor oil is the dispersed phase with viscosity $=7.42$ poise

- Temperature $23{ }^{\circ} \mathrm{C}$.

- $\mathrm{D}=14.81 \mu \mathrm{m}$. 


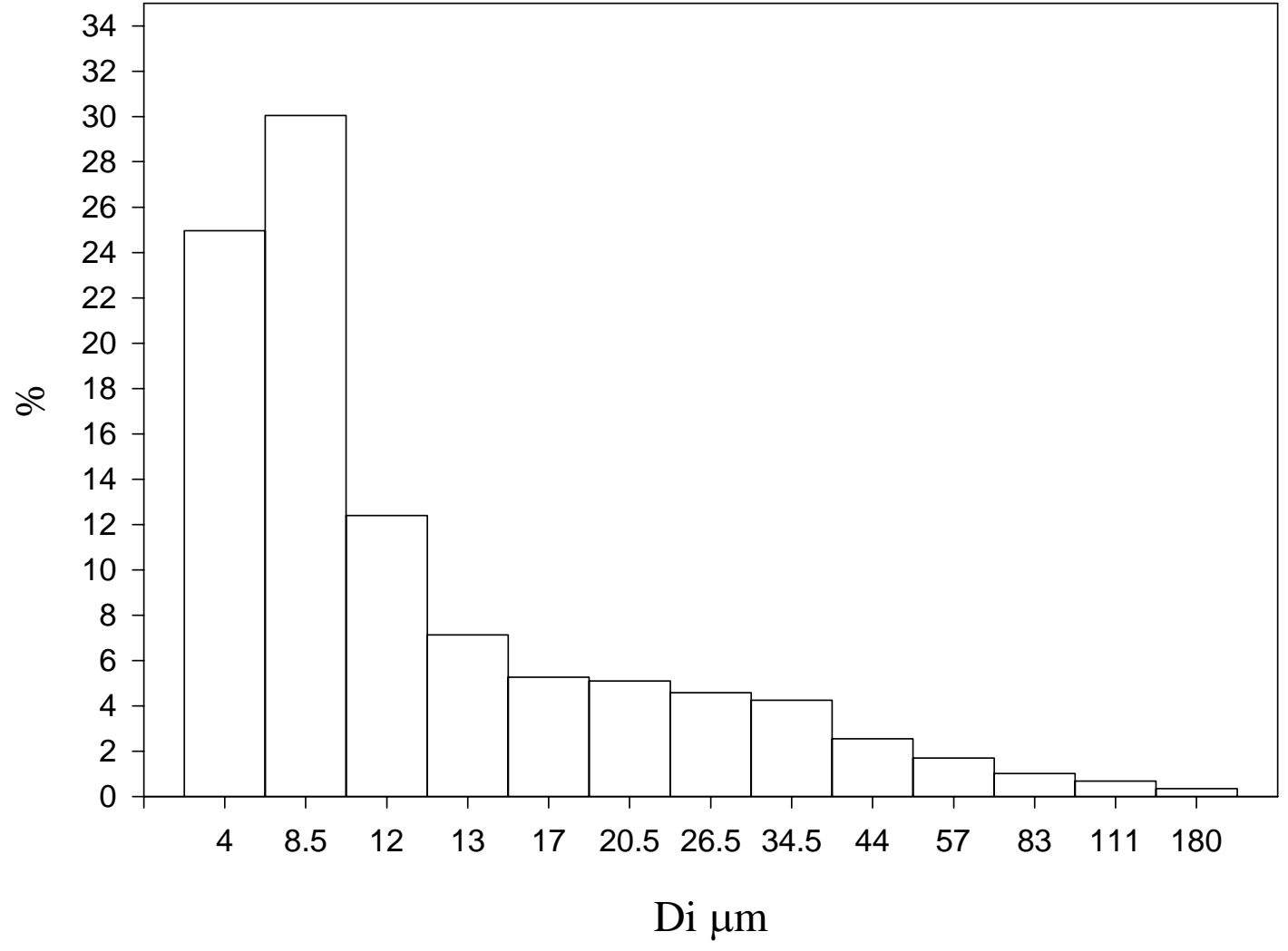

Figure C.28

- The size distribution reflect on Figure C.27 and Figure 4.11 


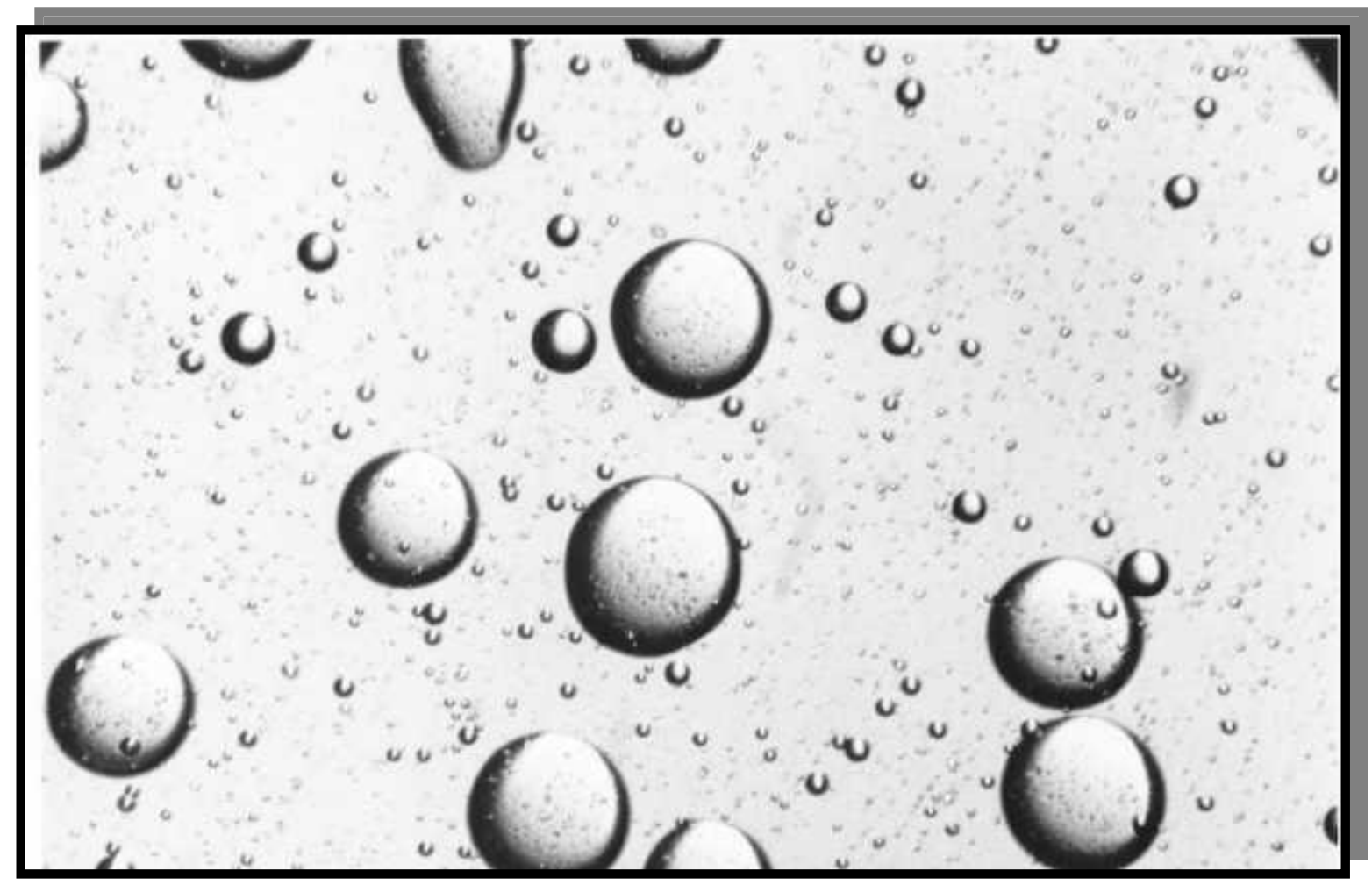

Figure C. 29

- Tube diameter $3 / 32$ in.

- Time of shearing 15.40 minutes.

- Concentration $5.0 \%(\mathrm{v} / \mathrm{v})$.

- Shear rate $11 \mathrm{~s}^{-1}$.

- Silicone oil is the continuous phase with viscosity $=0.48$ poise

- Castor oil is the dispersed phase with viscosity $=7.42$ poise.

- Temperature $23{ }^{\circ} \mathrm{C}$.

- $\mathrm{D}=16.59 \mu \mathrm{m}$. 


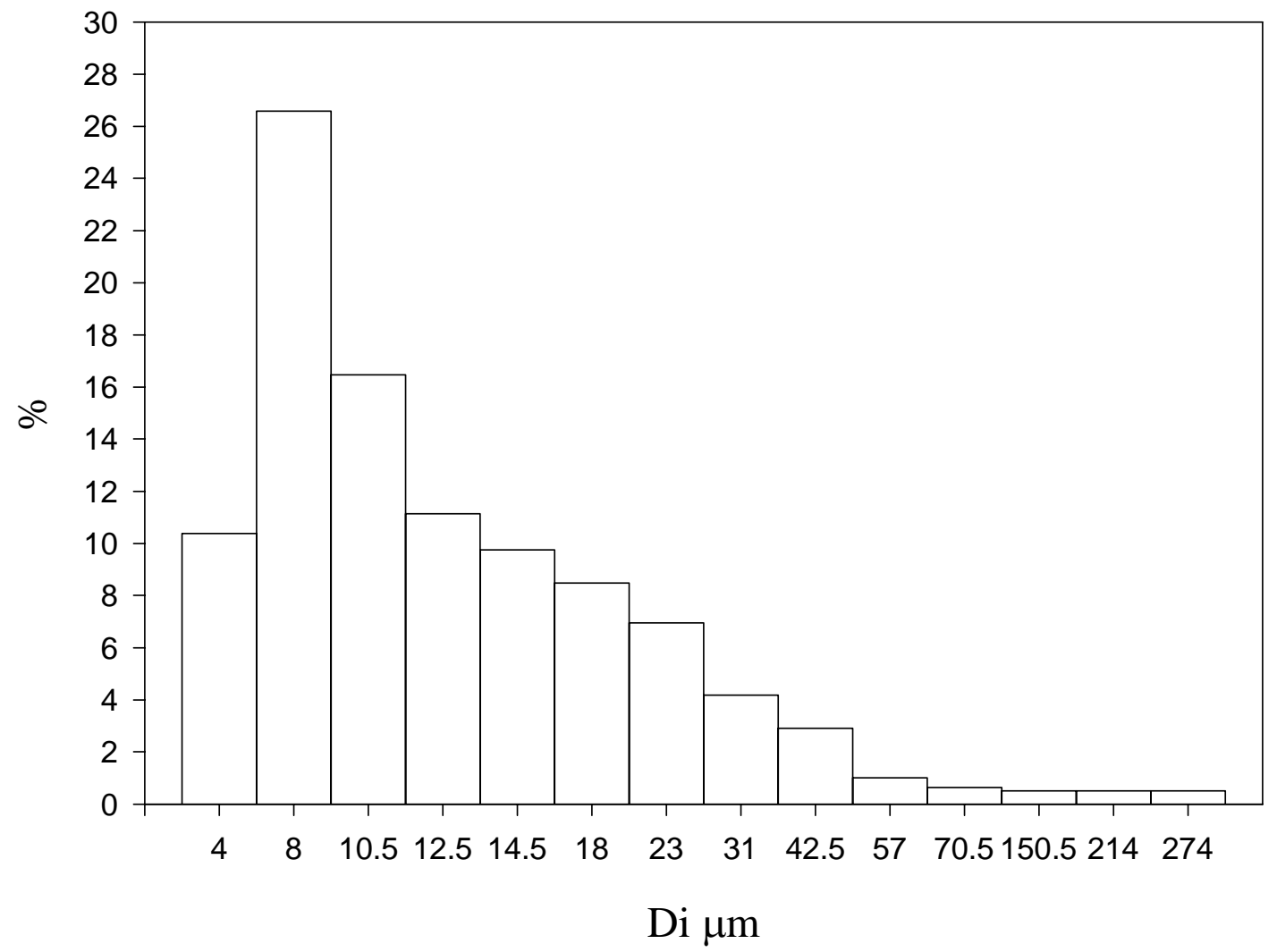

Figure C.30

- The size distribution reflect on Figure C.29 and Figure 4.11 


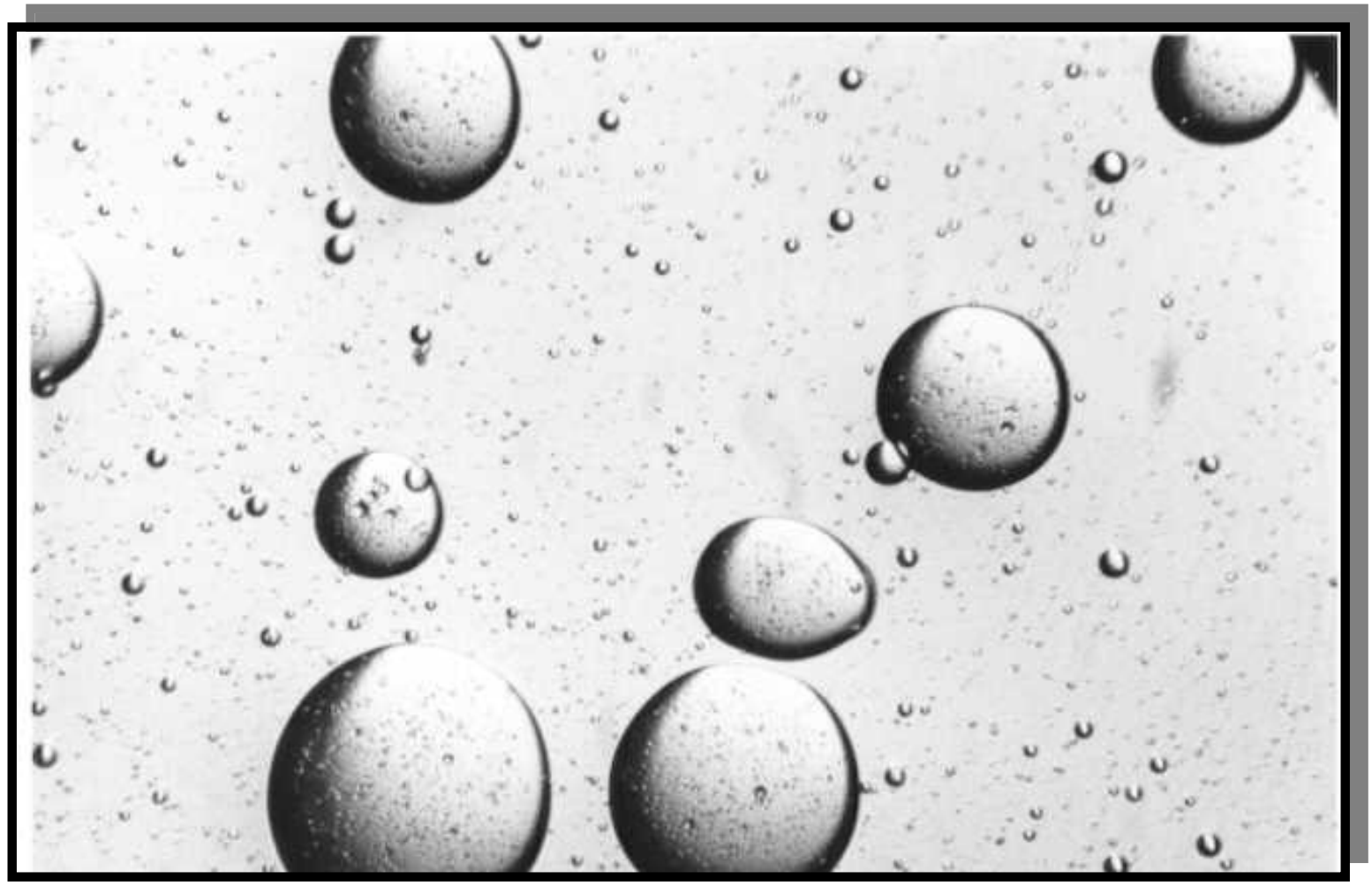

Figure C.31

- Tube diameter 3/32 in.

- Time of shearing 34.17 minutes.

- Concentration $5.0 \%(\mathrm{v} / \mathrm{v})$.

- Shear rate $11 \mathrm{~s}^{-1}$.

- Silicone oil is the continuous phase with viscosity $=0.48$ poise.

- Castor oil is the dispersed phase with viscosity $=7.42$ poise.

- Temperature $23{ }^{\circ} \mathrm{C}$.

- $\mathrm{D}=18.69 \mu \mathrm{m}$. 


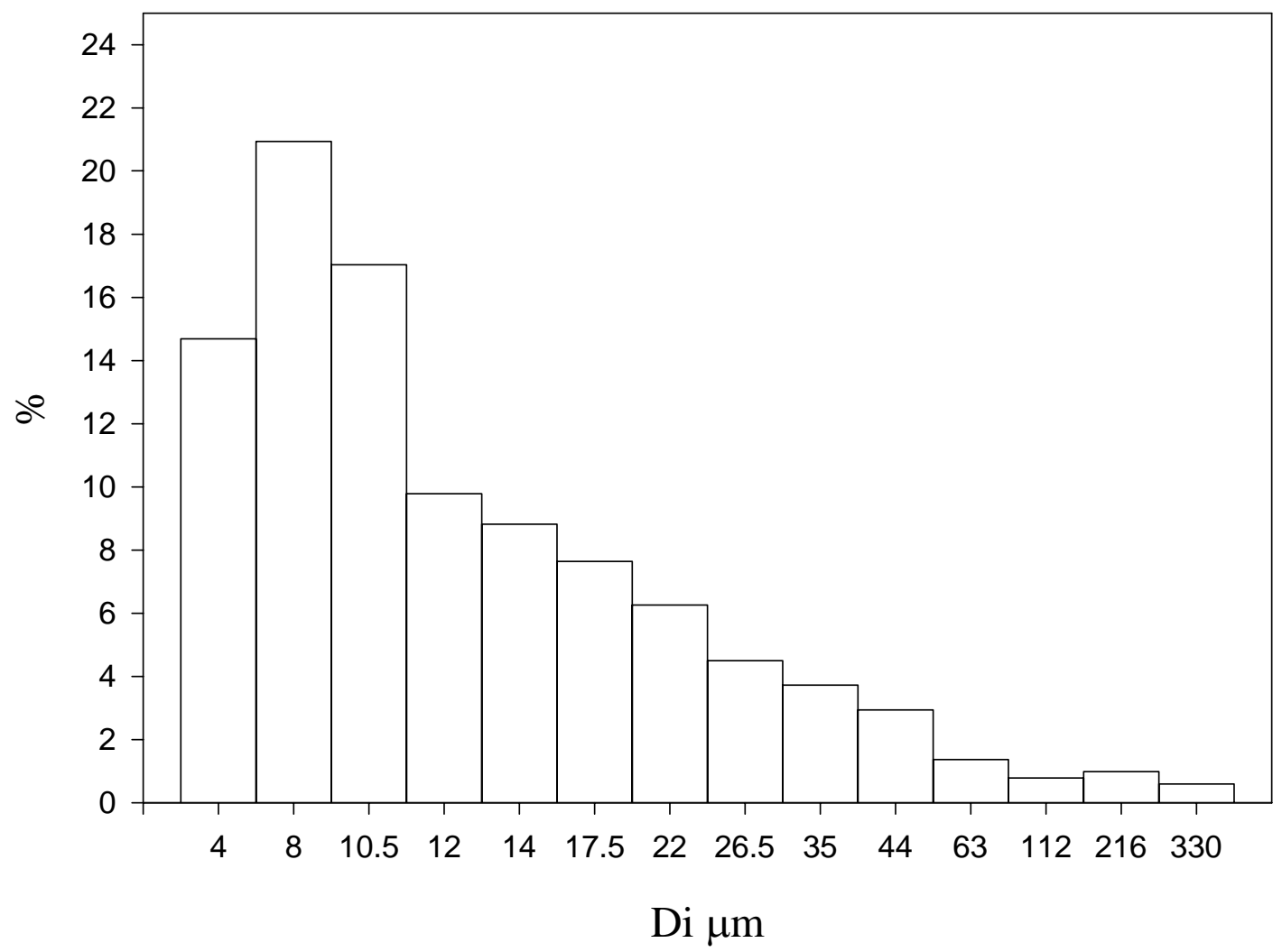

Figure C.32

- The size distribution reflect on Figure C.31 and Figure 4.11 


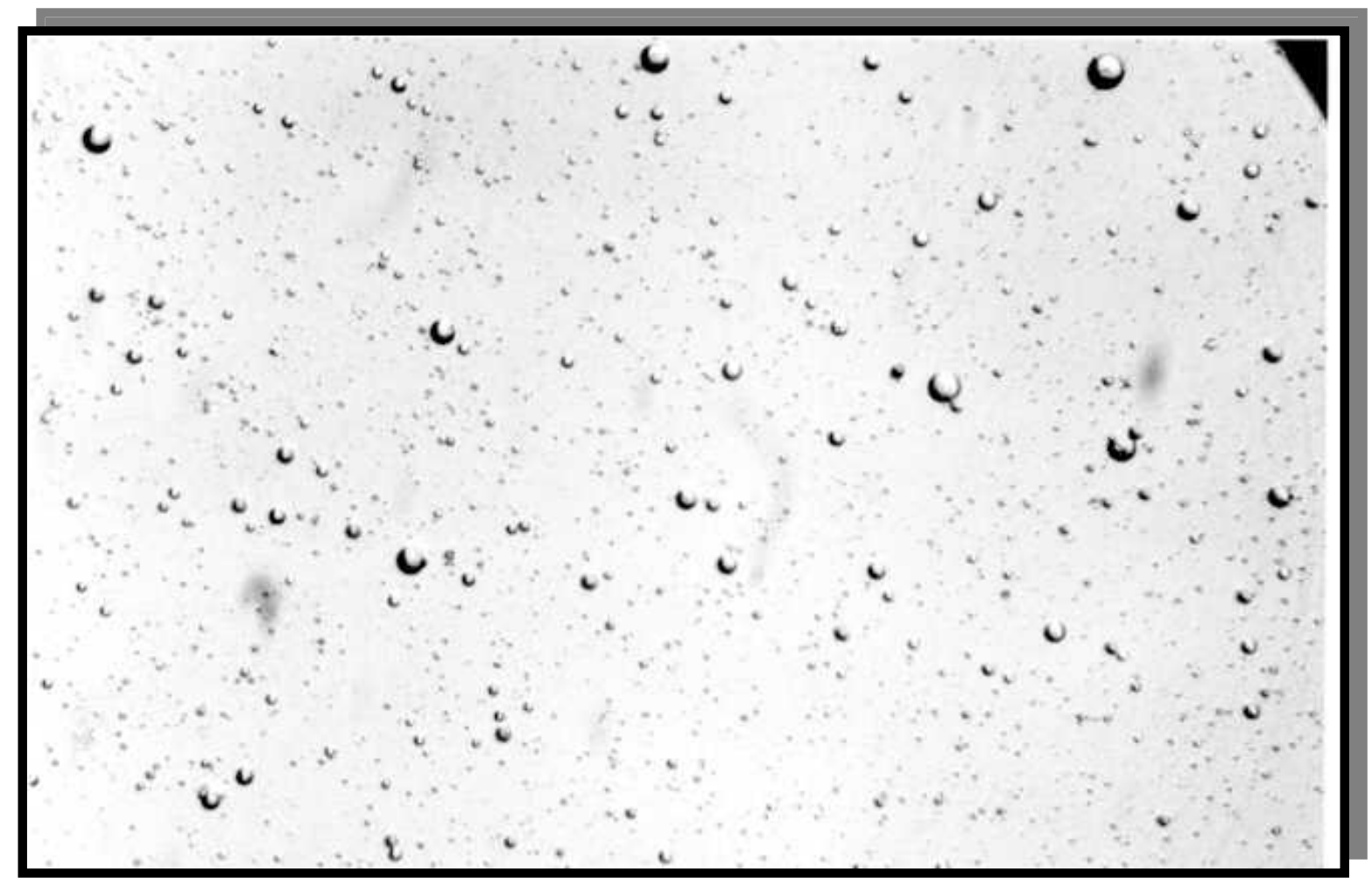

Figure C.33

- fresh emulsion

- Silicone oil is the continuous phase with viscosity $=0.48$ poise

- Castor oil is the dispersed phase with viscosity $=7.42$ poise

- Temperature $23{ }^{\circ} \mathrm{C}$.

- $\mathrm{D}=8.1 \mu \mathrm{m}$. 


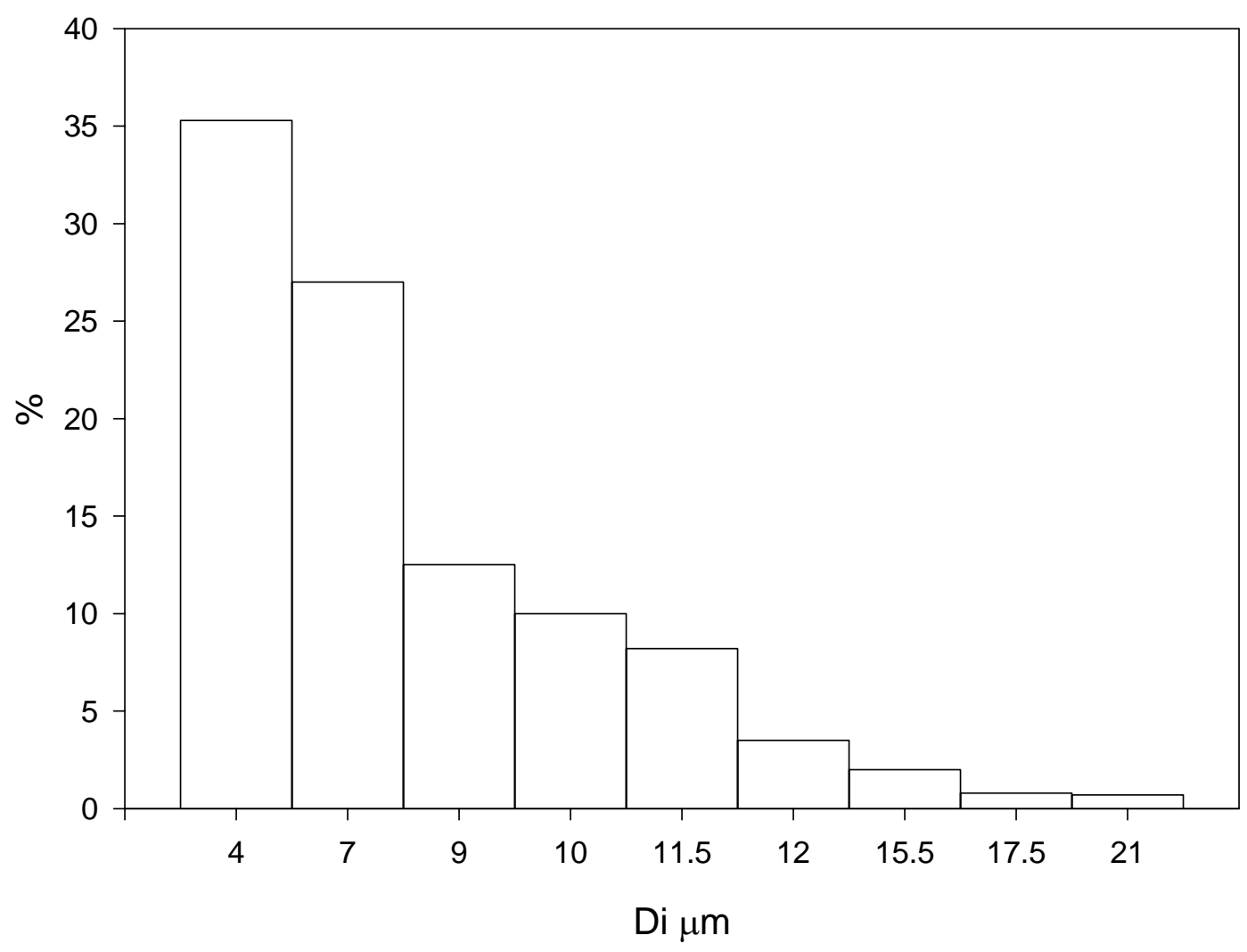

Figure C.34

- Fresh emulsion 


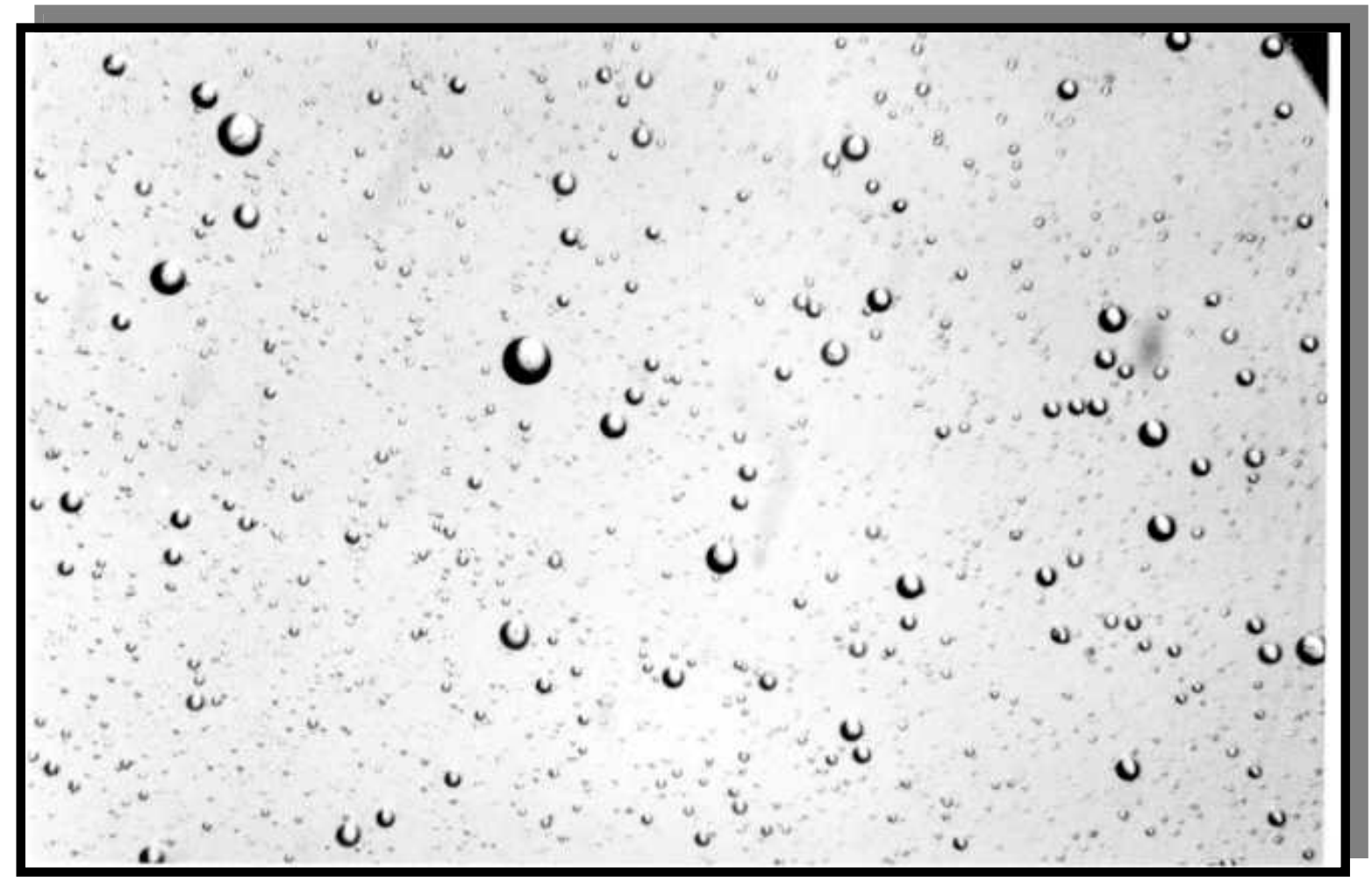

Figure C.35

- Emulsion is sheared using cone-and-plate device.

- Concentration $1.0 \%(\mathrm{v} / \mathrm{v})$.

- Time of shearing 4.00 minutes.

- Shear rates $10 \mathrm{~s}^{-1}$.

- Silicone oil is the continuous phase with viscosity $=0.48$ poise

- Castor oil is the dispersed phase with viscosity $=7.42$ poise

- Temperature $23{ }^{\circ} \mathrm{C}$.

- $\mathrm{D}=11.78 \mu \mathrm{m}$. 


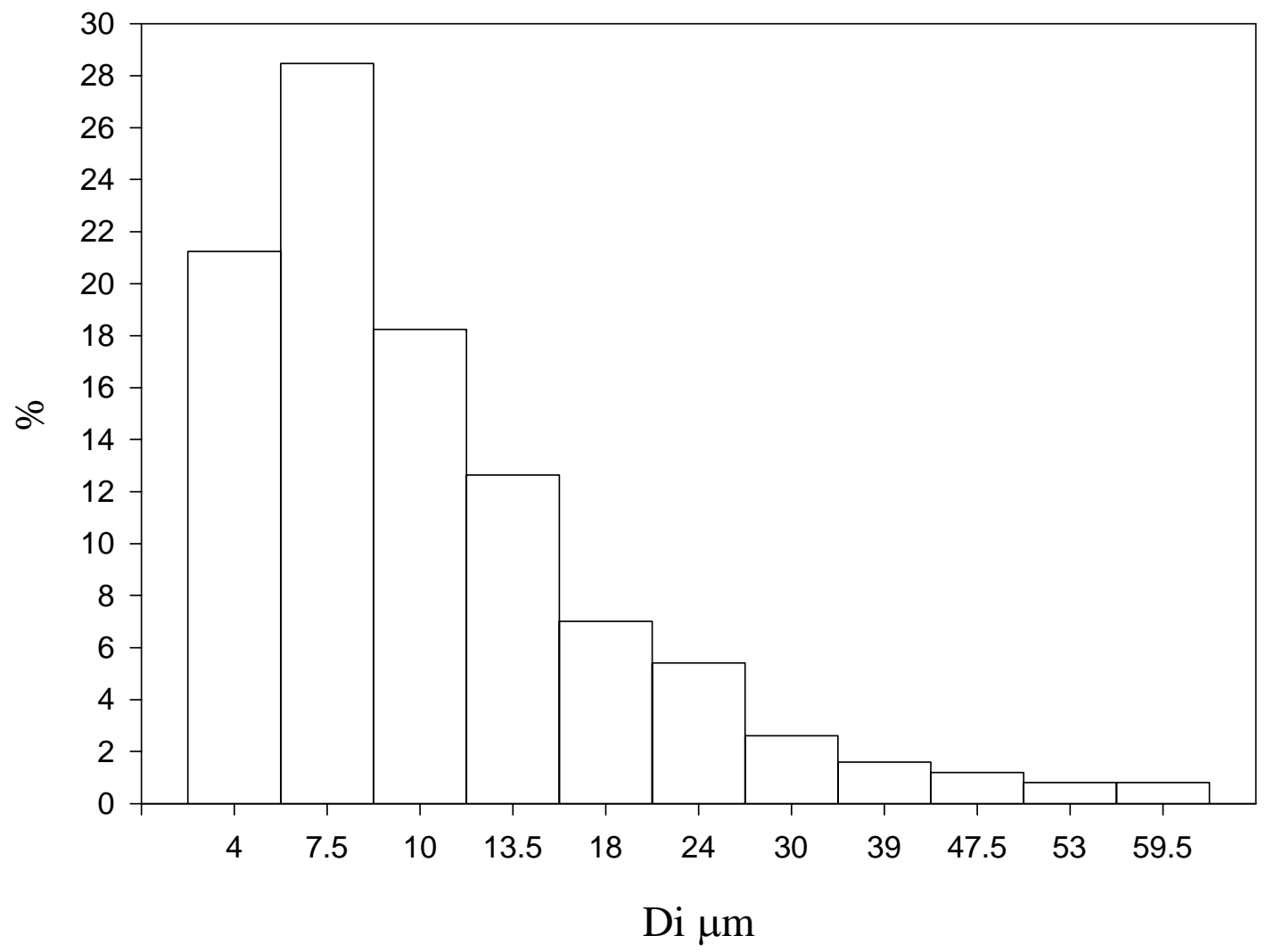

Figure C.36

- The size distribution reflect on Figure C.35 and Figure 4.8 


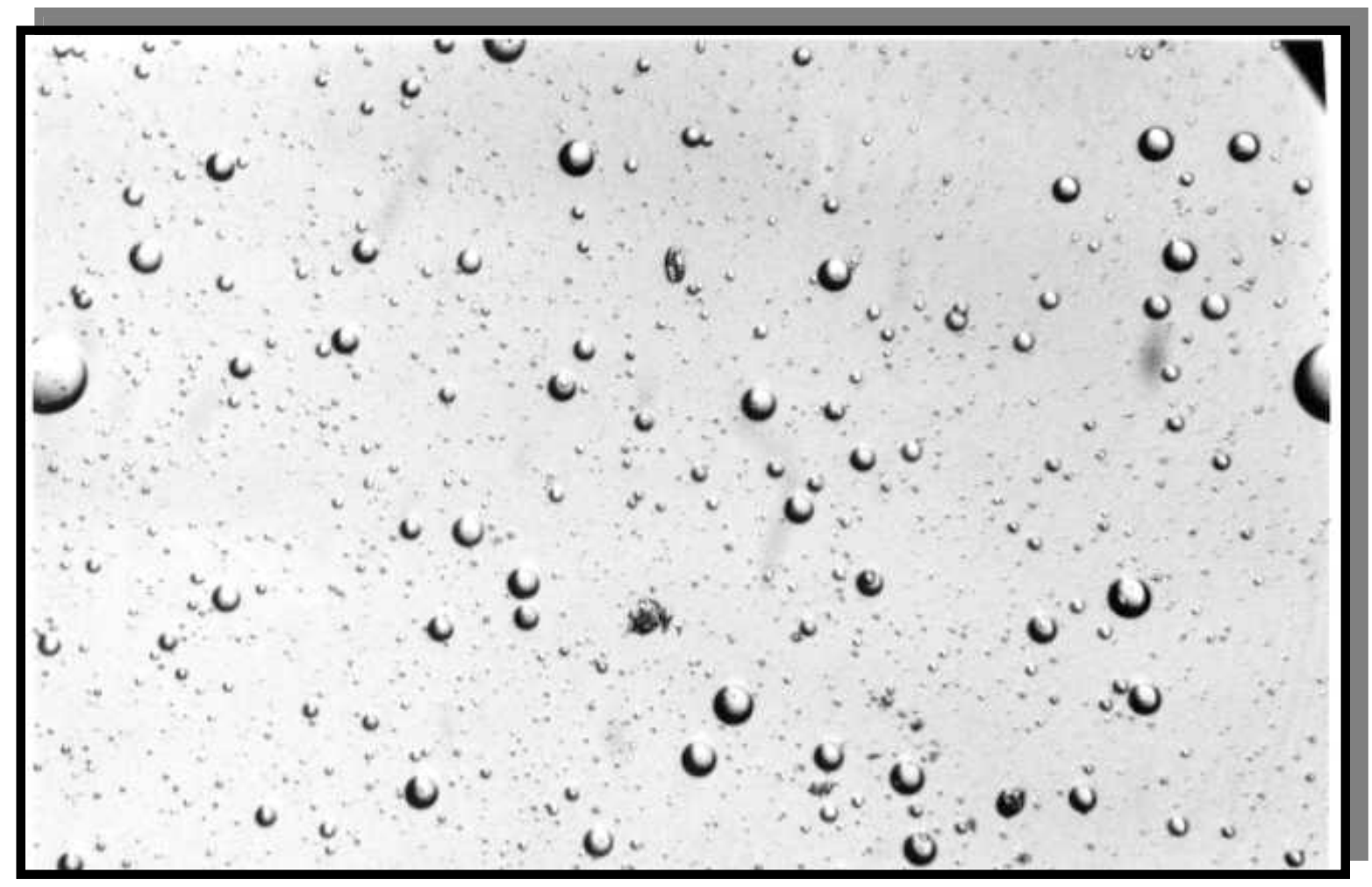

Figure C.37

- Emulsion is sheared using cone-and-plate device.

- Concentration $1.0 \%(\mathrm{v} / \mathrm{v})$.

- Time of shearing 10.00 minutes.

- Shear rates $10 \mathrm{~s}^{-1}$.

- Silicone oil is the continuous phase with viscosity $=0.48$ poise

- Castor oil is the dispersed phase with viscosity $=7.42$ poise

- Temperature $23{ }^{\circ} \mathrm{C}$.

- $\mathrm{D}=12.94 \mu \mathrm{m}$. 


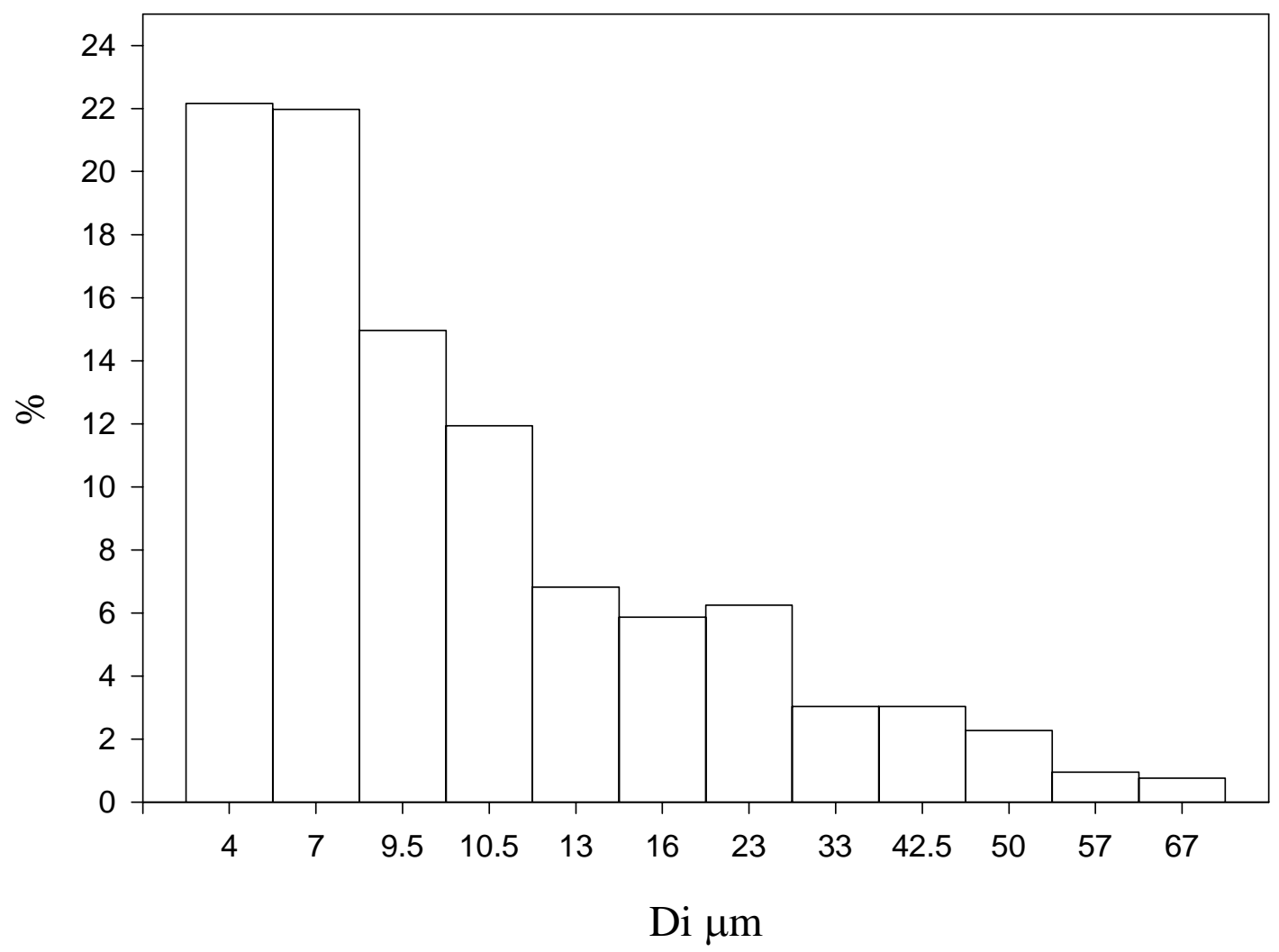

Figure C.38

- The size distribution reflect on Figure C.37 and Figure 4.8 


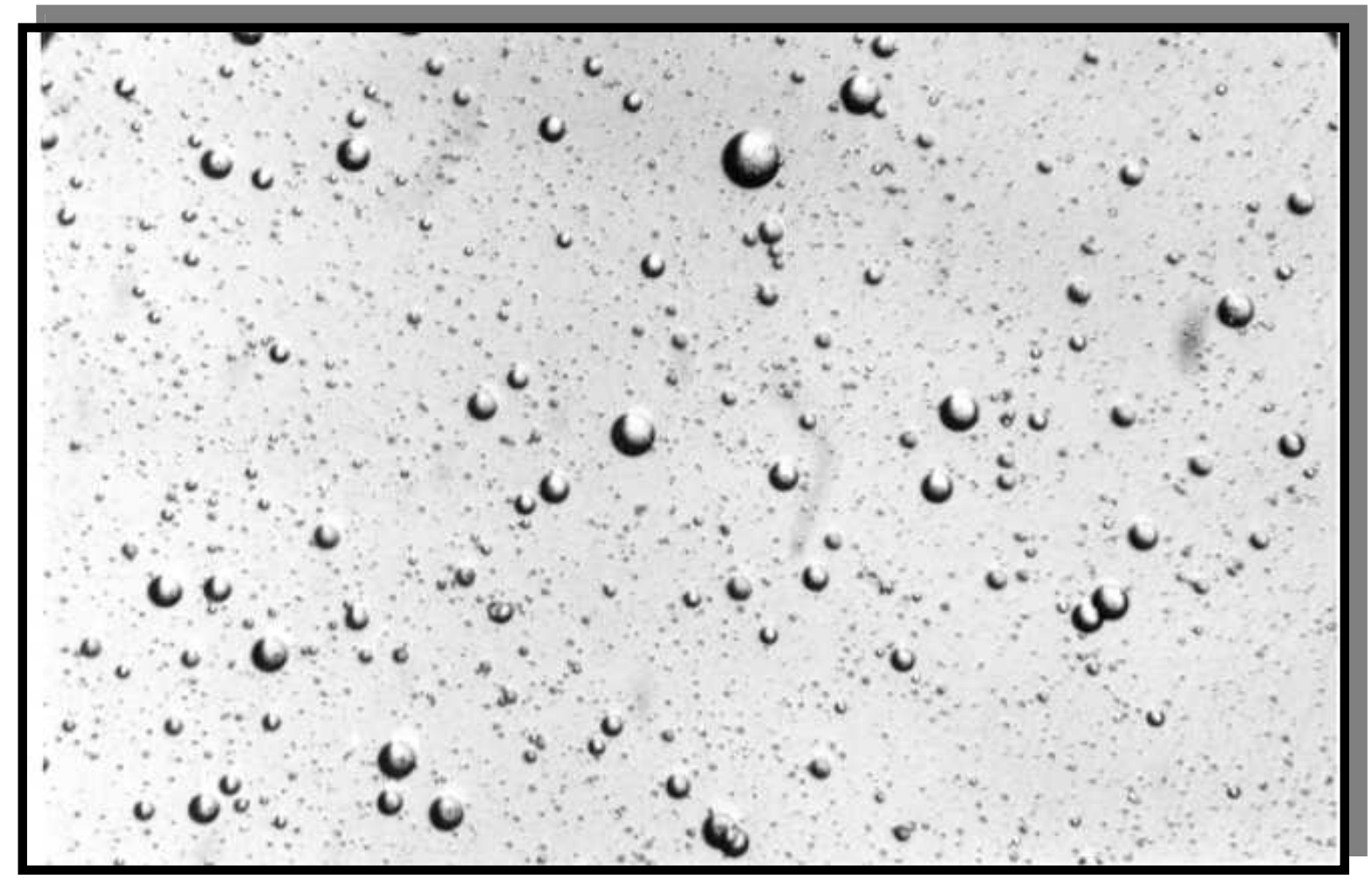

Figure C.39

- Emulsion is sheared using cone-and-plate device.

- Concentration $1.0 \%(\mathrm{v} / \mathrm{v})$.

- Time of shearing 15.00 minutes.

- Shear rates $10 \mathrm{~s}^{-1}$.

- Silicone oil is the continuous phase with viscosity $=0.48$ poise

- Castor oil is the dispersed phase with viscosity $=7.42$ poise

- Temperature $23{ }^{\circ} \mathrm{C}$.

- $\mathrm{D}=13.57 \mu \mathrm{m}$. 


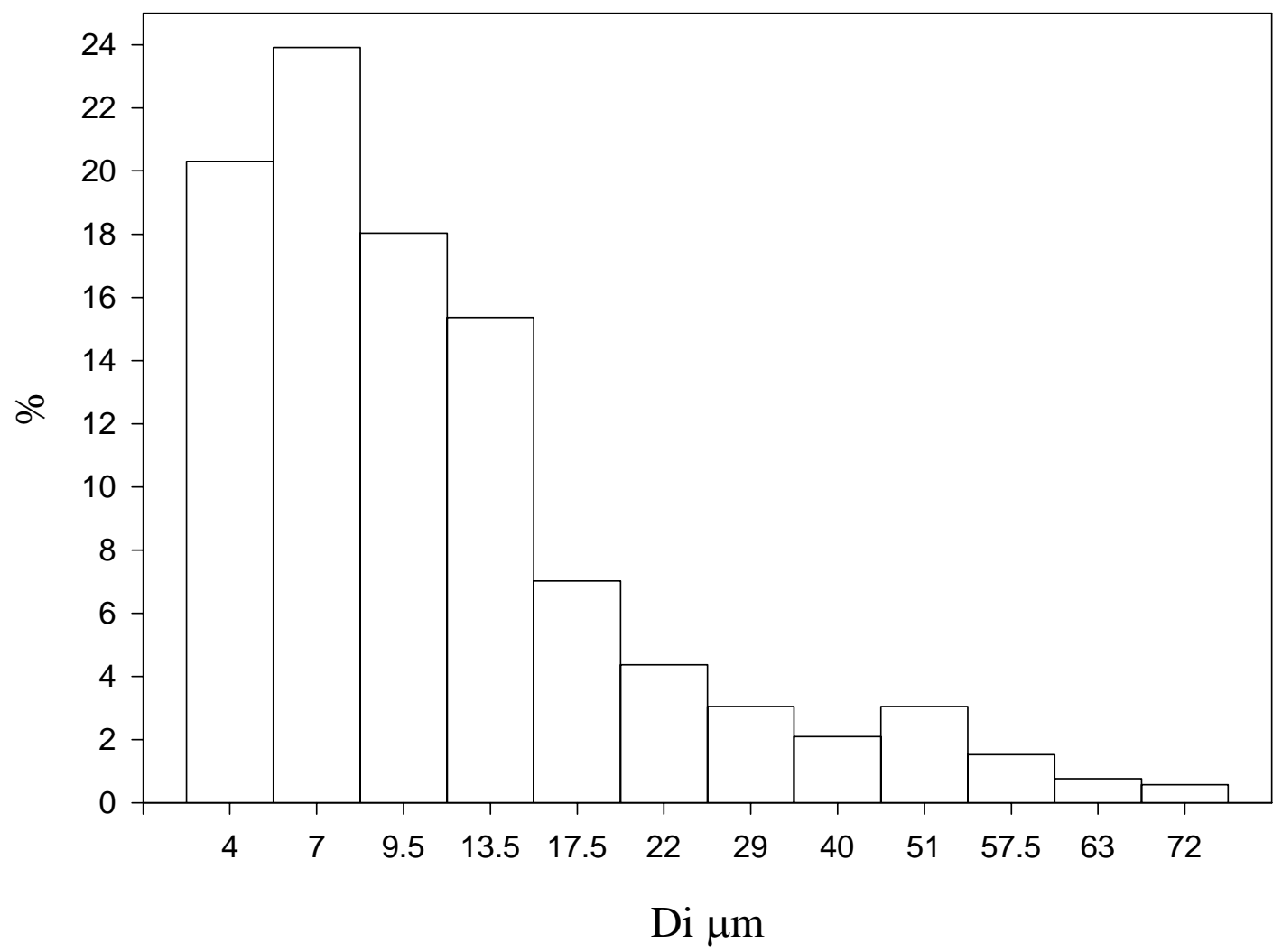

Figure C.40

- The size distribution reflect on Figure C.39 and Figure 4.8 


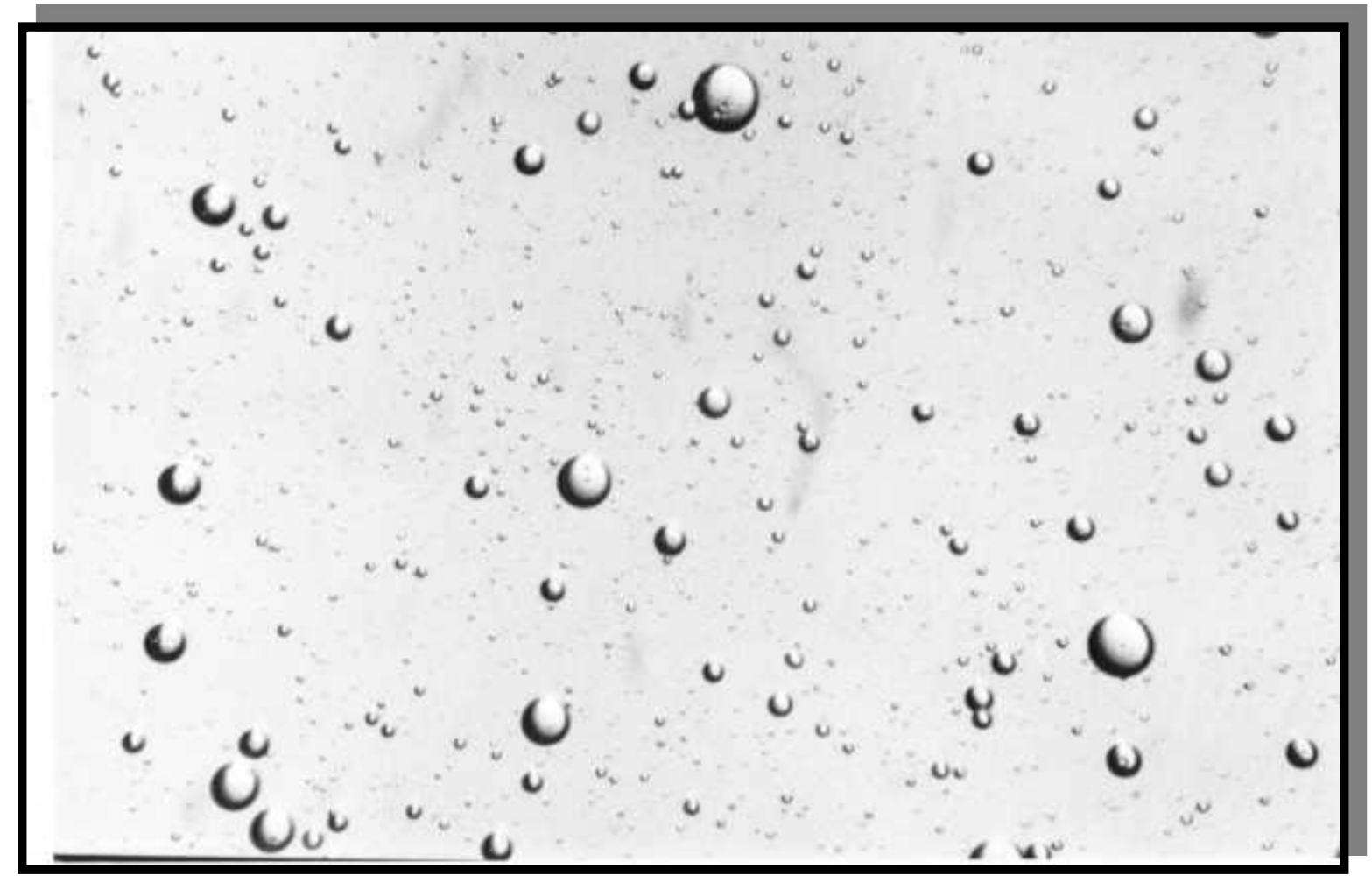

Figure C.41

- Emulsion is sheared using cone-and-plate device.

- Concentration $1.0 \%(\mathrm{v} / \mathrm{v})$.

- Time of shearing 20.00 minutes.

- Shear rates $10 \mathrm{~s}^{-1}$.

- Silicone oil is the continuous phase with viscosity $=0.48$ poise

- Castor oil is the dispersed phase with viscosity $=7.42$ poise.

- Temperature $23{ }^{\circ} \mathrm{C}$.

- $\mathrm{D}=14.10 \mu \mathrm{m}$. 


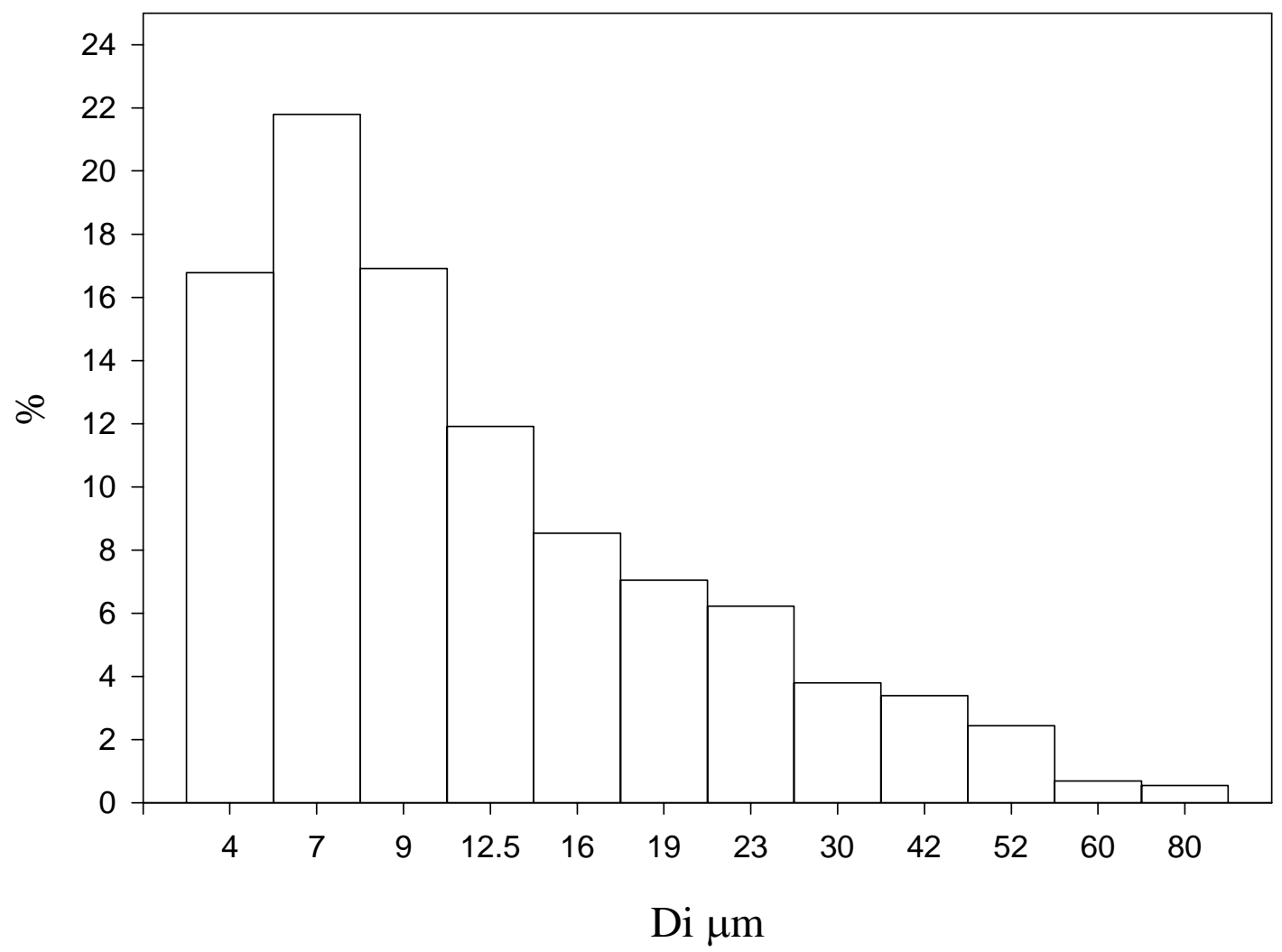

Figure C.42

- The size distribution reflect on Figure C.41 and Figure 4.8 


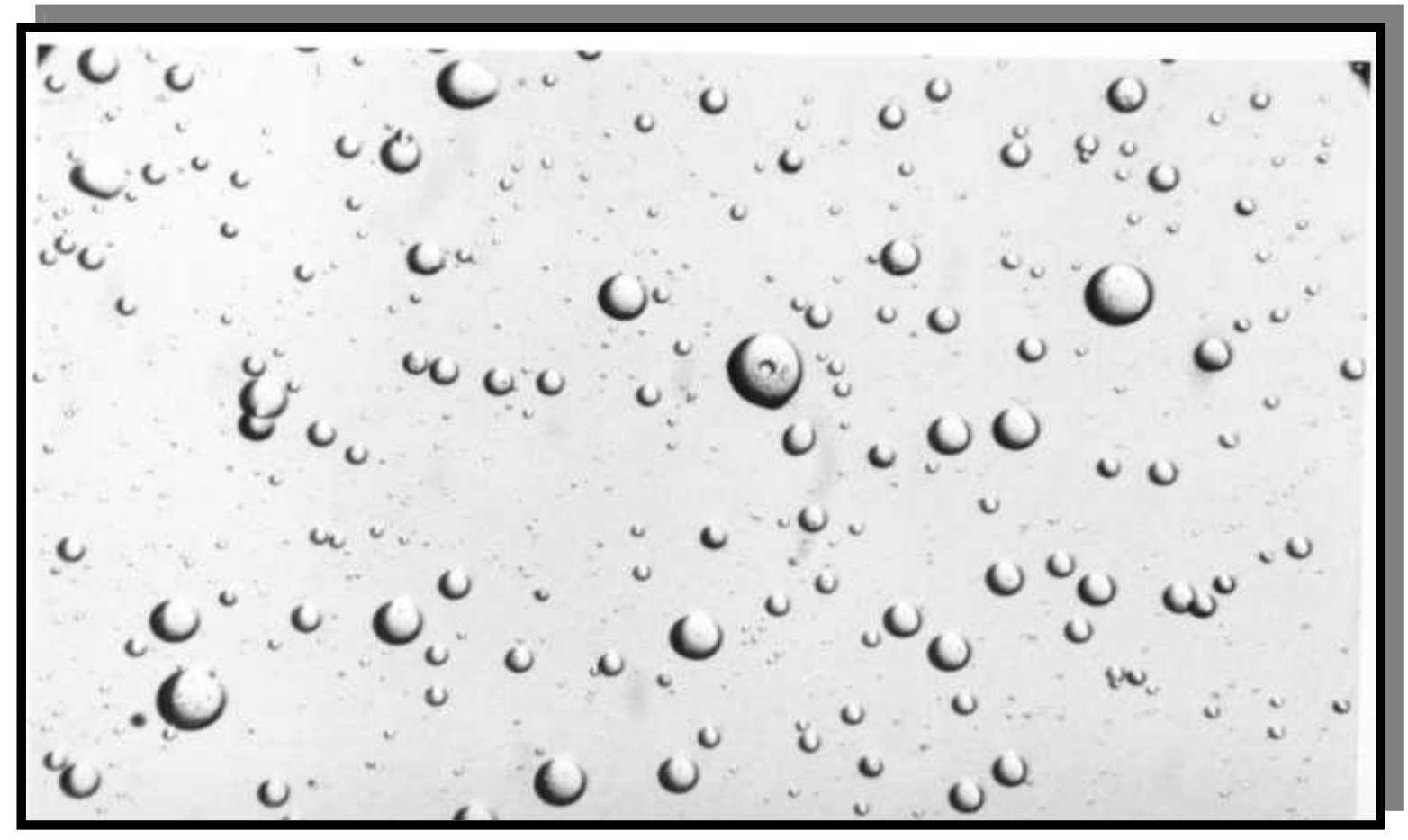

Figure C.43

- Emulsion is sheared using cone-and-plate device.

- Concentration $1.0 \%(\mathrm{v} / \mathrm{v})$.

- Time of shearing 35.00 minutes.

- Shear rates $10 \mathrm{~s}^{-1}$.

- Silicone oil is the continuous phase with viscosity $=0.48$ poise

- Castor oil is the dispersed phase with viscosity $=7.42$ poise.

- Temperature $23{ }^{\circ} \mathrm{C}$.

- $\mathrm{D}=14.83 \mu \mathrm{m}$. 


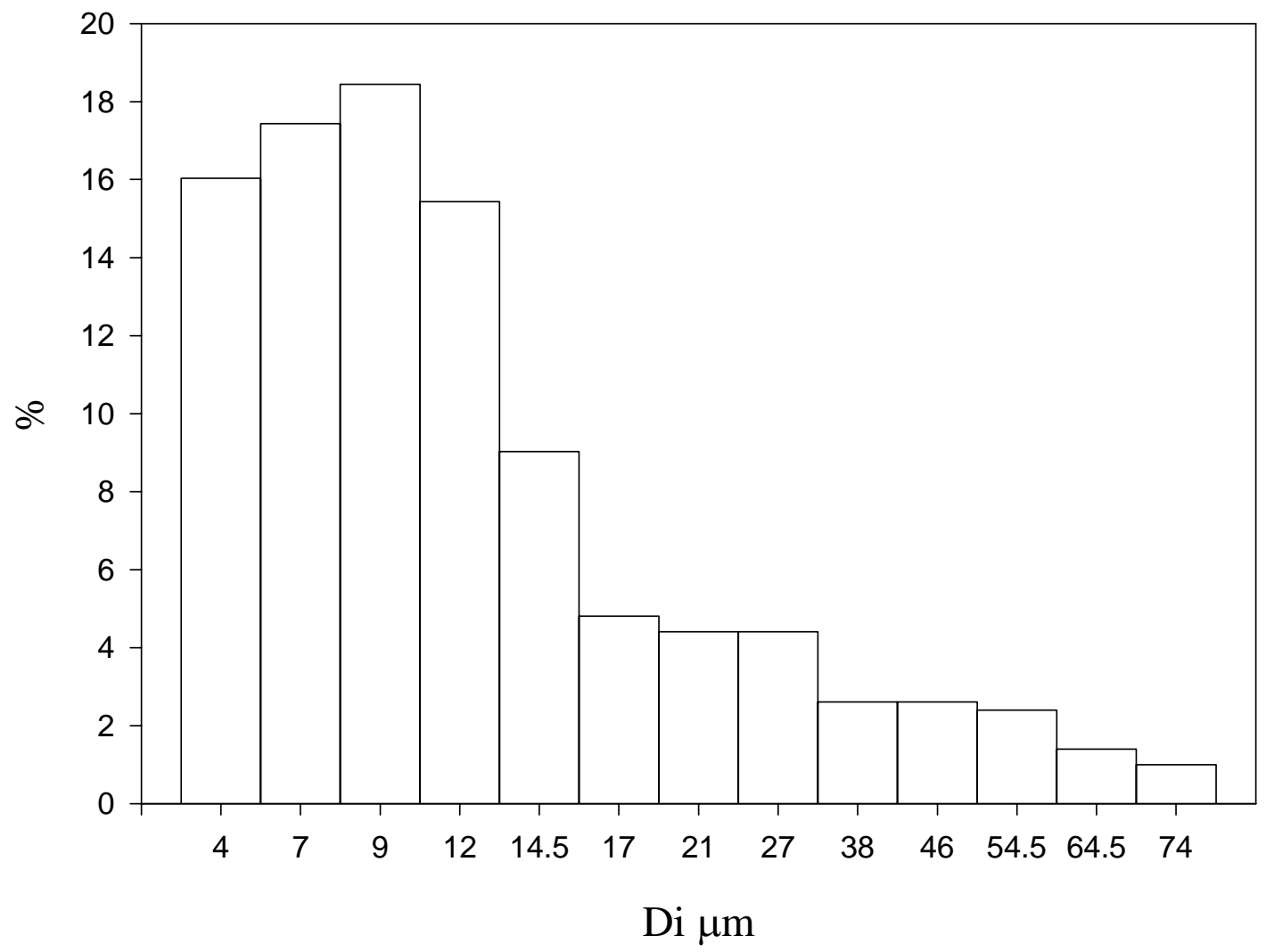

Figure C.44

- The size distribution reflect on Figure C.43 and Figure 4.8 


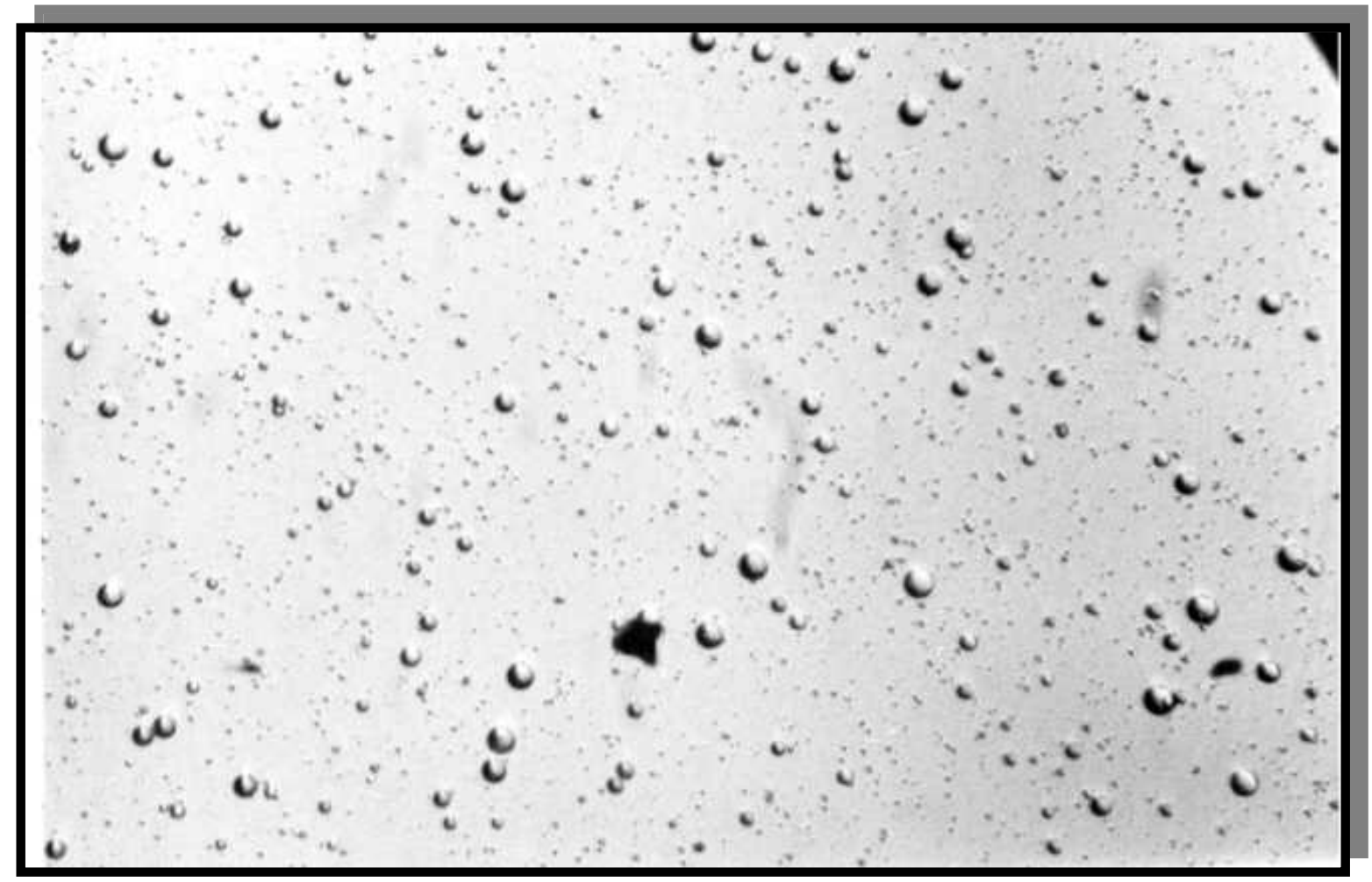

Figure C. 45

- Emulsion is sheared using cone-and-plate device.

- Concentration $1.0 \%(\mathrm{v} / \mathrm{v})$.

- Time of shearing 4.00 minutes.

- Shear rates $30 \mathrm{~s}^{-1}$.

- Silicone oil is the continuous phase with viscosity $=0.48$ poise

- Castor oil is the dispersed phase with viscosity $=7.42$ poise

- Temperature $23{ }^{\circ} \mathrm{C}$.

- $\mathrm{D}=11.68 \mu \mathrm{m}$. 


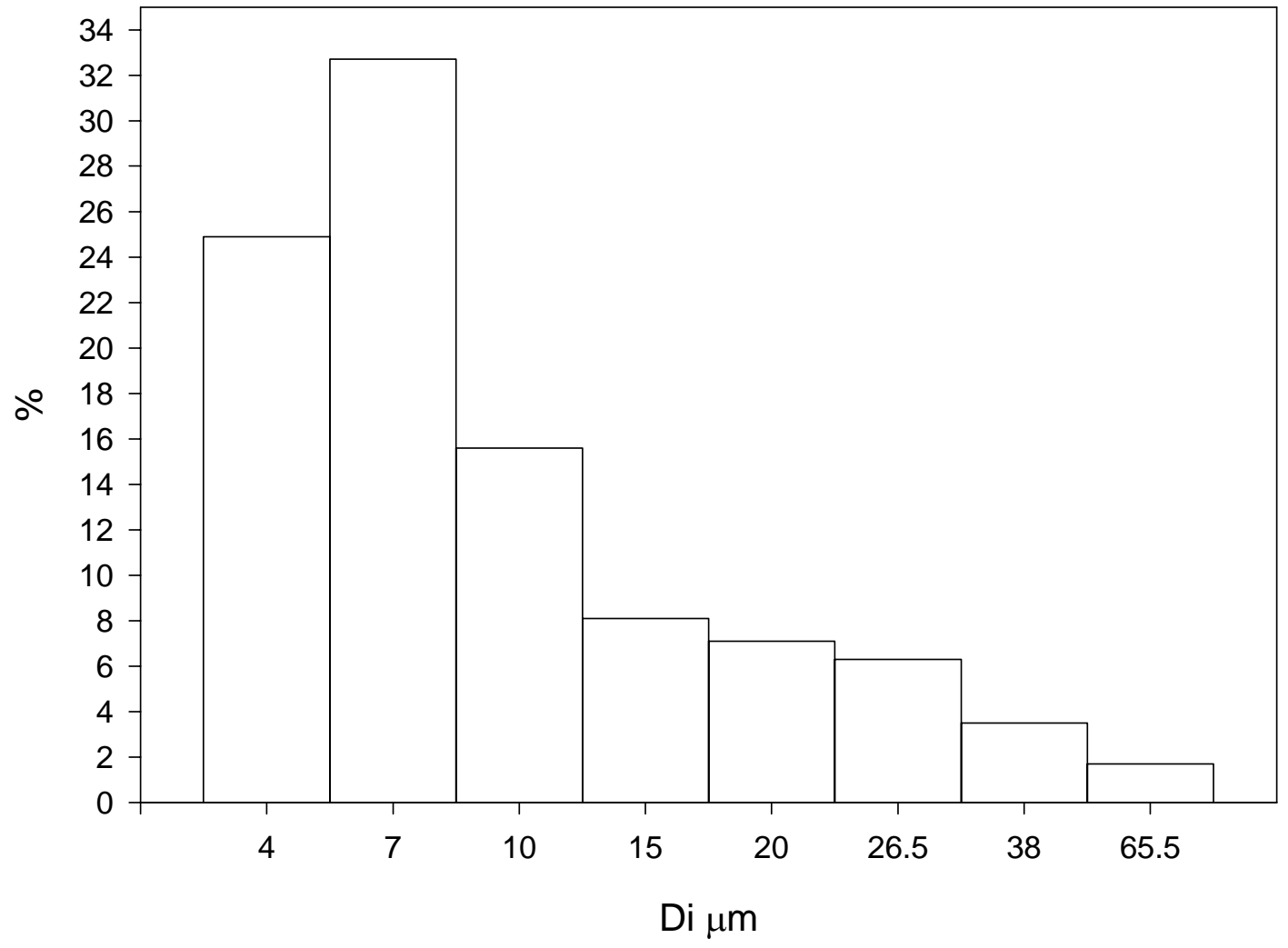

Figure C.46

- The size distribution reflect on Figure C.45 and Figure 4.8 


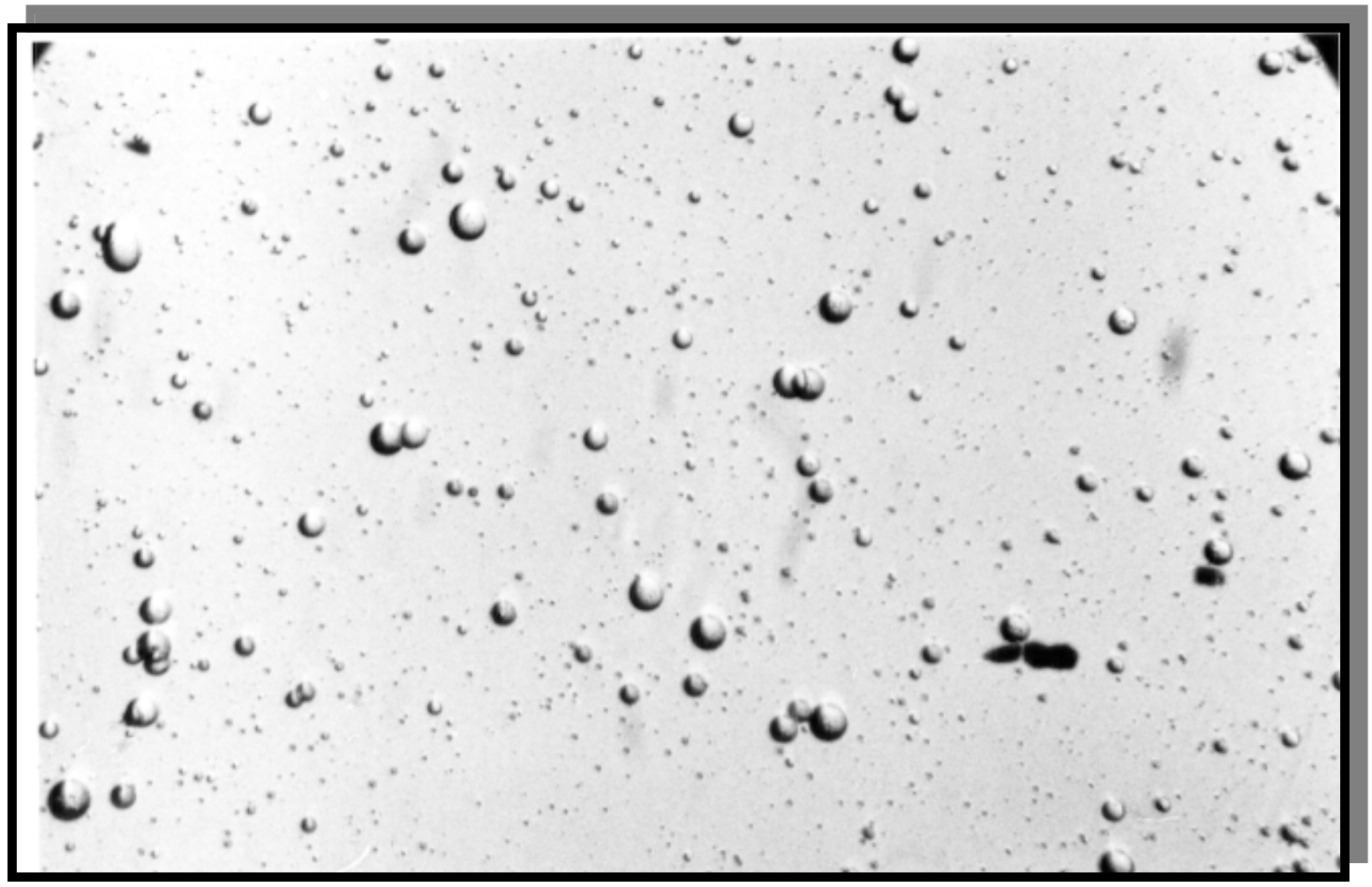

Figure C.47

- Emulsion is sheared using cone-and-plate device.

- Concentration $1.0 \%(\mathrm{v} / \mathrm{v})$.

- Time of shearing 10.00 minutes.

- Shear rates $30 \mathrm{~s}^{-1}$.

- Silicone oil is the continuous phase with viscosity $=0.48$ poise

- Castor oil is the dispersed phase with viscosity $=7.42$ poise

- Temperature $23{ }^{\circ} \mathrm{C}$.

- $\mathrm{D}=12.62 \mu \mathrm{m}$. 


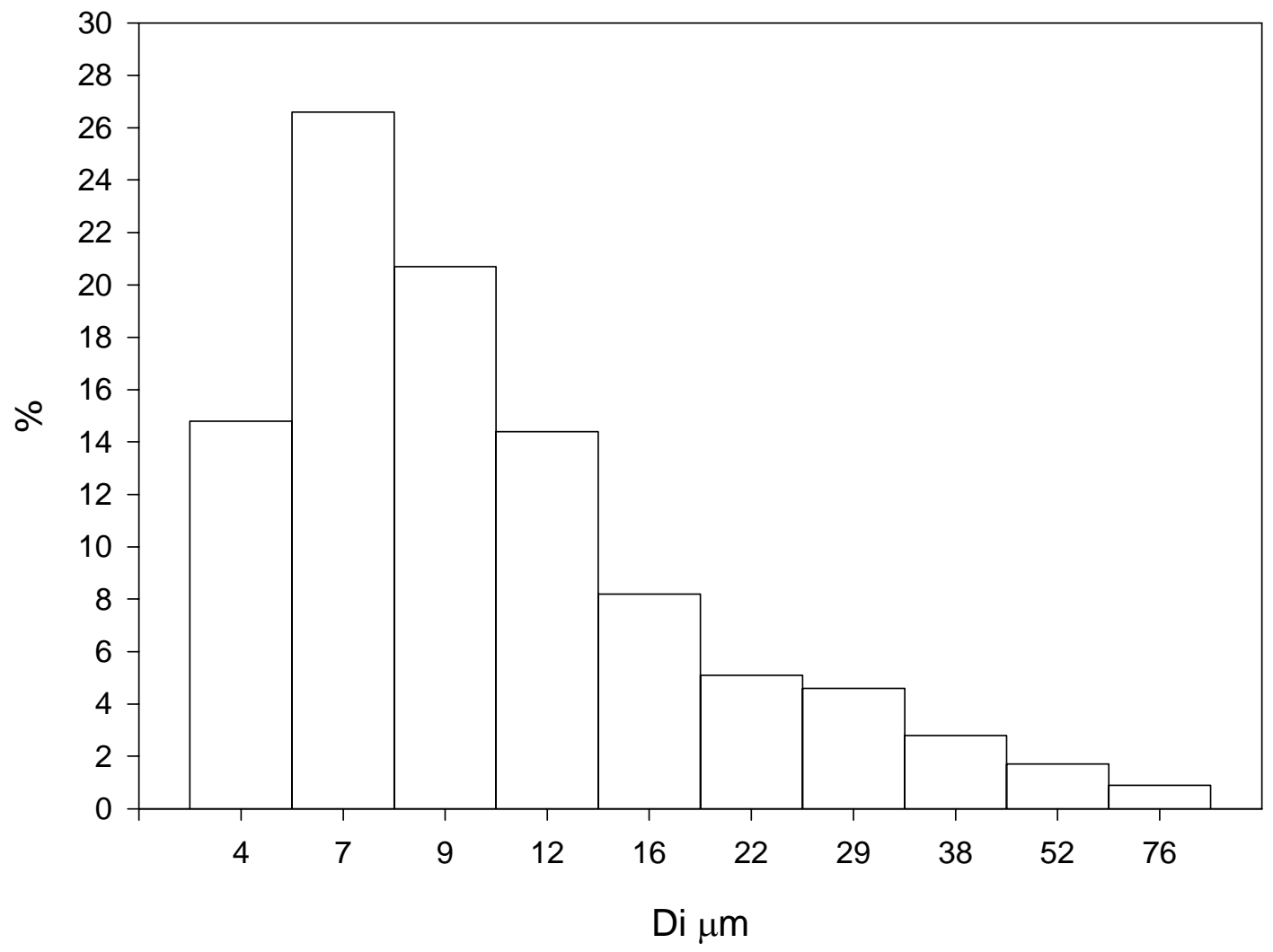

Figure C.48

- The size distribution reflect on Figure C.47 and Figure 4.8 


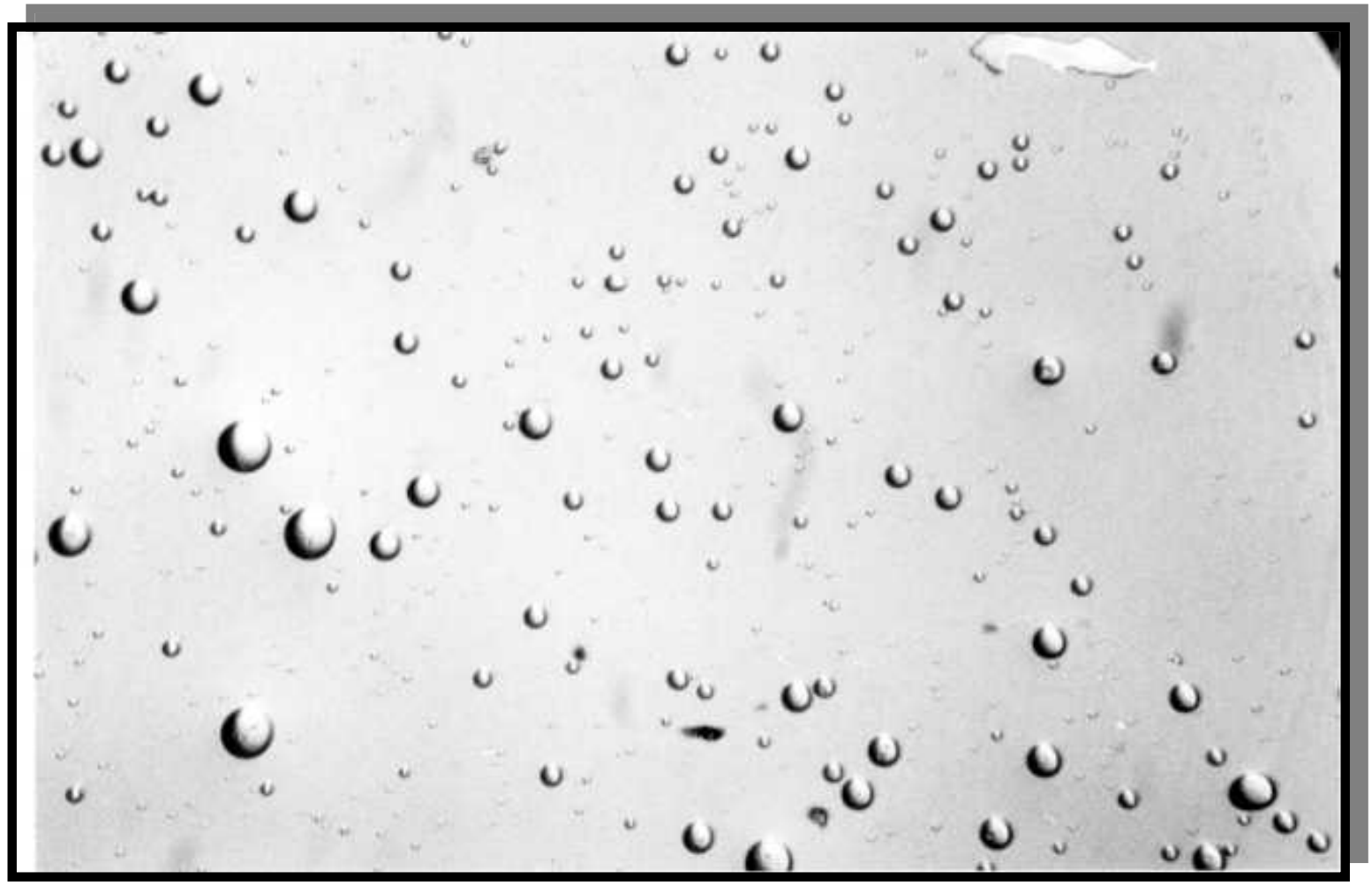

Figure C.49

- Emulsion is sheared using cone-and-plate device.

- Concentration $1.0 \%(\mathrm{v} / \mathrm{v})$.

- Time of shearing 15.00 minutes.

- Shear rates $30 \mathrm{~s}^{-1}$.

- Silicone oil is the continuous phase with viscosity $=0.48$ poise

- Castor oil is the dispersed phase with viscosity $=7.42$ poise.

- Temperature $23{ }^{\circ} \mathrm{C}$.

- $\mathrm{D}=13.26 \mu \mathrm{m}$. 


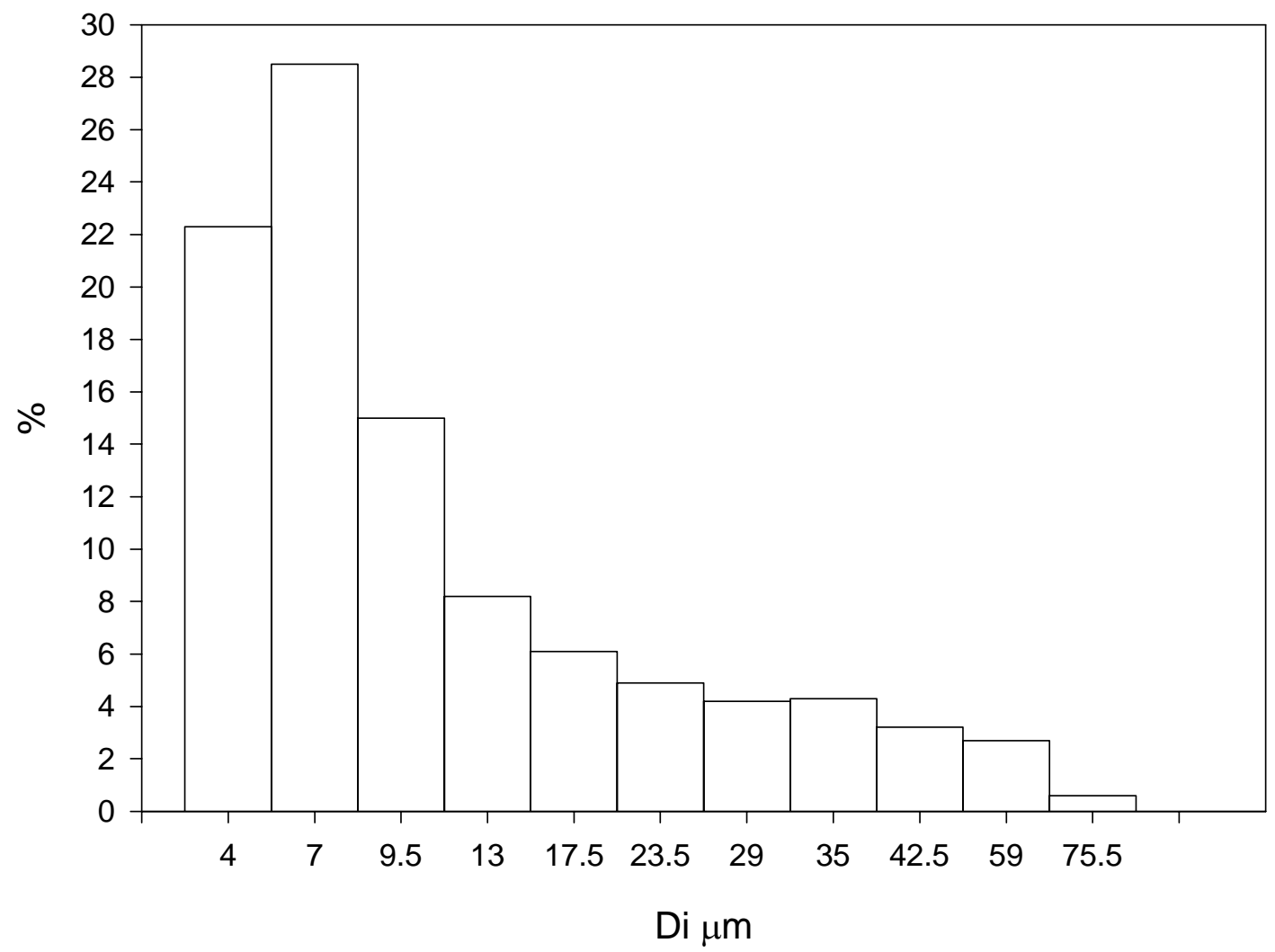

Figure C.50

- The size distribution reflect on Figure C.49 and Figure 4.8 


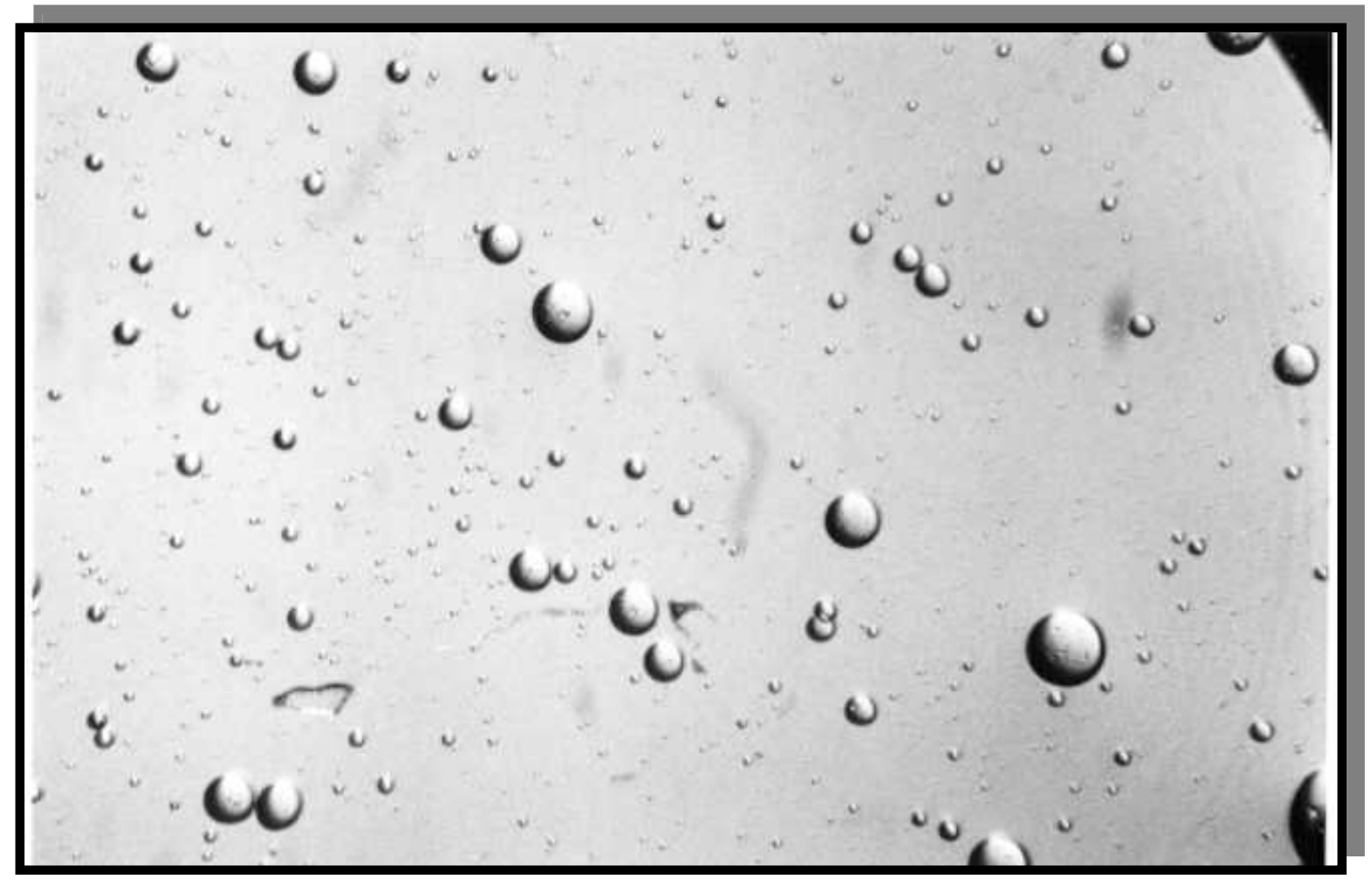

Figure C.51

- Emulsion is sheared using cone-and-plate device.

- Concentration $1.0 \%(\mathrm{v} / \mathrm{v})$.

- Time of shearing 20.00minutes.

- Shear rates $30 \mathrm{~s}^{-1}$.

- Silicone oil is the continuous phase with viscosity $=0.48$ poise

- Castor oil is the dispersed phase with viscosity $=7.42$ poise

- Temperature $23{ }^{\circ} \mathrm{C}$.

- $\mathrm{D}=13.57 \mu \mathrm{m}$. 


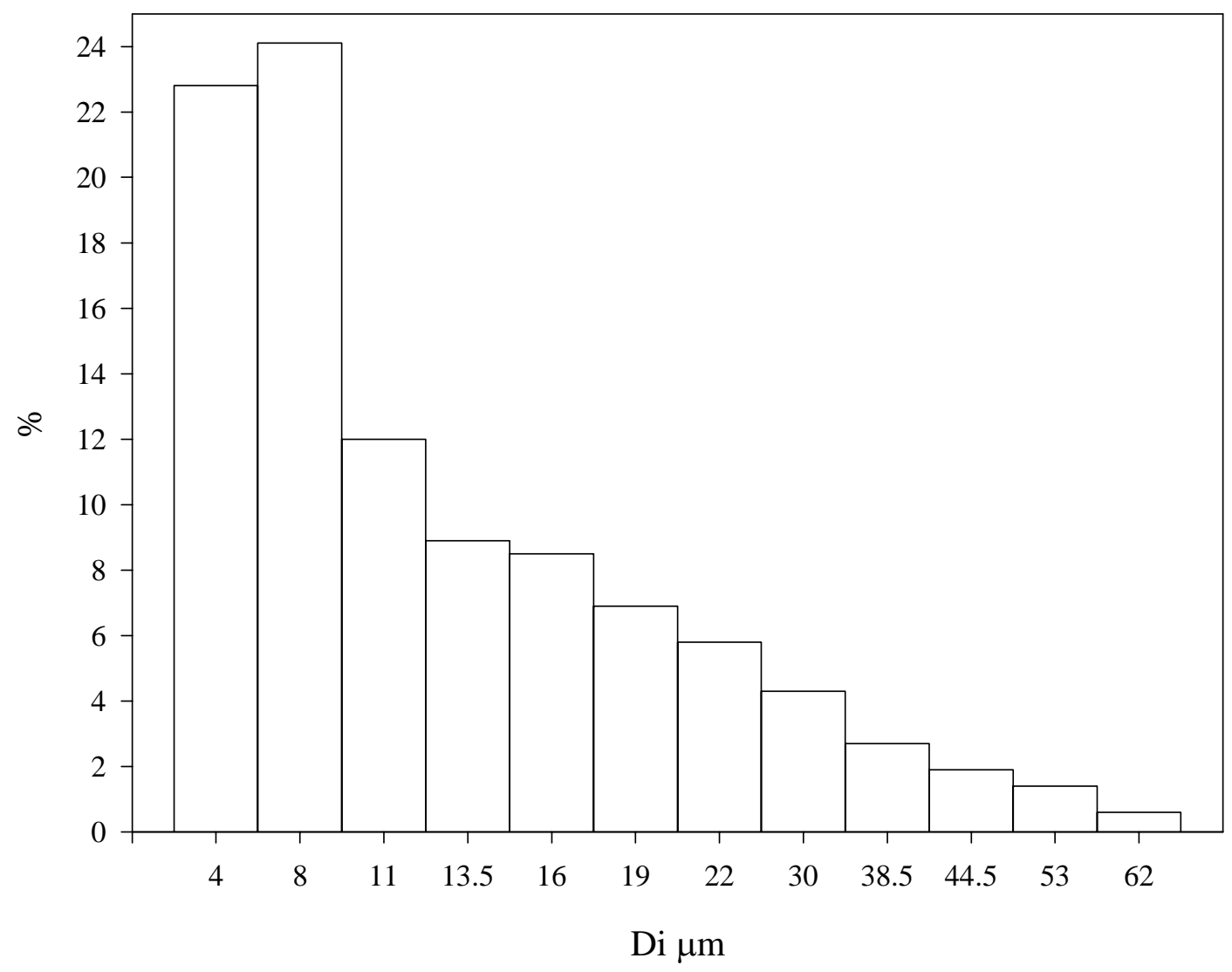

Figure C.52

- The size distribution reflect on Figure C.51 and Figure 4.8 


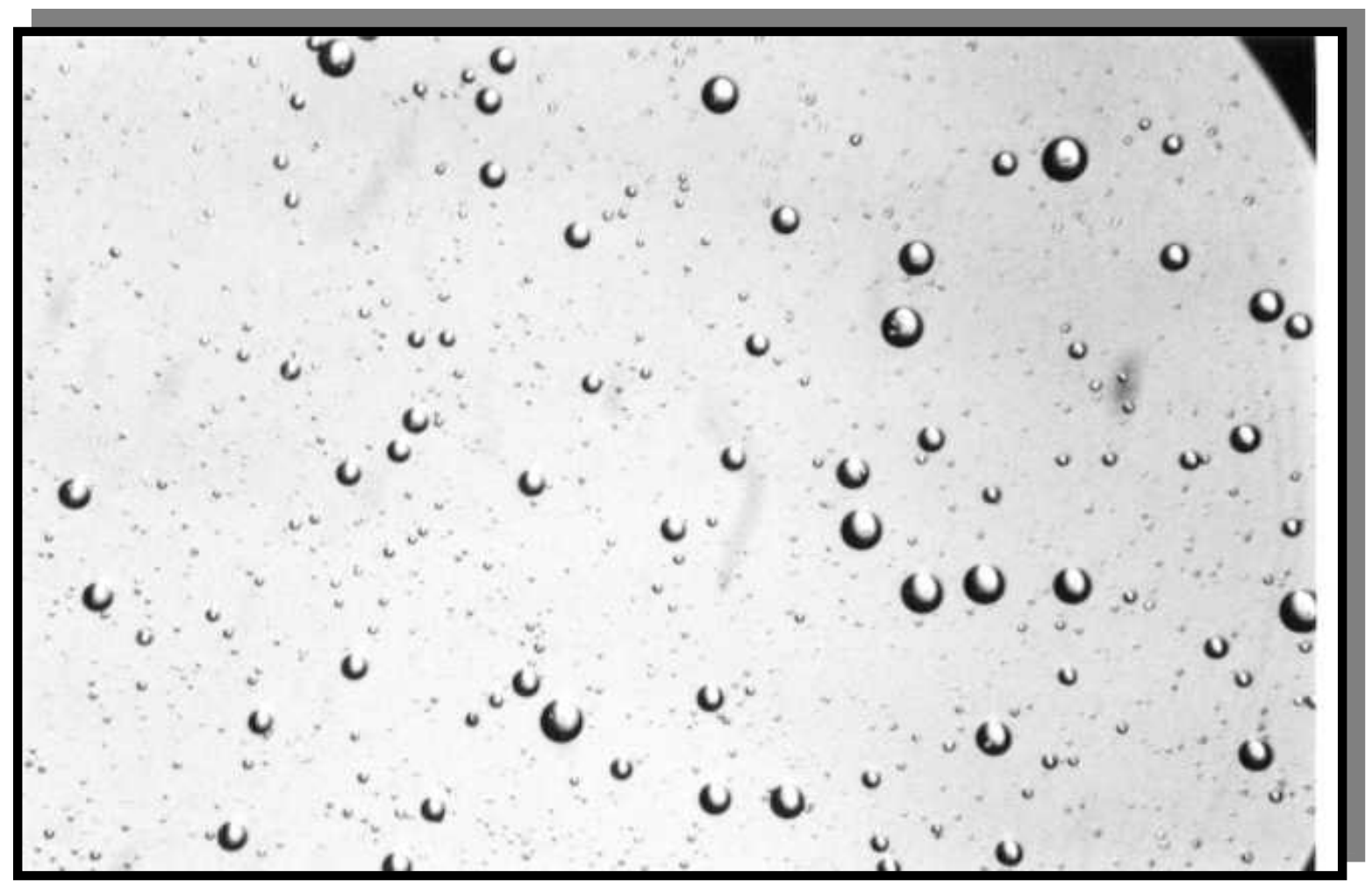

Figure C.53

- Emulsion is sheared using cone-and-plate device.

- Concentration $1.0 \%(\mathrm{v} / \mathrm{v})$.

- Time of shearing 35.00 minutes.

- Shear rates $30 \mathrm{~s}^{-1}$.

- Silicone oil is the continuous phase with viscosity $=0.48$ poise

- Castor oil is the dispersed phase with viscosity $=7.42$ poise

- Temperature $23{ }^{\circ} \mathrm{C}$.

- $\mathrm{D}=13.78 \mu \mathrm{m}$. 


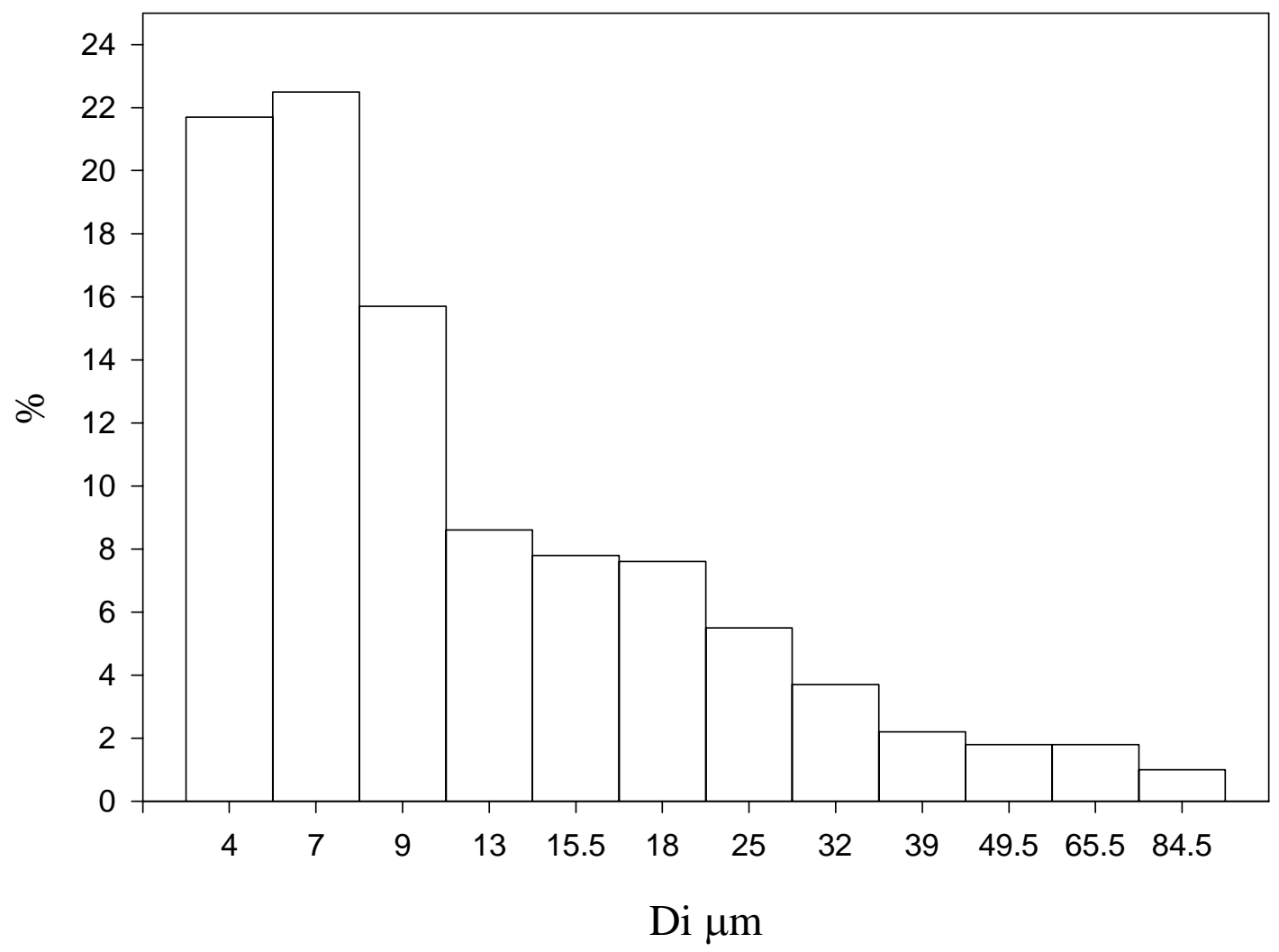

Figure C.54

- The size distribution reflect on Figure C.53 and Figure 4.8 


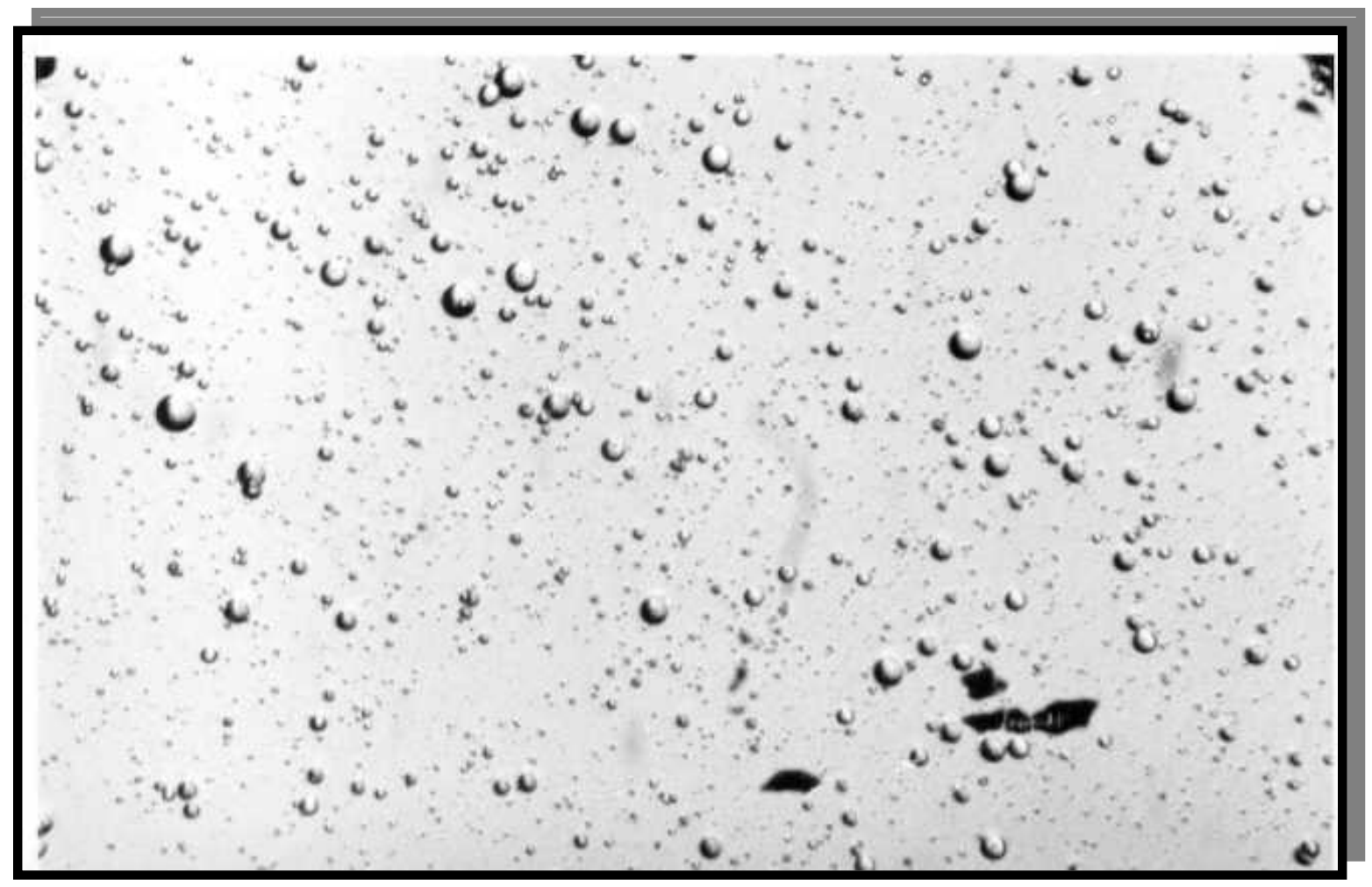

Figure C.55

- Emulsion is sheared using cone-and-plate device.

- Concentration $1.0 \%(\mathrm{v} / \mathrm{v})$.

- Time of shearing 4.00 minutes.

- Shear rates $50 \mathrm{~s}^{-1}$.

- Silicone oil is the continuous phase with viscosity $=0.48$ poise

- Castor oil is the dispersed phase with viscosity $=7.42$ poise.

- Temperature $23{ }^{\circ} \mathrm{C}$.

- $\mathrm{D}=11.68 \mu \mathrm{m}$. 


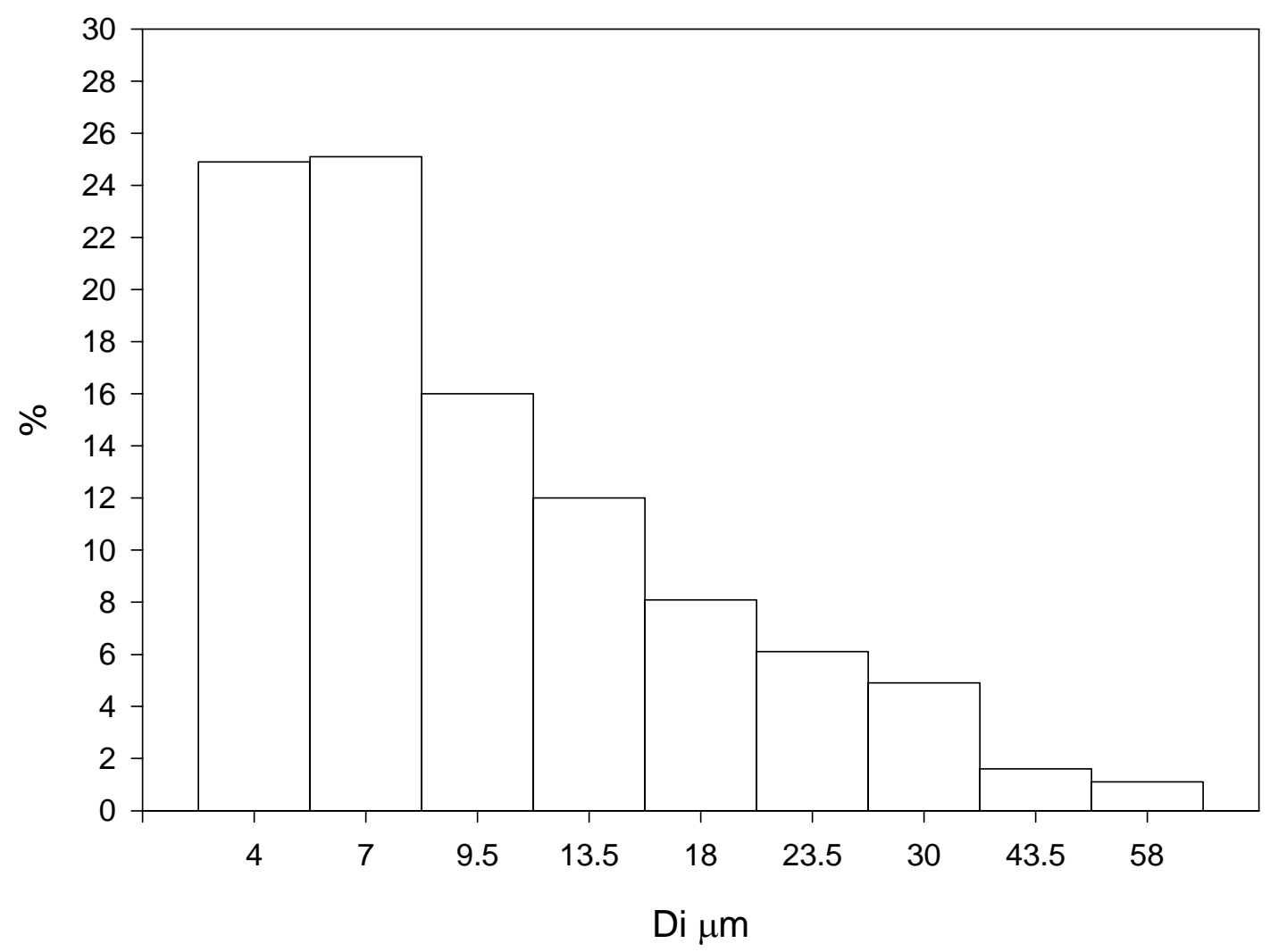

Figure C.56

- The size distribution reflect on Figure C.55 and Figure 4.8 


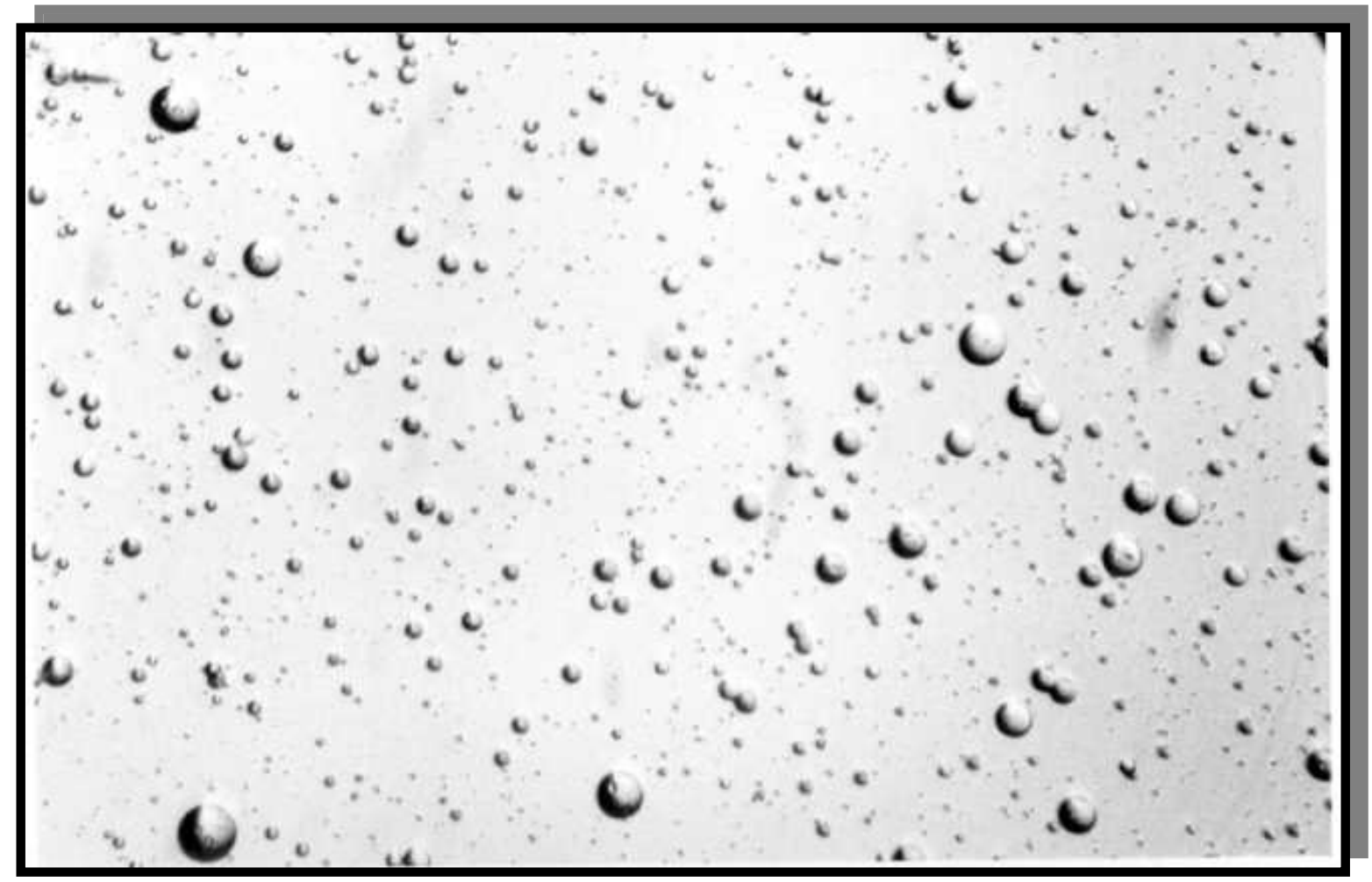

Figure C.57

- Emulsion is sheared using cone-and-plate device.

- Concentration $1.0 \%(\mathrm{v} / \mathrm{v})$.

- Time of shearing 10.00 minutes.

- Shear rates $50 \mathrm{~s}^{-1}$.

- Silicone oil is the continuous phase with viscosity $=0.48$ poise

- Castor oil is the dispersed phase with viscosity $=7.42$ poise

- Temperature $23{ }^{\circ} \mathrm{C}$.

- $\mathrm{D}=12.41 \mu \mathrm{m}$. 


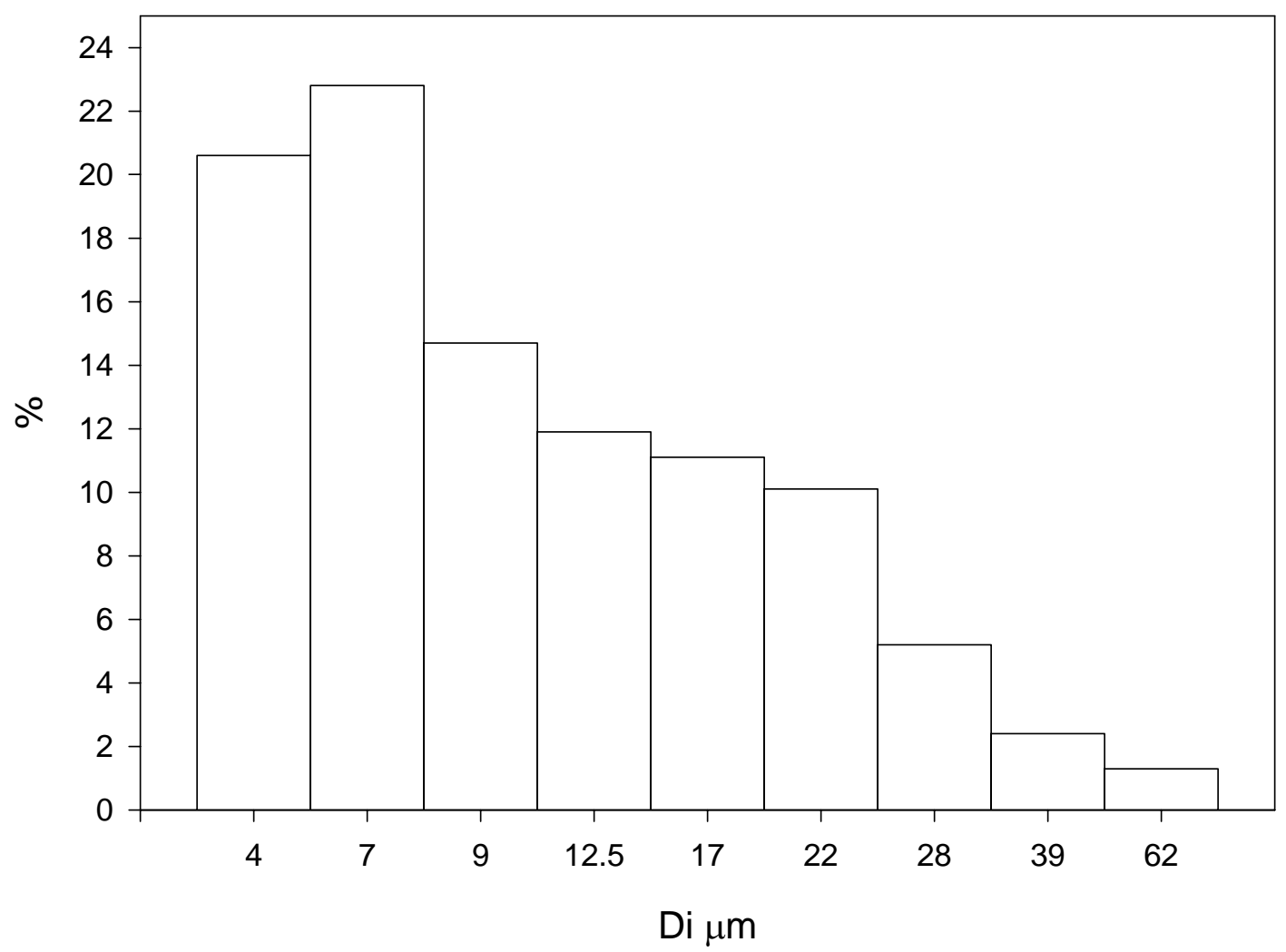

Figure C.58

- The size distribution reflect on Figure C.57 and Figure 4.8 


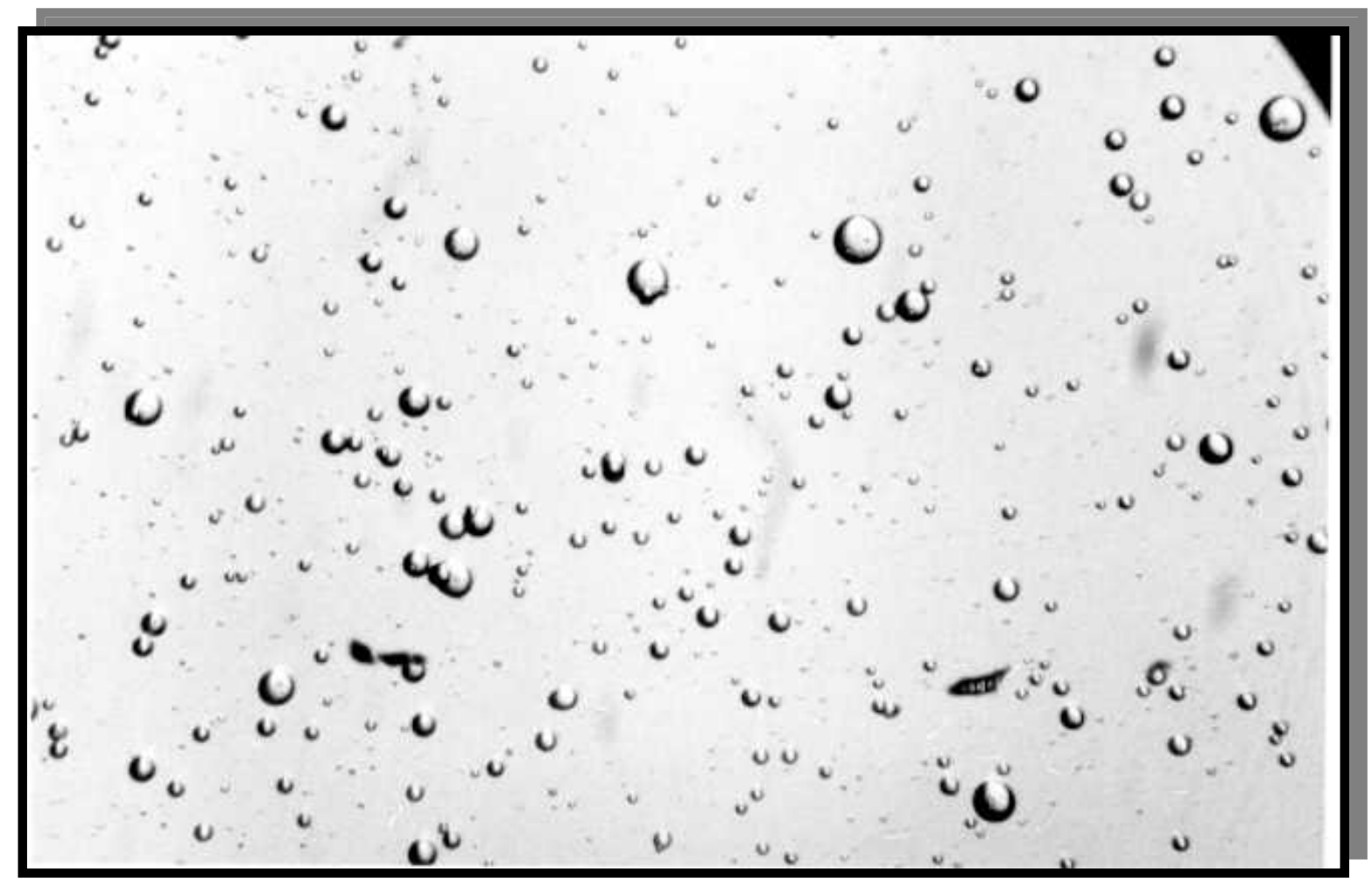

Figure C.59

- Emulsion is sheared using cone-and-plate device.

- Concentration $1.0 \%(\mathrm{v} / \mathrm{v})$.

- Time of shearing 15.00 minutes.

- Shear rates $50 \mathrm{~s}^{-1}$.

- Silicone oil is the continuous phase with viscosity $=0.48$ poise

- Castor oil is the dispersed phase with viscosity $=7.42$ poise.

- Temperature $23{ }^{\circ} \mathrm{C}$.

- $\mathrm{D}=12.73 \mu \mathrm{m}$. 


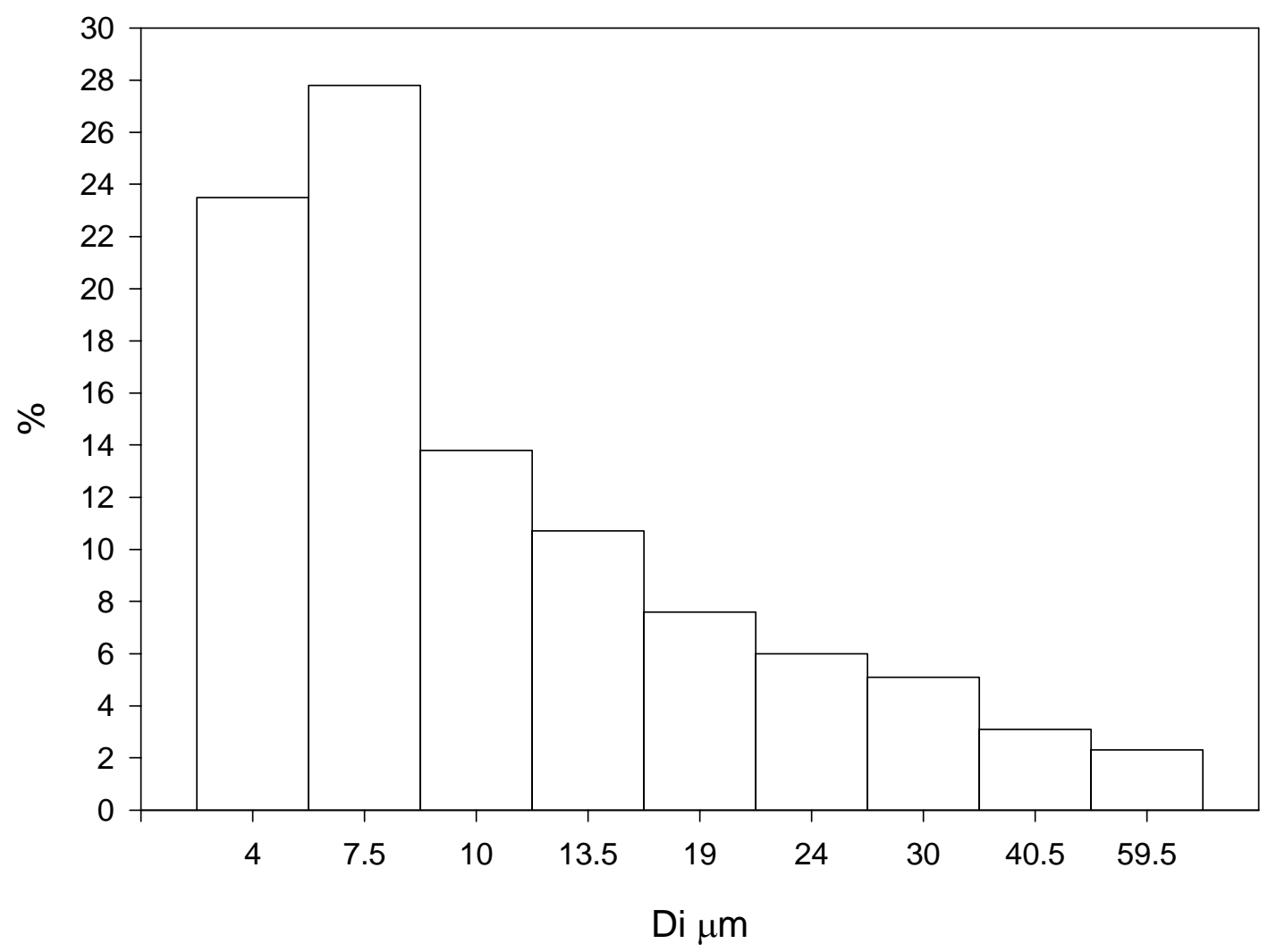

Figure C.60

- The size distribution reflect on Figure C.59 and Figure 4.8 


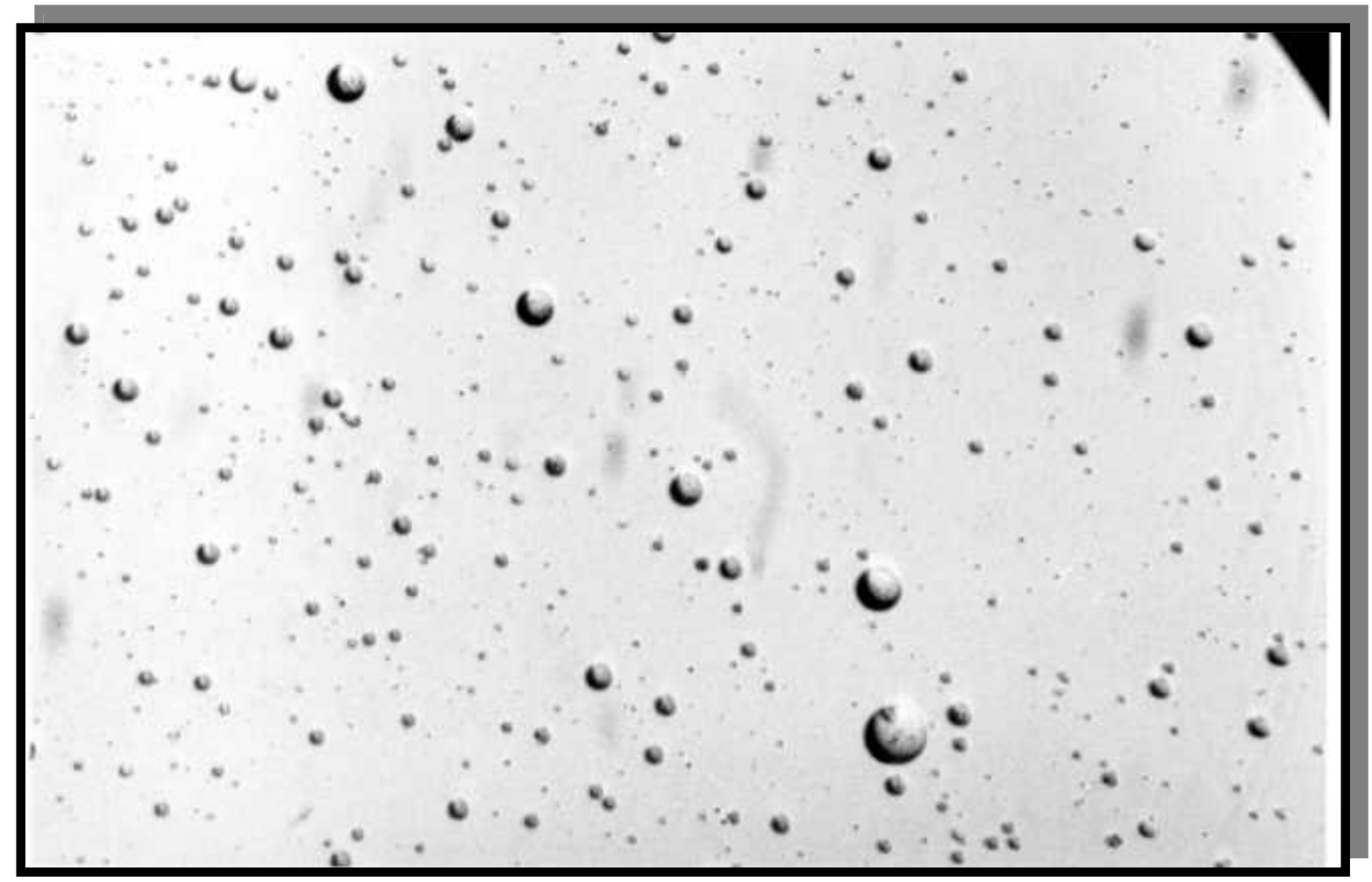

Figure C.61

- Emulsion is sheared using cone-and-plate device.

- Concentration $1.0 \%(\mathrm{v} / \mathrm{v})$.

- Time of shearing 20.00 minutes.

- Shear rates $50 \mathrm{~s}^{-1}$.

- Silicone oil is the continuous phase with viscosity $=0.48$ poise

- Castor oil is the dispersed phase with viscosity $=7.42$ poise

- Temperature $23{ }^{\circ} \mathrm{C}$.

- $\mathrm{D}=13.04 \mu \mathrm{m}$. 


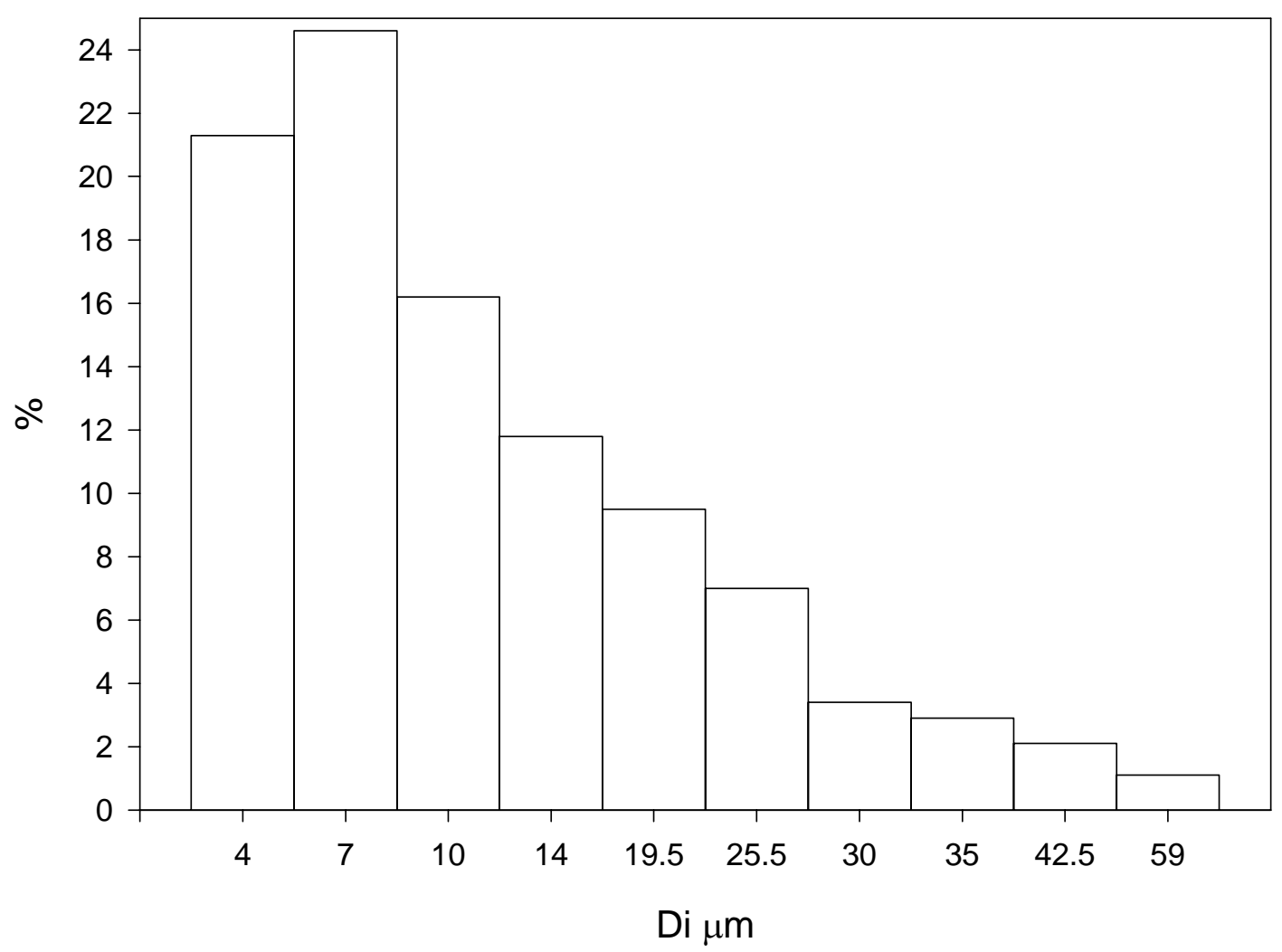

Figure C.62

- The size distribution reflect on Figure C.61 and Figure 4.8 


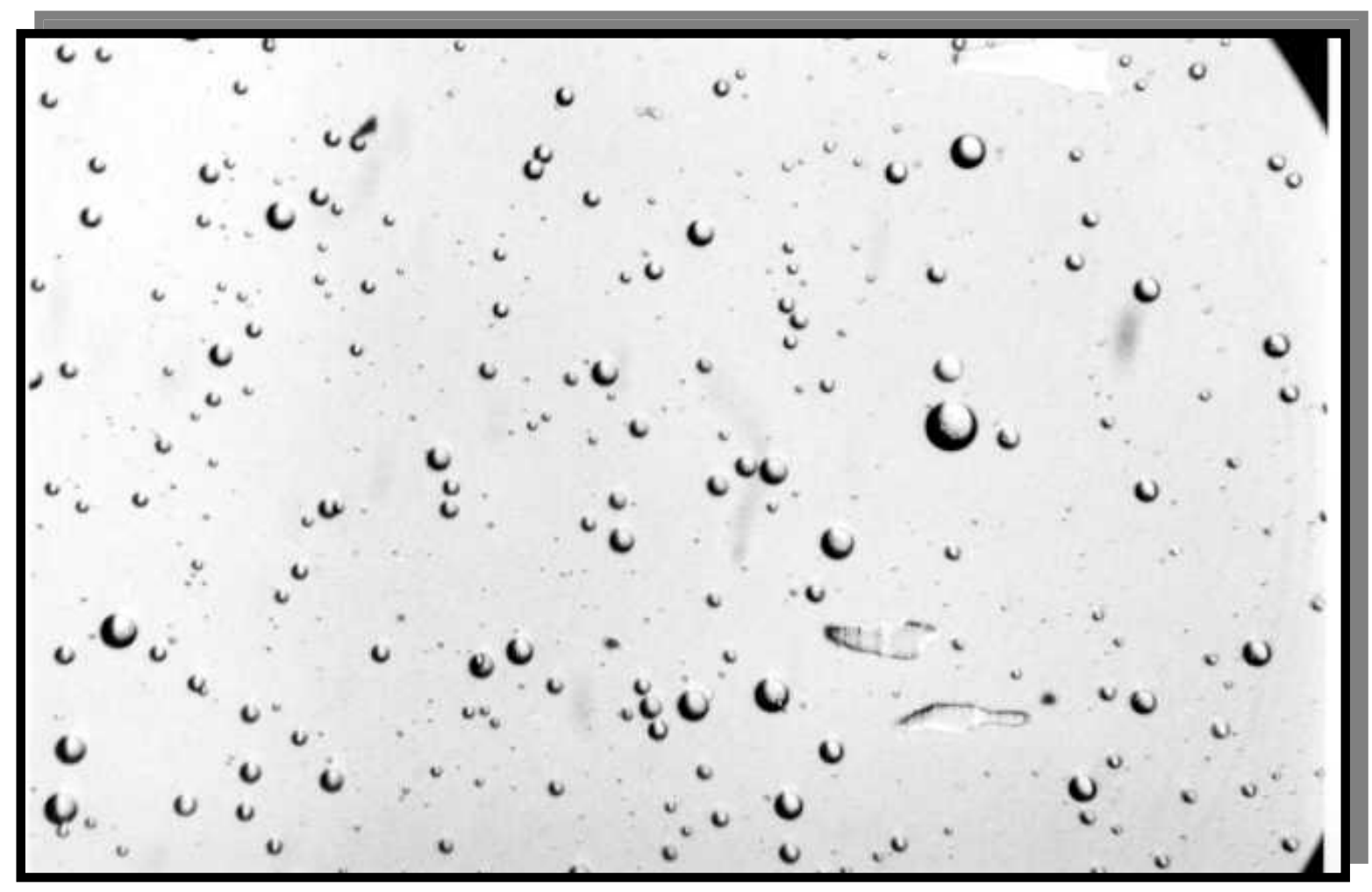

Figure 63

- Emulsion is sheared using cone-and-plate device.

- Concentration $1.0 \%(\mathrm{v} / \mathrm{v})$.

- Time of shearing 35.00 minutes.

- Shear rates $50 \mathrm{~s}^{-1}$.

- Silicone oil is the continuous phase with viscosity $=0.48$ poise

- Castor oil is the dispersed phase with viscosity $=7.42$ poise.

- Temperature $23{ }^{\circ} \mathrm{C}$.

- $\mathrm{D}=13.26 \mu \mathrm{m}$. 


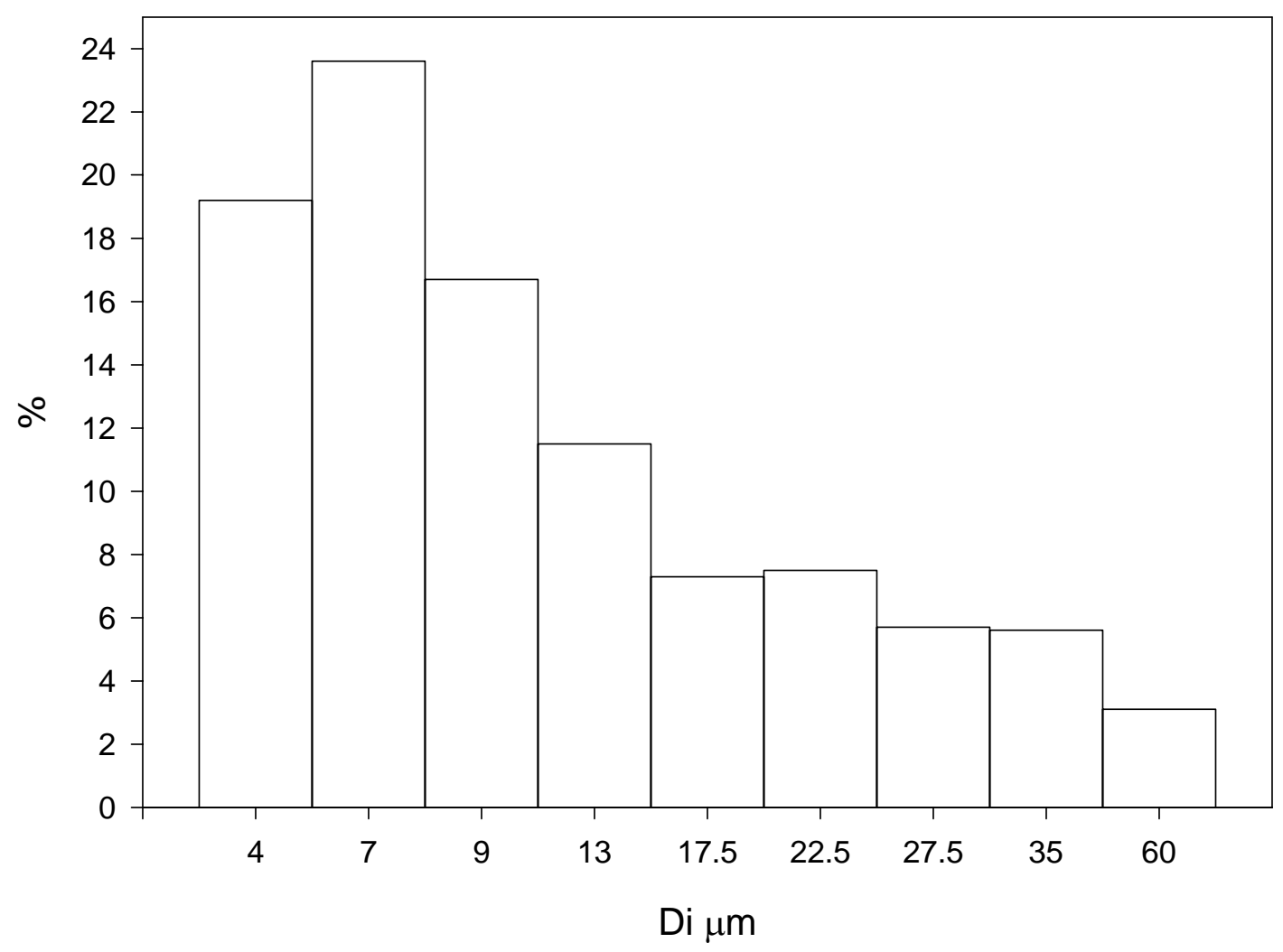

Figure C.64

- The size distribution reflect on Figure C.63 and Figure 4.8 


\title{
DROPLET COALESCENCE IN THE SHEAR FLOW OF MODEL EMULSIONS
}

\author{
By Adam Al-Mulla \\ A Thesis \\ Submitted to the College of Engineering \\ and Mineral Resources \\ at \\ West Virginia University \\ In Partial Fulfillment of the Requirements for the Degree \\ of Master of Science in Chemical Engineering
}

APPROVAL OF EXAMINING COMMITTEE

Charter D. Stinespring, Ph.D.

John W. Zondlo, Ph.D.

Rakesh K. Gupta, Ph.D., Chair

Date 